Oferecimento de QoS para computação em nuvens por meio de metaescalonamento 

SERVIÇO DE PÓS-GRADUAÇÃO DO ICMC-USP

Data de Depósito:

Assinatura:

\title{
Oferecimento de QoS para computação em nuvens por meio de metaescalonamento
}

\author{
Maycon Leone Maciel Peixoto \\ Orientadora: Profa. Dra. Regina Helena Carlucci Santana \\ Tese apresentada ao Instituto de Ciências Matemáticas e de \\ Computação - ICMC-USP, como parte dos requisitos para \\ obtenção do título de Doutor em Ciências - Ciências de \\ Computação e Matemática Computacional. 9( 56- 2】 \\ $5\left(9,6 \$^{\prime} \$\right.$.
}

USP - São Carlos

Agosto de 2012 
Ficha catalográfica elaborada pela Biblioteca Prof. Achille Bassi e Seção Técnica de Informática, ICMC/USP, com os dados fornecidos pelo(a) autor(a)

Peixoto, Maycon Leone Maciel Peixoto
Oferecimento de Qos para computação em nuvens por
meio de metaescalonamento / Maycon Leone Maciel
Peixoto Peixoto; orientador Regina Helena Carlucci
Santana. -- São Carlos, 2012 .
157 p.
Tese (Doutorado - Programa de Pós-Graduação em
Ciências de Computação e Matemática Computacional) --
Instituto de Ciências Matemáticas e de Computação,
Universidade de São Paulo, 2012.
1. Metaescalonamento. 2. Computação em Nuvens. 3.
Virtualização. 4. QoS. 5. Avaliação de Desempenho. I.
Santana, Regina Helena Carlucci, orient. II. Título.




\section{Agradecimentos}

A Deus, em primeiro lugar, por me conceder saúde, força e coragem para conquistar mais este objetivo na minha vida.

Aos meus pais, por todo o apoio e amor que foram a mim dedicados através de ensinamentos, conselhos, lições de vida e colaboração em todos os sentidos. Agradeço também aos meus tios e tias que sempre me motivaram a prosseguir.

A Professora Regina Santana pela orientação e suporte ao longo de todo o trabalho, além da amizade que se firmou em diversos momentos difíceis e felizes da minha vida.

Agradeço de maneira especial ao Tácito e Danilo, pois foram verdadeiros amigos que me deram abrigo na república Roliudi. Além disso, pelo convívio, ajuda e pela companhia ao longo desses anos. Além da colaboração de todos os amigos: Tim, Rigolin, Paulão, Guazzelli, Dionísio Leite pelo apoio, companheirismo e pela ajuda na revisão da tese. Em especial ao Dionisio, cuja amizade e trabalho em conjunto resultou em produtividade de pesquisa.

Aos professores do grupo de Sistemas Distribuídos e Programação Concorrente, que contribuíram com sugestões e críticas sempre construtivas. Ao Instituto de Ciências Matemáticas e de Computação - ICMC, formado por todos os funcionários, pela colaboração no desenvolvimento deste trabalho, que sempre se mostraram disponiveis nos momentos em que os solicitei.

A FAPESP, CNPq e CAPES pelo suporte financeiro.

$\mathrm{E}$ a todos que participaram direta ou indiretamente deste trabalho. 

Este projeto apresenta a proposta de uma arquitetura de Metaescalonador que leva em consideração o emprego de qualidade de serviço (GoS) para o ambiente de Computação em Nuvem. O Metaescalonador é capaz de realizar a alocação dos recursos dinamicamente, procurando atender as restrições temporais. Em resposta a esse dilema de escalonamento aplicado a Computação em Nuvem, este projeto propõe uma abordagem chamado MACC: Metascheduler Architecture to provide GoS in Cloud Computing. A função principal do MACC é distribuir e gerenciar o processamento das requisições de serviços entre os recursos disponíveis, cumprindo os termos agregados na SLA - Service Level Agreement. São apresentados resultados obtidos considerando-se diferentes algoritmos de roteamento e de alocação de máquinas virtuais. Os resultados apresentados são discutidos e analisados de acordo com as técnicas de planejamento de experimentos. 



\section{Abstract}

This project proposes a Metascheduler architecture that takes into account the use of quality of service (BoS) to cloud computing environment. The Metascheduler is capable of dynamically allocating resources, trying to meet the timing constraints. In response to this scheduling dilemma applied to cloud computing, this project proposes an approach called MACC - Metascheduler Architecture to Provide GoS in Cloud Computing. The main function of MACC is to distribute and to manage the service requests among available resources, meeting the aggregate terms in the SLA - Service Level Agreement. Results are presented considering different routing algorithms and allocation of virtual machines. The results are discussed and analyzed in accordance with the techniques of experimental design. 



\section{Sumário}

1 Introdução 1

1.1 Contextualização . . . . . . . . . . . . . . . . . . . . 1

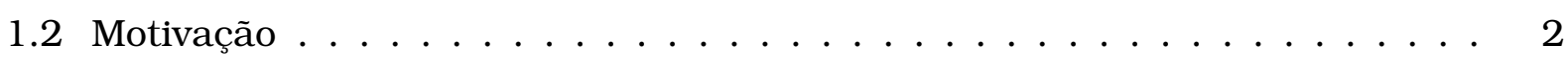

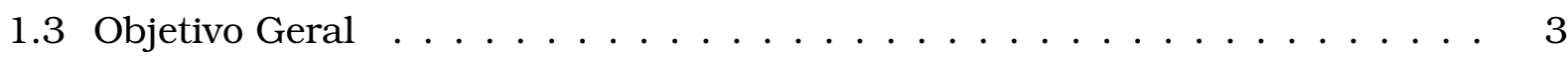

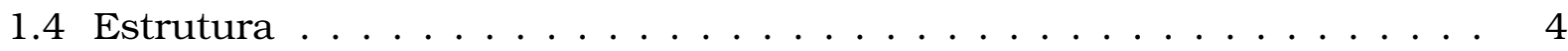

2 Computação em Nuvens $\quad 5$

2.1 Considerações Iniciais . . . . . . . . . . . . . . . . 5

2.2 Definição de Computação em Nuvem . . . . . . . . . . . . . . . 5

2.3 Modelos de Computação em Nuvens . . . . . . . . . . . . . . . . . 6

2.3.1 Benefícios da Computação em Nuvens . . . . . . . . . . . 7

2.3.2 Riscos da Computação em Nuvens . . . . . . . . . . . . . . . . . . 8

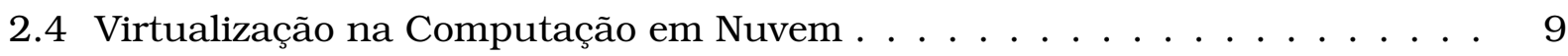

2.4.1 Características Gerais de Virtualização . . . . . . . . . . . . . . 9

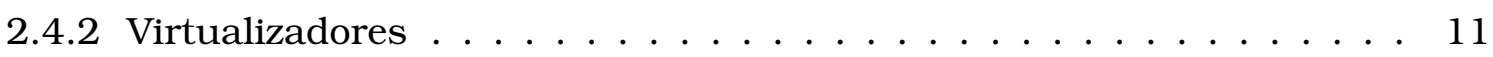

2.5 Intercloud . . . . . . . . . . . . . . . . . . 13

2.6 Modelos Econômicos . . . . . . . . . . . . . . . . . 14

2.6.1 Estruturas de Mercado . . . . . . . . . . . . . . . 16

2.7 Abordagem de Comunicação P2P f . . . . . . . . . . . . . . . . 18

2.7.1 Topologias em Redes P2P . . . . . . . . . . . . . . 18

2.7.2 Roteamento P2P . . . . . . . . . . . . . . . . . . 20

2.7 .3 Latência . . . . . . . . . . . . . . . . . . 24

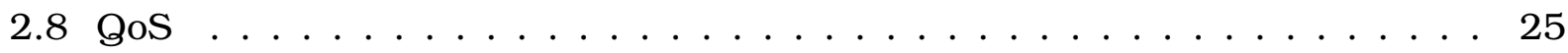

2.8 .1 GoS em nível de aplicação . . . . . . . . . . . . . . . . . . . . . . . . . . . . . . 25

2.8 .2 GoS em nível de rede . . . . . . . . . . . . . . . . . . . . 26

2.9 Ambiente de Simulação . . . . . . . . . . . . . . . . . . . . 28

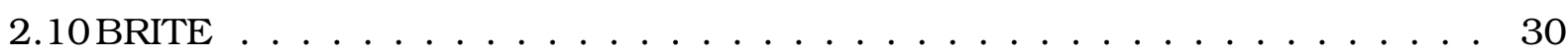

2.11 Considerações Finais . . . . . . . . . . . . . . . . 31 
3 Metaescalonadores $\quad 33$

3.1 Considerações Iniciais $\ldots \ldots \ldots \ldots$

3.2 Escalonamento Local e Metaescalonamento . . . . . . . . . . . . . . . . 33

3.3 Modelos de Comunicação dos Metaescalonadores . . . . . . . . . . . . . . . 34

3.4 Comparação entre as Abordagens de Metaescalonadores . . . . . . . . . . 35

3.4 .1 Arquiteturas . . . . . . . . . . . . . . 36

3.4 .2 Descoberta de Recursos . . . . . . . . . . . . . . . . . . 39

3.4 .3 Modelo de Serviço . . . . . . . . . . . . . . . . . . . 39

3.4 .4 Alocação de Recursos . . . . . . . . . . . . . . . . . . . . . . 40

3.4 .5 Reserva de Recursos . . . . . . . . . . . . . . . . . . . . . . . . . . . . . .

3.4 .6 Confiabilidade e Segurança . . . . . . . . . . . . . . . . . 42

3.5 Trabalhos Relacionados - Metaescalonadores em Intercloud . . . . . . . . 42

3.6 Considerações Finais . . . . . . . . . . . . . . . . . . 45

4 MACC - Metascheduler Architecture to provide GoS in Cloud Computing 47

4.1 Considerações Iniciais . . . . . . . . . . . . . . . . . . . . . . . . . . . . . . .

4.2 Visão Geral do MACC . . . . . . . . . . . . . . . . . . . . . 47

4.3 Detalhamento dos Componentes do MACC . . . . . . . . . . . . . . 49

4.3 .1 Camada de Aplicação . . . . . . . . . . . . . . . . . . . . . . . . . . . . . . . 49

4.3.2 Camada de Cliente/Servidor . . . . . . . . . . . . . . . . 49

4.3 .3 Camada de Núcleo . . . . . . . . . . . . . . . . . . 51

4.3 .4 Camada de Virtualização . . . . . . . . . . . . . . . . . . 52

4.3 .5 Camada de Infraestrutura Física . . . . . . . . . . . . . . . 53

4.4 Fluxo de Operação do MACC . . . . . . . . . . . . . . . . . . . 53

4.5 Projeto e Implementação do MACC . . . . . . . . . . . . . . . . . . 54

4.6 Métricas Consideradas pelo MACC . . . . . . . . . . . . . . 56

4.6.1 Custo $-($ Cost $-C) \ldots \ldots \ldots$. . . . . . . . . . . 56

4.6.2 Tempo Médio de Resposta - (Mean Response Time - MRT) . . . . . . . 57

4.6 .3 Confiabilidade - (Reliability $-R) \ldots \ldots \ldots$. . . . . . . 58

4.7 Algoritmos de Alocação de Máquinas Virtuais do MACC . . . . . . . . . . . 58

4.8 Ambiente Intercloud . . . . . . . . . . . . . . . . . 61

4.8 .1 Modelagem da Rede . . . . . . . . . . . . . . . . 62

4.8 .2 Algoritmos de Roteamento . . . . . . . . . . . . . . . . 66

4.9 Análise Comparativa dos Trabalhos Relacionados . . . . . . . . . . . 70

4.10 Considerações Finais . . . . . . . . . . . . . . . . 72

5 Estudo de Desempenho em uma Nuvem Privada $\quad 73$

5.1 Considerações Iniciais . . . . . . . . . . . . . . . . . . . . . . . . . . . . .

5.2 Preparação do Ambiente de Testes . . . . . . . . . . . . . . 73

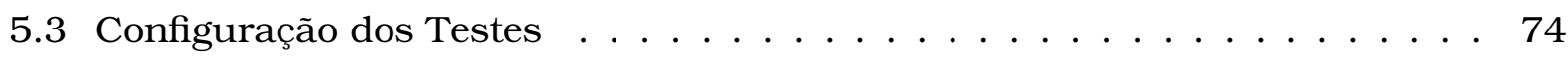

5.4 Avaliação dos Resultados . . . . . . . . . . . . . . . . . . . 75

5.4.1 Testes de Sobrecarga dos Virtualizadores . . . . . . . . . . . . 75

5.4 .2 Testes CPU-Bound . . . . . . . . . . . . . . . 76 
5.4 .3 Testes $I / O$-Bound $\ldots \ldots \ldots \ldots \ldots \ldots$

5.4 .4 Detalhamento da Carga nos Experimentos . . . . . . . . . . 80

5.5 Considerações Finais . . . . . . . . . . . . . . . . . . 82

6 Avaliação da Infraestrutura de Comunicação $\quad 85$

6.1 Considerações Iniciais . . . . . . . . . . . . . . . . . . . . . . . . . . . . . . .

6.2 Preparação do Ambiente de Testes . . . . . . . . . . . . . . 85

6.3 Comparação entre as Métricas . . . . . . . . . . . . . . . . . 87

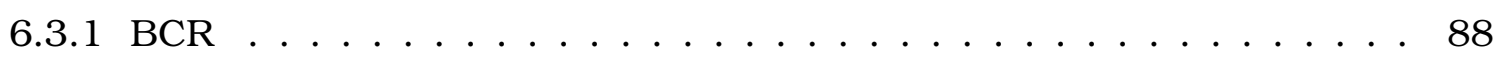

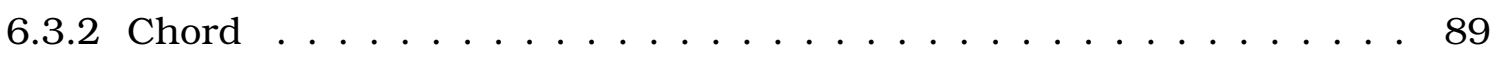

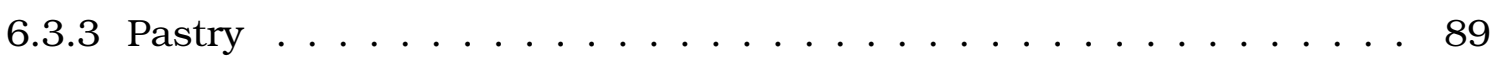

6.4 Comparação das Políticas de Roteamento . . . . . . . . . . . . . . . . 90

6.4.1 Comparação entre as Políticas RR e a BCR-Latência . . . . . . . . . . 90

6.4.2 Comparação entre as Políticas Chord-Latência e a Pastry-Salto . . . 92

6.4.3 Comparação entre as Políticas BCR-Latência e a Pastry-Salto . . . . 95

6.5 Considerações sobre as Avaliações de Políticas de Roteamento . . . . . . . . 97

6.6 Considerações Finais . . . . . . . . . . . . . . . . . . 98

7 Avaliação da Alocação de Máquinas Virtuais 99

7.1 Considerações Iniciais . . . . . . . . . . . . . . . . . . . . . . . . . . . . . . . . . . . . . .

7.2 Preparação do Ambiente de Testes . . . . . . . . . . . . . . . . . . . . . . . . . . . . . . . . . . .

7.3 Avaliação das Políticas de Alocação do MACC . . . . . . . . . . . . . . . . . . . . . . . . . 102

7.3.1 Algoritmo SD4c X Algoritmo RG . . . . . . . . . . . . . . . . . . . . . . . . . . . 102

7.3.2 Algoritmo PD2c X Algoritmo RG . . . . . . . . . . . . . . . 108

7.3 .3 Algoritmo PD2c X Algoritmo SD4c . . . . . . . . . . . . . . . . 113

7.3.4 Algoritmo PD2c X Algoritmo PDXc . . . . . . . . . . . . . 118

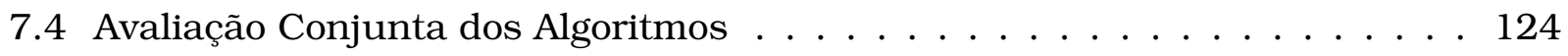

7.4 .1 Influência dos Fatores . . . . . . . . . . . . . 125

7.4 .2 Principais Efeitos dos Fatores . . . . . . . . . . . 126

7.4 .3 Interação entre os Fatores . . . . . . . . . . . . . . . 127

7.5 Avaliação da Satisfação Individual dos Usuários . . . . . . . . . . . . . 129

7.6 Avaliação da Sobrecarga dos Algoritmos de Alocação . . . . . . . . . . . . . 131

7.7 Considerações Finais . . . . . . . . . . . . . . . . . 132

8 Conclusões 133

8.1 Considerações Iniciais . . . . . . . . . . . . . . . . . . . . . 133

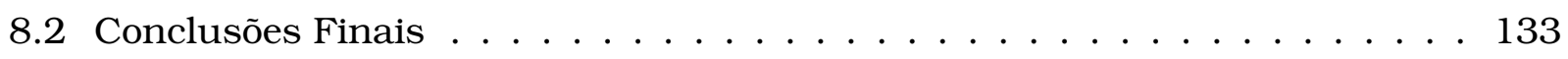

8.3 Dificuldades Relacionadas ao Projeto . . . . . . . . . . . . . . 135

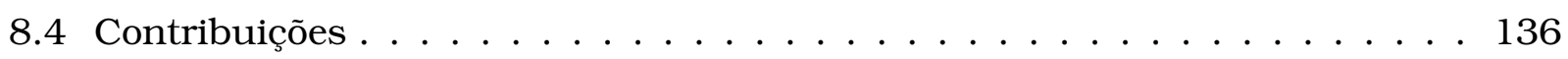

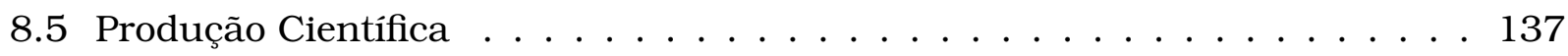

8.5.1 Artigos Publicados em Congressos . . . . . . . . . . . . . . 137

8.5.2 Artigos Aceitos para Publicação . . . . . . . . . . . . . . . . . . . . . . . . . . 137

8.5.3 Artigos Submetidos para Revista . . . . . . . . . . . . . . . 137

8.5 .4 Artigos Submetidos para Congresso . . . . . . . . . . . . 138 
8.5.5 Colaboração em Projetos de Pesquisa . . . . . . . . . . . . . . . 138

8.6 Trabalhos Futuros . . . . . . . . . . . . . . . . . 138 


\section{Lista de Figuras}

2.1 Arquitetura da Computação em Nuvem. . . . . . . . . . . . . . . . . 7

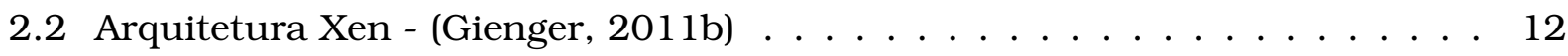

2.3 Arquitetura KVM (Gienger, 2011a). . . . . . . . . . . . . . . . 13

2.4 Modelo do ambiente Intercloud - Adaptado de (Buyya et al., 2010). . . . . . 14

2.5 Topologia Centralizada (Subramanian e Goodman, 2005) . . . . . . . . . . 19

2.6 Topologia em Anel (Subramanian e Goodman, 2005) . . . . . . . . . . . . . 19

2.7 Topologia Hierárquica (Subramanian e Goodman, 2005) . . . . . . . . . . . 20

2.8 Topologia Não-hierárquica (Subramanian e Goodman, 2005) . . . . . . . . . 20

2.9 Topologia Centralizada e Não-hierárquica (Subramanian e Goodman, 2005) 21

2.10 Protocolo DHT realizando roteamento em massa (Androutsellis-theotokis e

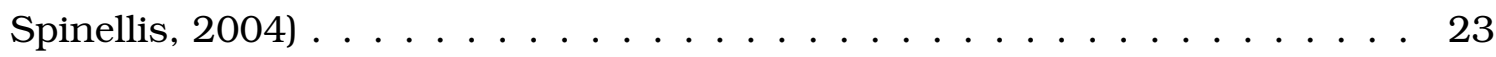

2.11 Protocolo DHT realizando roteamento em Anel (Stoica et al., 2001) . . . . . 24

2.12 Arquitetura do CloudSim - Adaptado de Calheiros et al. (2010). . . . . . . . 29

2.13 Módulos que Compõe o BRITE. Adaptado de (Medina et al., 2001) . . . . . . 30

3.1 Modelo centralizado. Adaptado de (Subramani et al., 2002) . . . . . . . . . . 34

3.2 Modelo distribuído. Adaptado de (Subramani et al., 2002) . . . . . . . . . 35

3.3 Modelo hierárquico. Adaptado de (Subramani et al., 2002) . . . . . . . . . 35

3.4 Itens sobre Metaescalonamento. . . . . . . . . . . . . . 36

3.5 Taxonomia sobre as Arquiteturas - Adaptado de Chard (2011). . . . . . . . . 38

3.6 Taxonomia sobre a Descoberta - Adaptado de Chard (2011). . . . . . . . . . 39

3.7 Taxonomia sobre os Serviços - Adaptado de Chard (2011). . . . . . . . . . . 40

3.8 Taxonomia sobre a Alocação - Adaptado de Chard (2011). . . . . . . . . . . . 41

3.9 Taxonomia sobre a Reserva - Adaptado de Chard (2011). . . . . . . . . . . . 42

3.10Taxonomia sobre Confiabilidade e Segurança - Adaptado de Chard (2011). . 43

4.1 MACC - Visão Geral. . . . . . . . . . . . . . . . . . . . . . . . . . . . 48

4.2 Diagrama de Sequência para o Tempo de Resposta. . . . . . . . . . . . . . 49

4.3 Protocolo de Negociação - Adaptado (Buyya et al., 2001) . . . . . . . . . . . . . 50

4.4 Fluxo de Operações do Metaescalonador. . . . . . . . . . . . . . . 53

4.5 Diagrama de Classes do Projeto MACC. . . . . . . . . . . . . . . 55 
4.6 Algoritmo RG. . . . . . . . . . . . . . . . . . . . . . . 59

4.7 Algoritmo SD4c. . . . . . . . . . . . . . . . . . 59

4.8 Algoritmo PD2c. . . . . . . . . . . . . . . . . 60

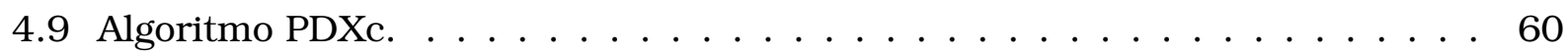

4.10 Visão Geral da Intercloud. . . . . . . . . . . . . . . . . 61

4.11 Modelo de Comunicação do MACC. . . . . . . . . . . . . . . . . . . 62

4.12 Modelo Topológico Utilizado. . . . . . . . . . . . . . . . . . . . . . . . . . . . . . . . 63

4.13 Distribuição Geográfica dos Data Centers. . . . . . . . . . . . . . . . . . 63

4.14 Diagrama de Classes - Infraestrutura de Comunicação. . . . . . . . . . . . . 64

4.15Fluxo de Comunicação Utilizado - Adaptado de (Calheiros et al., 2010). . . . 66

4.16Busca utilizando Round Robin. . . . . . . . . . . . . . . . . . . 67

4.17 Modelo de Busca realizado pela BCR. . . . . . . . . . . . . . . . 68

4.18 Topologia Pastry. . . . . . . . . . . . . . . . . 68

4.19Busca realizada pelo Pastry. . . . . . . . . . . . . . . 69

4.20Topologia Chord. . . . . . . . . . . . . . . 70

4.21 Processo de Busca Utilizado pelo Chord. . . . . . . . . . . . . . 70

5.1 Resultados de Sobrecarga. . . . . . . . . . . . . . . . . 76

5.2 Diferenças nos tempos de resposta . . . . . . . . . . . . . 76

5.3 Influência dos fatores no Primeiro conjunto de Experimentos . . . . . . . . 77

5.4 Diferenças nos Tempos de Resposta com a Mudança de Nível . . . . . . . . 78

5.5 Tempos de Resposta obtido pela Compilação do Apache . . . . . . . . . . . 78

5.6 Influência dos Fatores nos Tempos de Resposta . . . . . . . . . . . . . . . 79

5.7 Principais Efeitos provocados na Mudança de Níveis . . . . . . . . . . . . . . . 80

5.8 Influência dos fatores . . . . . . . . . . . . . . . . . 80

5.9 Principais mudanças nos níveis considerados . . . . . . . . . . . 81

5.10 Interação entre os fatores . . . . . . . . . . . . . . 82

6.1 Rede utilizada para 30 clientes e 15 Data Centers. . . . . . . . . . . . . . . . 86

6.2 Rede Utilizada para 60 Clientes e 15 Data Centers. . . . . . . . . . . . . . . 87

6.3 BCR - Efeito dos Fatores na variável RTT (s). . . . . . . . . . . . . . . . 89

6.4 Chord - Efeito dos Fatores. . . . . . . . . . . . . . . . . . 89

6.5 Pastry - Efeito dos Fatores. . . . . . . . . . . . . . . . . 90

6.6 Condução dos Experimentos. . . . . . . . . . . . . . . . . 90

6.7 Intervalo de Confiança. . . . . . . . . . . . . . . . . 91

6.8 Histograma - RTT . . . . . . . . . . . . . . . . . . . . . . . . . . . . . . . . . .

6.9 Interação dos Fatores. . . . . . . . . . . . . . . . . . . . . 92

6.10 Influência RTT - Normal. . . . . . . . . . . . . . . . . . . . . . . . . . . . . . . . .

6.11 Intervalo de Confiança. . . . . . . . . . . . . . . . 93

6.12 Histograma - RTT . . . . . . . . . . . . . . . . . . . . . . . . . . . . . . . . . .

6.13 Interação dos Fatores. . . . . . . . . . . . . . . . . . . . 94

6.14 Influência RTT - Normal. . . . . . . . . . . . . . . . . . . . . 95

6.15 Intervalo de Confiança. . . . . . . . . . . . . . . . . 95 


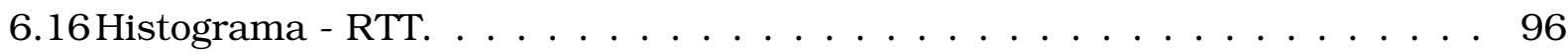

6.17 Interação dos Fatores. . . . . . . . . . . . . . . . . . 96

6.18 Interação dos Fatores. . . . . . . . . . . . . . . . . 96

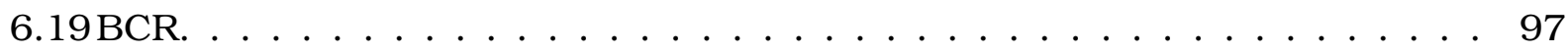

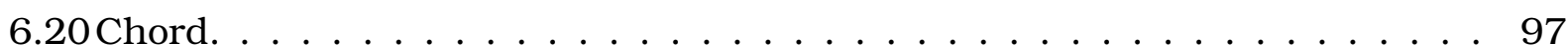

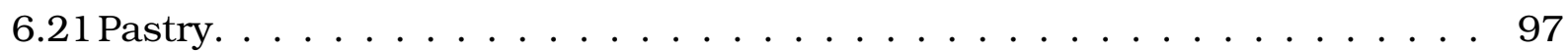

6.22 Sobrecarga dos Algoritmos de Roteamento. . . . . . . . . . . . . . . 98

7.1 Intervalo de Confiança - Tempo de Resposta Médio. . . . . . . . . . . . . . 102

7.2 Influência dos Fatores - Tempo de Resposta Médio. . . . . . . . . . . . . 103

7.3 Principais Efeitos - Tempo de Resposta Médio. . . . . . . . . . . . . . . 103

7.4 Interação entre os Fatores - Tempo de Resposta Médio. . . . . . . . . . . . . 104

7.5 Intervalo de Confiança - Custo. . . . . . . . . . . . . . . . . . 104

7.6 Influência dos Fatores - Custo. . . . . . . . . . . . . . . . . 104

7.7 Principais Efeitos - Custo. . . . . . . . . . . . . 105

7.8 Interação entre os Fatores - Custo. . . . . . . . . . . . . . . . . . . . . . . . . . . . . . . .

7.9 Intervalo de Confiança - Confiabilidade. . . . . . . . . . . . . . 106

7.10 Influência dos Fatores - Confiabilidade. . . . . . . . . . . . . . . 106

7.11 Principais Efeitos - Confiabilidade. . . . . . . . . . . . . . . . . . . . . . . . . . .

7.12 Interação entre os Fatores - Confiabilidade. . . . . . . . . . . . . . 107

7.13 Intervalo de Confiança. . . . . . . . . . . . . . . . . 107

7.14 Intervalo de Confiança - Tempo de Resposta Médio. . . . . . . . . . . . . . . 108

7.15 Influência dos Fatores - Tempo de Resposta Médio. . . . . . . . . . . . . . 109

7.16 Principais Efeitos - Tempo de Resposta Médio. . . . . . . . . . . . . . . . 109

7.17 Interação entre os Fatores - Tempo de Resposta Médio. . . . . . . . . . . . 109

7.18 Intervalo de Confiança - Custo. . . . . . . . . . . . . . 110

7.19Influência dos Fatores - Custo. . . . . . . . . . . . . . . . 110

7.20 Principais Efeitos - Custo. . . . . . . . . . . . . . 110

7.21 Interação entre os Fatores - Custo. . . . . . . . . . . . . . 111

7.22 Intervalo de Confiança - Confiabilidade. . . . . . . . . . . . . . . . 111

7.23 Influência dos Fatores - Confiabilidade. . . . . . . . . . . . . . . . 112

7.24 Principais Efeitos - Confiabilidade. . . . . . . . . . . . . . 112

7.25Interação entre os Fatores - Confiabilidade. . . . . . . . . . . . . . . . . . . . . . . 112

7.26 Intervalo de Confiança. . . . . . . . . . . . . . . . . . 113

7.27 Intervalo de Confiança - Tempo de Resposta Médio. . . . . . . . . . . . . . . 114

7.28 Influência dos Fatores - Tempo de Resposta Médio. . . . . . . . . . . . . . . 114

7.29 Principais Efeitos - Tempo de Resposta Médio. . . . . . . . . . . . . . . . . . 114

7.30 Interação entre os Fatores - Tempo de Resposta Médio. . . . . . . . . . . . 115

7.31 Intervalo de Confiança - Custo. . . . . . . . . . . . . . . . 115

7.32 Influência dos Fatores - Custo. . . . . . . . . . . . . . . . . 116

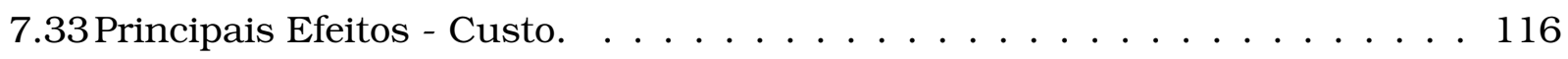

7.34 Interação entre os Fatores - Custo. . . . . . . . . . . . . . . . . 116

7.35Intervalo de Confiança - Confiabilidade. . . . . . . . . . . . . 117 
7.36 Influência dos Fatores - Confiabilidade. . . . . . . . . . . . . . . 117

7.37 Principais Efeitos - Confiabilidade. . . . . . . . . . . . 117

7.38 Interação entre os Fatores - Confiabilidade. . . . . . . . . . . . . . . 118

7.39 Intervalo de Confiança. . . . . . . . . . . . . . . . . . . . . . . . . . . . . 118

7.40 Intervalo de Confiança - Tempo de Resposta Médio. . . . . . . . . . . . . . 119

7.41 Influência dos Fatores - Tempo de Resposta Médio. . . . . . . . . . . . . . . 119

7.42 Principais Efeitos - Tempo de Resposta Médio. . . . . . . . . . . . . . 120

7.43 Interação entre os Fatores - Tempo de Resposta Médio. . . . . . . . . . . . 120

7.44 Intervalo de Confiança - Custo. . . . . . . . . . . . . . . . . 120

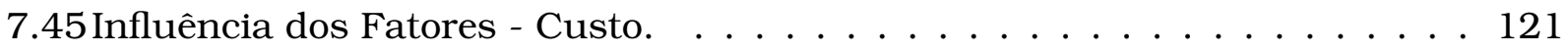

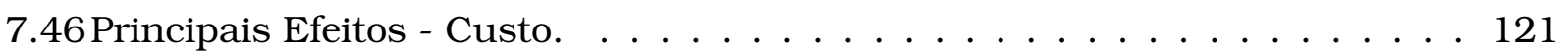

7.47 Interação entre os Fatores - Custo. . . . . . . . . . . . . . 121

7.48 Intervalo de Confiança - Confiabilidade. . . . . . . . . . . . . . . 122

7.49 Influência dos Fatores - Confiabilidade. . . . . . . . . . . . . . . . . . . . . . . . 122

7.50 Principais Efeitos - Confiabilidade. . . . . . . . . . . . 123

7.51 Interação entre os Fatores - Confiabilidade. . . . . . . . . . . . . . . 123

7.52 Intervalo de Confiança. . . . . . . . . . . . . . . . . . . 123

7.53 Intervalo de Confiança: Resumo. . . . . . . . . . . . . . . . . 124

7.54 Influência dos fatores - Tempo de Resposta Médio. . . . . . . . . . . . 125

7.55Influência dos fatores - Custo. . . . . . . . . . . . . . 126

7.56 Influência dos fatores - Confiabilidade. . . . . . . . . . . . 126

7.57 Efeitos dos fatores - Tempo de Resposta Médio. . . . . . . . . . . . . 127

7.58Efeitos dos fatores - Custo. . . . . . . . . . . . . . 127

7.59 Efeitos dos fatores - Confiabilidade. . . . . . . . . . . . 127

7.60 Interação dos fatores - Tempo de Resposta Médio. . . . . . . . . . . . . 128

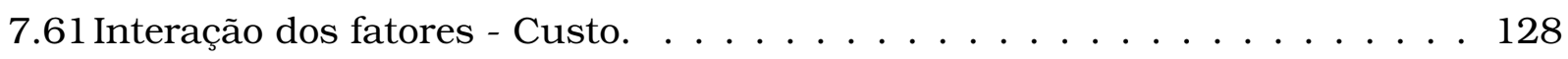

7.62 Interação dos fatores - Confiabilidade. . . . . . . . . . . . . . . 129

7.63 Eficiência do Algoritmo RG. . . . . . . . . . . . . . . . . . . . . . . 129

7.64 Eficiência do Algoritmo SD4c. . . . . . . . . . . . . . . . . . . . . . . . . . . . . . . . . . . . . .

7.65Eficiência do Algoritmo PD2c. . . . . . . . . . . . . . . . . 130

7.66 Eficiência do Algoritmo PDXc. . . . . . . . . . . . . . . . 131

7.67 Custos Médios para os Usuários A, B e C. . . . . . . . . . . . . 131

7.68 Sobrecarga dos Algoritmos de Alocação. . . . . . . . . . . . . . . . . 132 


\section{Lista de Tabelas}

2.1 Tabela de Rotas do Nó 67493 - (Androutsellis-theotokis e Spinellis, 2004) 24

3.1 Comparação entre os Metaescalonadores mais Conhecidos . . . . . . . . . . 37

4.1 Workload Engine - Estimação (\%) . . . . . . . . . . . . . . 51

5.1 Configuração do Ambiente de Testes (Fatores Fixos)

5.2 Projeto de Experimento

6.1 Fatores Fixos dos Experimentos . . . . . . . . . . . . . . 88

6.2 Projeto de Experimento

6.3 Projeto de Experimento

6.4 Projeto de Experimento

6.5 Projeto de Experimento

7.1 Fatores Fixos dos Experimentos . . . . . . . . . . . . 101

7.2 Projeto de Experimento

7.3 Projeto de Experimento

7.4 Projeto de Experimento 108

7.5 Projeto de Experimento 113

7.6 Projeto de Experimento 
7.7 Nome dos Fatores dos Experimentos 


\section{Lista de Abreviaturas}

API: Application Programming Interface

BoT: Bag-of-Tasks

CASA: Community Aware Scheduling Algorithm

CSF: Community Scheduler Framework

DC: Data center

DHT: Distributed Hash Table

DRIVE: Distributed Resource Infrastructure for a Virtual Economy

EC2: Elastic Compute Cloud

Iaas: Infrastructure as a Service

ISO/OSI: International Organization for Standardization / Open System Interconnection

IP: Internet Protocol

IDE: Integrated Development Environment

KVM: Kernel-based Virtual Machine

LRAM: Local Resource Allocation Manager

MACC: Metascheduler Architecture to provide BoS in Cloud Computing

MDS: Monitoring and Discovery System

MMDS: Manager of Monitoring and Discovery

NIST: National Institute of Standards and Technology

P2P: Peer to Peer

Paas: Plataform as a Service

PD2c: Predictive Dynamic 2 cores

PDXc: Predictive Dynamic $X$ cores

QoS: Quality of Services

RG: Random Generation

RTP: Real-time Transport Protocol

RTT: Round Trip-Time

SaaS: Software as a Service

SD4c: Slotted Dynamic 4 cores

SLA: Service Level Agreement

SIA: Standard Interface Access

SLA: Service Level Agreement

TB-WSLA: Template Base - Web Service Level Agreements

TCP: Transmission Control Protocol

TI: Tecnologia de Informação

WSRF: Web Services Resource Framework 
WWW: World Wide Web

vCPU: virtual CPU

VM: Virtual Machine

XML: eXtensible Markup Language 


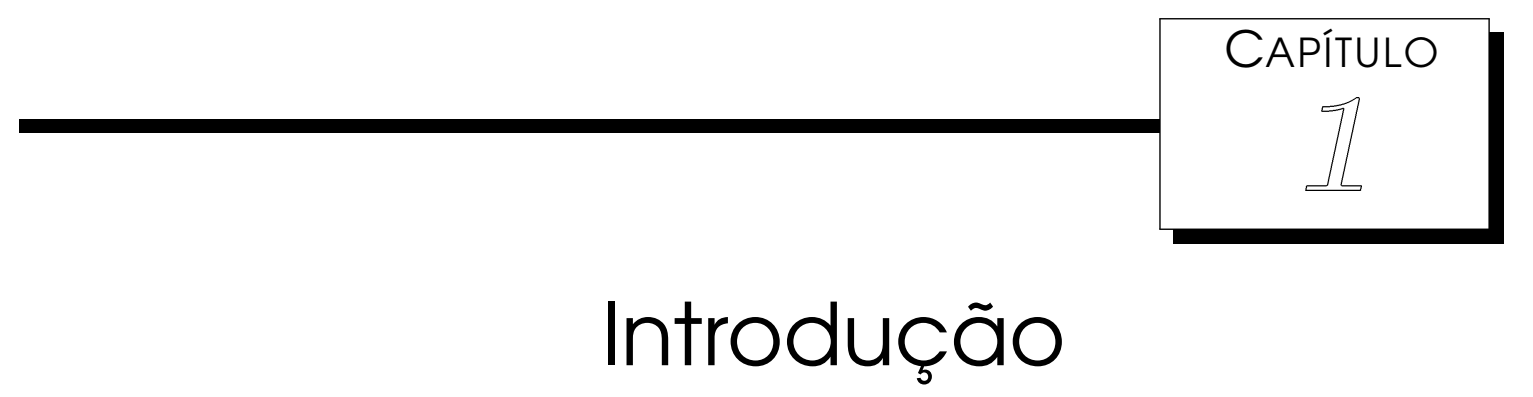

\subsection{Contextualização}

Em termos comercias, a Computação em Nuvens vem apresentando várias iniciativas comerciais, incluindo a Amazon Elastic Compute Cloud (EC2) ${ }^{1}$ e Google AppEngine ${ }^{2}$. Além disso, existem arquiteturas abertas para execuções científicas, tais como o Nimbus (Keahey et al., 2005) e o Eucalyptus (Nurmi et al., 2009) que proporcionam a difusão desse uso de paradigma computacional.

Devido a essas vantagens oferecidas pela Computação em Nuvem, esse modelo vem se difundido na indústria de Tecnologia da Informação (TI) e na academia (Xiong e Perros, 2009) (Kim et al., 2009) (Kamal, 2012). A Computação em Nuvem é um modelo desenvolvido para acesso a recursos e informação que se baseia em anos de pesquisas em várias áreas de computação, tais como sistemas distribuídos, virtualização, tolerância a falhas, balanceamento de carga, interoperabilidade, aplicações Web 2.0, Utility Computing e computação autônoma (Rimal et al., 2009).

O termo Computação em Nuvem origina-se de uma analogia a um conjunto de componentes que executam serviços para os clientes sob demanda, sendo que, em geral, o consumidor não tem ideia de onde esses serviços são processados, por isso se diz que os serviços estão sendo executados nas nuvens (Lee, 2010) (Wang et al., 2008). Um serviço na nuvem pode ser desde um aplicativo simples para verificar a previsão do tempo, até um ambiente de desenvolvimento integrado (IDE).

De acordo com o NIST - (National Institute of Standards and Technology) (Mell e Grance, 2011), a Computação em Nuvens é definida como um modelo que permite ubiquidade, conveniência e acesso sob-demanda para um conjunto de recursos compartilhados (redes, servidores e serviços) que podem ser rapidamente entregues com um esforço mínimo de gestão por parte dos usuários.

\footnotetext{
${ }^{1}$ http://www.aws.amazon.com/ec2/

${ }^{2}$ http://www.code.google.com/appengine/
} 
Na Computação em Nuvem, as requisições de usuário são processadas por entidades conhecidas como Data centers. Os Data centers podem utilizar a virtualização como principal mecanismo para a utilização eficiente do hardware. A virtualização é uma técnica que visa melhorar a utilização dos recursos de um sistema computacional, proporcionando escalabilidade durante o fornecimento dos serviços. Essa abordagem fornece oportunidade para indústria e para a academia, devido à sua flexibilidade de arquitetura (Ma et al., 2012).

\subsection{Motivação}

O desafio que está associado à virtualização é a capacidade de gerenciamento eficiente das máquinas virtuais visando aumentar a utilização dos recursos enquanto os serviços hospedados terão suas condições de contrato garantidas. Além disso, a virtualização deve proporcionar escalabilidade e tolerância a falhas. A partir dessas necessidades surge o ambiente conhecido como Intercloud. Dado que um Data center não possui recursos infinitos disponíveis, o ambiente Intercloud surge como uma maneira de manter o sistema de prestação de serviços disponível, mesmo quando um dos Data centers pertecentes a esse ambiente se encontrar em um estado sobrecarregado (Lu et al., 2011).

Intercloud é um ambiente que permite a utilização de recursos de uma forma escalável (Cayirci, 2011). Assim, o Intercloud funciona como uma rede global interligada, também conhecida como uma "nuvem de nuvens" (Buyya et al., 2010) (Chen et al., 2012). O conceito de Intercloud, que se tornou popular em 2009, permite resolver situações em que um cliente opta por usar um Data center que cumpre os acordos efetuados na SLA (Service Level Agreement), normalmente referente aos preços cobrados para serviços equivalentes (Toosi et al., 2011). Assim, por meio do Intercloud é possível estabelecer formas de pagamento em que o usuário paga pelo recurso em função do tempo utilizado, introduzindo uma nova oportunidade de negócio entre os provedores de serviços na Nuvem (Calheiros et al., 2012) (Mehdi et al., 2011).

Esses mecanismos que fornecem um ambiente com disponibilidade alta servem para ofertar aos provedores as condições necessárias de oferecimento de um nível adequado de qualidade de serviço (GoS). O oferecimento de GoS é necessário para garantir a satisfação do usuário, mesmo quando a carga de trabalho apresenta uma variabilidade alta de taxa de chegada e da taxa de serviço das requisições.

Garantir GoS não é uma tarefa trivial, especialmente no contexto de Computação em Nuvem (Pokharel e Park, 2009). Em função dos diversos tipos de consumidores, cada um com uma necessidade específica e a natureza imprevisível da Web, os recursos da Nuvem precisam ser monitorados, avaliados e adaptados continuamente a fim de assegurar um nível adequado de GoS (Cao et al., 2009) (Stantchev e Schröpfer, 2009) (Luo et al., 2010). Por conseguinte, a fim de proporcionar uma qualidade de serviço nesse ambiente é necessário dispor de um mecanismo de gestão dos recursos computacionais (Bernstein et al., 2011).

Vários pesquisadores investigam abordagens para usar Metaescalonadores, Brokers ou Coordenadores em um ambiente colaborativo de computação de alto desempenho 
(Quiroz et al., 2009) (Zhu e Agrawal, 2010) (Chieu et al., 2009) (Singhal et al., 2011) (Bi et al., 2010) (Rodero et al., 2010) (Jung et al., 2010) (Nguyen Van et al., 2009) (Cardosa et al., 2009) (An et al., 2010) (Gmach et al., 2009). Esses autores apresentam e discutem várias implementações, ferramentas e tecnologias para oferecer QoS nesses ambientes.

Esses estudos citados trabalham na forma reativa, ou seja, respondem a um estimulo, tais como as abordagens orientadas a feedback-control ou feed-forward. Ambas as técnicas sobre feedback envolvem a medição e ajuste de uma variável que é controlada por meio de uma retroalimentação. Entretanto, uma máquina leva em média 120 segundos para se ligar e permanecer em um estado funcional (Assunção et al., 2012). Isso significa que o tempo livre para realocar os recursos pode não ser suficiente, tornando essas técnicas insuficientes dependendo da carga de trabalho.

\subsection{Objetivo Geral}

Baseando-se na motivação apresentada na seção anterior, o objetivo deste trabalho é projetar, desenvolver e avaliar um metaescalonador que possibilite oferecer GoS em um ambiente de Intercloud. Para alcançar esse objetivo é proposta uma arquitetura de metaescalonamento que funciona de forma pró-ativa, e é chamada de MACC (Metascheduler Architecture to provide $\mathrm{BoS}$ in the Cloud Computing). O MACC monitora os recursos da Nuvem periodicamente e trata da gestão, fluxo de carga, escalonamento, execução e apresentação de resultados ao usuário. O MACC antecipa possíveis mudanças e melhora a capacidade de resposta do sistema. O funcionamento do MACC é dividido em duas etapas dependentes.

A primeira etapa envolve a busca de um data center localizado dentro da rede de comunicação da Intercloud que seja o mais adequado para o processamento dos serviços dos usuários. Nesse etapa, é necessário que os algoritmos de roteamento do MACC levem em consideração alguns dos parâmetros da rede, tais como: delay, jitter, largura de banda e distância.

Já a segunda etapa inicia-se quando o data center já foi escolhido. Nesse ponto, o MACC deve realizar a alocação organizada de recursos para que as restrições impostas pela SLA possam ser cumpridas, tais como: deadline e custo. Para isso, o MACC deve criar a quantidade de máquinas virtuais com as configurações adequadas para cada caso, sem que haja desperdício de recursos e de dinheiro. O modelo de controle pró-ativo utilizado no MACC procura prever o comportamento do sistema. Dessa forma, o MACC realiza a alocação de recursos de acordo com as necessidades do usuário. O componente Workload Engine está preparado para lidar com modelos que são conhecidos a priori, ou seja, é possível prever o comportamento com base em dados históricos.

A validação do MACC é realizada por meio de experimentos visando mostrar que os níveis de GoS desejados são obtidos. Os experimentos foram conduzidos de forma sistemática seguindo as técnicas estatísticas de planejamento de experimentos. Esses experimentos consideram os componentes do MACC e permitem identificar quais os fatores são os mais influenciam as métricas de QoS. 


\subsection{Estrutura}

O Capitulo 2 apresenta a fundamentação teórica sobre Computação em Nuvem, reunindo os principais conceitos utilizados no seu desenvolvimento e que são relevantes para este trabalho. A metodologia e a taxonomia sobre Metaescalonamento é mostrada no Capítulo 3. No Capítulo 4 é apresentada a arquitetura proposta neste trabaho - MACC Metascheduler Architecture to provide QoS in Cloud Computing, mostrando a estrutura geral de projeto e o funcionamento de cada componente. O Capítulo 5 apresenta um estudo sobre avaliação de desempenho sobre virtualização em uma Nuvem Privada. No Capítulo 6 aborda-se o modelo de comunicação utilizado pelo MACC e a sua avaliação de desempenho através de uma análise estatística. Já o Capítulo 7 aborda o modelo de alocação de máquinas virtuais utilizado pelo MACC e a sua avaliação de desempenho através de uma análise estatística. Por fim, no Capítulo 8 realiza-se as considerações finais e algumas direções para trabalhos futuros. 


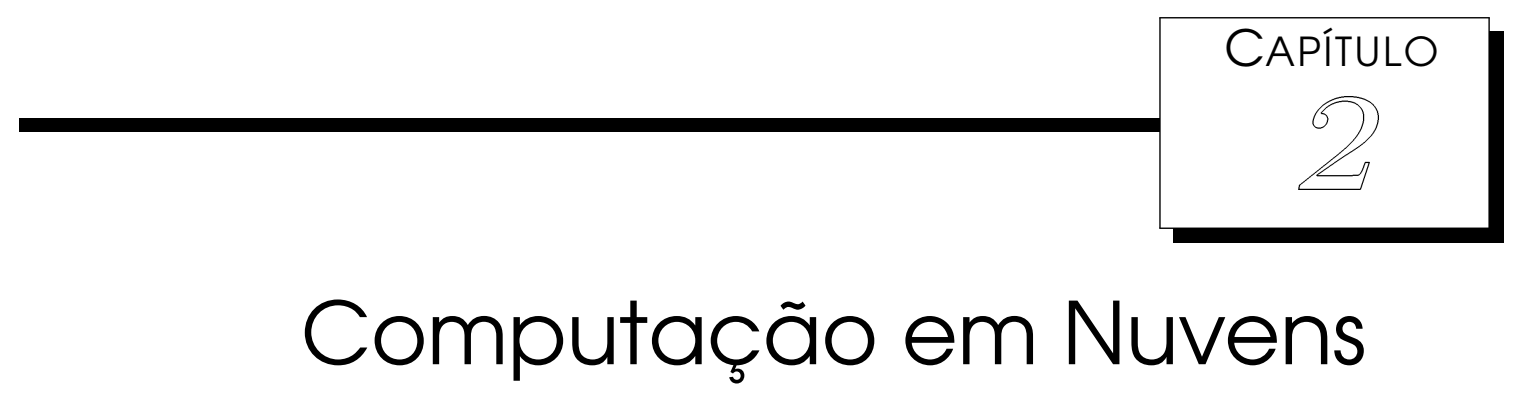

\subsection{Considerações Iniciais}

Neste capítulo são apresentados os aspectos conceituais que fundamentam a Computação em Nuvem. Esses aspectos conceituais relacionam as principais questões que envolvem o paradigma de Computação em Nuvem. O objetivo é mostrar os conceitos que estão relacionados com o metaescalonador para Computação em Nuvem descrito nesta tese, permitindo uma associação entre teoria e projeto.

\subsection{Definição de Computação em Nuvem}

Partindo da definição sobre Computação em Nuvens especificada pelo NIST, o modelo de Computação em Nuvens é composto de cinco características essenciais:

- Autoatendimento sob demanda: um consumidor pode provisionar recursos de computação, tais como processamento e armazenamento, sem a necessidade de interação humana com cada prestador de serviço.

- Acesso amplo à rede: recursos são disponibilizados sobre a rede e acessados através de mecanismos padronizados que permitam utilizar quaisquer tipos de plataforma, como por exemplo, telefones celulares, tablet, notebooks, e estações de trabalho.

- Agrupamento de recursos: os recursos são agrupados para atender múltiplos consumidores com diferentes recursos físicos e virtuais atribuídos dinamicamente à medida que a demanda do consumidor é alterada.

- Elasticidade eficiente: os recursos podem ser provisionados e liberados elasticamente, em alguns casos automaticamente, para se ajustar a necessidade, crescente ou decrescente. Para o consumidor, os recursos disponiveis para provisionamento 
parecem ser ilimitados e podem ser requisitados em qualquer quantidade e a qualquer momento.

- Monitoramento de serviço: os sistemas de Nuvem controlam e aperfeiçoam, automaticamente, o uso dos recursos, aproveitando uma capacidade de medição em algum nível de abstração apropriado para o tipo de serviço. O uso de recursos pode ser monitorado, controlado, criando-se relatórios que fornecem transparência, tanto para o provedor quanto para o consumidor.

\subsection{Modelos de Computação em Nuvens}

Vários estudos na literatura (Chieu et al., 2009), (Foster et al., 2008), (Leavitt, 2009), (Rimal et al., 2009) tem agrupado os serviços oferecidos pela Computação em Nuvem em três categorias. A primeira considera o Software como um Serviço (SaaS), caso em que o software que antes era instalado no computador do usuário, passa a ser fornecido como um serviço. A prestação desse serviço é possível devido ao avanço da Web 2.0, incluindo os Web Services (Peng et al., 2009).

Na segunda categoria tem-se a Plataforma como um Serviço (PaaS); onde as plataformas são fornecidas como um serviço, por exemplo, plataformas para desenvolvimento, como o Google Apps Engine e Microsoft Windows Azure. A PaaS pode ser usada para criar aplicativos web (SaaS), uma vez que fornece todas os recursos que seriam necessários, como um ambiente integrado de desenvolvimento e ambientes de teste (Rimal et al., 2009).

$\mathrm{Na}$ terceira categoria tem-se a Infraestrutura como um serviço (IaaS); sendo que a Infraestrutura computacional pode ser fornecida como um serviço através da tecnologia de virtualização.

As três categorias de serviços oferecidas formam as camadas da arquitetura da Computação em Nuvem, como ilustrado na Figura 2.1. Na visão bottom-up, é possível verificar a prestação de serviços que vão desde o hardware virtualizado, através da disponibilização de ambientes de construção de aplicações e, finalmente, a aplicação propriamente dita.

Analisando-se as características de implementação das nuvens que definem as restrições de acesso, pode-se identificar quatro modelos de implemetação de Nuvens (Carolan et al., 2009) (Mell e Grance, 2011):

- Nuvem Pública: Nuvens públicas são executadas por terceiros. Geralmente, eles fornecem serviços e infraestrutura para os consumidores. Este modelo de Nuvem é interessante para empresas que precisam de serviços flexíveis e temporários para executar uma tarefa, bem como para garantir a redução dos fatores de risco e custo. Os serviços da Nuvem podem ser gratuitos ou vendidos pelo provedor da Nuvem.

- Nuvem Privada: Nuvens privadas são construídas para adaptar as necessidades de um cliente específico. Trata-se de infraestrutura que pode ser alugada ou já é de propriedade do cliente. Além disso, neste modelo de Nuvem a gestão da 
Computação em Nuvem

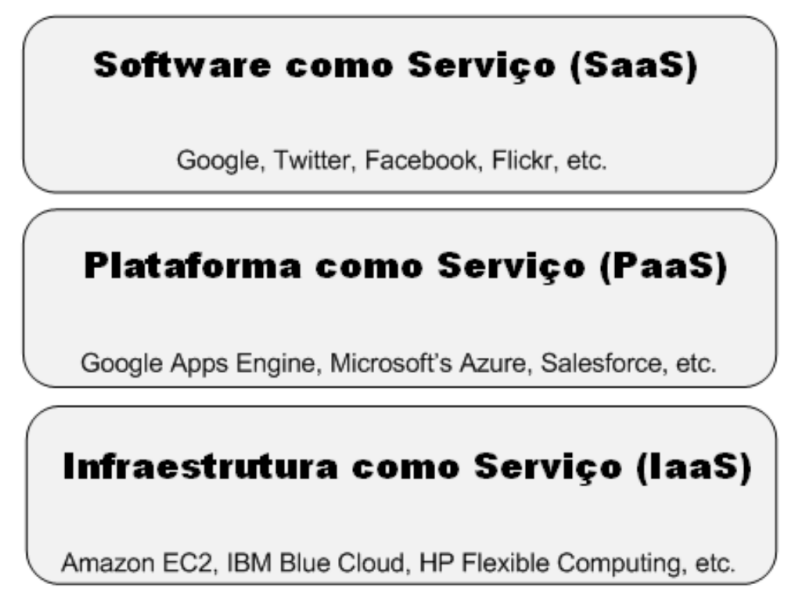

Figura 2.1: Arquitetura da Computação em Nuvem.

infraestrutura pode ser personalizada para as necessidades do cliente (controle sobre os dados, a segurança e a qualidade de serviço).

- Nuvem Híbrida: Nuvem híbrida é uma combinação de Nuvens públicas com Nuvens privadas e essa combinação pode melhorar a escalabilidade sob demanda. Além disso, este modelo é interessante devido ao fato de que quando uma Nuvem privada tem uma carga de trabalho alta, ela temporariamente compartilha o uso de recursos públicos para garantir o desempenho.

- Nuvem Comunitária: a infraestrutura de Nuvem é provisionada para o uso exclusivo de uma comunidade específica de consumidores que tem objetivos comuns, podendo ser controlada, gerenciada e operada por uma ou mais organizações pertecentes a essa comunidade.

Os modelos de Nuvem não representam, necessariamente, a localização física da Nuvem. Por exemplo, a Nuvem privada, apesar de representar um modelo de uma organização privada pode ser localizada externamente. No entanto, os clientes não precisam saber onde seus dados estão sendo processados ou armazenados. A ideia é que eles estão na "Nuvem"' e podem ser recuperados virtualmente na Internet.

\subsubsection{Benefícios da Computação em Nuvens}

Dependendo do cenário em que a Computação em Nuvens é empregada se podem obter benefícios. Entre os benefícios que as organizações podem obter estão relacionados (Carolan e Gaede, 2009):

- Redução do custo - Através do modelo de negócios da Computação em Nuvens os clientes pagam apenas pelos recursos que utilizarem, tais como ciclos computacionais, tráfego de entrada ou saída de dados e armazenamento, dentre outros. Outro ponto é evitar gastos com novos equipamentos necessários apenas momentaneamente. 
- Redução do capital de risco - O cliente apenas contrata o serviço do provedor da Nuvem, deixando os riscos fora da organização que contratou o serviço, uma vez que os novos equipamentos foram comprados pelo provedor e não pelo cliente. Já no caso de Nuvens privadas, o risco engloba toda a organização e não apenas individualmente cada sub-organização.

- Incremento de flexibilidade - As necessidades temporárias dos clientes podem ser satisfeitas rapidamente e sem novos investimentos em hardware.

- Maior agilidade nos negócios - A implantação de aplicativos novos e existentes no sistema de Computação em Nuvem é consideravelmente rápida, por isso se torna a plataforma perfeita para implantação das novas aplicações, aumentando a capacidade das já existentes.

\subsubsection{Riscos da Computação em Nuvens}

Como todo modelo, a Computação em Nuvens possui riscos a serem considerados (Carolan e Gaede, 2009):

- Risco do negócio - risco de rejeição ao realocar um aplicativo para uma Nuvem, onde os níveis de serviços não são comuns entre os provedores e os clientes.

- Barreiras arquitetônicas - devido a incompatibilidade do novo modelo arquitetural, alguns aplicativos podem ser impedidos de serem executados na Nuvem.

- Conformidade de regulamentação - questões de controle e segurança de negócios específicos, clientes ou dados pessoais ainda são discutidos na regulamentação dos serviços.

- Falta de visibilidade - cada provedor possui um nível de transparência, assim como políticas do serviço e dos processos de segurança.

- Latência - não é possível garantir uma regularidade do serviço, uma vez que o desempenho do mesmo está ligado com a latência da rede usada para acessar o serviço.

As tecnologias novas podem possuir benefícios e riscos que devem ser considerados individualmente para cada tipo de ambiente de Nuvem. A Computação em Nuvem não possui benefícios garantidos, tudo depende de um bom planejamento, de boas escolhas, do desenvolvimento dentre outros componentes que constituem o projeto. Um tipo de ambiente de Nuvem que possui certo potencial de vantagens é conhecido com Intercloud. A Intercloud surgiu a partir da necessidade dos provedores de Nuvens, que tinham como objetivo o oferecimento de GoS no contexto de balanceamento de carga, tempo de resposta e custo do serviço menores. O principal ponto para garantir condições ideias de infraestrutura ao ambiente Intercloud é o oferecimento de serviços on-demand e a utilização da técnica de virtualização (Buyya et al., 2010). 


\subsection{Virtualização na Computação em Nuvem}

A virtualização possibilita a execução de diversas máquinas virtuais em uma mesma máquina física, o que pode trazer benefícios como, flexibilidade, segurança e facilidade de configuração e gestão. O gerenciamento das máquinas virtuais é feito pelos hipervisores que controlam o acesso das máquinas virtuais ao hardware. O objetivo deste capítulo é realizar um estudo sobre o funcionamento e a influência dos hipervisores - (Xen e KVM) durante o processo de alocação de máquinas virtuais.

\subsubsection{Características Gerais de Virtualização}

A virtualização pode ser definida como a emulação de vários computadores lógicos em um único computador real, isso implica dizer que um único computador físico pode assumir o papel de vários computadores lógicos também chamados de máquinas virtuais (VMs). Cada máquina virtual fornece um ambiente completo aos seus utilizadores, semelhante a uma máquina física (Chieu et al., 2009). Assim, cada máquina virtual pode ter seu próprio sistema operacional, aplicações, serviços de armazenamento e rede (Carissimi, 2008). Virtualização é a principal tecnologia na Computação em Nuvem. Neste contexto, refere-se principalmente a abstração dos recursos físicos de TI para os usuários e aplicativos que os usam.

A virtualização permite que os servidores, dispositivos de armazenamento, hardware e outros possam ser tratados como um conjunto de recursos, em vez de sistemas separados, de modo que esses recursos podem ser alocados por demanda (Chieu et al., 2009). A virtualização de servidores oferece a opção de dividir os recursos computacionais, permitindo que diversas aplicações sejam executadas em ambientes isolados a partir de uma plataforma de hardware compartilhada ( $\mathrm{Pu}$ et al., 2010). A virtualização de um servidor permite que um único servidor físico execute simultaneamente mais de um sistema operacional, embora heterogêneos. Ao permitir que um servidor físico execute o software de virtualização, o uso de seus recursos se torna mais eficiente. Isso pode reduzir os custos operacionais e de gestão (Rose, 2004).

Podem-se resumir as tecnologias de virtualização em dois principais modelos. O primeiro modelo, chamado de Full virtualization oferece uma réplica do hardware subjacente, para que o sistema operacional e os aplicativos possam ser executados como se estivessem sendo executados diretamente no hardware (Carissimi, 2008). A principal vantagem dessa abordagem é que o sistema operacional hospedeiro é executado sem modificações na máquina virtual, que é a sua grande vantagem. Porém, existe um incoveniente dessa opção que é o número grande de dispositivos em um computador, sendo difícil implementá-los em uma máquina virtual de modo que seu comportamento seja idêntico ao seu funcionamento em uma máquina física. Para minimizar as desvantagens citadas, implementações de Full virtualization utilizam dispositivos genéricos que funcionam bem para a maioria dos dispositivos disponíveis, mas não garantem o uso de sua capacidade total. Além disso, alguns problemas técnicos gerados pela forma como os sistemas operacionais são implementados devem ser contornados, já que esses têm 
sido implementados para executar como uma única instância em uma máquina física, não disputando recursos com outros sistemas operacionais. Por exemplo, um sistema operacional convencional implementa memória virtual por paginação. Todo o processo de atribuição de gestão, lançamento e controle de acesso para as páginas devem ser respeitados. Para isso, o espaço de endereçamento do sistema host deve ser convertido para permitir a competição de recursos, resultando em desempenho reduzido.

O segundo modelo de virtualização, conhecido como Paravirtualização, é uma alternativa para contornar as desvantagens de "Full virtualization".' Nesse modelo, o sistema operacional é modificado para que a chamada para uma instrução sensível (instrução que altera o estado do sistema) seja substituída por uma chamada para um manipulador de interrupção de software (Carissimi, 2008). Com isso, a máquina virtual não precisa testar instrução por instrução, o que representa um ganho significativo no desempenho. Outra vantagem desse modelo é que os dispositivos de hardware são acessados por drivers próprios da máquina virtual, eliminando o uso de drivers genéricos que inibem o uso da capacidade total do dispositivo.

Assim, o modelo de Full virtualization não permite mudanças em um host executando em uma máquina virtual, ao contrário da Paravirtualização, onde os hosts devem ser modificados para ver a máquina virtual. Além disso, a Paravirtualização explora de forma mais adequada os recursos disponíveis da máquina física, porque os dispositivos de hardware são acessados pelos próprios drivers da VM - (Virtual Machine).

Dada as técnicas e tecnologias presentes, a virtualização está adaptada a infraestrutura dinâmica da Nuvem, porque oferece vantagens importantes para a gestão, compartilhamento e isolamento de recursos (Chieu et al., 2009). A virtualização pode ser definida como uma emulação de uma ou mais estações de trabalho/servidores em um único computador físico, em outras palavras, um único computador físico pode assumir o papel de vários computadores. A virtualização permite particionar um único sistema computacional em vários outros, esse paradigma é conhecido como máquinas virtuais. Cada máquina virtual fornece um ambiente completo muito similar a uma máquina física. Assim, cada máquina virtual pode ter seu próprio sistema operacional, aplicações e serviços de rede (Carissimi, 2008).

A Computação em Nuvem utiliza a virtualização como parte fundamental para alcançar seus objetivos de negócios. Os provedores de Computação em Nuvem, como a Amazon EC2 por exemplo, normalmente utilizam o virtualizador Xen (Barham et al., 2003) para virtualizar as máquinas que são fornecidas aos seus usuários (Rimal et al., 2009). Porém, para a criação de máquinas virtuais, além do Xen, existem ainda outros virtualizadores como: KVM (Kernel-based Virtual Machine) (Habib, 2008), Vmware (Rosenblum, 1999), Virtualbox (Watson, 2008) entre outros. Esses virtualizadores possuem como propósito geral virtualizar máquinas para o uso compartilhado. Contudo, apresentam características de implementação e visam atingir objetivos diferentes.

Existem na literatura trabalhos sobre avaliação de desempenho de virtualizadores, tais como: (Pu et al., 2010) (Pu et al., 2012) (You et al., 2009) (Ibrahim et al., 2011) (Liu et al., 2010), alguns considerando especificamente os virtualizadores Xen e/ou KVM (Lee et al., 2011) (Che et al., 2010), (Deshane et al., 2008), (Che et al., 2008), (Xu et 
al., 2008). Segundo (Che et al., 2008), a virtualização traz vantagens, entretanto traz também algumas desvantagens que levam a sobrecarga de desempenho. Um fator a ser considerado é o hipervisor, que atua como um componente do núcleo causando impacto no desempenho do sistema. Além disso, a virtualização da CPU, memória e operações de entrada e saída (I/O) são aspectos principais na concepção de monitores de máquinas virtuais. Por esse motivo, a avaliação dos monitores de máquinas virtuais é importante.

Em (Che et al., 2008) são avaliados os virtualizadores Xen e KVM, considerando fatores como: uso intensivo de CPU e desempenho em operações de leitura e escrita. O resultado obtido demonstrou que o Xen possui desempenho melhor do que o KVM em atividades estritamente CPU-bound e um desempenho pior nos testes que envolveram o uso de operações de I/O intensivo. Foram avaliadas também as principais características das máquinas virtuais com relação ao isolamento e escalabilidade. A maior diferença entre os virtualizadores está relacionada à escalabilidade, sendo que o Xen apresentou uma escalabilidade adequada, sendo capaz de compartilhar recursos de forma justa entre as máquinas virtuais.

No trabalho de Xu et al. (2008), além dos virtualizadores Xen e KVM, o virtualizador Vmware também foi utilizado na avaliação. Essa avaliação foi composta por: avaliação do desempenho global, isolamento e escalabilidade. Os resultados obtidos em relação aos fatores avaliados mostraram que a maior diferença de desempenho entre os virtualizadores foi constatada no teste de uso intensivo de I/O utilizando a rede, onde tanto o Vmware quanto o Xen apresentaram bons resultados. Esse comportamento se deve ao fato da eficiência das tecnologias implementadas com relação ao módulo de suporte de rede. O KVM obteve o pior desempenho devido aos módulos de rede do KVM serem novos e ainda estarem em fase de testes causando diminuição de desempenho. Quanto à escalabilidade, o Xen, assim como em trabalhos anteriores, provou ser a melhor solução com relação à escalabilidade fornecendo tempos escaláveis entre as máquinas virtuais.

\subsubsection{Virtualizadores}

Um dos pontos que devem ser observados quando se deseja utilizar virtualização é qual o propósito do sistema e consequentemente qual virtualizador deverá ser utilizado. Os virtualizadores são os responsáveis por proverem uma interface para administração e configuração das VMs.

\section{XEN}

Xen é um virtualizador para arquitetura $x 86$, que permite a execução de diversos sistemas operacionais nas máquinas virtuais, realizando o isolamento de recursos entre elas. O Xen é um software Open Source, lançado sob os termos da GNU. Qualquer distribuição Linux (Red Hat, SUSE, Debian, Mandrake) pode ser utilizada como host ou máquina física hospedeira (Crosby e Brown, 2006) (Barham et al., 2003).

A Figura 2.2 apresenta a arquitetura do hypervisor Xen. No topo do hypervisor existem dois tipos de máquinas virtuais denominadas "Domínios". O Domínio 0 ou 


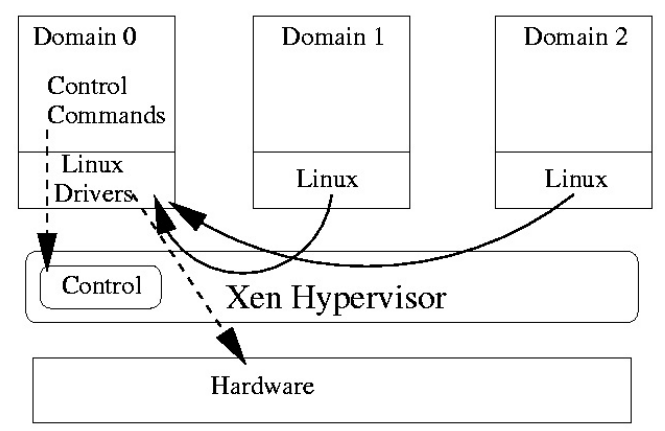

Figura 2.2: Arquitetura Xen - (Gienger, 2011b)

Dom0 é uma máquina virtual que possui privilégios para controlar o hypervisor, ou seja, todo acesso que necessite de recursos específicos ou recursos que tenham proteção com relação à concorrência devem passar pelo Dom0. Diferente do Dom0, o Domínio U ou DomU é uma máquina virtual normal, ou seja, é a máquina do usuário que está em funcionamento no host (Crosby e Brown, 2006). Uma característica que pode ser observada na Figura 2.2 é que o Xen funciona como paravirtualização, podendo aceitar outros sistemas operacionais.

Tanto o Dom0 quanto DomU precisam de sistemas operacionais especiais, isso se deve ao fato do Xen ser paravirtualizado. A VM não acessa as funcionalidades de hardware em baixo nível (acesso ao kernel), mas possui uma API padrão para comunicação com o hypervisor (XENBUS e dispositivos). Já o Dom0 é uma máquina virtual especial, uma vez que ela é quem faz as ligações entre os drivers dos dispositivos e o acesso direto ao kernel. Assim, o Domo tem acesso a todos os dispositivos e as DomUs não têm nenhum acesso privilegiado aos dispositivos (Crosby e Brown, 2006).

Além dessas características, o XEN permite que se manipule uma porção do processador. Através do comando sched-credit é possível determinar qual a porcentagem da utilização do core do processador.

\section{KVM}

O KVM (Kernel-based Virtual Machine) é um virtualizador do tipo virtualização completa com extensões de virtualização (Intel VT ou AMD-V). Assim, o KVM consiste em um módulo de kernel (kvm.ko), que fornece a infraestrutura de virtualização e um módulo de processador específico, intel.ko kvm ou amd.ko kvm (KVM, 2011).

Com o KVM é possivel executar múltiplas máquinas virtuais, em paralelo, sem a necessidade de modificar as máquinas convidadas. Cada máquina virtual possui um conjunto de hardware virtual privado: uma placa de rede, disco, placa gráfica, etc. A visão geral do KVM é ilustrada na Figura 2.3.

Os módulos de virtualização executam em modo kernel e quando a máquina virtual necessita realizar um acesso ao disco, por exemplo, o virtualizador trata essa requisição como uma solicitação de leitura de um programa comum, evitando assim passar por mais uma camada de software como ocorre no Xen (KVM, 2011) (Crosby e Brown, 2006). 


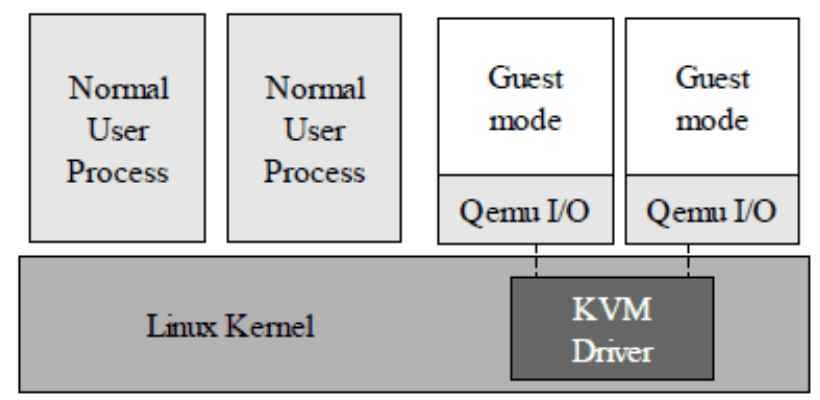

Figura 2.3: Arquitetura KVM (Gienger, 2011a).

O monitor de virtualização é considerado uma ferramenta dentro de um ambiente colaborativo, fornecendo melhores condições para que os provedores de serviço possam oferecer QoS aos usuários.

\subsection{Intercloud}

Os recursos da Nuvem (hardware e software) são, normalmente, limitados em termos de capacidade. E esse problema é agravado quando um único provedor de Nuvem (único Data center) oferece serviços para uma quantidade grande de usuários (Assunção et al., 2010). Dessa forma, conforme o número de consumidores de recursos aumenta torna-se mais complicado realizar o balanceamento de carga e por consequência melhorar o GoS oferecido (Sotiriadis et al., 2011).

Uma possibilidade para garantir o oferecimento de GoS é a união dos provedores de Nuvens, formando uma nova infraestrutura, chamada Intercloud, vista na Figura 2.4. Nesse caso, o compartilhamento é motivado por um escopo global que impulsiona o desempenho (Sotiriadis et al., 2011).

O ponto central sobre Intercloud está na hipótese que cada provedor de Nuvem não possui recursos suficientes. Se o provedor sobrecarregar sua infraestrutura computacional não será possível atender novas solicitações de serviço. Assim, cada provedor de Nuvem poderia requisitar o uso de recursos computacionais de outros provedores pertencentes aquele ambiente.

Para viabilizar o acesso aos recursos entre os provedores de uma Intercloud torna-se necessário a existência de interfaces abertas e padronizadas. Grandes empresas como a HP, Intel, Yahoo e outras tem iniciado esforços para desenvolver essas interfaces (Buyya et al., 2010).

Outro tema que tem sido estudado está relacionado ao conceito de conectar os recursos. Esse tema é vinculado a Meta-computação e envolve pricipalmente a questão sobre o escalonamento de recursos. Nesse caso, o escalonamento não é um problema específico, mas um conjunto de problemas, devido às diferentes necessidades e várias características de cada grupo de recursos. De modo semelhante, o escalonamento em Intercloud pode ser visto como um mecanismo de escalonamento de Meta-computação, 


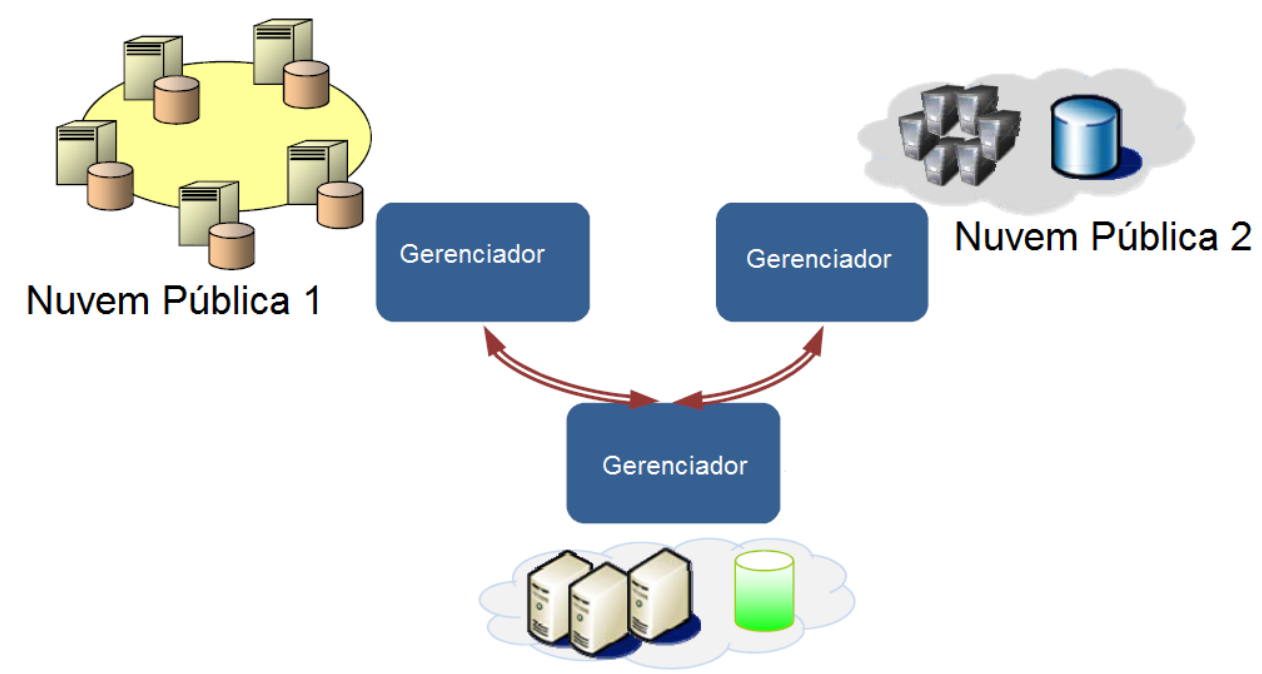

Nuvem Pública 3

Figura 2.4: Modelo do ambiente Intercloud - Adaptado de (Buyya et al., 2010).

no qual um conjunto de recursos interconectados formam uma comunidade colaborativa (Christodoulopoulos et al., 2009) (Xhafa e Abraham, 2010) (Sotiriadis et al., 2011).

A forma de pagamento pelo uso dos recursos oferecidos por provedores de Nuvens geram oportunidades de negócios entre os fornecedores, introduzindo assim o conceito de Mercados Econômicos em Computação em Nuvens, que será discutido na próxima seção.

\subsection{Modelos Econômicos}

Em um ambiente de Computação em Nuvem, existem os produtores (donos de recursos, que utilizam os data centers) e os consumidores (usuários de recursos) e cada um deles tem seus próprios objetivos. Além disso, tanto os recursos quanto os usuários estão geograficamente distribuídos em zonas de tempos diferentes ${ }^{1}$. As abordagens mais comuns para o gerenciamento de um ambiente complexo como esse podem utilizar políticas orientadas ao sistema ou orientadas ao usuário.

A abordagem orientada ao sistema visa otimizar o desempenho do sistema e é comumente usada em gerenciamento de recursos em um único domínio administrativo. As abordagens orientadas ao sistema adotam uma estratégia convencional, cujo objetivo é melhorar o desempenho do sistema, por exemplo: throughput, utilização, e taxa de execução mais breve, na qual o escalonamento decide quais serviços são executados em qual configuração de recurso.

As abordagens orientadas ao usuário, por outro lado, concentram esforços para atendimento das questões que envolvem os usuários e contribuem com o cumprimento de requisitos de GoS. Um exemplo dessa abordagem é a garantia de certos níveis de desempenho baseados em atributos de usuários, tais como a deadline e o custo (Buyya

\footnotetext{
${ }^{1}$ Respectivos fusos-horários.
} 
et al., 2002). Isso significa que os usuários podem negociar um preço particular para processamento de sua requisição baseado na demanda, no valor absoluto, na prioridade, ou no orçamento previsto, levando a um modelo baseado em economia (Buyya et al., 2002).

As características de um escalonamento baseado em economia levam em consideração a dinamicidade do ambiente e são orientadas e direcionadas especificamente aos usuários finais. O modelo baseado em economia preocupa-se com os serviços prestados a um usuário final e que eles paguem pelo acesso a um recurso de acordo com o valor negociado. As políticas baseadas em preço funcionam de acordo com a demanda dos usuários e as ofertas dos recursos, o que leva a uma competição nesse modelo. Assim, um usuário compete com outros usuários e os proprietários de recursos competem com outros proprietários de recursos.

Modelos baseados em economia competitiva fornecem políticas/algoritmos e ferramentas para o compartilhamento de recursos em sistemas de Computação em Nuvem. Esses modelos podem ser baseados em "escambo" ${ }^{2}$ ou por preço. No modelo baseado em escambo, todos os participantes devem possuir um recurso para trocá-lo por outro, por exemplo, trocar uma unidade de armazenamento de dados por ciclos de processamento. Por outro lado, no modelo baseado em preço, todos os recursos têm um preço, que é baseado na demanda, oferta, valor, e a riqueza em um sistema econômico. Adicionalmente, pode-se assegurar a estabilidade, ou seja, o equilíbrio financeiro da Grade (Berman et al., 2003).

Com relação aos mecanismos de gerência de uma Computação em Nuvem, é necessário que os serviços prestados levem em consideração tanto os consumidores de recursos quanto os proprietários, e que eles continuem adaptados com relação às mudanças nas disponibilidades do ambiente. Esses requisitos introduzem um número substancial de desafios relacionados a virtualização que precisam ser resolvidos tais como: autonomia, heterogeneidade, políticas, alocação de recursos, controle online, negociação de recursos e escalonamento baseado em $\operatorname{QoS}$.

Os benefícios de se adotar uma abordagem baseada em economias são, (Buyya et al., 2002):

- contribuir para o crescimento da malha colaborativa, oferecendo incentivo para os proprietários de recursos, uma vez que eles lucram com a disponibilização de seus recursos.

- ajudar a regular a oferta e demanda para os recursos.

- oferecer um incentivo econômico para os usuários reduzirem suas prioridades de execução de serviço em troca de um menor gasto, dessa forma, os serviços mais críticos são realizados primeiramente.

- prover uma base comum para comparação de necessidades por meio da opção dos usuários expressarem seus requisitos e objetivos sob os termos atuais.

\footnotetext{
${ }^{2} \hat{E}$ a troca de um bem ou serviço por outro.
} 
- oferecer um tratamento igual para todos os recursos. Permitindo a negociação de diferentes recursos, incluindo potência computacional, memória, armazenamento, latência e largura de banda de rede, dados e outros dispositivos.

- permitir a construção de sistemas escaláveis já que existe uma infra-estrutura distribuída sobre todos os usuários e proprietários de recursos.

- fornecer uma base efetiva e simples para serviços diferenciados por aplicações diferentes em tempos diferentes.

\subsubsection{Estruturas de Mercado}

Uma estrutura de mercado pode influenciar o preço adotado, pois ela é dependente de três variáveis principais: número de entidades produtoras, diferenciação do produto e a existência de barreiras e entradas de novas empresas. Em uma estrutura de concorrência ideal podem ser identificadas as seguintes hipóteses (Vasconcellos, 2002):

- Atomicidade: existem muitos vendedores e compradores, de tal forma que a saída de algum deles não irá influenciar a economia de forma geral.

- Homogeneidade: não existe diferença entre os bens ou serviços de mesma finalidade que são produzidos. Assim, não existe a necessidade de um comprador criar preferências.

- Mobilidade de agentes: não existem impedimentos para entrada de vendedores ou compradores ao mercado.

- Racionalidade: os vendedores têm o objetivo de maximizar seus lucros, enquanto os compradores sua satisfação.

- Transparência de mercado: todos os participantes envolvidos no mercado possuem acesso livre as informações, tais como: preços, orçamentos, lucros dos concorrentes.

- Mobilidade de bens: não são considerados critérios que envolvam a localidade. Portanto, não existe preferência em função da distância do vendedor.

Já uma estrutura de mercado de concorrência imperfeita é mais próxima da realidade das características de:

- Várias empresas produzindo um bem ou serviço com a mesma finalidade.

- Fornecimento de bem ou serviço diferenciado como forma de atrair clientes.

- Modificações dos preços dos seus próprios bens ou serviços.

Nestes casos, a diferenciação de serviço acontece quando o fornecedor promove seu serviço com características de qualidade, com alguma especificação técnica superior ou algum meio promocional, como brindes. 
Em um mercado de concorrência imperfeita é comum acontecer o Oligopólio, que é uma estrutura onde existem poucos vendedores, restringindo a:

- Concentrado: ocorre quando um setor possui poucos vendedores e os compradores ficam sem opções de compra.

- Competitivo: ocorre quando um setor possui vários vendedores, porém o domínio de mercado $^{3}$ fica sob um número de poucos vendedores.

Já em uma estrutura de Monopólio, apenas uma empresa domina o mercado, impossibilitando que os compradores possam escolher outros vendedores. Dessa forma, a estrutura propicia ao vendedor maximizar seus lucros, pois ele é livre para determinação de preços de seus bens ou serviços (Teixeira, 2006).

\section{Localização e Negociação por Recursos}

Quando um cliente necessita utilizar um recurso da Nuvem, normalmente, ele deve descrever no mínimo três parâmetros: as características do recurso a ser utilizado, o preço máximo a ser pago, e o prazo para execução do pedido (Buyya et al., 2005). Essas informações são utilizadas para iniciar o processo de localização de recursos que possam atender os critérios especificados e selecionar o recurso a ser utilizado. O componente responsável por essa função é o Metaescalonador.

No processo de negociação, tanto o Metaescalanador quanto o provedor de recurso podem efetuar alterações nos parâmetros contratuais (alterar o valor do orçamento, mudança no prazo de execução, dentre outros). Quando é encontrado um ponto que ambos os lados ficam satisfeitos a negociação é dita como atendida, caso contrário, ela não irá obter sucesso (Teixeira, 2006).

De acordo com a necessidade do usuário o Metaescalonador pode atuar de formas distintas, (Buyya et al., 2005):

- Otimização do deadline: Este tipo de estratégia realiza o processamento do serviço o mais rápido possível, mas não deixa de cumprir a restrição do orçamento contratado.

- Otimização do preço: Este tipo de estratégia preocupa-se primeiramente com o orçamento, mas apesar de reduzir os custos fica dentro do prazo contratado.

\section{Mecanismos de Pagamento}

Quando se utiliza o modelo econômico em Computação em Nuvem é necessário que exista um mecanismo de pagamento. É através desse mecanismo que serão efetuados o controle do saldo de cada um dos participantes e a transferência de créditos referentes à utilização de um recurso compartilhado. Para um participante utilizar um recurso é necessário que ele tenha créditos. Existem alguns mecanismos para o pagamento ser efetuado:

\footnotetext{
${ }^{3}$ Preferência do consumidor.
} 
- Pré-pago: o usuário paga pelo acesso a um recurso antes de iniciar utilização.

- Pós-pago: o usuário só irá pagar depois de utilizar o recurso.

- PAYGO (Pay as you go): o pagamento é feito de forma progressiva, à medida que se vai utilizando.

Pode-se efetivar o pagamento através de (1) NetCheque, onde os usuários registrados em servidores de contas do NetCheque podem escrever cheques e enviá-los para os provedores de serviços. Quando depositado, o saldo é transferido automaticamente entre as contas de crédito e débito. (2) NetCash, esse tipo de esquema suporta o anonimato e utiliza o sistema do NetCheque para realizar a troca de saldos. (3) Paypal, é um esquema que utiliza cartão de crédito para efetuar o pagamento. A transação é criptografada utilizando uma chave pública e só pode ser lido pelo credor, ou, dependendo da abordagem, por um terceiro elemento responsável que está envolvido na negociação (Buyya et al., 2001).

\subsection{Abordagem de Comunicação P2P}

Os sistemas ponto a ponto (P2P) surgiram em consequência ao crescimento da Internet, que abrange milhões de computadores e de usuários, exigindo acesso a recursos compartilhados (Subramanian e Goodman, 2005). Os sistemas P2P representam uma forma de construir sistemas e aplicativos distribuídos, onde os dados e recursos computacionais são derivados da colaboração de muitos pontos na Internet de maneira uniforme. Os pontos que compõe uma rede P2P podem atuar tanto como servidores quanto como clientes sem uma coordenação centralizada (Subramanian e Goodman, 2005).

Os recursos em redes P2P são completamente independentes de localização e os pontos podem entrar ou sair do sistema de forma imprevisível dependendo da disponibilidade do ponto que possua o recurso (Jin et al., 2008). Os serviços prestados por essas redes, na maioria das vezes, são baseados em compartilhamento de arquivos (por exemplo, Gnutella ${ }^{4}$ Kazaa $^{5}$ ) ou sistemas que utilizam transferência de dados em tempo-real (por exemplo, a telefonia, com o Skype (Baset e Schulzrinne, 2004)) (Jin et al., 2008).

A abordagem utilizada neste projeto não se baseia na troca ou compartilhamento de arquivos, mas sim no acesso aos recursos da topologia P2P por meio do roteamento de requisições entre os participantes do ambiente de Nuvem.

\subsubsection{Topologias em Redes P2P}

A topologia refere-se a comunicação que une o ponto que agrega os recursos e os pontos que solicitam esses recursos. Essa comunicação é representada entre os pares de pontos e é feita diretamente através de uma conexão.

\footnotetext{
${ }^{4}$ http://rfc-gnutella.sourceforge.net/

${ }^{5}$ http://www.kazaa.com/
} 
As redes $\mathrm{P} 2 \mathrm{P}$ podem possuir diferentes topologias dependendo do objetivo da aplicação (Subramanian e Goodman, 2005). A topologia centralizada, apresentada na Figura 2.5, é baseada no conceito cliente/servidor. É necessário um servidor centralizado, que é usado para gerenciar os arquivos e bancos de dados dos usuários. O cliente conecta-se ao servidor para informar seu endereço e os nomes de todos os recursos disponíveis que ele está disposto a compartilhar. Isso é feito toda vez que o aplicativo é iniciado. As informações coletadas pelos pares são utilizadas pelo servidor para criar um banco de dados centralizado que mapeia os nomes de arquivos para conjuntos de endereços (Subramanian e Goodman, 2005).

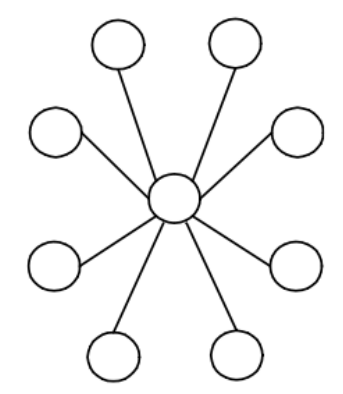

Figura 2.5: Topologia Centralizada (Subramanian e Goodman, 2005)

A topologia centralizada possui a desvantagem de possuir um servidor central que pode se tornar um gargalo e um ponto único de falha (Subramanian e Goodman, 2005). Em contraste à topologia centralizada existe a topologia em anel, apresentada na Figura 2.6.

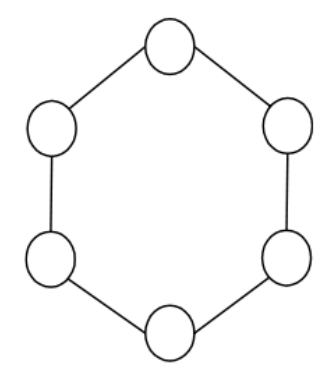

Figura 2.6: Topologia em Anel (Subramanian e Goodman, 2005)

A topologia em anel consiste em um conjunto de máquinas que trabalham em conjunto para proporcionar balanceamento de carga e alta disponibilidade. Esta topologia é geralmente usada quando todas as máquinas estão relativamente próximas na rede, o que leva essa topologia a ser utilizada dentro de uma organização onde os pontos são conhecidos.

Outra forma de estruturar uma topologia é usar hierarquias. Uma topologia hierárquica pode ser entendida como a forma de estruturar os pontos que formam a rede seguindo uma estrutura logica de ligações. Essa forma de topologia assemelha-se a uma árvore (Subramanian e Goodman, 2005), a Figura 2.7 apresenta essa topologia.

Diferente da topologia hierárquica que possui uma organização lógica de pontos, tem-se a topologia não hierárquica ou descentralizada, Figura 2.8. Nas primeiras 


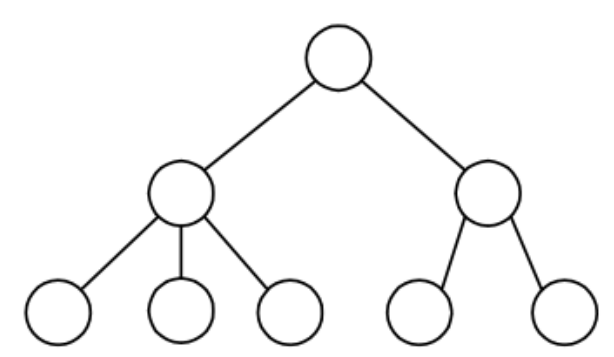

Figura 2.7: Topologia Hierárquica (Subramanian e Goodman, 2005)

concepções de redes P2P, um dos objetivos era criar redes sem um servidor centralizado. Assim, quando um ponto deseja se conectar a rede, ele se comunica com um ponto que sempre esta disponivel. Esse ponto fornece o endereço de um ou mais pares já existentes. Cada ponto possui informações sobre seus vizinhos (Subramanian e Goodman, 2005).

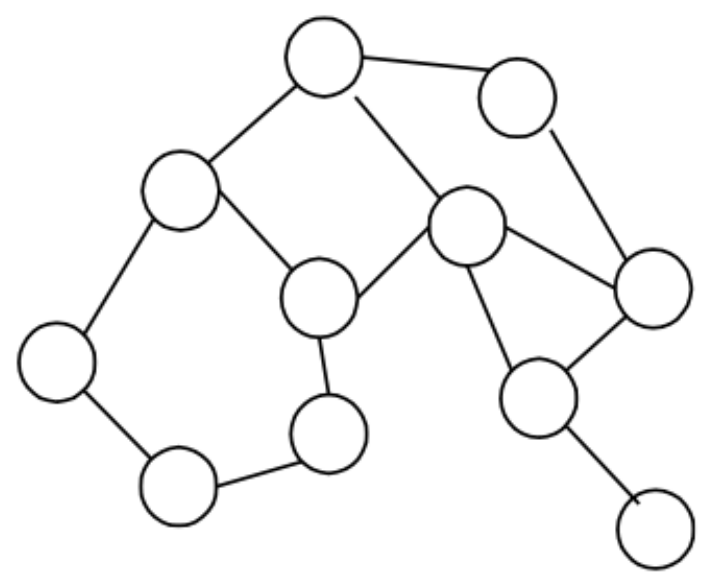

Figura 2.8: Topologia Não-hierárquica (Subramanian e Goodman, 2005)

As topologias, nos sistemas P2P, podem ser utilizadas em sua forma básica, como apresentadas nesta seção, ou podem ser combinadas para formar sistemas mais complexos. A combinação das topologias depende da aplicação que irá utilizar esta topologia.

Um exemplo de combinação de topologias é apresentado na Figura 2.9, que é o modelo utilizado pelo skype, que combina a funcionalidade de servidores centrais para o armazenamento de informação de localidade e é não-hierárquico (Baset e Schulzrinne, 2004).

\subsubsection{Roteamento P2P}

$\mathrm{O}$ roteamento em redes $\mathrm{P} 2 \mathrm{P}$ podem seguir duas abordagens: estruturada $\mathrm{e}$ não-estruturada. A abordagem estruturada utiliza uma DHT (Tabela Hash Distribuída), e é formado por um sistema estruturado e distribuído que forma uma rede de sobreposição (Jin et al., 2008)(Androutsellis-theotokis e Spinellis, 2004). 


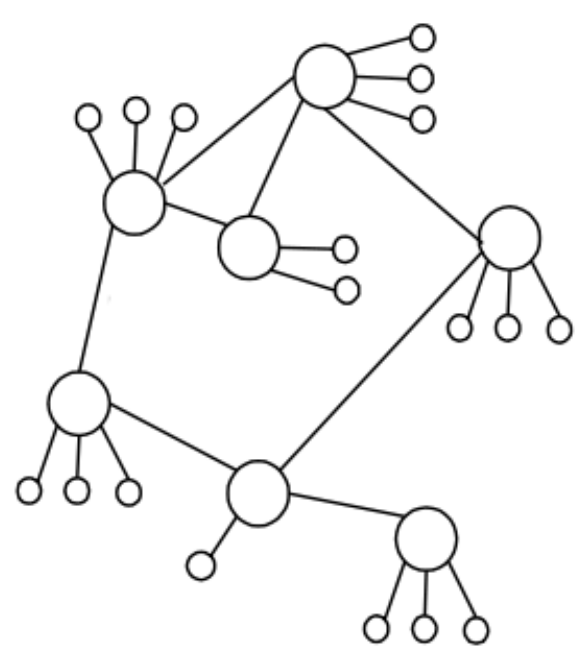

Figura 2.9: Topologia Centralizada e Não-hierárquica (Subramanian e Goodman, 2005)

Por outro lado, a abordagem não-estruturada é caracterizada por não possuir organização predefinida para uma topologia de sobreposição (Quinellato, 2009). Os pontos ao se conectarem, estabelecem conexões aleatórias entre os participantes e a busca por um recurso se baseia na propagação de mensagens (inundação). As redes P2P não-estruturadas utilizam técnicas como força bruta, busca em largura e busca em profundidade para a busca de serviços, que aumentam a complexidade da busca por um recurso dentro da rede (Androutsellis-theotokis e Spinellis, 2004). Esses tipos de redes possuem como vantagem o custo com a manutenção da rede (entrada, saída e organização dos pontos) com algoritmos simples se comparados com os utilizados na abordagem estruturada (Quinellato, 2009).

Os DHTs das redes estruturadas possuem uma tabela hash, que posiciona os arquivos em locais determinados por um identificador do recurso. Esta tabela é distribuída entre os pontos que compõe a rede P2P e cada ponto é responsável um por um intervalo de identificadores. Os objetos são posicionados na rede de acordo com a relação entre o seu identificador e o ponto responsável por ele (Quinellato, 2009) (Jin et al., 2008). As redes P2P estruturadas possuem como desvantagem o aumento no custo da manutenção relacionado ao posicionamento dos pontos na estrutura de sobreposição e reorganização quando os pontos saem da rede, levando a algoritmos mais complexos (Quinellato, 2009).

Várias pesquisas vêm sendo feitas a respeito de roteamento em redes $\mathrm{P} 2 \mathrm{P}$, visando redes P2P não estruturadas e redes P2P estruturadas (Jin et al., 2008)(Ranjan et al., 2010)(Stoica et al., 2001)(Rowstron e Druschel, 2001)(Ratnasamy et al., 2002)(Zhu e Hu, 2005)(Androutsellis-theotokis e Spinellis, 2004). Redes P2P não estruturadas, como Gnutella, usam técnicas de inundação para a transmissão dos pedidos de recursos na rede P2P.

Nas abordagens de roteamento P2P estruturadas, são utilizados protocolos baseados em DHT que são compostos por pares <key:value $>$ espalhados entre os pontos que compõe a rede P2P estruturada (Jin et al., 2008). A chave utilizada para a 
busca de um recurso pode ser uma palavra-chave de um nome ou descrição de serviço (Androutsellis-theotokis e Spinellis, 2004)(Jin et al., 2008). Essa chave é utilizada em uma função hash e o valor armazenado na tabela hash que pode ser qualquer objeto ou uma cópia ou uma referência a chave.

Os diferentes protocolos baseados em DHT, apesar de terem o mesmo objetivo, possuem implementações diferentes e, consequentemente, desempenhos diferentes dependendo da abordagem considerada. Assim, é necessário investigar quais funcionalidades se enquadram melhor para este projeto.

$\mathrm{Na}$ literatura são encontrados os protocolos Chord, Pastry, Tapestry (Androutsellis-theotokis e Spinellis, 2004), que são protocolos de roteamento P2P baseados em DHT. Estes protocolos são compostos por uma rede de sobreposição de auto-organização de pontos conectados à Internet (Rowstron e Druschel, 2001).

\section{Tapestry e Pastry}

As redes P2P hierárquicas possuem propriedades de localização de rotas, onde cada ponto possui informações sobre as rotas com as solicitações do cliente e interage com instâncias locais de um ou mais pontos (Androutsellis-theotokis e Spinellis, 2004).

Assim, cada nodo na rede possui um identificador numérico único nodeid, um nodo envia a mensagem para o nodo com um nodeid que está numericamente mais próximo do valor da chave entre todos os nodos ativos (Rowstron e Druschel, 2001). O número esperado de etapas no roteamento é $O(\log N)$, onde $N$ é o número de nodos na rede (Androutsellis-theotokis e Spinellis, 2004).

Para minimizar a distância percorrida pelas mensagens os protocolos baseados em DHT levam em consideração a localização da rede de acordo com a métrica de proximidade escalar que pode ser o número de saltos de roteamento IP (Rowstron e Druschel, 2001).

Na Figura 2.10 é demonstrada a busca pelo nodo que possui a identificação (nodeid) 34567 partindo do nodo 67493 utilizando o protocolo Tapestry (Androutsellis-theotokis e Spinellis, 2004). Nesse protocolo cada nodo possui uma tabela com os identificadores de seus vizinhos e a busca é feita digito por digito do identificador partindo da direita para a esquerda.

A Tabela 2.1 apresenta a tabela de rotas do nodo com a $i d=67493$. Cada nodo dentro da rede Tapestry possui sua própria tabela de rotas, facilitando assim o roteamento dentro da rede de sobreposição demonstrado na Figura 2.10 (Androutsellis-theotokis e Spinellis, 2004).

Uma abordagem que segue a mesma ideia do protocolo Tapestry é o protocolo Pastry (Rowstron e Druschel, 2001) que é um protocolo que difere da abordagem Tapestry apenas na realização da localidade da rede e replicação de objetos, essa localidade é feita através de um conhecimento prévio da rede, dai o nome PASTry (Rowstron e Druschel, 2001). 


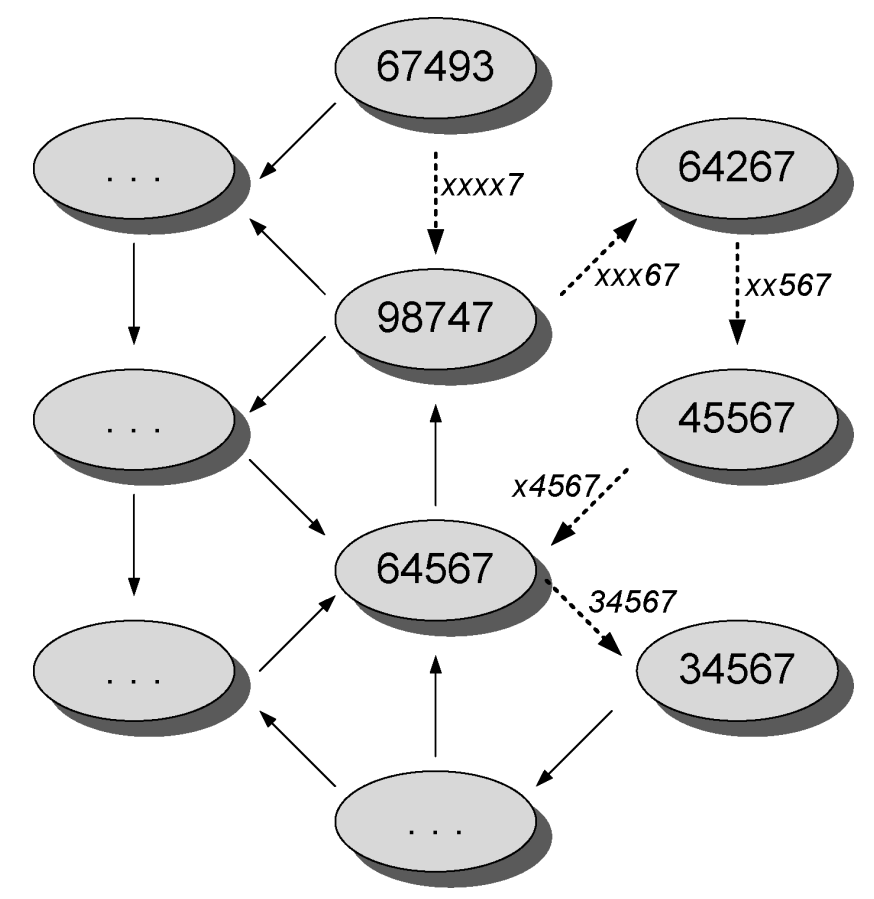

Figura 2.10: Protocolo DHT realizando roteamento em massa (Androutsellis-theotokis e Spinellis, 2004)

\section{Chord}

Uma abordagem diferente para a realização de roteamento em sistemas $\mathrm{P} 2 \mathrm{P}$, é a utilização do protocolo Chord, que trabalha em forma de anel no roteamento dentro da rede P2P. O protocolo Chord é apresentado pela Figura 2.11. De acordo com a Figura 2.11 nota-se que essa abordagem trabalha de forma diferente se comparado com as abordagens Tapestry e Pastry. Cada nodo da Chord necessita de informações de rota sobre os outros nodos que compõe a rede Chord. Quando um nodo entra na rede Chord, o mesmo realiza uma busca para descobrir quem será seu sucessor. Feito isso ele comunica ao nodo sucessor e antecessor que ele está disponível. Essa operação apenas ocorre na região onde o nodo está entrando, diminuindo assim as trocas de posição dos outros nodos que não estão envolvidos na operação (Stoica et al., 2001).

Como a tabela de roteamento é distribuída, um nodo resolve a função hash comunicando-se com outros nodos dentro de seu domínio, alem do antecessor e do sucessor. Em uma Chord com $N$ nodos, cada nodo mantém informações somente sobre os $O(\log N)$ nodos próximos a ele e resolve todas as pesquisas com $O(\log N)$ mensagens para os outros nodos (Stoica et al., 2001). O protocolo Chord mantém informações de roteamento, como os nodos que entram e saem do sistema, com alta probabilidade de resultados de cada evento em não mais que $O\left(\log ^{2} N\right)$ mensagens, a complexidade aumenta se a tabela de nodos não for atualizada constantemente (Stoica et al., 2001).

Um nodo da Chord requer informações sobre $O(\log N)$ nodos para o encaminhamento eficiente, mas normalmente o desempenho fica em déficit quando a informação na tabela de roteamento está desatualizada (Stoica et al., 2001). Isto é importante porque, na prática, os nodos entram e saem da rede de forma arbitrária, e a consistência do rotea- 
Tabela 2.1: Tabela de Rotas do Nó 67493 - (Androutsellis-theotokis e Spinellis, 2004)

\begin{tabular}{lccccc}
\hline & Nível 5 & Nível 4 & Nível 3 & Nível 2 & Nível 1 \\
\hline 0 & 07493 & x0493 & xx093 & xxx03 & xxxx0 \\
1 & 17493 & x1493 & xx093 & xxx13 & xxxx1 \\
2 & 27493 & x2493 & xx093 & xxx23 & xxxx2 \\
3 & 37493 & x3493 & xx093 & xxx33 & xxxx3 \\
4 & 47493 & x4493 & xx093 & xxx43 & xxxx4 \\
5 & 57493 & x5493 & xx093 & xxx53 & xxxx5 \\
6 & $\mathbf{6 7 4 9 3}$ & x6493 & xx093 & xxx63 & xxxx6 \\
7 & 77493 & x7493 & xx093 & xxx73 & xxxx7 \\
8 & 87493 & x8493 & xx093 & xxx83 & xxxx8 \\
9 & 97493 & x9493 & xx093 & xxx93 & xxxx9 \\
\hline
\end{tabular}

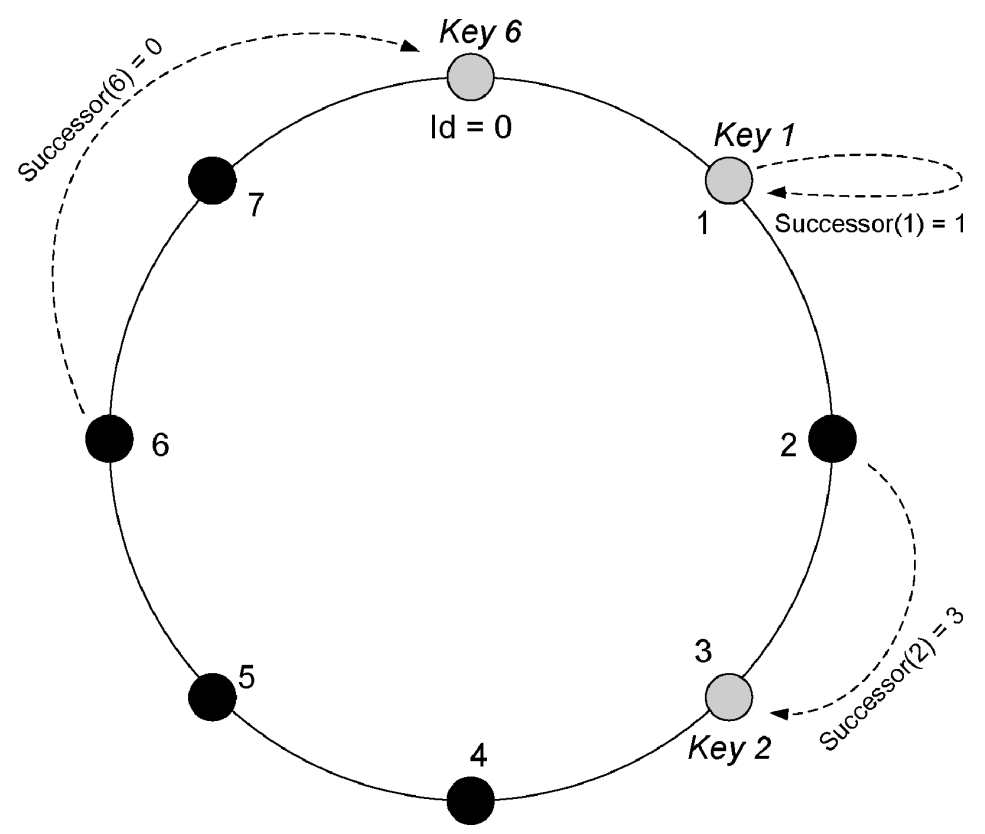

Figura 2.11: Protocolo DHT realizando roteamento em Anel (Stoica et al., 2001)

mento com a complexidade $O(\log N)$ torna-se difícil de manter (Androutsellis-theotokis e Spinellis, 2004).

\subsubsection{Latência}

Clientes que estão a longas distâncias dos provedores de Computação em Nuvem poderão sentir a influência da latência em suas aplicações, particularmente se houver muito tráfego na rede e se os serviços dos clientes forem solicitados em grande quantidade, causando sobrecargas nos servidores (Leavitt, 2009). Um ponto que será considerado para a construção das redes P2P é a latência entre o nodo que solicita um serviço e o nodo que possui o serviço, observando as influencias que podem ocorrer dentro da rede (congestionamento, por exemplo) e o comportamento dos protocolos de roteamento. 
Para medir a latência são utilizados pontos de referência. Esses pontos de referência normalmente são usados como pontos de partida para medições de latências entre os nodos que solicitam um serviço e o nodo destino que possui o serviço (Lopes e Baquero, 2003). A utilização de protocolos baseados em DHT pode diminuir a latência na busca de informações dentro da Computação em Nuvem, uma vez que os protocolos DHT possuem heurísticas para escolher as entradas na tabela de roteamento, referindo-se aos nodos que estão mais próximos uns dos outros, o que diminui a latência entre os nodos (Balakrishnan et al., 2003).

\subsection{QOS}

Qualidade de Serviço (GoS) pode ser definida como a percepção do usuário em relação a eficiência de um dado serviço. GoS significa prover algum tipo de garantia sobre um serviço, tais como: perdas mínimas, desempenho máximo, pequeno tempo de resposta, exatidão e consistência dos dados recebidos (Vasiliou, 2000).

Porém, prover GoS não é uma tarefa trivial, uma vez que o ambiente da Nuvem é afetado pela dinamicidade e desafios da rede Internet. Outro problema é como determinar se o um provedor de serviço cumpre com o nível de GoS desejado pelo usuário. Para resolver esse problema, é proposto um estabelecimento de acordos, como uma SLA (Service Level Agreement) entre os usuários e os provedores.

\subsubsection{QoS em nível de aplicação}

Independentemente do contexto envolvido, os tipos de gerenciamento de GoS devem incluir requisitos, tais como: mapeamento e negociação de $\mathrm{BoS}$, estabelecimento de uma SLA, monitoração de GoS (Guo et al., 2007)(Foster et al., 1999). O mapeamento dos melhores atributos de GoS não é uma tarefa simples e ela depende dos objetivos do usuário. Geralmente, usuários podem requisitar certos níveis de qualidade o qual o provedor não está preparado para cumprir, por exemplo, uma disponibilidade de 99,99\%. Existe uma grande quantidade de atributos de qualidade de serviço que podem ser considerados: tempo de resposta, throughput, interoperabilidade, dependabilidade, etc. A dependabilidade é um atributo que pode ser destacado, uma vez que envolve algumas características relevantes, tais como:

- Confiabilidade: é a propriedade de um protocolo em garantir a entrega dos dados de um serviço executado.

- Disponibilidade: define a probabilidade de um sistema estar em funcionamento em um determinado momento, considerando as pausas para executar reparos.

- Segurança (Safety): está relacionada à probabilidade de operação adequada de um serviço. Caso contrário, deve ser interromper o funcionamento para evitar possíveis danos. 
- Proteção (Security): este atributo considera os problemas relacionados a falta de proteção contra falhas maliciosas, fraudes, erros, etc., procurando garantir a privacidade, autenticidade e não repúdio de dados.

Uma vez que os atributos de $\mathrm{BoS}$ foram mapeados, surge a necessidade de determinar os niveis desses atributos. Neste ponto, também é necessária uma negociação entre usuários e fornecedor de serviços. Geralmente, como resultado dessa negociação é estabelecido um acordo de nível de serviço (SLA), que contém os níveis desejados pelo consumidor e que serão fornecidos pelo prestador por um custo específico.

O estado da arte em Computação em Nuvem não tem suporte ou se limita a dinâmica de negociação de SLAs (Buyya, 2009). Além disso, uma característica que torna a prestação de GoS mais complicada é o oferecimento de um serviço sob demanda. Por exemplo, em um ponto o cliente pode requisitar mais processamento, pois o trabalho aumentou subitamente. Neste caso, a Nuvem irá fornecer mais recursos da CPU através de uma alocação dinâmica de recursos. No entanto, deve-se considerar a quantidade de recursos necessária para manter o nível de qualidade de serviço que foi estabelecido no acordo de SLA. Para resolver essas questões, precisa-se de um acompanhamento de BoS.

Além dos atributos de qualidade de serviço, o deadline também deve ser considerado para representar a qualidade. Em um sistema de tempo real (RTS - Real Time System), o requisito de $\mathrm{GoS}$ a ser considerado é o tempo (máximo) para que um serviço possa ser concluído. Do ponto de vista comercial, é interessante considerar o atributo orçamento que indica o custo máximo que o usuário deseja pagar para conseguir um prazo. Um exemplo de uma plataforma de Nuvem que utiliza os conceitos de prazo e orçamento é o Aneka (Buyya, 2009). Aneka é uma plataforma de software para o desenvolvimento de aplicações distribuídas na Nuvem (Vecchiola et al., 2009).

\subsubsection{QoS em nível de rede}

A Computação em Nuvens é um novo paradigma de computação e seu modelo enfatiza a habilidade de realizar a computação de serviços sob demanda. Normalmente, a Computação em Nuvens é realizada em provedores especializados, conhecidos como data centers (Peixoto et al., 2010).

Com a difusão desses provedores de Computação em Nuvens surgiu a necessidade de utilização de serviços entre os participantes desse novo tipo de ambiente, conceituando assim uma organização de Computação em Nuvens colaborativa. Os provedores de Computação em Nuvens podem estar em diferentes localizações geográficas pela Internet com o objetivo de oferecer melhores serviços aos seus clientes, tais como: segurança, confiabilidade e tolerância a falhas (Buyya et al., 2010) (Peixoto et al., 2010).

Essa forma distribuída de oferecimento de serviços por meio de Computação em Nuvem visa facilitar o nível de acesso a recursos e serviços mesmo entre diferentes organizações, criando assim uma rede colaborativa. Entretanto, não é suficiente ocorrer a comunicação entre as entidades colaborativas que estão dispersas geograficamente. Além disso, essa comunicação deve vir acompanhada de características que propor- 
cionem aspectos de GoS. Os usuários do ambiente formado por uma organização de Computação em Nuvens precisam de um mecanismo para identificar os participantes que possam atender as suas necessidades com relação as métricas de GoS (Peixoto et al., 2010).

Os provedores de Computação em Nuvem devem ter mecanismos e políticas para a distribuição de carga entre os diferentes data centers. Esses mecanismos e políticas visam a determinar a localização ideal para os serviços de hospedagem de uma aplicação para atingir níveis razoáveis GoS (Buyya et al., 2010).

Em uma organização de Computação em Nuvem a interligação entre os diversos provedores pode ser feita utilizando uma rede P2P. Entretanto, o sistema P2P deve ser bem definido para que o desempenho adequado seja atigindo entre as chamadas de comunicação das entidades (Buyya et al., 2010).

A garantia de requisitos mínimos relacionados à qualidade dos serviços oferecidos por sistemas computacionais tem sido um tema de crescente relevância no âmbito acadêmico e industrial nos últimos anos. No contexto das tecnologias de rede, têm-se aplicações em todos os níveis da arquitetura de protocolos, com destaque para os avanços realizados nas camadas inferiores. Na camada de aplicação, por outro lado, os esforços são mais recentes.

As redes $\mathrm{IP}^{6}$ constituem a infraestrutura de milhares de redes de computadores em todo o mundo com uma expectativa constante de crescimento. A disseminação desse padrão deve-se, em parte, à velocidade de expansão da Internet e ao estabelecimento do $\mathrm{TCP} / \mathrm{IP}^{7}$ como protocolo de suporte às aplicações em redes. O predomínio dos computadores usando TCP/IP nas suas comunicações tornam o IP o padrão universal de suporte para aplicações na Internet, e o faz presente em milhões de máquinas espalhadas por todo o mundo.

As redes IP foram desenvolvidas sob requisitos pouco exigentes de confiabilidade ${ }^{8} \mathrm{e}$ tendo como objetivo a possibilidade serem utilizadas sobre qualquer tipo de meio físico. Como o IP é um protocolo simples, ele tem algumas restrições como, por exemplo, a falta de garantia no trânsito de pacotes, atrasos, etc. Com o crescimento das aplicações (voz, multimídia, vídeo-conferência, etc.) sobre IP, as limitações desse protocolo ficaram mais evidentes, motivando a buscar por alternativas para adequá-lo à nova realidade. Deve-se ainda destacar que a banda ${ }^{9}$ de comunicação está compartilhada com um número cada vez maior de usuários, podendo ocorrer congestionamento e possíveis perdas de pacotes.

Para obter qualquer tipo de garantia de que o serviço será realizado é preciso aplicar métodos que permitam atingir um nível de qualidade satisfatório e confiável para os dados e aplicações. A implementação de um esquema de reserva de recursos, como o protocolo de tempo real $\mathbf{R T P}^{10}$, depende da utilização do serviço de entrega do IP subjacente, e portanto, da custosa intervenção na infraestrutura da rede. Isso evidencia

\footnotetext{
${ }^{6}$ Internet Protocol - RFC 791.

${ }^{7}$ Transmission Control Protocol / Internet Protocol.

${ }^{8}$ No sentido de garantia de desempenho.

${ }^{9}$ Banda é um expressão pouco rigorosa mas bastante difundida para referir-se à capacidade de transmissão (throughput) da rede.

${ }^{10}$ Real-time Transport Protocol - RFC 1889.
} 
a importância de avanços em métodos alternativos para o campo das aplicações que necessitem realizar operações em tempo-real (Brun et al., 2002).

A GoS pode ser explicada como a percepção do usuário quanto à eficiência de um serviço. No caso da comunicação, pode relacionar-se às características de tempo de resposta e à perfeição na transferência do conteúdo. GoS pode ser definida, no contexto da camada de rede, como a capacidade de um elemento em prover certo grau de garantia do cumprimento dos requisitos de seu tráfego e serviços oferecidos, tais como níveis mínimos de perdas e atrasos de dados requisitados pelo usuário.

GoS pode ser definida em termos absolutos ou relativos. Por exemplo, em termos absolutos pode-se especificar que: "a perda de pacotes não excederá 3\%" ou "nenhum pacote atrasará mais que $100 \mathrm{~ms}$. Já em termos relativos garante-se apenas que a classe mais alta receberá um serviço melhor (ou no mínimo não pior) que qualquer classe mais baixa (Vasiliou, 2000).

Substancial desenvolvimento nesse campo tem se dado no estudo e na elaboração de técnicas aplicáveis às camadas inferiores das arquiteturas de redes de comunicação (tendo como base o modelo de referência ISO/OSI ${ }^{11}$ ). Da mesma forma, contratos dinâmicos podem utilizar algum protocolo de sinalização, que possibilitam solicitar serviço sob demanda, indicando a necessidade do usuário em um dado momento (Zhao et al., 2000).

\subsection{Ambiente de Simulação}

A execução de projetos de Computação em Nuvem em ambientes reais, testbeds, pode limitar o experimento no que se diz respeito a escalabilidade. Além disso, os resultados são difíceis de serem reproduzidos e o custo envolvido no processo de adquirir esses recursos pode se tornar inviável para avaliação de abordagens. Uma alternativa é a utilização de ferramentas de simulação que oferecem a possibilidade de avaliação de hipóteses em um ambiente capaz de se reproduzir os testes.

De acordo com Calheiros et al. (2010), as abordagens baseadas em simulação oferecem benefícios significativos, tais como:

- Repetir os experimentos em um ambiente controlado.

- Minimizar os custos financeiros.

- Identificar os pontos fracos das abordagens de forma mais rápida, permitindo o ajuste através da realimentação de informações.

- Permitir o provedor identificar os melhores preços cobrados para os diferentes cenários de cargas de serviços, possibilitando aumentar o lucro do provedor juntamente com a otimização da utilização dos recursos.

Assim, neste projeto, optou-se por trabalhar com a ferramenta de simulação chamada CloudSim (Calheiros et al., 2010). O CloudSim permite a modelagem tanto do sistema

\footnotetext{
${ }^{11}$ International Organization for Standardization / Open System Interconnection.
} 
quanto do comportamento dos sistemas de Computação em Nuvem, tais como data centers, máquinas virtuais e políticas de alocação de recursos. O CloudSim adota uma arquitetura de multicamadas modulares para realizar a gerência dos seus componentes de forma separada. Esses componentes são apresentados na Figura 2.12.

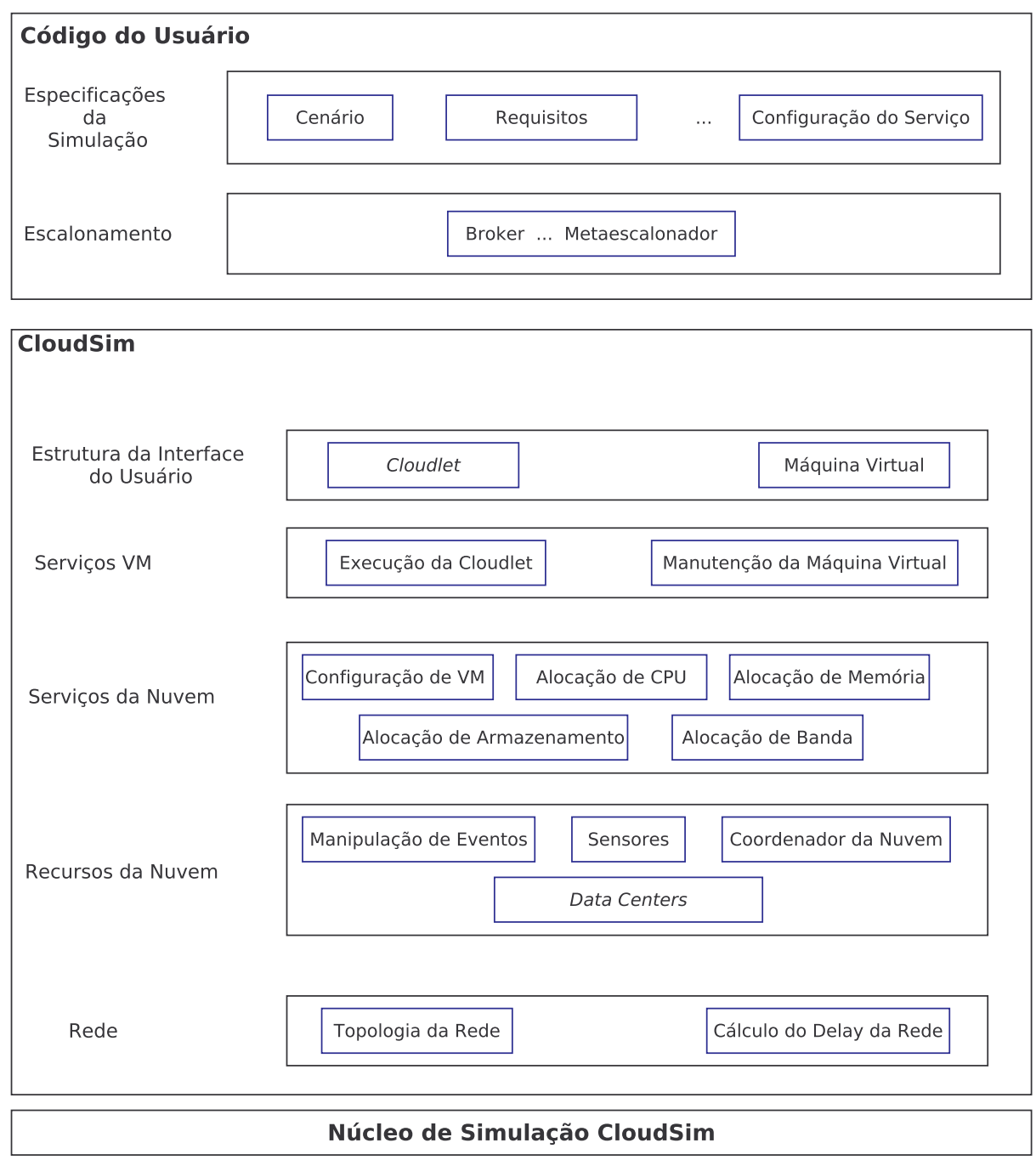

Figura 2.12: Arquitetura do CloudSim - Adaptado de Calheiros et al. (2010).

O CloudSim possui vários módulos que são, por sua vez, divididos em três categorias:

- Código do Usuário - onde são definidos os cenários da simulação como a configuração dos data centers, quantidade de hosts, preço dos recursos, número de clientes e a quantidade de brokers ou metaescalonadores.

- CloudSim - módulo para definição das políticas que irão ser desenvolvidas na Nuvem. Por ser separado por módulos o desenvolvimento de novas políticas pode ser feita de forma independente.

- Núcleo de Simulação - nesse módulo são encontrados os gerenciadores de eventos e as filas utilizadas pelo simulador. 
Dentre os módulos que compõe a arquitetura do CloudSim está o módulo de rede. A presença deste módulo demonstra que o simulador não se preocupa apenas com os serviços (cloudlets), máquinas virtuais e data centers, mas também como a comunicação é realizada na Nuvem. De acordo com (Calheiros et al., 2010), o simulador não conta com entidades reais para a simulação de entidades de rede, como roteadores ou switches, em vez disso, é utilizada a latência que uma mensagem possui entre sua entidade de origem (cliente) para a entidade destino (data center). A latência entre essas entidades é armazenada em uma matriz do tipo $\mathrm{NxN}$ e a informação de delay é utilizada sempre que uma mensagem é enviada entre a origem e o destino.

O CloudSim é auxiliado nas atividades relacionadas à rede pelo gerador de topologias BRITE. O BRITE é utilizado para compor arquivos de configuração que possuem as características da rede como quantidade de nodos presente na rede e o peso das arestas de ligação entre estes nodos.

\subsection{BRITE}

O BRITE é um gerador de topologias que não se restringe a apenas uma forma de gerar topologias. Por se tratar de um gerador de topologias genérico ele fornece várias formas de construir topologias e faz uso, basicamente, de dois modelos de distribuição de nodos (Medina et al., 2001). A Figura 2.13 apresenta uma visão geral do BRITE.

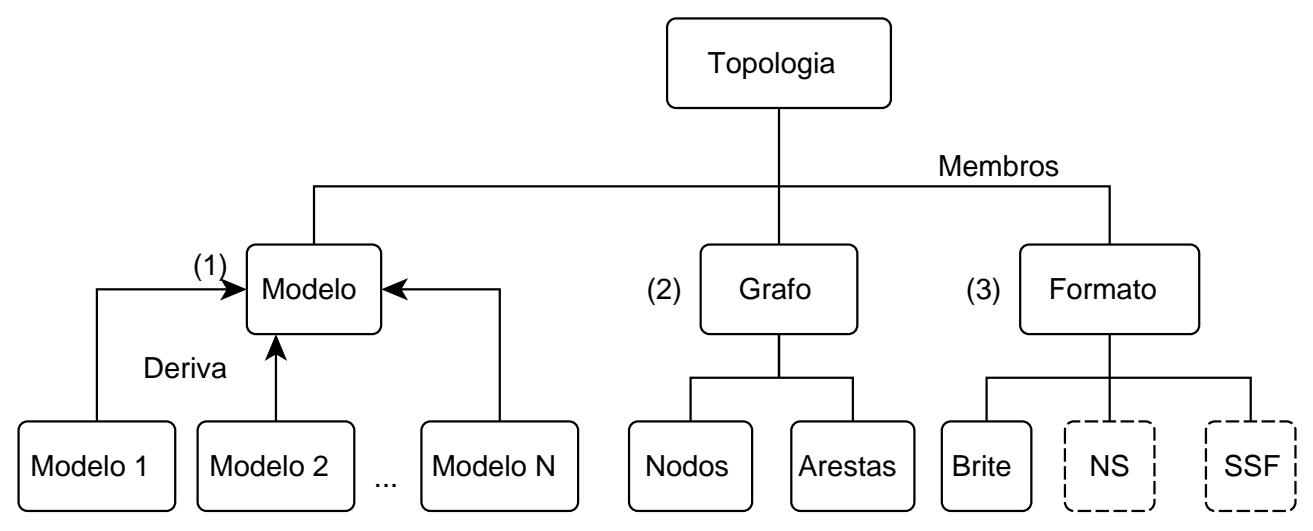

Figura 2.13: Módulos que Compõe o BRITE. Adaptado de (Medina et al., 2001)

O grafo gerado pelo BRITE possui as informações sobre a quantidade de nodos que irão compor a simulação e as ligações entre esses nodos. Assim, de posse da topologia gerada pelo BRITE, é fornecido, por meio de simulação, um ambiente onde a Nuvem pode ser avaliada considerando várias características. Dentre as características que podem ser analisadas está a rede, possibilitando assim o uso do CloudSim para o desenvolvimento de políticas de roteamento que podem ser utilizadas por provedores de Computação em Nuvem. 


\subsection{Considerações Finais}

Esse capítulo apresentou uma revisão sobre os principais conceitos relacionados à Computação em Nuvem. Esses conceitos apontam para um aumento da utilização de plataformas baseadas em serviços. Entretanto, deve ser feita uma análise prévia para identificação dos benefícios e riscos associados a esse paradigma computacional. Entre os benefícios da utilização da Computação em Nuvens está a possibilidade da formação de um ambiente Intercloud. O Intercloud permite obter escalabilidade na forma de acesso aos recursos, com a opção de se adotar um modelo econômico como mecanismo de controle. Além disso, o Intercloud pode ser formado por um sistema P2P que lida com a forma de apresentação das entidades na rede de comunicação. Considerando esses fatores agregados ao uso da Intercloud, é possivel obter um ambiente com fornecimento de GoS. Esses conceitos estão inseridos na proposta da arquitetura de metaescalonador desta tese. No próximo capítulo são apresentados os trabalhos relacionados sobre Metaescalonamento que podem ser aplicados ao ambiente Intercloud. 


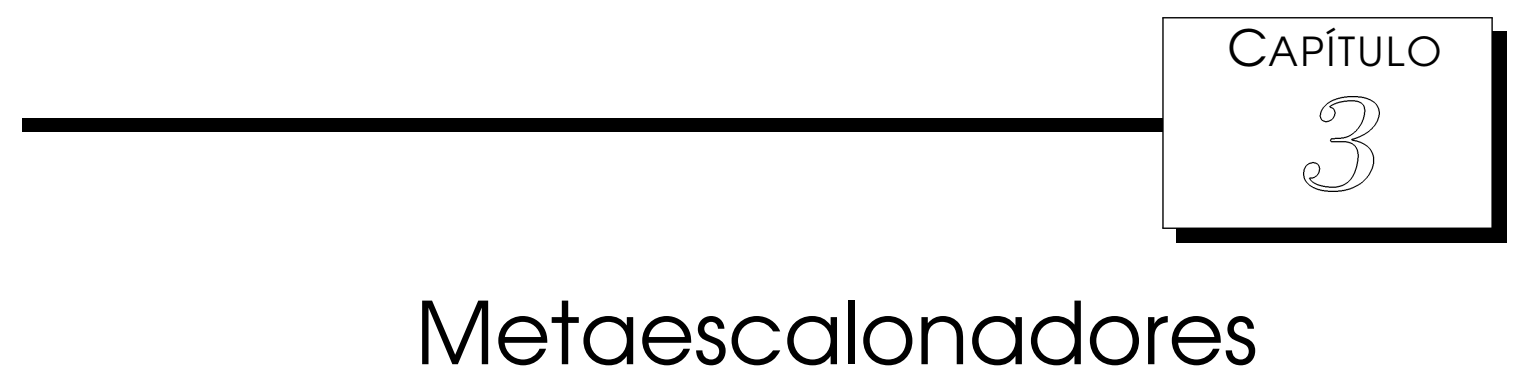

\subsection{Considerações Iniciais}

Os escalonadores são processos que possuem a responsabilidade de alocar tarefas em geral aos recursos que serão responsáveis por sua execução. Desta forma, os escalonadores fazem parte de um mecanismo de gerenciamento das tarefas que serão executados nos recursos disponíveis. Quando o mecanismo de gerenciamento controla recursos de um único ambiente, o termo usado para descrevê-lo é escalonador local de recursos. Por outro lado, quando vários ambientes são gerenciados por um único mecanismo que não possui controle direto sobre os recursos, tem-se os Metaescalonadores (Yamini et al., 2011). Este capítulo apresenta o estado da arte dos metaescalonadores e o seu uso em grades e para a Computação em Nuvens.

\subsection{Escalonamento Local e Metaescalonamento}

Metaescalonadores e escalonadores locais são duas abordagens utilizadas em diferentes tipos de sistemas distribuídos, tais como cluster, grade e Nuvens (Xhafa e Abraham, 2010). Essas duas abordagens têm como objetivo a alocação e o gerenciamento de recursos, embora cada uma tenha perspectivas diferentes. O escalonador local é utilizado em nível de escalonamento de cluster. Já os Metaescalonadores são utilizados em sistemas distribuídos que são constituídos por vários domínios administrativos e não é permitido o acesso direto aos recursos dentro desses domínios (Christodoulopoulos et al., 2009) (Buyya et al., 2010). Não é permitido acessar os recursos diretamente pois cada entidade possui suas próprias regras de controle sobre os recursos, além disso é necessário garantir a privacidade sobre as políticas internas.

Em resumo, um Metaescalonador (Vadhiyar e Dongarra, 2002):

- provê uma interface consistente para usuários acessarem o sistema. 
- coordena a comunicação entre os vários escalonadores locais.

- fornece um ponto de acesso comum.

- torna possível o acesso e coordenação global, enquanto mantém o controle local e a propriedade do recurso.

Outra importante função do Metaescalonador é conseguir gerenciar vários domínios administrativos com diferentes topologias de rede. Nesse contexto, alguns modelos de comunicação devem ser considerados para que o metaescalonamento consiga ser útil às necessidades dos usuários (Sotiriadis et al., 2011).

\subsection{Modelos de Comunicação dos Metaescalonadores}

O modelo de comunicação é uma questão importante quando o assunto é a escalabilidade dentro da Computação em Nuvem. A conexão entre os usuários e os prestadores de serviços, normalmente, afeta a maneira como os serviços são oferecidos aos usuários, portanto, o uso de um determinado modelo afeta as decisões de projeto no que diz respeito a conceitos sobre a ordem topológica e disponibilidade dos serviços.

Há três modelos principais de comunicação que podem ser utilizados na Computação em Nuvem, estes modelos são: o modelo centralizado, modelo distribuído e modelo hierárquico (Peixoto et al., 2010).

No modelo centralizado, Figura 3.1, há uma Metaescalonador principal que mantêm informações de carga de trabalho sobre todas as organizações participantes da Nuvem (Subramani et al., 2002). Todos as requisições que são enviadas para a Nuvem são recebidas por um Metaescalonador que vai tomar a decisão de que organização irá executá-la. Este modelo tem algumas desvantagens causadas pela centralização, como difícil escalabilidade e problemas com tolerância a falhas. Porém, possui vantagens sobre o desempenho praticado já que os dados centralizados permitem uma visão geral e a possibilidade de tomar melhores decisões.

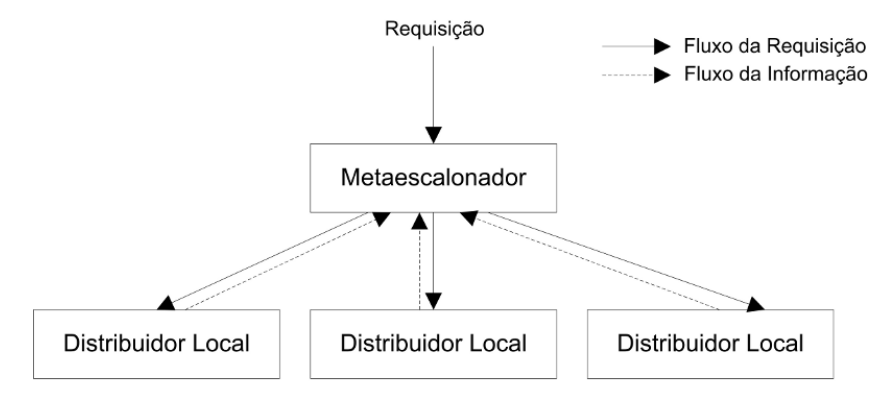

Figura 3.1: Modelo centralizado. Adaptado de (Subramani et al., 2002)

No modelo distribuido, Figura 3.2, cada organização tem seu próprio Metaescalonador que periodicamente consulta os outros Metaescalonadores para obter informações de carga instantânea da Nuvem (Subramani et al., 2002). As requisições são enviadas 
para o Metaescalonador local que irá decidir se a organização local irá executá-la ou se será migrada para outra organização com maior disponibilidade.

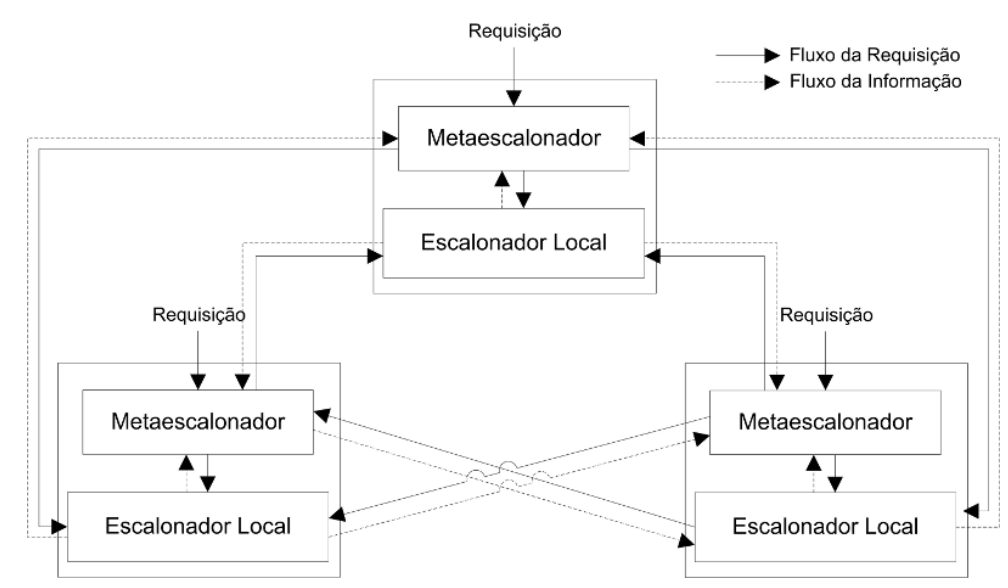

Figura 3.2: Modelo distribuído. Adaptado de (Subramani et al., 2002)

No modelo hierárquico, Figura 3.3, o fluxo de trabalho é compartilhado entre os Metaescalonadores (Subramani et al., 2002). Nesse modelo as requisições são enviadas para o Metaescalonador e não existe fila de serviços, o Metaescalonador envia a requisição para a organização que estiver disponível. Cada organização pode usar diretivas de agendamento diferentes devido ao fato de possuírem um Metaescalonador local.

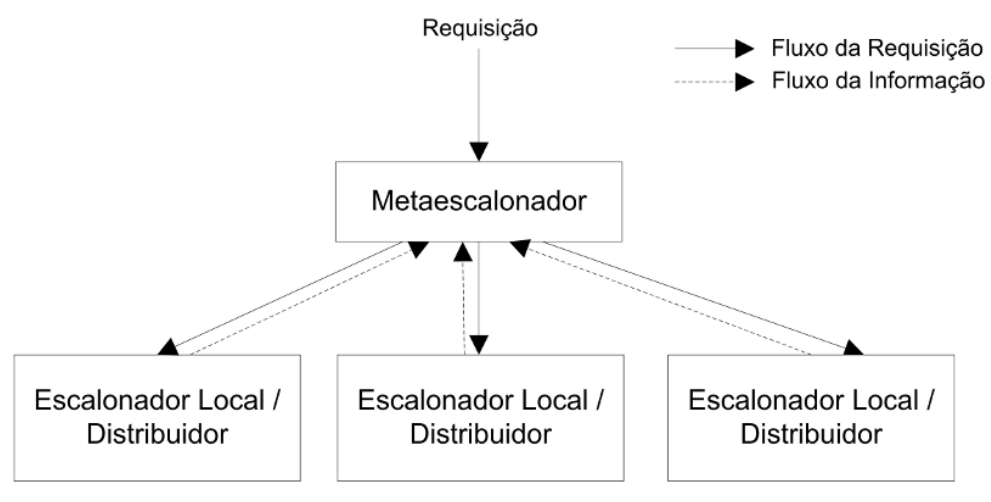

Figura 3.3: Modelo hierárquico. Adaptado de (Subramani et al., 2002)

Esses modelos apresentados são os modelos básicos que podem ser utilizados pela Nuvem. Outras formas de comunicação podem estender esses conceitos e criar novos modelos para aumentar o desempenho das atividades de comunicação nas nuvens.

\subsection{Comparação entre as Abordagens de Metaescalonadores}

Um Metaescalonador esconde a complexidade do mecanismo de escalonamento do usuário e provê uma forma transparente para execução dos serviços (Liu et al., 2008) (Heidt et al., 2008) (Mann, 2005). Além disso, um Metaescalonador tem como 
objetivo melhorar a utilização dos recursos juntamente com a qualidade de serviço oferecida ao usuário (Vanderster et al., 2006) Li e Lo (2012). Nesse cenário, cujos provedores não divulgam informações privadas tais como a carga de trabalho ou a potência computacional (normalmente heterogênea), o Metaescalonador tem entre suas funções aquela de tomar decisões que satisfaçam as necessidades dos usuários (Netto e Buyya, 2009) Chen e Tseng (2012).

Existem alguns Metaescalonadores para casos específicos em computação em grade, como pode ser visto na Tabela 3.1. Essa tabela foi feita a partir de um levantamento bibliográfico, onde a cada Metaescalonador compete a solução de problemas na área de Grid. Entretanto, nenhum deles é adequado para lidar com as questões que envolvem especificamente a Computação em Nuvens. É necessário que um Metaescalonador leve em conta as características das Nuvens, tais como: o cliente desconhece os detalhes de implementação da aplicação, o estado/operação do hardware responsável pelo serviço prestado, ou onde ele está localizado e suas configurações, além da possibilidade de alocação utilizando a virtualização desses recursos. Assim, são necessários Metaescalonadores que permitam aos clientes utilizarem os serviços de maneira transparente (Wäldrich et al., 2006).

Uma taxonomia sobre os metaescalonadores, adaptada de (Krauter et al., 2002) (Kertesz e Kacsuk, 2006) (Chard, 2011), (Yeo e Buyya, 2006), é apresentada na Figura 3.4, devido a complexidade envolvida em cada um dos itens, optou-se por explicar os pontos separadamente nas próximas sub-seções.

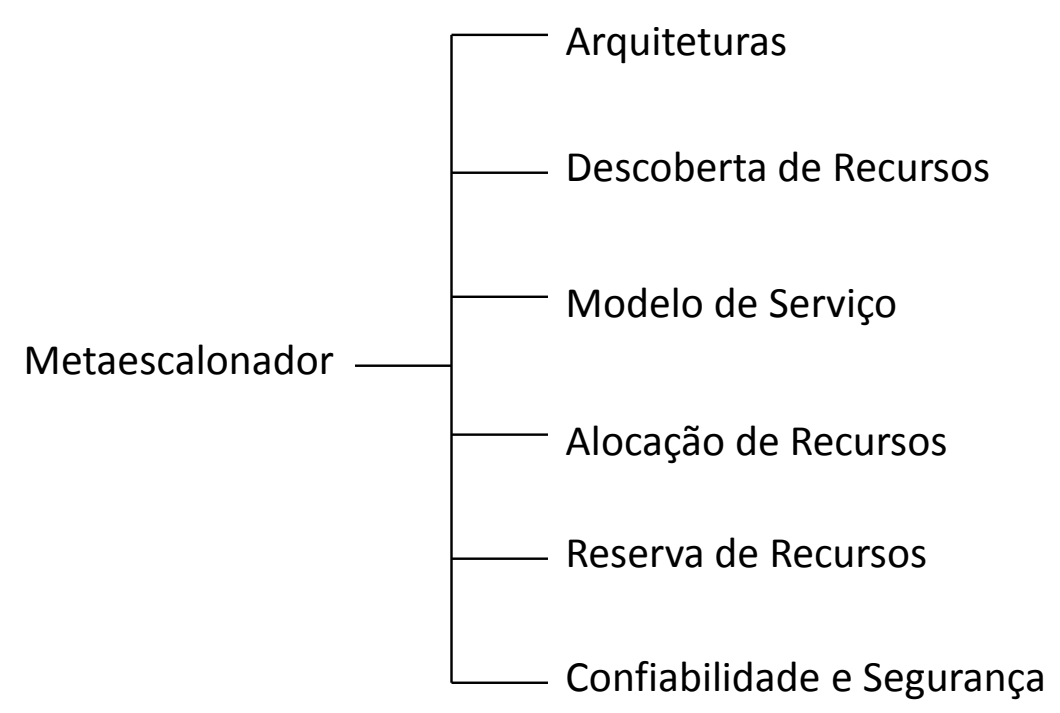

Figura 3.4: Itens sobre Metaescalonamento.

\subsubsection{Arquiteturas}

A arquitetura de um Metaescalonador, Figura 3.5, depende do ambiente em que ele está sendo utilizado e de seus objetivos (Krauter et al., 2002) (Kertesz e Kacsuk, 


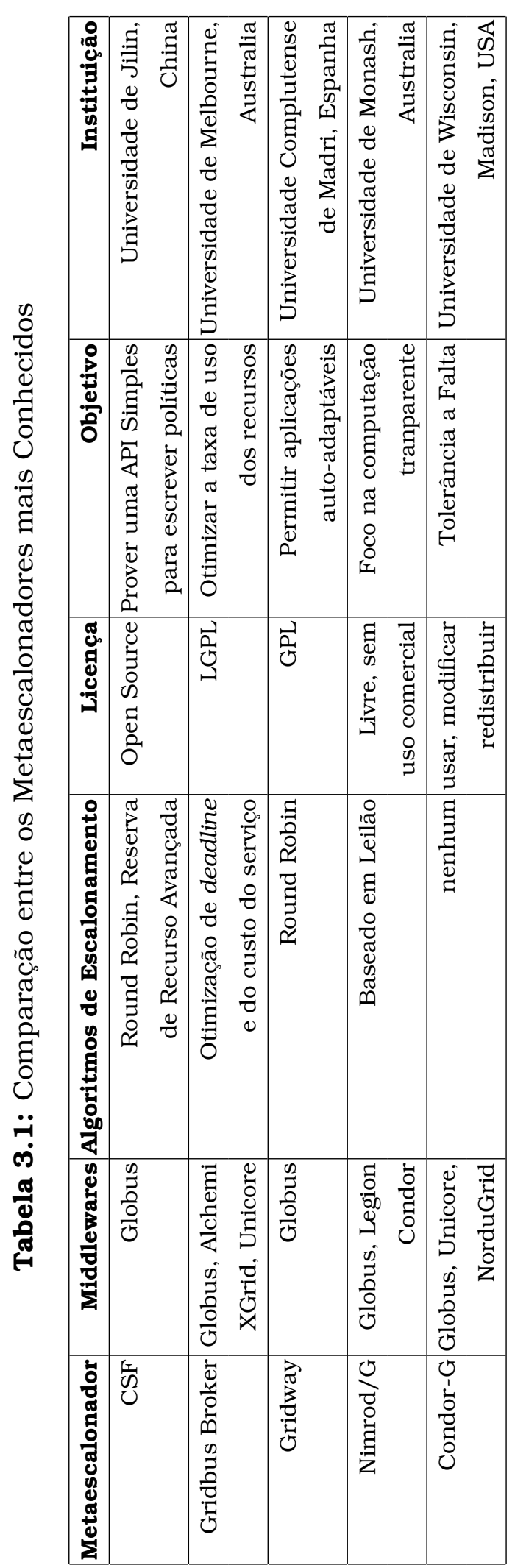


2006). Tipicamente, os Metaescalonadores estão hospedados em recursos dedicados para prover confiabilidade, disponibilidade e desempenho.

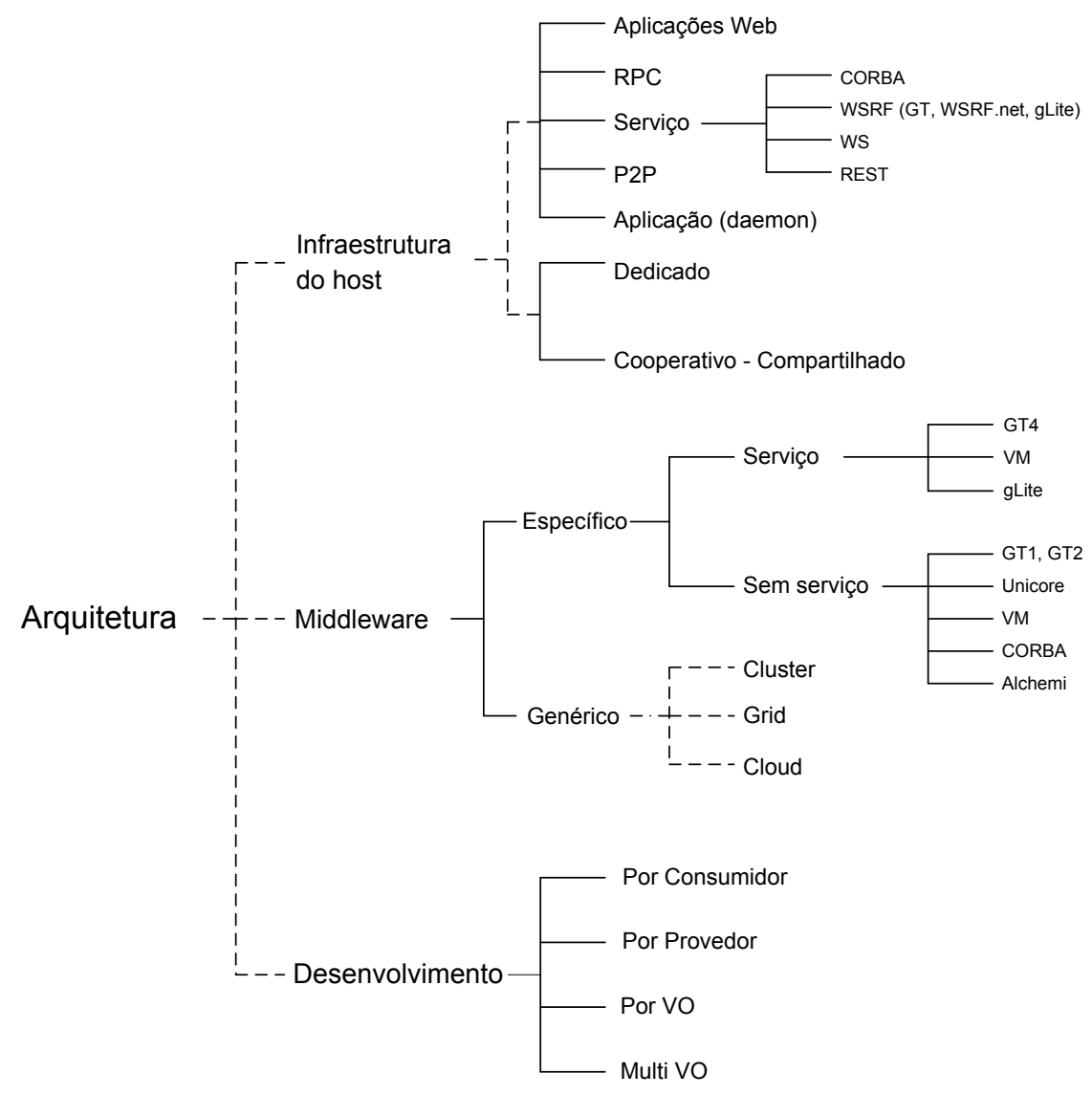

Figura 3.5: Taxonomia sobre as Arquiteturas - Adaptado de Chard (2011).

Alguns Metaescalonadores são implementados como processos daemons, utilizando protocolos de comunicação proprietários, tais como o Nimrod/G (Buyya et al., 2000), Tycoon (Lai et al., 2005), e Sharp (Fu et al., 2003). Outros Metaescalonadores possuem uma infraestrutura baseada em serviço para permitir a escalabilidade, tais como o WSRF - (Web Services Resource Framework) usado no DRIVE - (Distributed Resource Infrastructure for a Virtual Economy) (Chard, 2011), CSF - (Community Scheduler Framework) (Xiaohui et al., 2006) e no GMarteGS (Moltó et al., 2008). Outras opções de utilizar os Metaescalonadores incluem as aplicações Web (AuYoung et al., 2004), e aplicações baseadas em P2P que é utilizado pelo Grid Federation (Ranjan et al., 2005).

Tipicamente os metaescalonadores são projetados para serem usados em um domínio particular com um tipo específico de middleware, tais como o Globus (Foster e Kesselman, 1997). Existem metaescalonadores que não são projetados para um tipo específico de middleware, porém mesmo utilizando um middleware genérico o objetivo, normalmente, é para ser utilizado em um ambiente distribuído, tais como grades, cluster e nuvens. 
Sobre o desenvolvimento das arquiteturas, frequentemente, os Metaescalonadores provêm transparência sobre o conjunto de recursos para o usuário. Metaescalonadores baseados em servidores são desenvolvidos em nível de organização, permitindo acesso aos múltiplos usuários através do mesmo serviço ou portal de comunicação de uma VO - (Virtual Organization).

\subsubsection{Descoberta de Recursos}

A parte de descoberta de recursos tem um papel importante dentro do contexto de um Metaescalonador. O mecanismo de descoberta, visto na Figura 3.6, é normalmente oferecido pela plataforma de middleware utilizada. Por exemplo, o sistema de descoberta e monitoração do Globus - (MDS) provê um conjunto de informações que podem ser utilizadas pelos recursos de propagação.

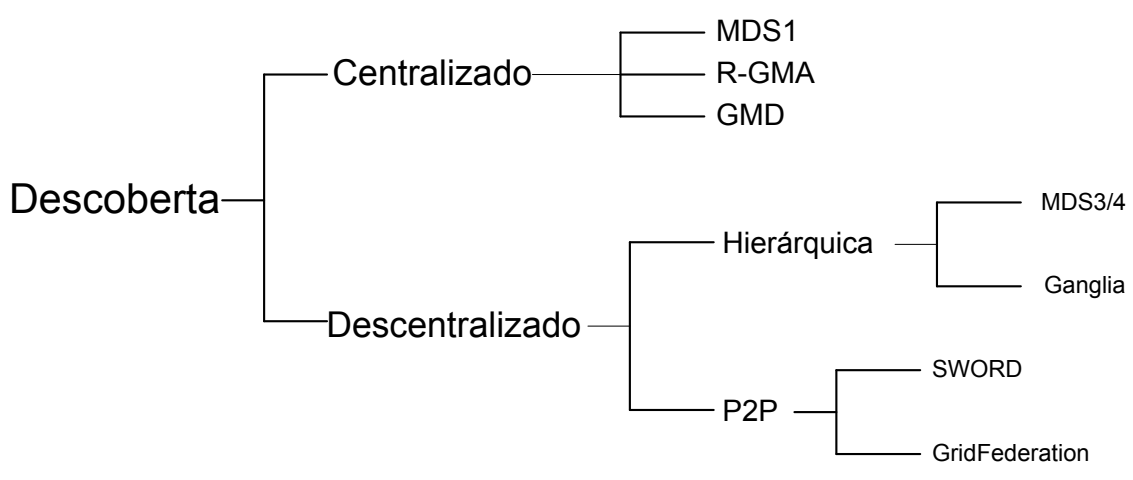

Figura 3.6: Taxonomia sobre a Descoberta - Adaptado de Chard (2011).

Sistemas de descoberta de informação distribuídos podem ser usados para minimizar algumas das limitações vistas no modelo centralizado. A descoberta de recursos na forma distribuída é geralmente baseada em abordagens hierárquicas ou P2P. No modelo hierárquico o serviço de informação é configurado para compartilhar informações em uma estrutura do tipo em árvore. O Ganglia (Massie et al., 2004) é uma das mais proeminentes arquiteturas de descoberta de recursos hierárquicas.

No modelo baseado em P2P, as informações encontram-se distribuídas. Em estruturas P2P puras pode-se afirmar que nenhum nó tem função mais importante do que outro. Pela própria definição, essa arquitetura é tolerante a falhas, auto-organizável e altamente escalável. Por causa disso existem várias arquiteturas P2P propostas na literatura (Ranjan et al., 2008).

\subsubsection{Modelo de Serviço}

A representação das características de uma tarefa pode variar entre consumidores e provedores, uma vez que existe autonomia para realizar a alocação de recursos nesses ambientes heterogêneos distribuídos. Para facilitar a alocação distribuída, as tarefas devem ser representadas pelas principais características. Assim, o modelo de serviço utilizado, tipicamente, depende do middleware escolhido, entretanto alguns 
Metaescalonadores são capazes de representar serviços genéricos. A Figura 3.7 descreve a taxonomia sobre os modelos de serviços empregados pelos Metaescalonadores.

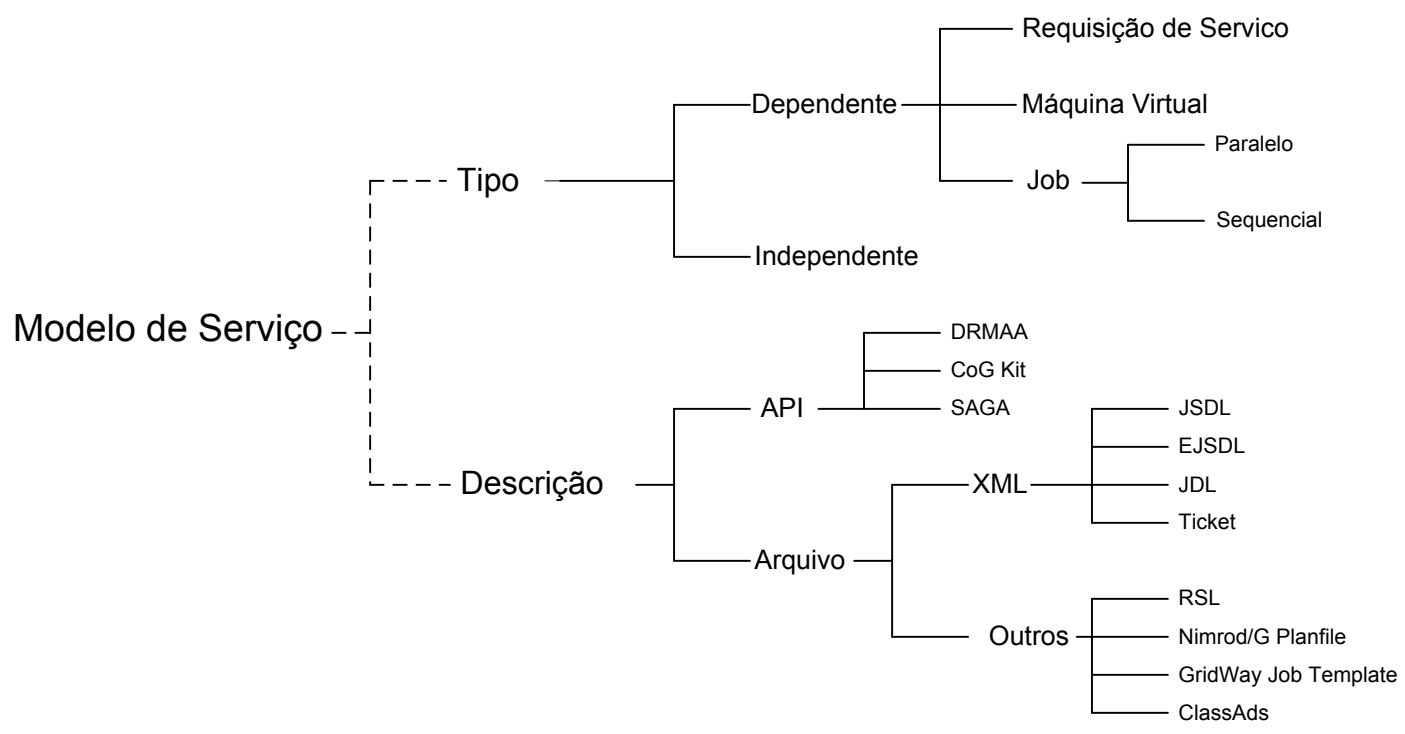

Figura 3.7: Taxonomia sobre os Serviços - Adaptado de Chard (2011).

A descrição de um serviço pode ser feita utilizando tanto arquivos XML como arquivos não XML, dessa forma é possível realizar uma classificação de domínio entre os serviços, permitindo uma alocação de acordo com os requisitos dos serviços.

\subsubsection{Alocação de Recursos}

A tarefa mais importante de um Metaescalonador é a alocação de recursos (Chard, 2011). A alocação de recursos envolve a atribuição adequada entre os requisitos do serviço de um consumidor e as características de recursos do provedor. A Figura 3.8 mostra a taxonomia de alocação de recursos de um Metaescalonador.

Existe tanto a abordagem centralizada quanto a abordagem descentralizada. $\mathrm{Na}$ abordagem centralizada uma única entidade gerencia todos os serviços e recursos do sistema. Na abordagem descentralizada um grupo de entidades gerencia um subgrupo de recursos no sistema. O modelo centralizado é simples para criar e gerenciar, e devido à visão global do sistema ele pode tomar decisões eficientes. Entretanto, no modelo centralizado não existe tolerância a falhas e é menos escalável do que o modelo distribuído.

Embora a abordagem descentralizada talvez escale melhor e forneça a tolerância a falhas, é mais complicado coordenar as decisões de alocação com múltiplas entidades requisitando serviços. Essa falta de uma coordenação pode resultar em uma alocação menos eficiente. Adicionado ao fato que essa abordagem necessite de mecanismos de segurança para troca de informações aumentando a sobrecarga na rede.

Em uma arquitetura coordenada cada Metaescalonador deve trocar informações com outros Metaescalonadores antes de realizar a alocação de algum recurso (Sharp e Grid 


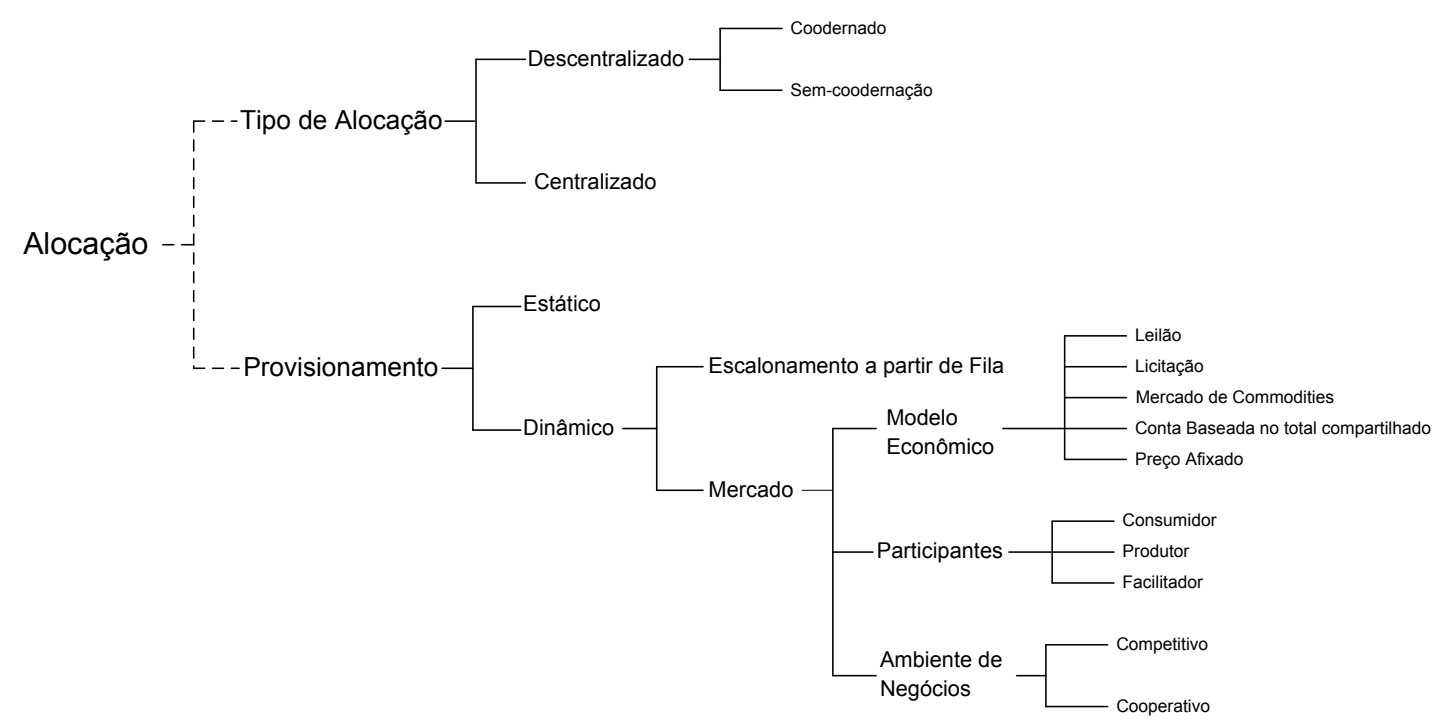

Figura 3.8: Taxonomia sobre a Alocação - Adaptado de Chard (2011).

Federation). Em um modelo não coordenado (GridWay (Leal et al., 2009), Tycoon, Nimrod/G e CSF) as decisões de escalonamento são feitas independentemente das informações que poderiam ser obtidas de outros Metaescalonadores.

Várias abordagens são utilizadas para a atribuição de serviços aos recursos. Algumas são feitas de forma estática (baseadas em políticas simples) ou dinamicamente que são propostas sobre aspectos que envolvem a carga atual do recurso e os requisitos do serviço. A maioria dos Metaescalonadores utiliza algoritmos dinâmicos baseados em fila para determinar o recurso que irá executar o serviço em questão. Técnicas baseadas em fila trabalham aplicando políticas e heurísticas para determinar qual serviço da fila deverão ser atendidas, tais como: CSF, EMPEROR (L. Adzigogov e Polymenakos, 2005), e GridWay.

\subsubsection{Reserva de Recursos}

A Figura 3.9 representa a taxonomia para reserva avançada de recursos. A reserva de recursos é utilizada para o planejamento e coordenação das alocações de recursos. Vários escalonadores locais trabalham com reserva de recursos, entretanto, isso não é comum no caso de um Metaescalonador. Assim, existem duas abordagens gerais disponiveis para o Metaescalonador. A primeira é repassar a responsabilidade de gerência para o escalonador local, (LRM) - Local Resource Management). A segunda é implementar uma nova arquitetura de reserva, podendo ser flexível ou não flexível. A abordagem flexível define uma janela na qual o serviço pode ser executado, já a não flexível determina um tempo no futuro para o serviço ser executado. Dos Metaescalonadores considerados somente o Tycoon, Sharp e SORMA (Neumann et al., 2007) possuem a opção de reserva de recursos. 


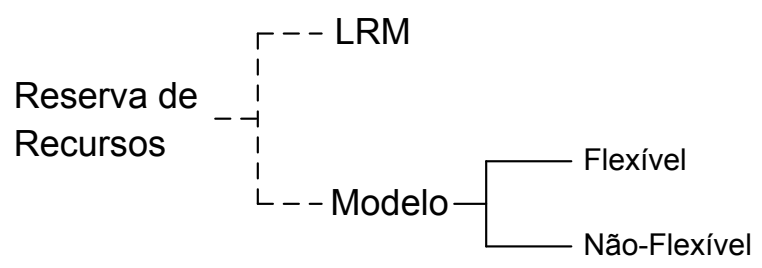

Figura 3.9: Taxonomia sobre a Reserva - Adaptado de Chard (2011).

Existem alguns esforços na comunidade de Metaescalonadores para melhorar a capacidade de reserva de recursos. O GridWay não apresenta suporte a reserva de recursos, porém, existem planos para desenvolvê-lo (Meinl, 2008). O CSF provê o serviço de reserva de recursos o qual interage diretamente com o escalonador local. O GridBus (Buyya e Venugopal, 2004) tem sido usado para criar reserva de recursos no Aneka (Chu et al., 2007) utilizando o protocolo de oferecimento alternado que provê negociação bilateral para estabelecer a reserva garantida (Venugopal et al., 2008).

Por fim, o CloudSim (Calheiros et al., 2010) também tem uma extensão que permite a reserva de recursos avançada, permitindo simulações complexas com vários tipos de análises de algoritmos.

\subsubsection{Confiabilidade e Segurança}

No caso de Computação em Nuvens, onde os domínios administrativos estão espalhados geograficamente, apresentam-se novas complicações em termos de segurança não vistas em sistemas centralizados. Dentro do ambiente distribuído existem diversos itens de segurança a serem levados em conta, tais como: autenticação dos participantes, autorização de ações por parte do usuário, estabelecimento de confiança entre os participantes e os componentes do Metaescalonamento, e garantia de comunicação segura sobre uma rede insegura (Ranjan, 2007) (Santos et al., 2009). A Figura 3.10 apresenta uma taxonomia sobre confiabilidade e segurança que ajuda a compreender as necessidades desse ambiente.

Os provedores de Computação em Nuvens devem prover mecanismos de segurança, incluindo acesso restrito físico e lógico ao hypervisor que pertence a camada de virtualização do recurso (Tolnai e von Solms, 2010). A integridade e a disponibilidade do hypervisor são as características mais importantes para garantir a integridade e disponibilidade de uma Nuvem pública construída sobre um ambiente virtualizado (Mather et al., 2009).

\subsection{Trabalhos Relacionados - Metaescalonadores em Intercloud}

A arquitetura de metaescalonador proposta nesta tese tem como objetivo o desenvolvimento de um metaescalonador que oferece BoS em Intercloud. Diversos outros metaescalonadores tem como objetivo realizar a gerência dos recursos em um 


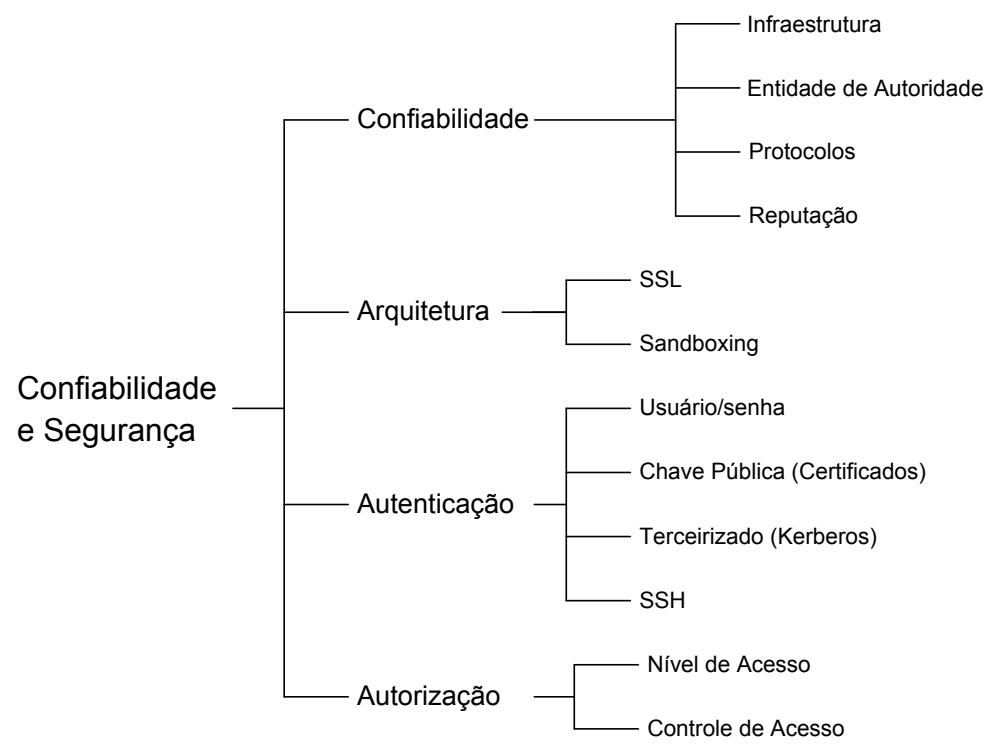

Figura 3.10: Taxonomia sobre Confiabilidade e Segurança - Adaptado de Chard (2011).

ambiente do tipo Intercloud. Sotiriadis et al. (2011) apresenta uma revisão desses metaescalonadores. Uma avaliação de cada uma dessa abordagens é feita nesta seção.

Em Weissman e Grimshaw (1996) é proposto um sistema de escalonamento para sistemas distribuídos baseado em um sistema de gerenciamento de recursos locais (LRMS - Local Resource Management System). Cada participante desse ambiente deve iniciar um gerenciador local e um gerenciador global de recursos. Especificamente, o gerenciador global contém duas interfaces, a interface do gerenciador de escalonamento para os escalonadores locais e, o escalonador da grade para os gerenciadores de escalonamento remoto. O compartilhamento de informações é baseado em arquivos estáticos que os escalonadores podem acessar a qualquer momento.

Schwiegelshohn e Yahyapour (1999) apresenta um Metaescalonador chamado NWIRE (Net-Wide-Resources). O escalonador consiste de um Meta-Gerenciador que é responsável por controlar um conjunto de domínios (Meta-Domínios) e tem com acesso ao Gerenciador de Recursos; o LRMS. O NWIRE considera várias características de escalonamento incluindo a existência de escalonadores convencionais, reserva de recursos e mercado de recursos baseado em mecanismos de economia.

Já em Anand et al. (1999), é feita uma discussão sobre um algoritmo dinâmico descentralizado que realiza estimativa de carga. Primeiro, o método estima a carga de espera para execução do serviço (de acordo com o tamanho da fila) e depois organiza a ordem de execução baseado nessas estimativas. O objetivo é utilizar a estimativa para aumentar as possibilidades de ganho sobre o balanceamento.

No trabalho apresentado por Daval-Frerot et al. (2000) existe um negociante (resource trader) em cada organização que age como um Metaescalonador, intermediando os vários consumidores e provedores. Assim, os vários negociantes interagem entre si, o que permite que eles negociem valores sobre os recursos que podem ser alocados. Essa 
colaboração de negociantes ocorre com o objetivo de maximizar a função de utilização dos recursos.

Subramani et al. (2002) demonstra um modelo de escalonamento de computação distribuída que adapta-se às mudanças do uso dos recursos (Shah et al., 2007). A ideia central é propor um Metaescalonador que distribui uma tarefa para vários lugares, ao invés de mandá-lo para o lugar menos sobrecarregado. Especificamente, quando se manda a tarefa para mútiplos lugares a chance de ocorrer o backfilling é maior. O backfilling é uma técnica que tenta balancear os objetivos de utilização e manutenção com base no FCFS (First Come First Served). Esse algoritmo requer que cada requisição especifique seu tempo de execução máximo. Enquanto a requisição na posição inicial da fila está esperando para ser atendida, é possivel por outra requisição menor em execução, especialmente se ela não irá atrasar o início da requisição que está na posição inicial da fila (Mu'alem e Feitelson, 2001).

O modelo apresentado em (Butt et al., 2003) utiliza o gerenciador de recursos do Condor para escalonar tarefas para os recursos ociosos, e somente irá invocar o mecanismo de agrupamento de Condors quando as máquinas estão ocupadas. Os resultados mostraram que esse tipo de agrupamento pode reduzir o tempo máximo de espera na fila.

Outra infraestrutura de escalonamento baseada em Bag-of-tasks - BOT é o OurGrid. O OurGrid é uma coleção de peers que constituem uma comunidade. O sistema contém um mecanismo que possibilita o acesso dos membros dessa comunidade aos recursos, chamado de Swan. O critério utilizado para o escalonamento é a reputação e a disponibilidade (Andrade et al., 2003).

Lai et al. (2005) discute sobre um sistema de alocação de recursos baseado em mercado. Nesse tipo de ambiente o mecanismo de escalonamento é baseado em leilões. Cada provedor de recurso executa um leilão para os seus recursos. O Metaescalonador comunica com o Serviço de Localização de Serviço (SLS) o qual contém um índice de recursos leiloados. Esse tipo de solução pode levar ao uso não coordenado de específicos recursos, inviabilizando o balanceamento de carga.

Em (Shah et al., 2007) são propostos dois algoritmos de escalonamento: Melisa e o Balanceamento de Carga sobre a Chegada. A diferença dos dois está na escala de aplicação, sendo que o Melisa atua melhor em escalas maiores e o Balanceamento de Carga sobre a Chegada obtém melhores resultados em escalas menores. Especificamente, o Melisa calcula a carga dos nós utilizando a taxa de chegada dos nós e a taxa de serviço. Em seguida, os autores concluíram que o Balanceamento de Carga sobre a Chegada iria balancear as chegadas dos jobs maiores.

A técnica apresentada em (Iosup et al., 2007) consiste de um Metaescalonador que utiliza uma arquitetura hierárquica no qual os recursos do mesmo nível podem cooperar entre si. Essa abordagem descentralizada permite que várias organizações diferentes cooperem entre si mesmo sem ponto de controle central. Quando uma organização requer um auxílio, uma conexão entre os recursos locais e os recursos remotos é desempenhada de forma automática. 
O GridWay Leal et al. (2009), apresenta um modelo descentralizado de escalonamento para resolver as questões que envolvem múltiplas organizações que trabalham de forma de cooperativa. Esse esquema propõe um Metaescalonador para cada infraestrutura da organização. Esse método é uma alternativa para a configuração centralizada.

Uma abordagem utilizando a técnica Fuzzy é mostrada em (Fölling et al., 2009). Esse esquema realiza a identificação de situações onde algoritmos robustos podem ser usados para distribuição de carga em ambientes descentralizados. Os resultados avaliados mostraram que as trocas entre as políticas levam a melhoras tanto do tempo de resposta quanto da utilização dos recursos.

O problema onde o Broker deve realizar seleções de recursos em múltiplos cenários de ambiente distribuído é descrito e avaliado em (Rodero et al., 2010). Os hosts e as organizações virtuais são representadas como Metabrokers que podem se comportar como se fossem roteadores de informação. Os autores dizem que o desempenho não é penalizado significativamente, e melhores resultados podem vir, usando informação de desempenho dinâmica.

Uma abordagem baseada em Licitação é apresentada em (Wang et al., 2010). Esse modelo é utilizado para seleção de recursos quando o ambiente está sobrecarregado. Os autores dizem que não é possível obter informações globais atualizadas em um ambiente dinâmicos, como é o caso da Computação em Nuvens. Assim, eles propõem uma heurística que tenta minimizar o tempo de reposta, mostrando segundo os experimentos executados, melhores resultados do que outras abordagens.

Uma abordagem de escalonamento dinâmico descentralizado é proposto em (Huang et al., 2011). Nomeada CASA (Community Aware Scheduling Algorithm), essa abordagem funciona como um escalonamento de duas fases. Na primeira fase, que é a fase de submissão de tarefa, procura-se o nó mais adequado a partir de todo o sistema. Na segunda fase, que é a fase de escalonamento dinâmico, tem como objetivo melhorar as decisões do escalonamento de forma interativa. Os resultados mostrados pelos autores permitem concluir que os resultados são significativos comparados as outras abordagens aplicadas.

Existem ainda outras abordagens, como é o caso de (Rodero et al., 2009) (Xu et al., 2011), que buscam melhorar os resultados para o tempo de execução e para a justiça, respectivamente. Ambas as abordagens empregam heurísticas para resolver o problema de seleção de recursos em um ambiente de Intercloud.

\subsection{Considerações Finais}

A Seção 3.5 apresenta a evolução dos Metaescalonadores em Intercloud desde o surgimento de escalonadores para sistemas distribuídos em 1996 até os Metaescalonadores para Computação em Nuvem que vem sendo propostos em trabalhos recentes. Nessa evolução observa-se inicialmente uma convergência para os sistemas em grade. Em seguida, a utilização desses Metaescalonadores de propósito geral para o uso nas Nuvens. Entretanto, ainda existem questões abertas para discussão sobre escalonamento. O objetivo foi relacionar os trabalhos sobre metaescalonamento cujo ambiente em destaque 
é do tipo da Intercloud, especificamente, em ambientes com infraestrutura distribuída e com a característica dinâmica. Por essa razão, os trabalhos avaliados foram aqueles com foco no modelo de Metaescalonamento. Assim, durante esse estudo, foi constatado que a maior parte dessas Meta-abordagens tinha preocupações em lidar com uma infraestrutura flexível, escalar, heterogênea e/ou dinâmica. Atualmente em sistemas de Nuvens, os existentes Metaescalonadores não estão preparados para localizar e controlar os serviços em execução como acontece com a infraestrutura em grade. Também, os Metaescalonadores de propósitos gerais podem não lidar de forma suficiente para os casos específicos que ocorrem na Computação em Nuvens. 


\section{MACC - Metascheduler Architecture to provide QoS in Cloud Computing}

\subsection{Considerações Iniciais}

Conforme visto nos capítulos anteriores, a Computação em Nuvem vem oferecendo um novo paradigma que envolve a presença de provedores ofertando serviços para clientes geograficamente distribuídos. Esse paradigma envolve a utilização de diversos tipos de recursos que podem levar à necessidade de se considerar aspectos relacionados a BoS.

Este capítulo descreve o MACC - (Metascheduler Architecture to provide GoS in Cloud Computing), que tem como objetivo garantir GoS aos usuários pertecentes ao ambiente Intercloud. Para obter esse objetivo, o MACC identifica quais recursos disponiveis na Nuvem podem atender aos requisitos dos usuários e aplica as políticas que favorecem a distribuição de carga entre os provedores da Intercloud. O MACC é uma arquitetura de metaescalonamento que realiza a distribuição dos serviços solicitados pelos usuários entre os vários provedores de serviços de uma Intercloud e torna possível o oferecimento de GoS. Uma das funções do MACC é garantir a manutenção dos critérios de GoS. $\mathrm{Na}$ visão do cliente, a requisição por um serviço ocorre de forma transparente, sendo responsabilidade do MACC o gerenciamento completo do serviço.

\subsection{Visão Geral do MACC}

A Figura 4.1 apresenta uma visão geral do MACC. O MACC é composto por cinco camadas. A camada mais alta, denominada Camada de Aplicação é onde se originam as requisições e serviços a serem executados. A segunda é a Camada de Cliente/Servidor é responsável pelo controle do fluxo de serviço. Essa camada é 
composta por dois componentes, Controle de Admissão e Controle de Valores. A terceira camada é chamada de Camada de Núcleo, é nessa camada que ocorrem as principais operações do Metaescalonador, por exemplo, a definição de configuração das máquinas virtuais a serem criadas. Nessa camada de núcleo estão os principais componentes de gerenciamento, tais como Cache UDDI, LRAM, Políticas de Escalonamento, Workload Engine, MDSN. A quarta é a Camada de Virtualização, e é onde estão presentes os softwares responsáveis pela realização de virtualização das máquinas físicas. Por fim, a última é a Camada de Infraestrutura Fisica, e é onde estão todos os recursos computacionais.

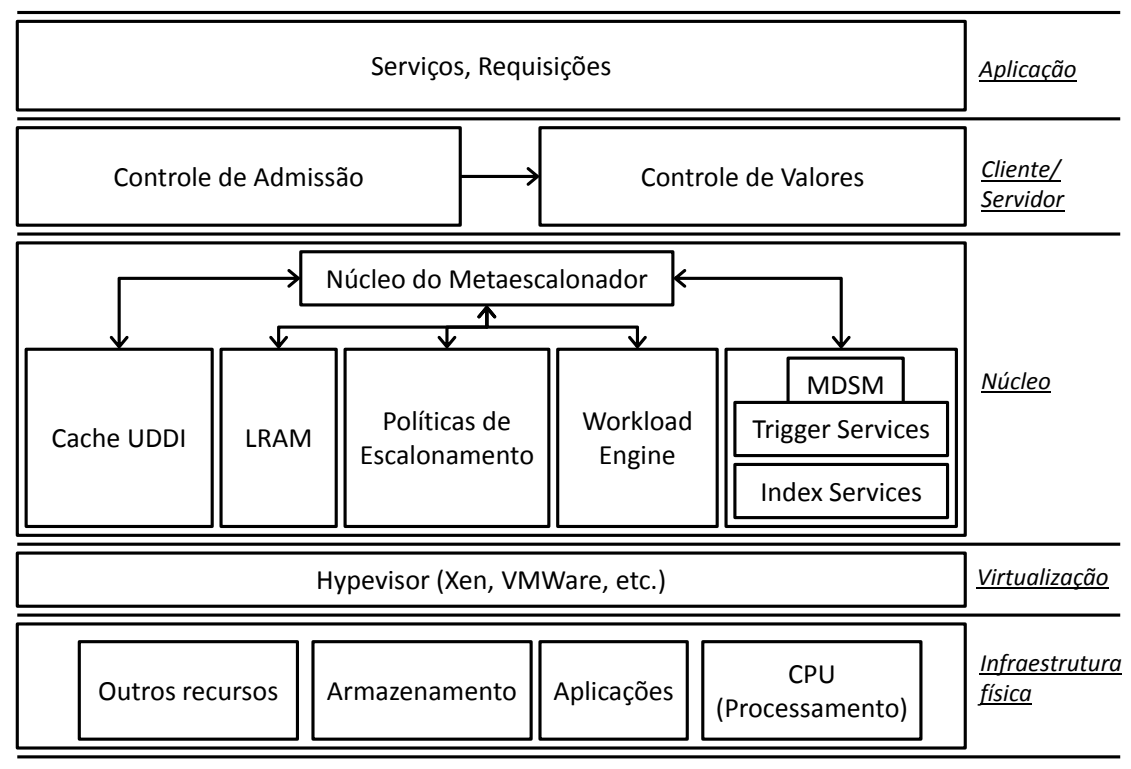

Figura 4.1: MACC - Visão Geral.

Os componentes presentes nas camadas realizam trocas de informações entre si. A Figura 4.2 mostra, de forma resumida, essas trocas de informaçõe para o processamento de um serviço. Primeiramente, o usuário envia a requisição para execução do(s) serviço(s) acompanhada dos critérios de GoS pretendidos. A requisição é recebida pelo controle de admissão que verifica a disponibilidade de atendimento por meio de uma consulta ao componente MDSM, responsável pela monitoração dos recursos. Caso haja disponibilidade, o controle de admissão encaminha a requisição para o módulo Trade - (Controle de Valores), esse componente é o responsável pela definição do preço a ser cobrado por aquele serviço. Depois da definição do preço, a requisição é encaminhada para o núcleo do metaescalonamento que determina onde e de que maneira o serviço será ofertado. Depois de processado o serviço na nuvem, os resultados são encaminhados para o usuário.

As funções de cada um dos componentes presentes na arquitetura do MACC são apresentadas na próxima seção. 


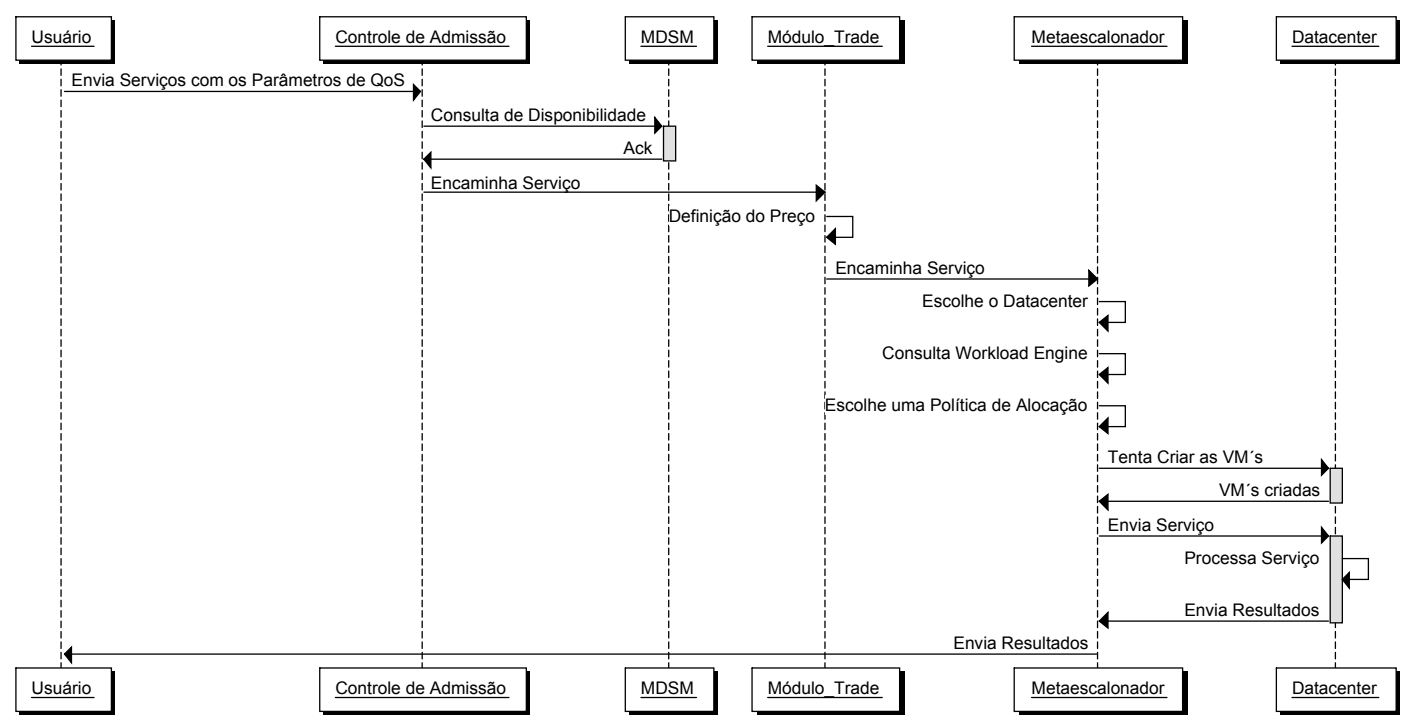

Figura 4.2: Diagrama de Sequência para o Tempo de Resposta.

\subsection{Detalhamento dos Componentes do MACC}

Os componentes do MACC são descritos a seguir:

\subsubsection{Camada de Aplicação}

- Serviços e Requisições: em sua visão atual o MACC lida com dois tipos de serviços: leves e pesados. Os serviços leves consistem de requisições com baixa necessidade de processamento (tais como a recuperação de páginas Web ou transações de negócios on-line). Já os serviços pesados consideram requisições de serviços com processamento intensivo, representando a utilização de Computação em Nuvem por aplicações científicas, por exemplo, uma renderização de imagens.

\subsubsection{Camada de Cliente/Servidor}

- Controle de Admissão: O Controle de Admissão é um componente do MACC que realiza o controle do fluxo de serviços que podem ser aceitos de acordo com métricas de utilização. O mecanismo de controle de admissão é utilizado como um importante meio de controle da qualidade serviço. A redução de requisições aceitas no sistema proporciona melhores índices de GoS. Entretanto, aumentar o número de descartes pode prejudicar a satisfação do cliente.

- Controle de Valores ou Trade Cliente/Servidor: realiza o controle desde a construção do preço de um serviço até sua negociação com os clientes. Devido ao crescimento atual dos sistemas computacionais colaborativos é necessário um mecanismo de gerência para lidar com as questões de negócio. Uma das soluções para realizar o gerenciamento de uma Computação em Nuvem colaborativa é a utilização de modelos econômicos (Buyya et al., 2002). Algumas soluções para 
ambientes distribuídos já utilizam modelos econômicos para o controle de, por exemplo, o throughput e a utilização de CPU.

A utilização de modelos econômicos no MACC permite analisar e prever a forma pela qual os participantes realizam as trocas de serviços. Normalmente, no início de uma transação, um cliente busca um preço menor e o provedor um preço maior. Adotando o modelo baseado em troca, é estabelecida uma "moeda" de troca básica, chamada de crédito. Fundamentalmente, as federações podem assumir tanto o papel de provedores de recursos (adquirir créditos) quanto o de consumidores de recursos (consumir créditos).

Para determinar a forma que funcionará a transação é utilizado neste trabalho um protocolo de comunicação entre o cliente e o provedor de serviço, como mostrado na Figura 4.3. Esse protocolo é proposto por Buyya et al. (2001). Inicialmente é criada uma conexão de comunicação entre o provedor e o cliente. Em seguida, o cliente produz uma requisição TB-WSLA - (Template Base - Web Service Level Agreements) ${ }^{1}$ contendo todas as informações sobre a métrica de QoS desejada. Um cliente pode acessar múltiplos provedores; portanto, esse protocolo tem um timeout determinando por quanto tempo o orçamento é válido. Depois de o acordo ser aceito por ambos os lados, é assinalada a confirmação da GoS. Finalmente, a conexão é fechada (Benkner e Engelbrecht, 2006); (Buyya et al., 2001).

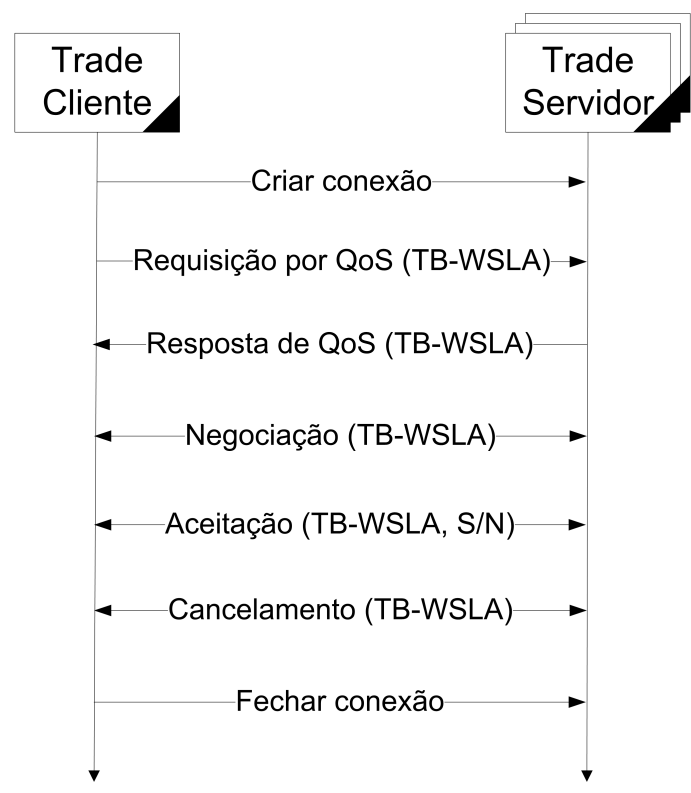

Figura 4.3: Protocolo de Negociação - Adaptado (Buyya et al., 2001).

O modelo econômico adotado neste projeto é baseado na oferta/demanda. Este tipo de abordagem habilita o ambiente a compartilhar os seus recursos. No caso da oferta/demanda, a oferta refere-se à quantidade de um bem ou serviço que os produtores desejam vender. Já a demanda é a quantidade de um bem ou serviço que os consumidores desejam adquirir. O preço dos bens ou serviços é influenciado

\footnotetext{
${ }^{1}$ Modelo Básico de uma WSLA.
} 
pela oferta e a demanda. Se a demanda e a oferta de um serviço forem iguais é atingido o chamado Equilíbrio de Mercado, onde o preço é estacionário. Se a demanda é superior à oferta, os consumidores tendem a elevar o valor de lance, o que causa um aumento de preço sobre o serviço. Por outro lado, se a oferta é maior que a demanda, os vendedores tendem a diminuir os preços.

No esquema adotado no MACC, o provedor publica os seus serviços e os clientes escolhem previamente o melhor serviço de acordo com alguma métrica desejada. Isso significa que os provedores cujas contribuições são maiores terão maior garantia de desempenho quando necessitarem de algum serviço. Assim, essa abordagem torna possível regular as prioridades a partir do escalonamento, pois, quem prover mais recursos, acumulará mais créditos e poderá pagar por métricas mais rígidas. Portanto, esse tipo de ambiente oferece flexibilidade e amplitude de desempenho para todos os interessados. Outro ponto a favor desta abordagem é que ela reage de forma adequada às mudanças do ambiente e não necessita de um coordenador, que seria o mecanismo responsável por gerenciar o ambiente.

\subsubsection{Camada de Núcleo}

- Workload Engine: Para estimar o tempo de execução de um determinado serviço, utiliza-se o componente Workload Engine. Para determinar o tempo, o componente considera a taxa de utilização dos recursos no momento em que o acesso foi solicitado. O tempo de execução é fornecido por meio de um valor médio e um desvio $\Delta$.

O Workload Engine é usado para a obtenção do tempo relativo - TS - do serviço $i$, em outras palavras, é possível estimar quanto tempo o serviço $i$ levará para ser executado em função da taxa de utilização e baseado no histórico de tempos relativos aos serviços, representado pela Tabela 4.1. O $\Delta$ representa um desvio em relação à média do tempo dos serviços. O Metaescalonador utiliza este componente para um melhor escalonamento das requisições enviadas aos recursos. Por exemplo, se a taxa de utilização é $30 \%$ e o serviço $i$ é requerido, a variável $T S_{i}$ recebe $y i+\Delta^{*}$, onde $\Delta^{*}$ é o tempo com o desvio.

Tabela 4.1: Workload Engine - Estimação (\%)

\begin{tabular}{|r|r|r|r|}
\hline Taxa de Utilização (\%) & Serviço 1 & Serviço 2 & Serviço i \\
\hline $0 \vdash 25$ & $x 1+\Delta^{*}$ & $x 2+\Delta^{*}$ & $x i+\Delta^{*}$ \\
\hline $25-50$ & $y 1+\Delta^{*}$ & $y 2+\Delta^{*}$ & $y i+\Delta^{*}$ \\
\hline $50-75$ & $z 1+\Delta^{*}$ & $z 2+\Delta^{*}$ & $z i+\Delta^{*}$ \\
\hline $75 \dashv 100$ & $w 1+\Delta^{*}$ & $w 2+\Delta^{*}$ & $w i+\Delta^{*}$ \\
\hline
\end{tabular}

Por meio do componente Workload Engine, o Metaescalonador pode construir o melhor conjunto de recursos disponiveis e encaminhar seus detalhes para o componente LRAM - (Local Resource Allocation Manager). 
- Trigger Service: Esse componente dispara um evento que avisa a camada de núcleo do MACC quando uma máquina virtual entra em um estado sobrecarregado ou indisponivel. Esses estados são configurados, em tempo de projeto, para que o Metaescalonador possa tomar ações, na forma reativa, respondendo a alguma mudança no ambiente.

- Index Service: Esse componente armazena informações sobre as variáveis do sistema e sobre os serviços em execução. Periodicamente, são coletadas informações a respeito do funcionamento de cada máquina física e virtual, através de medições dos recursos computacionais, tais como: CPU, memória, lista de requisições por serviços, utilização dos discos.

- QoS: Retrata as informações sobre a GoS atual de forma dinâmica. Esse componente permite realizar um acompanhamento do estado da qualidade de serviço aplicada, e está relacionado com a capacidade da arquitetura em cumprir os requisitos propostos na SLA.

- SLA - (Service Level Agreement): Registra os contratos estabelecidos entre o cliente e o provedor. Esse módulo é o responsável por armazenar os contratos estabelecidos entre os usuários e os provedores.

- LRAM - (Local Resource Allocation Manager): Gerenciador de Alocação de Recursos Local, é o componente do MACC responsável pela tarefa que envolve segurança e tolerância a falhas durante o escalonamento. É por meio desse componente que os recursos são alocados, atribuídos, autenticados, autorizados e auditados.

- Cache:UDDI - (Cache: Universal Description, Discovery and Integration): Armazena informações sobre serviços locais e sobre os serviços remotos conhecidos. Especificamente, é um serviço de diretório de páginas amarelas local pelo qual se pode registrar (publicar) e buscar (descobrir) serviços. Esse componente utiliza uma interface padrão para acesso aos serviços, essa interface é chamada de SIA (Standard Interface Access).

- Políticas de Escalonamento: Diretório das políticas de roteamento e das políticas de alocação de máquinas virtuais. As políticas que fazem parte desse componente são descritas nas Seções 4.7 e 4.8.2.

\subsubsection{Camada de Virtualização}

Essa camada é denominada hipervisor ou monitor da virtualização, ela é responsável por construir as interfaces virtuais com base nos recursos computacionais disponíveis. A camada de virtualização deve isolar uma máquina virtual da outra de modo que não exista nenhuma interferência entre ambas. Os hipervisores de virtualização devem prover essa funcionalidade. Dentre as atividades dessa camada estão a virtualização de armazenamento, virtualização de rede, virtualização de gerenciamento e a virtualização de serviços. 


\subsubsection{Camada de Infraestrutura Física}

Essa camada diz respeito aos recursos computacionais disponiveis para execução dos serviços. A infraestrutura do ambiente de computação em nuvem normalmente é composta por um número significativo de máquinas físicas, conectadas por meio de uma rede. Cada máquina física tem as mesmas configurações de software (hipervisores), mas pode ter variação na capacidade de hardware em termos de CPU, memória e armazenamento em disco. Esses recursos computacionais são gerenciados pelo MACC e o fluxo de comunicação é descrito na próxima seção.

\subsection{Fluxo de Operação do MACC}

O processo de comunicação completo do MACC é descrito na Figura 4.4. Esse processo tem início quando algum usuário envia uma requisição de serviço. Essa requisição é intermediada pelo componente Controle de Admissão. Assim, é aplicada a política de admissão que pode aceitar ou descartar as requisições do sistema. Essa política pode ser baseada na taxa de utilização da CPU. Se o sistema não estiver em sobrecarga, a requisição é enviada para o Trade Servidor, o qual é o responsável pela negociação do serviço provido junto ao componente Trade Cliente. Neste momento, as partes envolvidas, cliente e provedor, estabelecem seus objetivos de negociação, estipulando assim no SLA, o valor e prazo de execução do serviço.

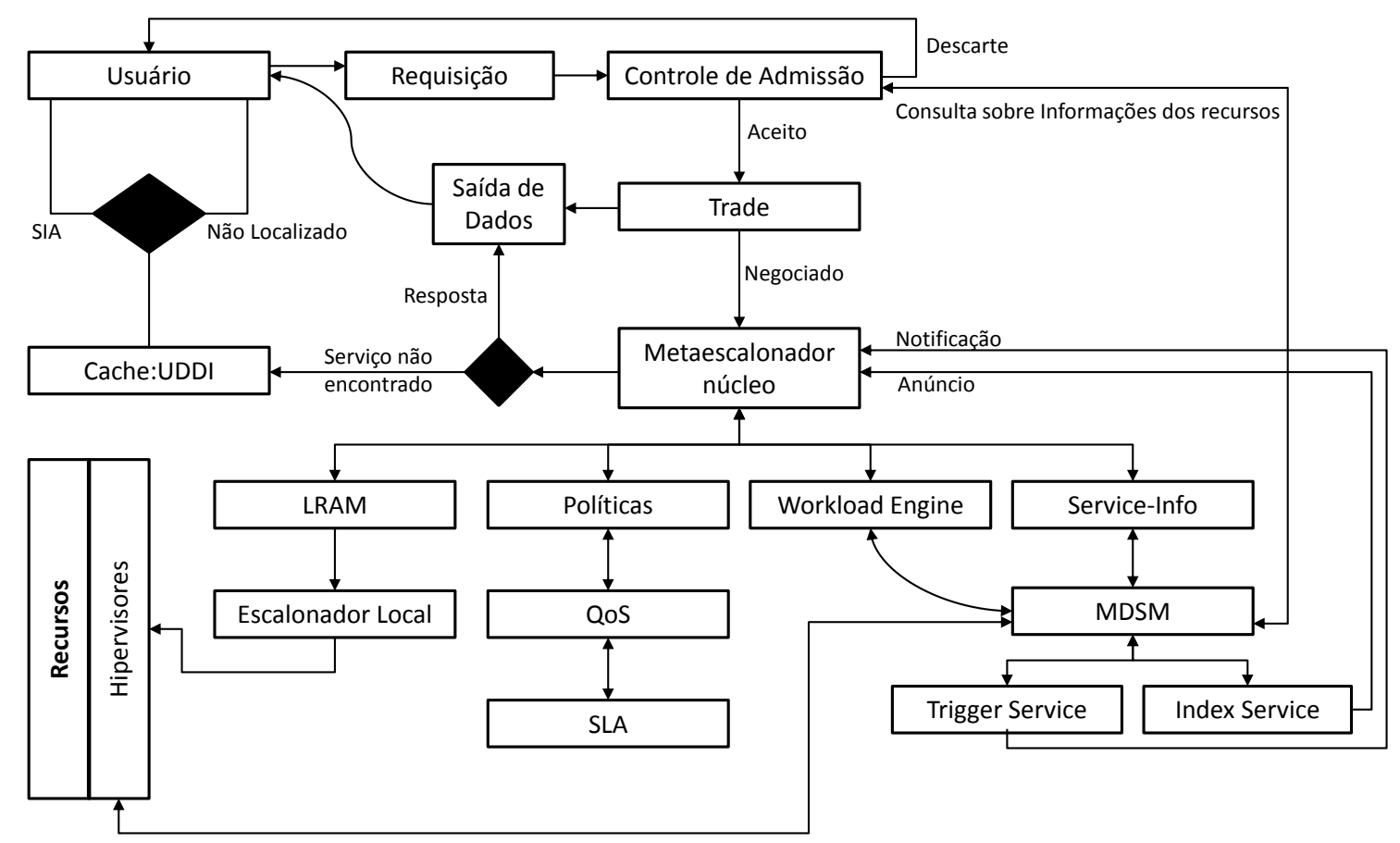

Figura 4.4: Fluxo de Operações do Metaescalonador.

O Metaescalonador consulta o componente MDSM - (Monitoring and Discovery System Manager) para localizar os registros de serviços disponíveis. Caso o serviço não seja localizado localmente, é efetuada uma operação de localização no componente 
Cache:UDDI. Se esse componente possui a informação sobre o serviço desejado é retornada a SIA - (Standard Interface Access) para o cliente. O componente Cache:UDDI armazena somente a SIA de serviços que são de federações conhecidas (por meio dos seus vizinhos) ou acessos anteriores. Se o serviço não for localizado no componente Cache:UDDI é retornada uma mensagem ao usuário informando que o serviço não foi localizado.

Se o serviço foi localizado localmente, o Metaescalonador invoca o componente Index Service para descobrir os recursos da Nuvem. O Index Service realiza o endereçamento de cada recurso requisitando dados de desempenho. Durante a execução do serviço, podem ocorrer as notificações de mudanças dos estados dos recursos que são de responsabilidade do componente Trigger Service, por exemplo, se o recurso se torna indisponível ou sobrecarregado.

É uma operação normal do Metaescalonador interagir com os gerentes dos recursos locais (dentro das entidades) da Nuvem. Com as informações dos serviços e recursos disponiveis, as políticas de escalonamento podem ser determinadas. O escalonamento considera ainda informações de GoS e dos contratos realizados com os usuários (SLA). Finalizando, as requisições são encaminhadas pelo componente LRAM -Local Resource Allocation Manager. Em seguida ao processo de término de execução desse serviço, os dados de resposta são retornados para o usuário.

Quando um usuário requisita um serviço para um Metaescalonador, três resultados são possíveis: (i) a localização do serviço e o retorno da resposta do serviço, (ii) a informação de onde o serviço pode ser localizado, ou (iii) a informação que o Metaescalonador não possui conhecimento sobre o serviço.

\subsection{Projeto e Implementação do MACC}

Nesta seção são fornecidas informações relacionadas às classes implementadas que envolvem o projeto MACC e o simulador CloudSim. A visão geral do projeto de diagrama de classes é mostrada na Figura 4.5. Os retângulos em negrito representam as classes modificadas ou criadas.

As classes são descritas da seguinte forma:

- BwProvisioner: essa é uma classe abstrata que modela a regra de provisionamento de largura de banda para as máquinas virtuais.

- Cloudlet: essa classe modela os serviços que são executados no ambiente de Computação em Nuvem, tais como: aplicações baseadas em contexto, rede social, aplicações baseadas em negócios. Todos os serviços têm instruções pré-atribuidas, por exemplo, tamanho ${ }^{2}$ e sobrecarga da transferência de dados, tanto de entrada como de saída.

\footnotetext{
${ }^{2}$ Representa a carga dada em MI - (Milhões de Instruções).
} 


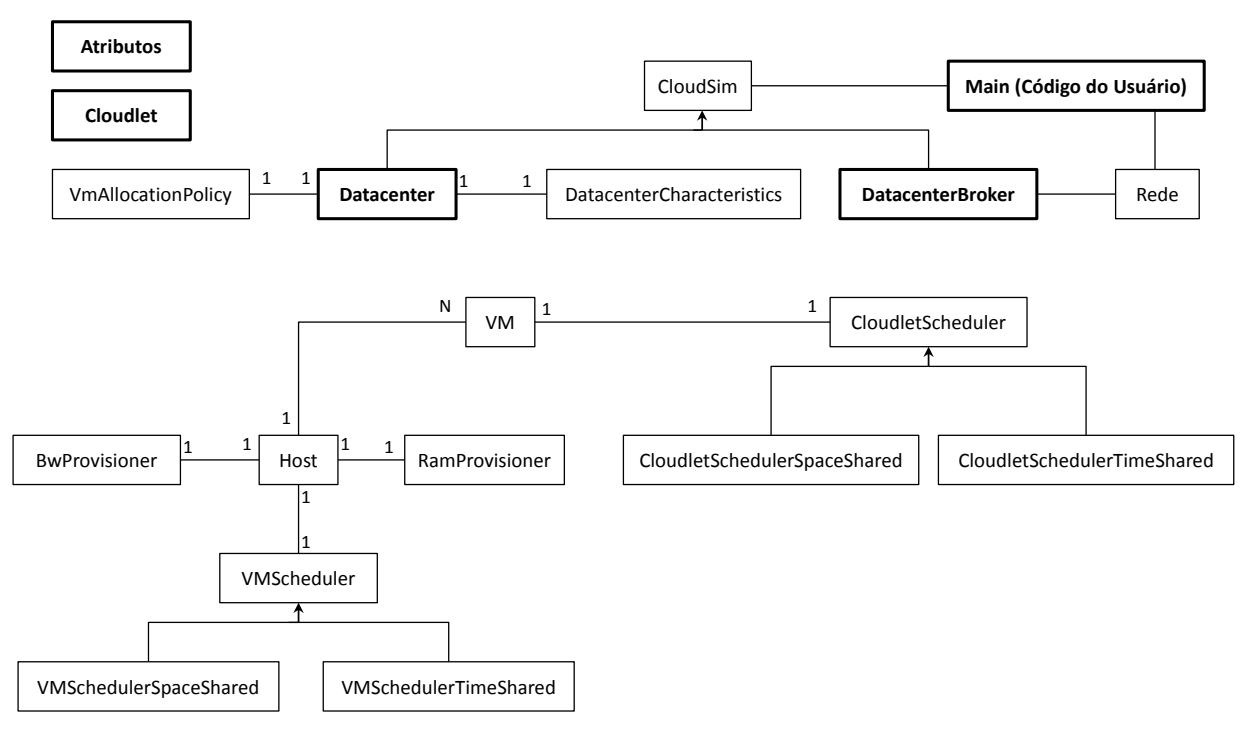

Figura 4.5: Diagrama de Classes do Projeto MACC.

- CloudletScheduler: essa é uma classe abstrata que é utilizada para implementação de políticas que determinam a forma de compartilhamento dos recursos de processamento entre as Cloudlets de uma VM.

- Datecenter: essa classe modela o nível de infraestrutura dos serviços dado pelos hardwares presentes. Ela encapsula um conjunto de computadores físicos que podem ser tanto homogêneos como heterogêneos. Permite que se configurem alguns dispositivos, tais como: memória, núcleos de processador, capacidade de armazenamento. Além disso, essa classe é a responsável por realizar a computação do preço sobre a VM utilizada.

- DatacenterBroker: essa classe modela um broker ou metaescalonador, o qual é reponsável por mediar as negociações entre os usuários e os provedores da Nuvem, fornecendo requisitos de $\mathrm{GoS}$.

- Atributos: essa classe registra os parâmetros utilizados durante o planejamento de experimentos.

- DatecenterCharacteristics: essa classe possui informações detalhadas sobre as características dos recursos presentes na classe Datacenter.

O MACC realiza a modelagem das cargas de trabalho que possuem o comportamento tanto para serviços leves quanto para serviços pesados. Por isso é necessário que o MACC trabalhe de forma proativa. Foi utilizada a distribuição exponencial para representar o intervalo de chegada das requisições que solicitam o serviço a ser executado. Já a taxa de serviço é representada por uma distribuição uniforme, os serviços leves possuem uma carga que varia entre cinco mil instruções até seis mil instruções. Por outro lado, os serviços pesados possuem uma variação de carga entre vinte mil e trinta mil instruções. 
As cargas de trabalho utilizadas pelo MACC são baseadas em modelos com conhecimento sobre a taxa de chegada e a taxa de serviço. Assim, é viável a utilização do componente Workload Engine para realizar uma estimativa baseada no histórico dos tempos, tais como as predições feitas por QRSM (Myers et al., 2009) e ARMAX (Candy, 2006). Esses dois trabalhos fornecem estimativas adequadas para traces e cargas de trabalho reais. O MACC realiza uma estimação simples baseada na média histórica, com responsabilidade do componente Workload Engine.

\subsection{Métricas Consideradas pelo MACC}

Para a avaliação do resultados obtidos com a execução das requisições pelo MACC foram utilizadas três variáveis de resposta: Custo, Tempo Médio de Resposta e Confiabilidade. Essas três variáveis de resposta fornecem informações uteis sobre o processo em estudo.

\subsubsection{Custo - (Cost - C)}

O preço de um recurso pode influenciar na sua utilização, porque os consumidores tendem a escolher aqueles que têm o menor preço. O componente Trade Servidor lida com um mecanismo para ajuste automático do preço, objetivando maximizar a taxa de utilização dos recursos. O ajuste do preço deve ser realizado para atender as mudanças do ambiente econômico. O administrador do provedor pode determinar o peso de cada parâmetro envolvido, tais como: demanda $(\alpha)$, oferta $(\beta)$, demanda/oferta $(\varrho)$, taxa de utilização $(\delta)$ e $(\gamma)$, e deadline $(\epsilon)$ variando de 0 a 1. Para o ajuste do preço são considerados os seguintes parâmetros, adaptado de (Teixeira, 2006):

- Demanda $\left(d_{i}\right)$ : O preço para executar um serviço é proporcional a sua demanda, onde $\left(d_{i-1}\right)$ foi a última demanda obtida. Equação 4.1.

$$
d_{i}=\frac{\left(d_{i}-d_{i-1}\right)}{d_{i-1}} * \alpha
$$

- Oferta $\left(O_{i}\right)$ : O preço para executar um serviço é inversamente proporcional ao seu grau de oferecimento. Equação 4.2.

$$
O_{i}=\frac{\left(O_{i}-O_{i-1}\right)}{O_{i-1}} * \beta
$$

- Demanda/Oferta $\left(d O_{i}\right)$ : Representa a relação entre o montante requisitado e o montante oferecido para um serviço. Se a oferta é mais alta do que a demanda, o preço tende a diminuir. Entretanto, se a demanda é mais alta do que a oferta, o preço tende a aumentar. Caso exista uma igualdade entre demanda e oferta, pode-se dizer que o ambiente alcançou o equilíbrio. Equação 4.3.

$$
d O_{i}=\frac{\left(d_{i}-O_{i}\right)}{\min \left(d_{i}, O_{i}\right)} * \varrho
$$


- Taxa de utilização $\left(U_{i}\right)$ : Se a taxa de utilização é alta, é possível aumentar o valor dado ao serviço. Se esse serviço está sendo pouco utilizado, o preço cobrado pode estar alto e deve ser reduzido. Equação 4.4 .

$$
U_{i}=\left(\left(1-\frac{U_{i-1}}{100}\right) * \delta\right)+\left\lfloor\frac{U_{i-1}}{100}\right\rfloor * \gamma
$$

- Deadline $\left(D_{i}\right)$ : Essa variável referencia o tempo de entrega de um serviço. Se esse tempo é alto, o preço torna-se baixo. Por outro lado, se esse tempo é baixo, o preço torna-se alto. Equação 4.5.

$$
D_{i}=\frac{\left(D_{i}-D_{i-1}\right)}{D_{i-1}} * \epsilon
$$

A Equação 4.6 mostra como obter o novo preço $\left(P_{i}\right)$ em relação a estes parâmetros que mudam sobre o tempo (dado por $i$ ).

$$
P_{i}=P_{i-1}\left(1+\left(d_{i}-O_{i}\right)+d O_{i}-D_{i}-U_{i}\right)
$$

Depois do estabelecimento do preço base $\left(P_{i}\right)$, o valor do serviço é negociado. O MACC procura atender a requisição dentro do prazo contratado e considera a Equação 4.7 para obtenção do Custo Médio (C).

$$
C=\sum_{i=0}^{i=n} P_{i}
$$

Utilizando-se o MACC é possível realizar o compartilhamento, seleção, e agregação de vários recursos geograficamente distribuídos. Para lidar com essas questões e incluir o suporte a um modelo orientado a negócios, os provedores de recursos necessitam de técnicas e mecanismos que suportam a especificação de preço e esquemas genéricos para aumentar a utilização, e protocolos que suportam a publicação de serviços e a negociação.

\subsubsection{Tempo Médio de Resposta - (Mean Response Time - MRT)}

O MACC considera dois tipos de resposta, o MRT (Mean Response Time), Equação 4.8, e o RTT (Round Trip-Time), Equação 4.9. O MRT considera tempo de rede interno $(\mathrm{Na})$, tempo de fila $(T f)$ e o tempo de serviço $(T s)$. O MRT não considera o tempo de rede externo a entidade (Internet) $(N b)$. Por outro lado, o RTT considera o tempo de rede externo (Internet), tempo de rede interno, tempo de fila e o tempo de serviço.

$$
\begin{gathered}
M R T=N a+T f+T s \\
R T T=M R T+N b
\end{gathered}
$$




\subsubsection{Confiabilidade - (Reliability - $R$ )}

Considera-se que um usuário estará satisfeito com o serviço a ele oferecido quando obtiver uma porcentagem alta de requisições atendidas em média abaixo do limiar de qualidade contratado. Logo, analiticamente, o MACC pode tomar como índice de satisfação do usuário a equação (4.10), em que são relacionadas a quantidade total de requisições submetidas pelo $i$-ésimo usuário $\left(R_{i}\right)$ e o número de vezes em que a média do tempo de resposta de sistema dessas requisições ficou abaixo do limiar contratado $\left(N_{i}\right)$.

Uma requisição é bem atendida quando seu tempo médio de resposta for menor ou igual ao tempo médio de resposta somado a um desvio padrão aceitável contratado. Quanto mais próximo de $R_{i}$ for o valor de $N_{i}$, maior será a satisfação proporcionada ao usuário $i$. Esta é uma métrica suficiente para avaliar o desempenho de um escalonador no cumprimento dos níveis de $\mathrm{GoS}$ por ele oferecidos.

$$
S_{i}=\frac{N_{i}}{R_{i}}
$$

O mecanismo de controle de admissão pode influenciar na satisfação de um dado usuário. Se alguma requisição é descartada pelo algoritmo do controle de admissão é criada uma penalização. A cada requisição descartada é decrementado o número de vezes em que a média do tempo de reposta do sistema dessas requisições ficou abaixo do limiar contratado $\left(N_{i}\right)$.

Por meio destes conceitos e métricas pode-se estruturar as políticas de escalonamento propostas, além de possibilitar aos algoritmos algumas ferramentas de controle para monitorar e tomar decisões sobre a qualidade de serviço oferecida.

\subsection{Algoritmos de Alocação de Máquinas Virtuais do MACC}

Depois de escolhido qual data center da Intercloud irá atender a requisição do usuário é necessário alocar o número/configurações das máquinas virtuais para executar as requisições, que são do tipo BoT - (Bag of Tasks). A alocação de máquinas virtuais ocorre de acordo com os critérios da política selecionada. As políticas que foram implementadas e estão disponíveis no MACC são:

Random Generator - (RG): O algoritmo RG, Figura 4.6, funciona sem conhecimento das necessidades dos usuários. A quantidade de máquinas virtuais é obtida a partir de um número aleatório reduzido a um vetor numerado. Já a potência computacional e a quantidade de cada vCPU são fixas. O objetivo é utilizar esse algoritmo, de forma proativa, em cenários onde não existe uma estimativa sobre a carga do sistema.

A fase 1 do algoritmo RG é responsável por definir aleatoriamente o número de VMs a serem criadas. Na fase 2 são definidas de maneira fixa quatro vCPUs por máquina virtual. $\mathrm{E}$ a fase 3 define que cada vCPU possui um core físico.

Os demais algoritmos do MACC utilizam informações sobre o estado dos recursos. Os módulos MMDS e Workload Engine trabalham em conjunto para realizar a estimativa de carga. Além disso, os algoritmos levam em conta a limitação física da máquina host, prevenindo falhas e indisponibilidade. 


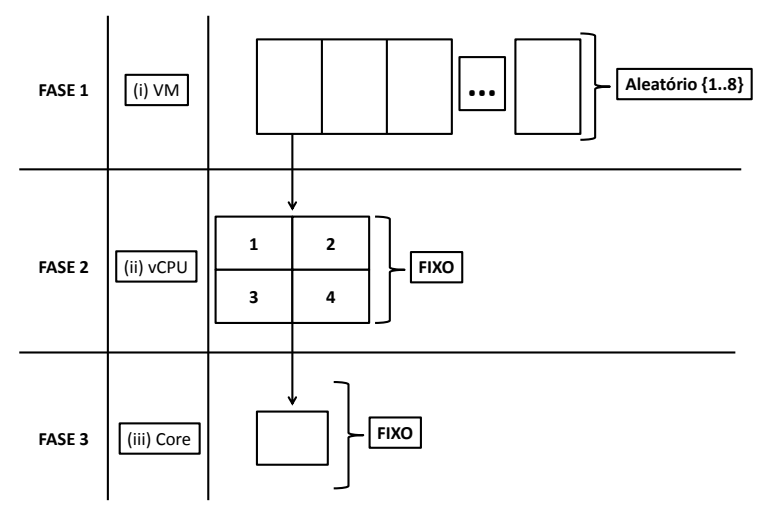

Figura 4.6: Algoritmo RG.

Slotted Dynamic 4 vCores - (SD4c): O algoritmo SD4c, Figura 4.7, utiliza a relação de quantidade de serviços a serem realizados por unidade de tempo. Dessa forma, na fase 1 são construídas $\mathrm{N}$ máquinas virtuais de acordo com a demanda. A fase 2 define cada uma dessas máquinas virtuais com quatro vCPUs cada. A potência computacional de cada vCPU é fixa, tal como a quantidade de vCPU. Na fase 3 é definida que cada vCPU pode possuir dois, quatro ou oito cores de acordo com a demanda. Entretanto, é a quantidade de máquinas virtuais criadas que define a velocidade de processamento dos serviços do usuário. O objetivo é atender os contratos estipulados na SLA, considerando as restrições temporais (deadlines). Além da quantidade de vCPUs indicada na construção da máquina virtual, também deve-se indicar a memória e a capacidade de armazenamento.

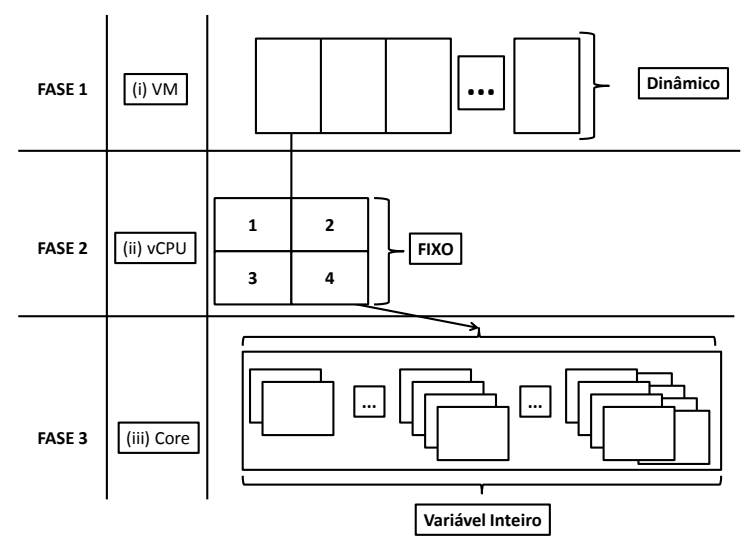

Figura 4.7: Algoritmo SD4c.

Predictive Dynamic 2 vCores - (PD2c): O algoritmo PD2c, Figura 4.8, utiliza informações dos serviços para extrair o custo e o deadline. Dessa forma, é possível realizar uma estimativa sobre o tempo de execução e alocar a quantidade ideal de máquinas virtuais (fase 1). O processo de definição da fase 2, que trata da potência computacional de cada uma das duas vCPUs ocorre na forma variável proporcional. Esse modelo variável proporcional (fase 3) realiza a utilização de apenas uma fatia do 
core físico e não o core inteiro. Esse tipo de abordagem já é utilizado pelo hipervisor XEN. Embora o algoritmo PD2c crie máquinas virtuais com propriedades dinâmicas, existe ainda um balanceamento entre o custo e o deadline, tentando minimizar o total gasto na criação de todas as máquinas virtuais que irão atender as requisições dos usuários.

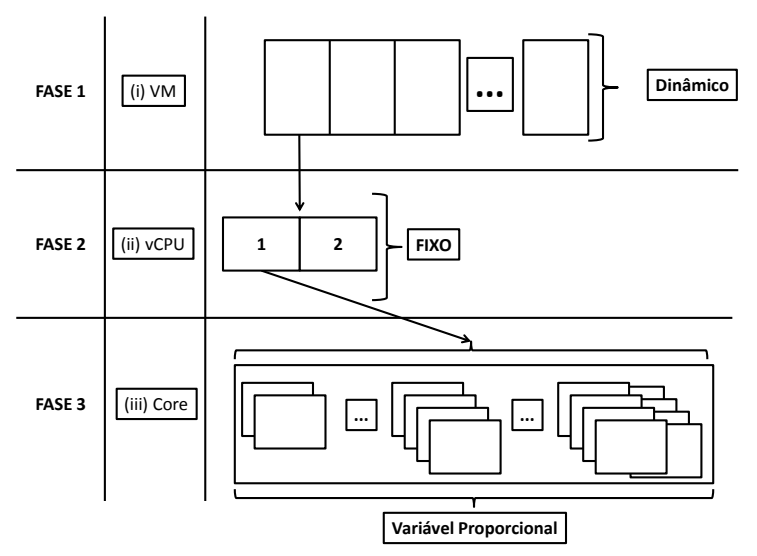

Figura 4.8: Algoritmo PD2c.

Predictive Dynamic X vCores - (PDXc): O algoritmo PDXc, Figura 4.9, possui todos os parâmetros variáveis. Tanto a quantidade de (fase 1) máquinas virtuais quanto (fase 2) potência computacional de cada vCPU e por fim, (fase 3) a quantidade de cores de cada vCPU. Com base na estimativa realizada para a carga de trabalho em função do tempo solicitado pelo usuário, realiza-se a configuração para as três fases. Esse algoritmo fornece uma característica flexível que permite utilizar melhor os recursos ao mesmo tempo em que cumpre as restrições temporais impostas na SLA.

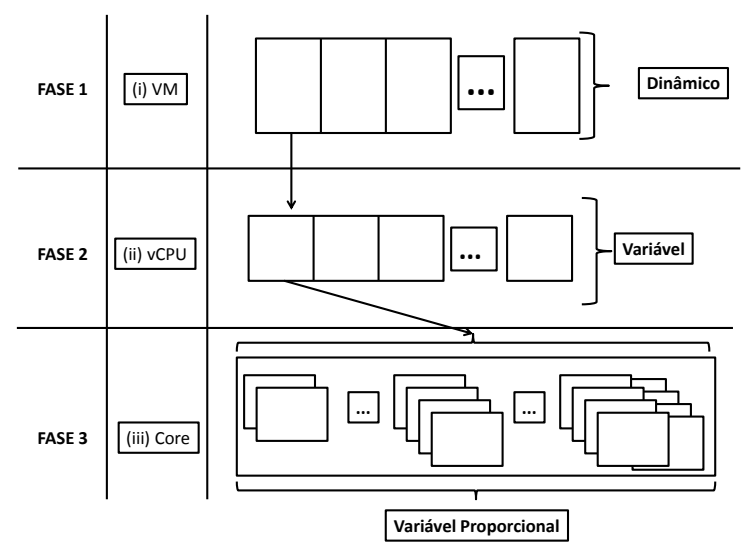

Figura 4.9: Algoritmo PDXc. 


\subsection{Ambiente Intercloud}

O modelo de comunicação, Intercloud, adotado pelo MACC é apresentado na Figura 4.10. Nesse modelo existe a separação entre as camadas de sobreposição e a definição de protocolos de como ocorre o encaminhamento de um serviço pelo MACC.

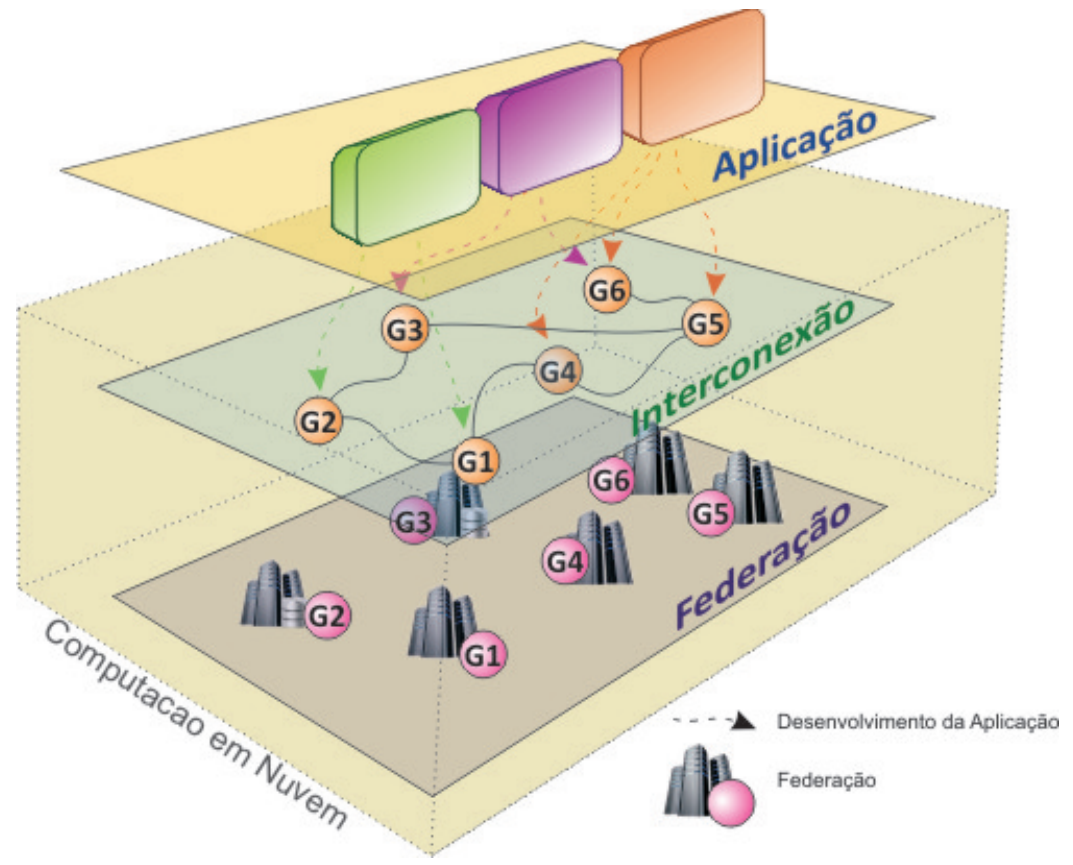

Figura 4.10: Visão Geral da Intercloud.

Conforme apresentado na Figura 4.10, o cliente solicita um serviço ao MACC que irá consultar em sua camada de interconexão qual o data center mais adequado, segundo as considerações de GoS, para atender a solicitação do cliente. As informações de delay utilizadas pelo MACC são obtidas na camada da Intercloud que contém os data centers. Assim, o modelo de comunicação adotado pelo MACC é composto por:

- Camada de Aplicação - Essa camada consiste na aplicação que o cliente está solicitando ou irá solicitar, além de obter as informações de localidade referente ao cliente;

- Interconexão - É a camada onde são coletadas as informações sobre a rede e sobre a disponibilidade dos data centers. Essa camada possibilita a pesquisa baseada nas informações de rede do cliente e do data center. Essa camada permite o desenvolvimento das políticas de roteamento;

- Intercloud é a camada onde os data centers irão executar as solicitações dos clientes.

Como é mostrada na Figura 4.10, a camada de interconexão e a camada de Intercloud estão presentes na Nuvem. Como a computação em Nuvem entrega aplicativos e serviços na Internet, as camadas de interconexão e Intercloud são desenvolvidas na Nuvem 
devido a coleta de informações necessárias para o funcionamento do MACC. Essas informações são utilizadas pelo MACC para formar a busca por recursos. A Figura 4.11 apresenta o modelo de comunicação hierárquico P2P utilizado pelo MACC.

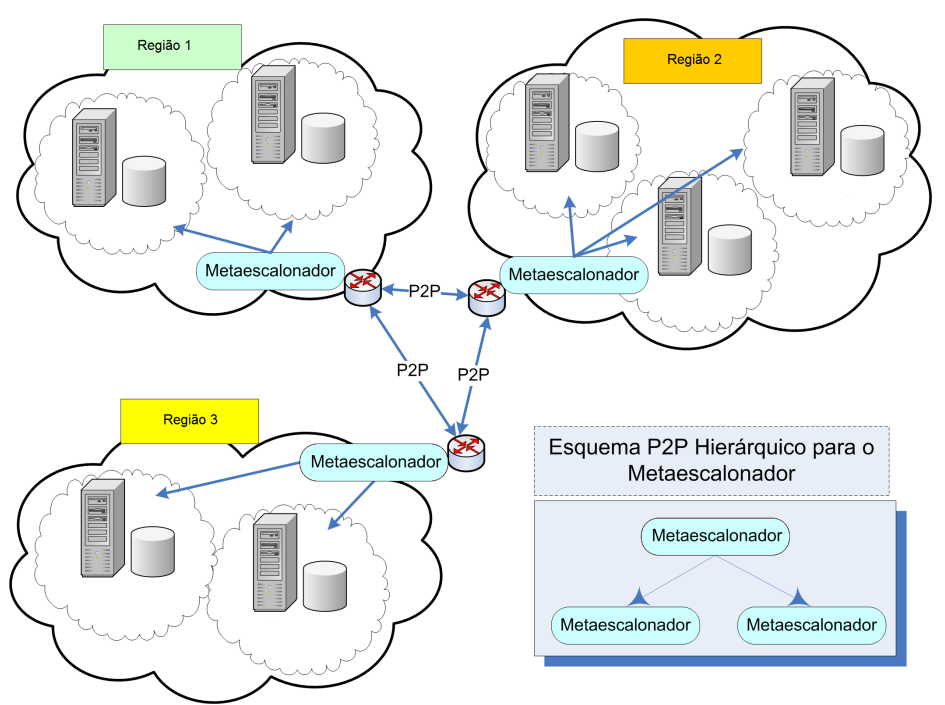

Figura 4.11: Modelo de Comunicação do MACC.

O MACC adota um modelo P2P hierárquico baseado em DHT - (Tabelas Hash Distribuídas). Esse modelo possui uma distribuição lógica que é formada por uma camada de sobreposição, cada região possui seu próprio metaescalonador que verifica as condições da rede para o correto encaminhamento das requisições dos clientes. Utilizando esse modelo, o cliente irá ser atendido pelo data center que estiver mais próximo a ele diminuindo assim a latência na comunicação entre o cliente e o data center.

O MACC, através da utilização da camada de interconexão, utiliza políticas de roteamento para a descoberta dos data centers que possuem menores latências aumentando assim a qualidade da entrega dos serviços aos clientes. O modelo de comunicação proposto neste projeto pode ser utilizado para outros objetivos como apresentado em (Vernekar e Game, 2012) que utiliza um modelo de comunicação similar ao do MACC para o desenvolvimento de componentes para alocação de recursos na Nuvem.

\subsubsection{Modelagem da Rede}

O CloudSim possui módulos relacionados à rede que permitem que a mesma seja utilizada para verificar qual o impacto da comunicação nas atividades da Nuvem (Buyya et al., 2010). A modelagem de rede do MACC foi realizada em conjunto com o trabalho de mestrado de Leite (2012).

As funcionalidades do CloudSim, que são relacionadas à rede, são: a topologia de rede e o cálculo da latência. A topologia de rede foi gerada utilizando o BRITE (Medina et al., 2001). Para a geração dessa topologia foi necessário definir alguns parâmetros como: o algoritmo para ligação dos nós e a quantidade de nós de cada topologia. O modelo de 
topologia utilizado foi o top-down (Medina et al., 2001). Esse modelo é formado pela ligação de vários sistemas autônomos (AS) como apresentado na Figura 4.12.

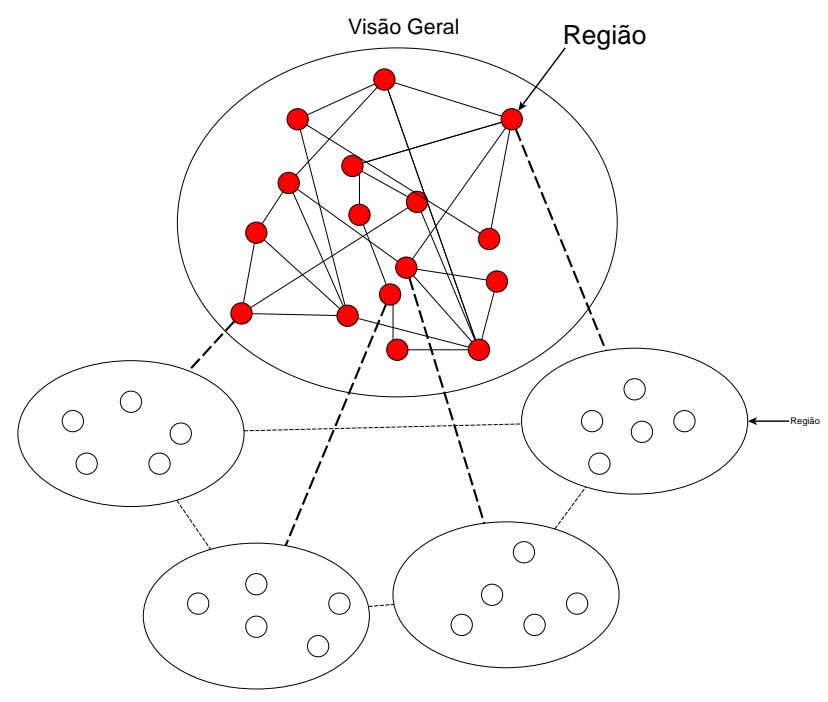

Figura 4.12: Modelo Topológico Utilizado.

O modelo de topologia, apresentado pela Figura 4.12, é composto por regiões de sistemas autônomos (em negrito na figura) e a ligação dessas regiões com outras regiões de sistemas autônomos. A topologia foi utilizada para simular a distribuição dos data centers e clientes ao redor do mundo. Além de auxiliar no desenvolvimento dos algoritmos de descoberta de serviço, uma vez que as regiões possuem limites de domínios. A Figura 4.13 apresenta uma visão geral da possivel distribuição dos data centers (DC) que podem estar dispersos geograficamente.

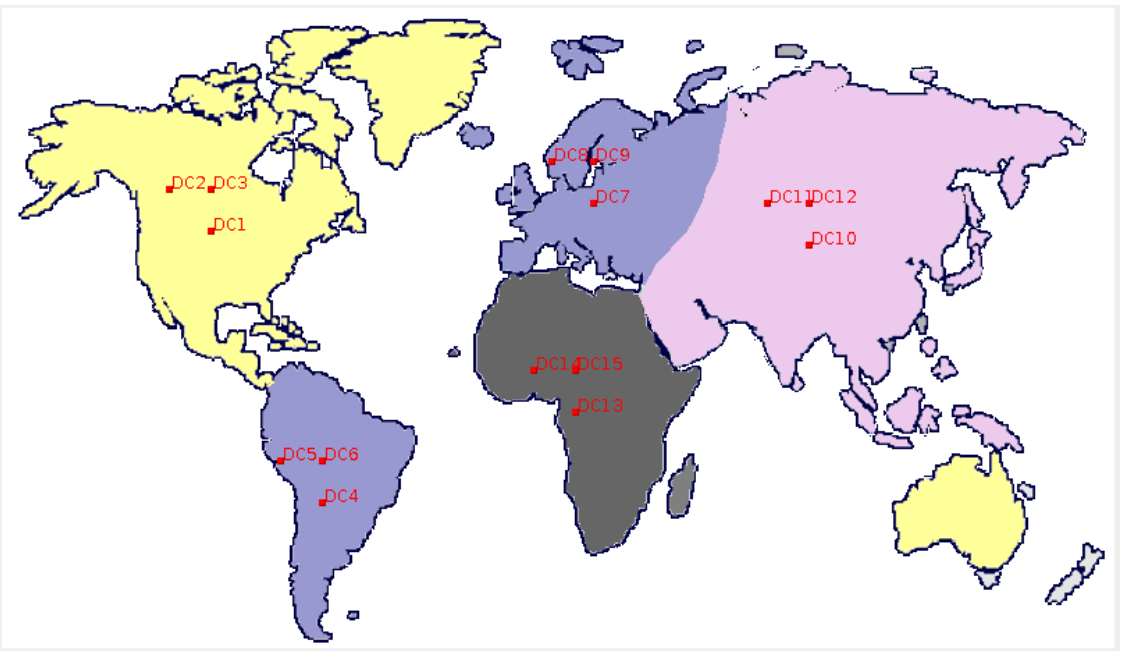

Figura 4.13: Distribuição Geográfica dos Data Centers.

Utilizando a topologia top-down como modelo topológico, foram geradas as topologias utilizadas na variação da quantidade de clientes. Foram utilizados para a composição da topologia: o Waxman como modelo de ligação de nós e a geração do grafo utilizou 
a quantidade de nós referentes ao número de usuários e data centers que compõem os modelos dos experimentos.

Além das informações anteriormente citadas, para gerar uma topologia BRITE é necessário definir parâmetros como: tamanho do plano (espaço vetorial), tamanho do quadrante do plano, número de nós, tipo de ligação dos nós e parâmetros utilizados pelo modelo de distribuição de nós (Medina et al., 2001). Na geração da topologia foram usados os valores padronizados para todos os atributos exceto o número de nós que é relacionado à soma de clientes e data centers que variou de acordo com os cenários simulados.

Após a modelagem da rede, que utiliza a quantidade de clientes e data centers para essa modelagem, foi necessário integrar essas topologias ao simulador. O simulador possui o código aberto para uso sob a licença GPL - (General Public License). Dessa forma, foi possivel modificar algumas classes para que os requisitos de projeto fossem atendidos. As classes utilizadas são apresentadas na Figura 4.14. Os retângulos em negrito representam as classes modificadas ou criadas.

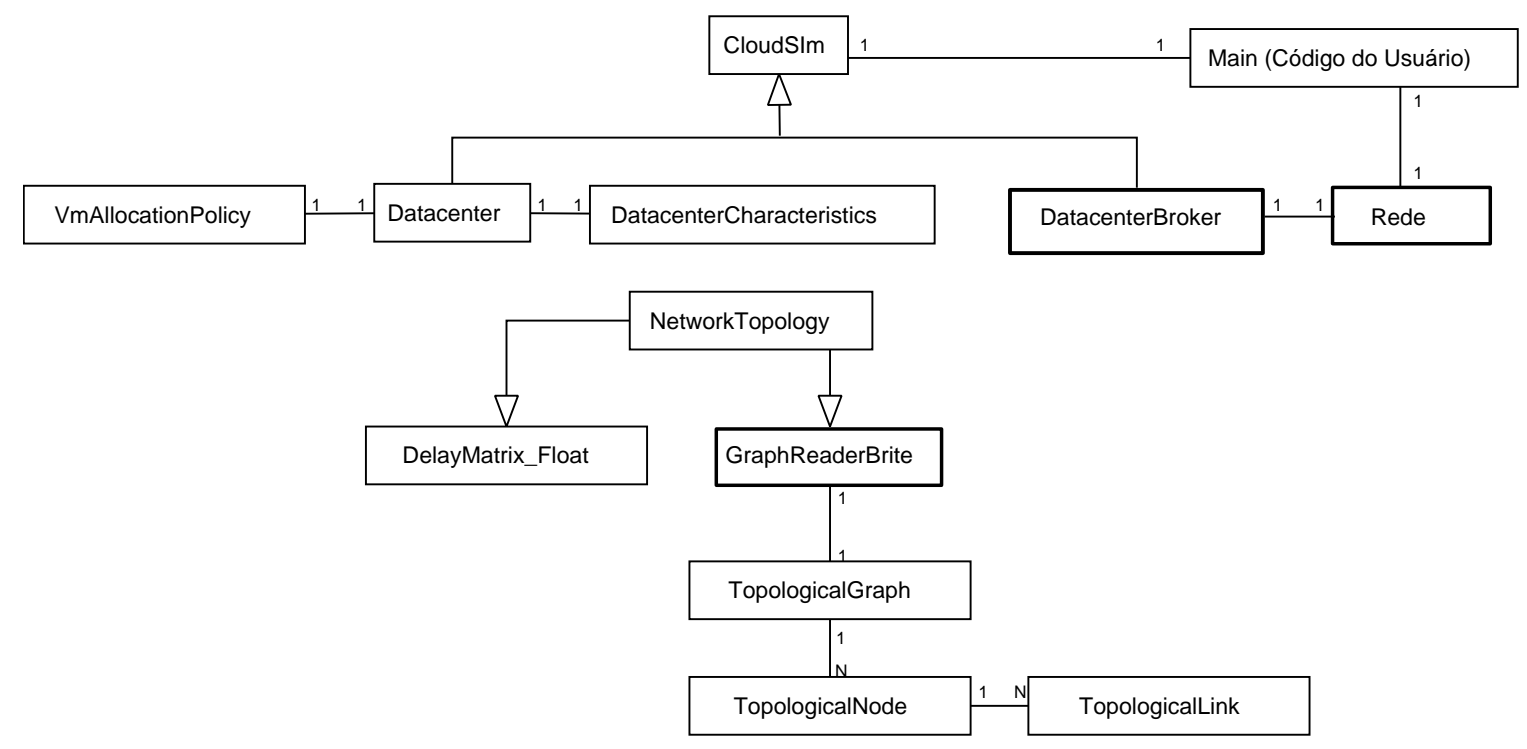

Figura 4.14: Diagrama de Classes - Infraestrutura de Comunicação.

O diagrama de classes, Figura 4.14, é referente às classes dos módulos do CloudSim que foram utilizados e como discutido anteriormente, como o simulador é separado por módulos é possível simular cenários que não sejam dependentes. Por exemplo, se o objetivo é simular a criação de máquinas virtuais, não é necessário que outros módulos sejam utilizados (Buyya et al., 2010).

Devido a esse fato, o diagrama de classes apresentado não possui uma relação direta com as outras classes. Quando a rede é utilizada na simulação, as demais classes que integram o módulo de rede do CloudSim são utilizadas.

A classe CloudSim, Datacenter, VmAllocationPolicy, DatacenterCharacteristics e DatacenterBroker são as principais classes utilizadas pelo MACC. O escalonamento local é 
feito na classe Datacenter bem como o cálculo dos recursos utilizados. As políticas de máquinas virtuais e as características do data center são utilizadas pelo MACC para analisar como a qualidade de serviço está sendo ofertada aos clientes e como está o cumprimento dos contratos ou SLAs.

A classe CloudSim é a responsável por manter as filas de eventos e o controle das entidades do simulador. Essa classe não sofreu qualquer modificação ao longo do desenvolvimento do projeto.

A classe Rede foi criada para definir, dentre os nós da topologia, quais entre os nós disponibilizados são mapeados como data center e quais os nós disponibilizados são mapeados para os clientes.

Além de definir quais os nós disponibilizados para as entidades, essa classe também é responsável por fazer o mapeamento entre as entidades do simulador e os nós da topologia invocando assim métodos pertencentes à classe Networktopology para realizar essa função. A classe Networktopology possui uma dependência de outras classes que são responsáveis pelo reconhecimento da rede e a geração das matrizes de distância.

A leitura do BRITE é realizada pela classe GraphReaderBrite que informa a composição do grafo à classe NetworkTopology. Para realização dessa leitura, é informado qual o arquivo de topologia e a partir dos identificadores dos nós e das arestas o simulador conhece a topologia de rede. A classe GraphReaderBrite está em negrito no diagrama pois foi feito uma modificação no seu modelo. Como a topologia é estática, foi necessário atribuir uma distribuição na leitura das arestas baseado no método Random do Java.

Essa modificação permitiu que a rede tivesse um comportamento dinâmico e que pode ser repetido e controlado, pois é baseado na semente da simulação. Já a classe DelayMatrix_Float faz parte da construção da matriz de distâncias entre os nós. Nessa classe, foi adicionado um método para contar a quantidade de saltos de um nó para outro. Esse método consiste em verificar quantas iterações são necessárias para ir de um nó origem para um nó destino sem considerar os pesos das arestas.

Esse método auxiliou no desenvolvimento dos experimentos para avaliar qual métrica utilizar nos experimentos. Além de construir a matriz de distâncias, a classe DelayMatrix_Float é responsável pelo cálculo da latência da rede.

O cálculo da latência da rede é utilizado para fazer a integração entre as entidades do CloudSim e a topologia da rede e, a partir das informações de latência de um nó origem para um nó destino, formar uma matriz de latência. Essa matriz de latência é utilizada pelos algoritmos de roteamento que usam a latência como métrica para a descoberta dos data centers.

A Figura 4.15 apresenta o fluxo de comunicação utilizado pelo CloudSim nas transações de envio e recebimento de mensagens (Buyya et al., 2010).

O fluxo apresentado na Figura 4.15 é utilizado pelo simulador para acrescentar os tempos gastos na rede ao tempo final da simulação. Como apresentado na Figura 4.15, o cliente cria uma mensagem e a envia para ser processada. Nessa operação é acrescentado ao tempo de simulação o tempo de envio da mensagem (1). A mensagem é recebida e enviada para ser processada. O tempo de envio (2) é acrescentado ao tempo 


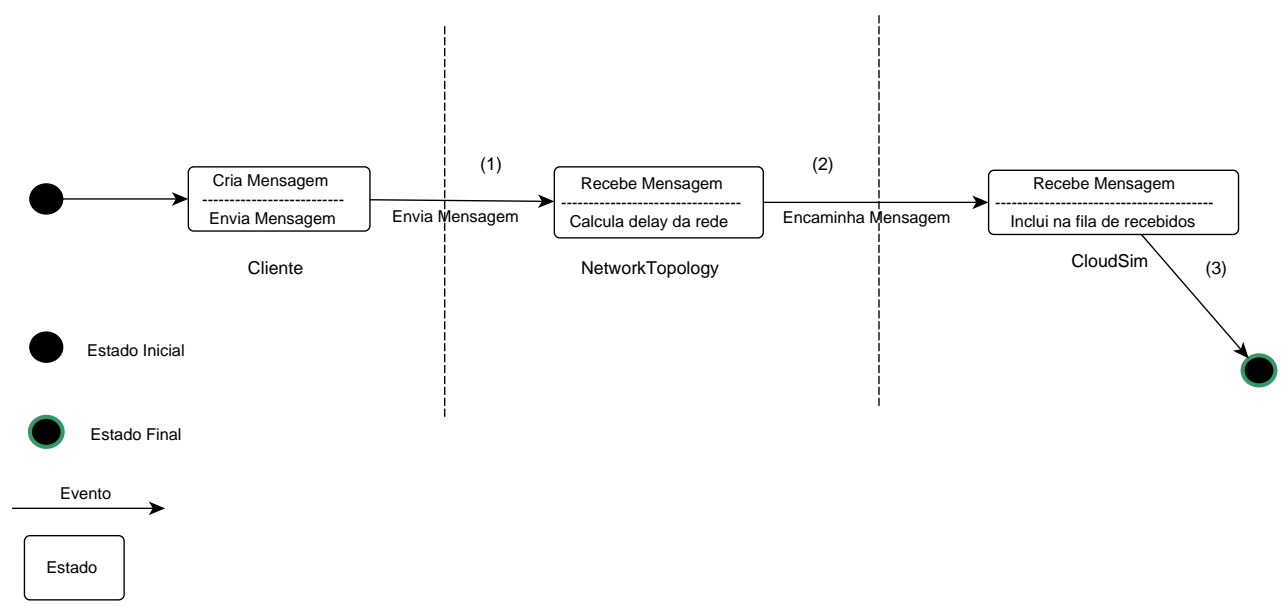

Figura 4.15: Fluxo de Comunicação Utilizado - Adaptado de (Calheiros et al., 2010).

de simulação. Por fim, o tempo de entrega das solicitações (3) também é adicionado ao tempo de simulação.

Dessa forma, é utilizada a latência entre a origem e o destino para simular o comportamento do experimento considerando a execução e a comunicação da rede. Sempre que o cliente fizer uma solicitação é acrescentado ao tempo da simulação a sua latência. Ao fim da simulação tem-se: $\mathbf{T r}=\mathbf{3 d + t}$, onde, $\operatorname{Tr}$ é o tempo de resposta, d é o delay obtido na comunicação e t representa o tempo de execução dos serviços pelos data centers. Por fim, o desenvolvimento deste projeto de doutorado utilizou a classe DatacenterBroker para o desenvolvimento das políticas de roteamento.

O simulador CloudSim não tem um modelo de roteamento, sendo necessário o desenvolvimento do mesmo. Sendo assim, baseado na literatura, foram desenvolvidos algoritmos de roteamento na classe DatacenterBroker possibilitando assim que as políticas de roteamento fossem disponibilizadas ao código do usuário, o que viabilizou a avaliação de desempenho das mesmas.

\subsubsection{Algoritmos de Roteamento}

Linnolahti (2004) discute a forma de se utilizar métricas para construção de algoritmos de roteamento, tais como: a quantidade de saltos e as informações referentes ao estado do link. Dessa forma, os algoritmos desenvolvidos utilizaram como métricas: (i) a quantidade de saltos entre a origem e o destino e (ii) a informação de latência entre um nó origem e um nó destino.

Dentre as políticas de roteamento, foram implementadas e estão disponíveis no MACC:

\section{Round Robin - (RR)}

O Round Robin é uma política bem difundida para a seleção de serviços. Ela é determinada por meio de uma lista circular onde cada data center possui a sua "vez"de 
receber as solicitações dos clientes. Nessa abordagem nenhuma característica da rede é considerada para a seleção do data center não causando assim qualquer sobrecarga ao MACC na tomada de decisões. Essa abordagem foi utilizada por ser utilizada por vários provedores de serviço de Nuvem com o objetivo de balanceamento de carga (Murata et al., 2010) (Oprescu e Kielmann, 2010) (Frincu e Craciun, 2011).

A Figura 4.16 representa um cliente fazendo uma solicitação ao MACC. O MACC possui uma lista de data centers disponíveis e envia o primeiro da lista ao cliente. Após essa disponibilização o data center é indicado como já utilizado; portando retirado do inicio da lista. O data center selecionado, representado pelo índice em negrito, aguarda até que a lista seja esvaziada para voltar a ficar apto a receber solicitações.

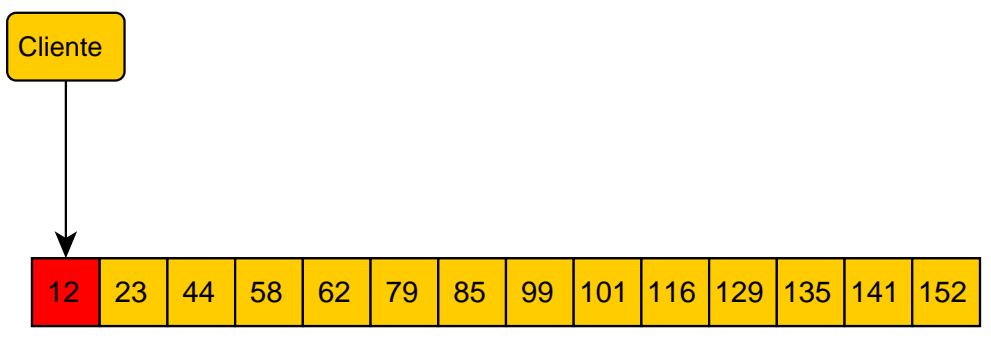

Lista de Data centers disponíveis

Figura 4.16: Busca utilizando Round Robin.

\section{Baseada na Capacidade da Rede - (BCR)}

A Busca Baseada na Capacidade da Rede (BCR) é uma politica que considera as informações da rede para a busca do melhor data center. Nessa abordagem é analisada a métrica utilizada para formar a busca. Se a métrica utilizada for a quantidade de saltos, o cliente irá consultar todos os data centers para descobrir, dentre eles, qual possui a menor quantidade de saltos. O mesmo ocorre quando a latência é utilizada como métrica.

A BCR sempre irá retornar a melhor opção para o cliente, contudo, ela possui uma desvantagem com relação à quantidade de interações geradas, pois cada cliente irá consultar todos os data center disponiveis.

Como apresentado na Figura 4.17, é verificado entre todos os data centers disponíveis, qual deles apresenta a menor distância para o cliente. No caso da Figura 4.17 o índice em negrito não é retirado da lista de data centers aptos a receber solicitações. O MACC não retira o índice da tabela devido a estimativa de capacidade de processamento para cada data center. Essa estimativa é feita pelo componente do MACC chamado Workload Engine.

Uma solução para a limitação relacionada ao número de iterações apresentadas pela BCR é utilizar outras abordagens que fazem uso de informações da rede. Nesse sentido foram utilizadas as abordagens P2P. 


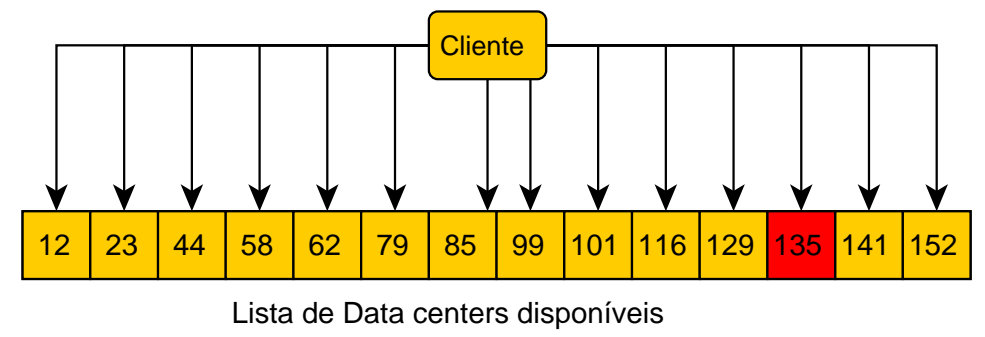

Figura 4.17: Modelo de Busca realizado pela BCR.

\section{Pastry - (P)}

Segundo (Rowstron e Druschel, 2001) uma rede de sobreposição Pastry deve possuir um identificador numérico único chamado nodeid. Esse nodeid é utilizado para enviar mensagens entre os nós que possuam os nodeids numericamente mais próximos do valor da chave entre todos os nós ativos. Como não foram utilizadas descrições de serviço, os nodeids foram gerados através do mapeamento da rede facilitando, assim, a identificação das entidades do simulador. Essas entidades correspondem aos data centers e aos clientes. A topologia utilizada pela abordagem Pastry se assemelha a uma árvore e o processo de busca assemelha-se ao processo de busca binária. A Figura 4.18 ilustra a camada de sobreposição utilizada pelo Pastry.

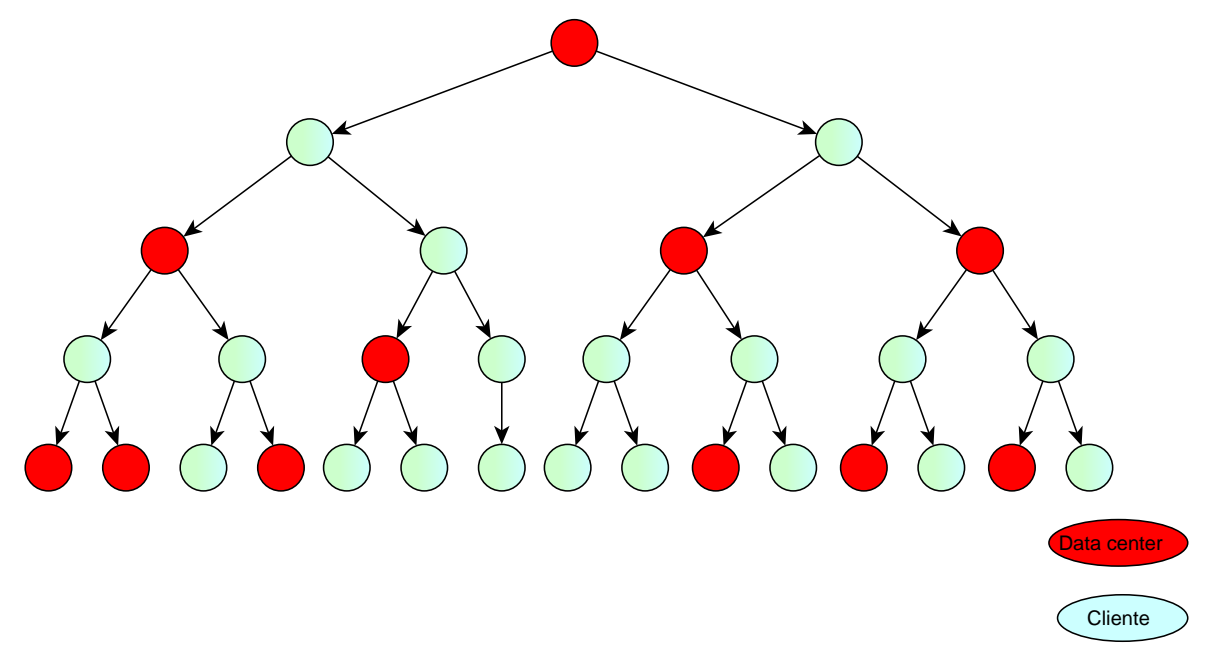

Figura 4.18: Topologia Pastry.

A topologia apresentada na Figura 4.18 é voltada para a descoberta do data center com as melhores condições para o cliente. A busca é iniciada no nó raiz da árvore e segue para a direita ou para a esquerda dependendo de qual nó possui a menor distância no momento da busca. Essa informação é armazenada pelo MACC e ao final da operação o MACC tem conhecimento de qual data center é o mais adequado. O processo de busca é demonstrado na Figura 4.19, onde são apresentados os passos realizados na busca. 


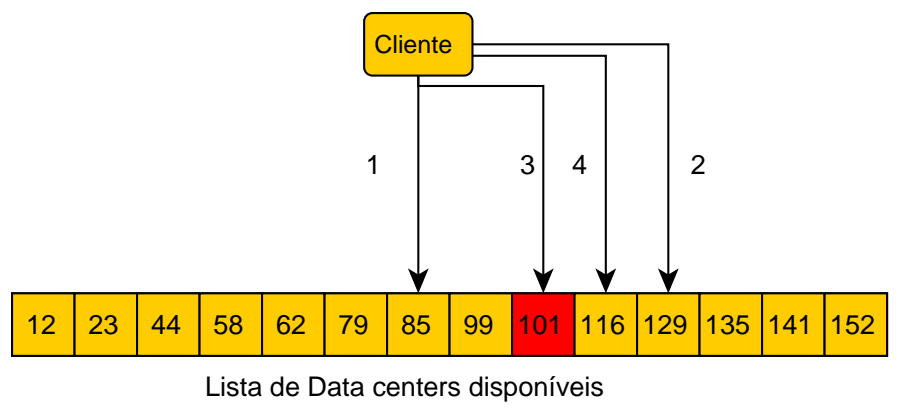

Figura 4.19: Busca realizada pelo Pastry.

A busca é iniciada na metade da lista e continua até que o espaço de busca definido pelos nodeids termine. No caso da Figura 4.19 é demonstrada uma busca onde o data center adequado é o de identificação 101. O índice do data center continua na lista de aptos à execução de serviços. A vantagem do Pastry em relação ao BCR é a diminuição no espaço de busca. Essa política não consulta todos os nós para a tomada de decisão. Esse fato diminui a quantidade de iterações realizadas pelo MACC.

A segunda abordagem utilizada foi a Chord que possui topologia e lógica de busca diferentes das apresentadas pelo Pastry.

\section{Chord - (C)}

Uma abordagem diferente para a criação da camada de sobreposição e consequentemente a realização de roteamento em sistemas P2P, é a utilização da abordagem Chord. A topologia formada pelo Chord é em forma de anel e a partir dessa topologia a busca é realizada (Stoica et al., 2001). O Chord trabalha de forma diferente da apresentada pelo Pastry. O MACC, de posse das informações sobre a rede, forma a busca de acordo com a região em que o cliente se encontra. Um exemplo da topologia do Chord é apresentada na Figura 4.20.

Os clientes são encaminhados a uma região de acordo com os nodeids do cliente aos data centers mais próximos (Stoica et al., 2001). Depois de verificar qual a região que o cliente melhor se encaixa, o MACC realiza a busca nos data centers da região em que o cliente faz parte. A Figura 6.12 apresenta o processo de busca realizado pela abordagem Chord.

A lista de data centers é ordenada de acordo com a região onde eles se encontram. Sendo assim, depois que o MACC identifica a região que o cliente pertence, a busca é realizada apenas nos data centers mais próximos ao cliente. Assim como o Pastry, o Chord possui um espaço de busca menor se comparado ao BCR. O fato da busca ser concentrada em regiões próximas ao cliente faz com que a quantidade de iterações realizadas pelo MACC seja menor. Uma menor quantidade de iterações proporciona menos sobrecarga ao MACC. 


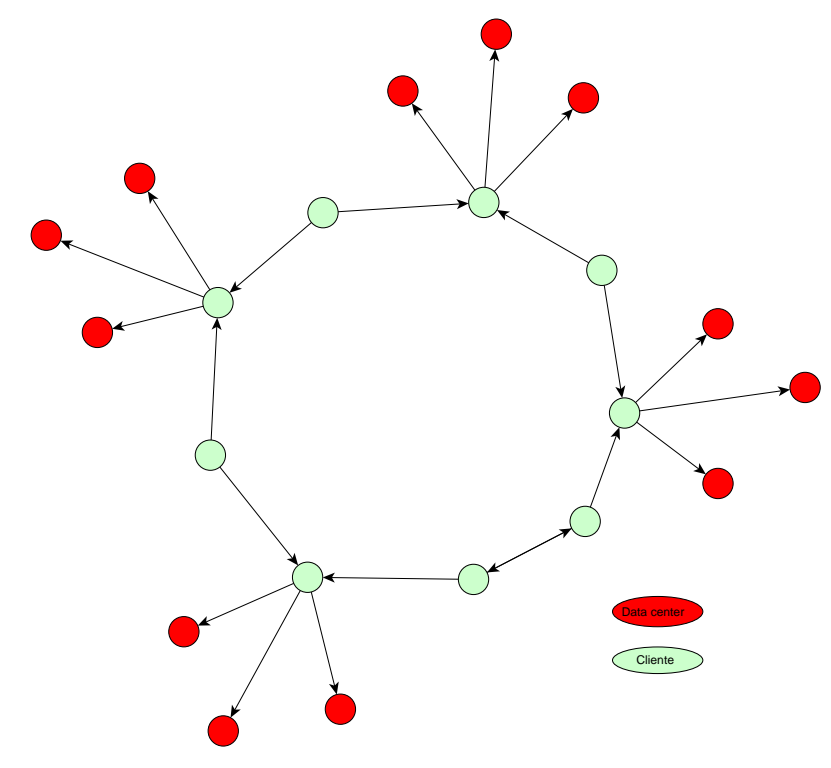

Figura 4.20: Topologia Chord.

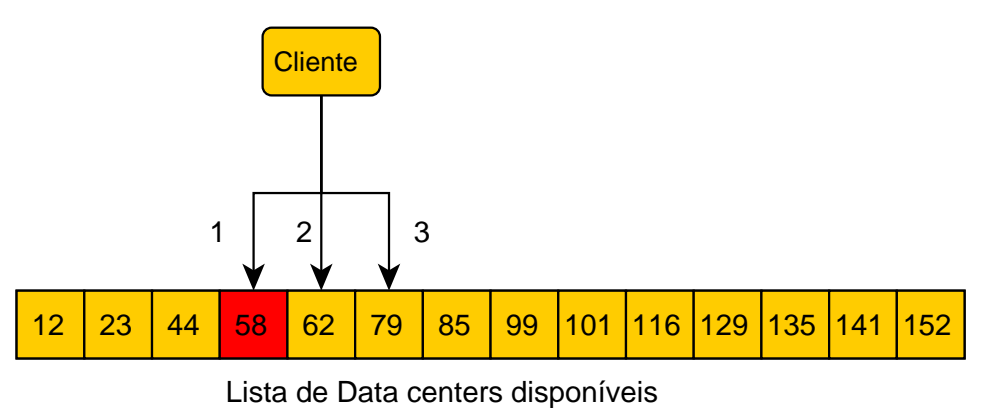

Figura 4.21: Processo de Busca Utilizado pelo Chord.

\subsection{Análise Comparativa dos Trabalhos Relacionados}

Neste Capítulo foi apresentado o MACC (Metascheduler Architecture to provide BoS in Cloud Computing). O MACC é um Metaescalonador responsável pela gerência dos serviços dos usuários dentro de uma Intercloud.

Especificamente, os Metaescalonadores possuem técnicas para realizar a alocação de máquinas virtuais. O processo de alocação de máquinas virtuais em Computação em Nuvens é complexo, pois a melhor configuração de software e hardware devem ser feitas para garantir que os alvos de GoS possam ser atendidos, enquanto ocorre a maximização da utilização do sistema (Calheiros et al., 2011).

No trabalho de Quiroz et al. (2009) é proposto um mecanismo dinâmico de alocação de máquinas virtuais. Nesse trabalho, é necessário determinar tanto o número de instâncias virtualizados quanto os seus tipos. Essa abordagem em duas fases é semelhante à utilizada pelo MACC, porém não trata aspectos relacionados à restrição temporal (deadlines) como o MACC. 
Em Zhu e Agrawal (2010) é apresentado um mecanismo dinâmico para alocação de máquina virtual baseado em teoria de controle considerando o orçamento. Entretanto, essa abordagem considera apenas a reconfiguração da máquina virtual disponível, aumentando ou diminuindo sua capacidade. Nesse esquema não é possível aumentar ou diminuir o número de máquinas virtuais para um cliente como faz o MACC.

Diferentemente do MACC que trabalha de forma proativa, outros trabalhos (Chieu et al., 2009) (Abdelzaher et al., 2002) (Singhal et al., 2011) (Zhu et al., 2006) propõem um algoritmo reativo, baseado em teoria de controle, para alocação dinâmica de máquina virtuais. Entretanto, os autores não apresentam de maneira clara a sobrecarga sobre a realização de mudanças no cenário, pois a capacidade é alterada à medida que a exigência dos requisitos dos usuários sofre mudanças.

Já no trabalho apresentado por (Bi et al., 2010), é proposto um modelo para provisionamento de aplicações multicamadas em Computação em Nuvens baseado na fila de rede. Os autores utilizam uma técnica de alocação baseada em cluster virtualizados que constrói um modelo de fila flexível. Esse modelo permite determinar o número de máquinas virtuais em cada camada das aplicações virtualizados. Diferente do MACC, esse trabalho não considera uma estimativa de carga de cada serviço, mas sim do conjunto de serviços que estão na fila da camada de aplicação.

Tanto em Lee et al. (2010) quanto em Rodero et al. (2010) são propostas abordagens que utilizam o modelo de rede para maximizar os lucros ou reduzir os custos através da criação do melhor número de máquinas virtuais. Enquanto essas abordagens utilizam a taxa de chegada de serviços para determinar o número de máquinas virtuais, o MACC utiliza além da fila de serviços a carga presente nela.

Jung et al. (2010) propõe o sistema Mistral, o qual gerencia o consumo de energia dos recursos e melhora o desempenho dos serviços. Entretanto, essa abordagem só é funcional quando se tem acesso a infraestrutura física da organização, o que não acontece tipicamente em um ambiente Intercloud. Assim, o Mistral é compativel para executar onde a infraestrutura e as aplicações são oferecidas pelo mesmo provedor, enquanto o MACC pode funcionar nesse cenário, tanto quanto em um cenário Intercloud, ou seja, onde existem provedores em diferentes organizações.

Os trabalhos implementados em Xu et al. (2006); Goiri e Guitart (2007); Bobroff et al. (2007); Khanna et al. (2006) Wood et al. (2007) e Singh et al. (2008), focam na questão da gestão de alocação de recursos entre múltiplos domínios rodando na mesma máquina. Nesses trabalhos, é proposta a constante monitoração sobre a utilização dos recursos e realocando-os de acordo com as necessidades. Assim, o sistema calcula a utilização da CPU por domínio e de acordo com o uso pode aumentar ou diminuir o uso de forma autônoma. O sistema aloca determinada quantidade de memória ou vCPU ou pode migrar o domínio para outro host. Diferente do MACC que não realiza a migração, pois dentro dos cenários trabalhados a sobrecarga que envolve a migração de um domínio tornaria esse tipo de operação dispendiosa.

Várias propostas na literatura são baseadas em uma função utilidade (Utility Function) para alocar recursos dinamicamente (Walsh et al., 2004) (Menasce e Bennani, 2006) (Chase et al., 2001) (Nguyen Van et al., 2009) (Cardosa et al., 2009) (Kusic et 
al., 2008). Nesses trabalhos existe um mecanismo que localiza um número ótimo e o tamanho adequado de máquinas virtuais para serem alocadas. $O$ foco desses trabalhos se assemelha aos objetivos do MACC, porém, esses trabalhos são baseados em programação inteira, o que significa que a convergência para encontrar a solução ótima pode levar tempo, comprometendo o resultado encontrado em função do tempo.

Em (An et al., 2010), é proposto o uso de modelos econômicos para a alocação de recursos em Computação em Nuvens. Nesse artigo os autores focam sobre a negociação de mercado dinâmica. Em comparação com o MACC, também existe o estabelecimento de preço inicial, porém, além disso, no MACC, os preços são regidos por uma SLA, onde se deixa claro os termos que envolvem os deveres e direitos tanto do provedor de serviços quanto do consumidor.

Existem alguns trabalhos, (Gmach et al., 2009) (Zhu et al., 2008), que realizam a alocação dinâmica de CPU para cumprir os objetivos de GoS. Além disso, é oferecida a diferenciação de serviço por meio da alocação baseada em prioridades. O que diferencia esses trabalhos deste trabalho de doutorado é a garantia de GoS fim-a-fim que é proporcionada pelo MACC. Existe uma preocupação em garantir GoS tanto em nível de rede como em nível de aplicação.

Alguns trabalhos já utilizam o MACC como aporte teórico às suas pesquisas, tais como: (Suresh e Vijayakarthick, 2011) (Khoshdel et al., 2011) (Adhipta et al., 2011) (de Alencar et al., 2011). Outro trabalho proposto em (Vernekar e Game, 2012), basicamente deriva o conceito proposto pelo MACC (Peixoto et al., 2010) na construção de um projeto de alocação de recursos baseado em componente.

\subsection{Considerações Finais}

Este capítulo apresentou o MACC, incluindo as descrições detalhadas dos seus componentes e protocolos. Um ponto importante, é que a arquitetura de metaescalonador proposta é baseada em um modelo pró-ativo, favorecendo a distribuição de carga entre as entidades e oferencendo QoS no ambiente Intercloud. O MACC é projetado para funcionar em um mercado aberto por meio do uso de protocolos econômicos. O MACC funciona em duas etapas, na primeira etapa é realizada a seleção da entidade responsável por processar o serviço. Na segunda etapa, é realizada a criação adequada de máquinas virtuais na entidade escolhida na primeira etapa.

Os próximos capítulos desta tese irão focar, particulamente, em um conjunto de experimentos sobre o MACC. O objetivo desse conjunto de experimentos é deixar claro o desempenho do MACC, validando a arquitetura no ambiente Intercloud. Esse desempenho será apresentado através da identificação dos principais fatores que afetam as variaveis de resposta no ambiente, e apresentar as soluções existentes para esse problema. 


\section{Estudo de Desempenho em uma Nuvem Privada}

\subsection{Considerações Iniciais}

Este capítulo apresenta um estudo de desempenho sobre virtualizadores em uma Nuvem Privada. Por meio deste estudo é possivel entender e validar os aspectos gerenciais das políticas de alocação de máquinas virtuais do MACC. Para essa avaliação, as técnicas estatísticas e as técnicas de avaliação de desempenho são seguidas e os resultados obtidos são devidamente analisados e interpretados.

Os virtualizadores podem gerenciar várias máquinas virtuais sendo executadas em paralelo. A avaliação entre o Xen e o KVM, por meio de experimentação, tem como intuito realizar uma comparação entre eles, considerando características comuns aos dois virtualizadores, por meio da seleção correta da carga de trabalho e definição dos fatores e níveis. Essa avaliação permite fazer uma leitura estatística das duas abordagens, além de permitir que os resultados encontrados sirvam como base para ensaios em ambientes controlados, como é o caso do ambiente de simulação.

\subsection{Preparação do Ambiente de Testes}

A metodologia utilizada para realização dos experimentos é o planejamento de experimento fatorial completo apresentada por Jain (1991). Nessa metodologia de planejamento de experimentos é definido que para um conjunto de experimentos é necessário definir os fatores fixos (fatores invariáveis desde o primeiro até o último experimento) e os fatores variáveis (fatores que irã ser comparados nos experimentos).

Os experimentos foram conduzidos utilizando um único servidor PowerEdge DELL T410 onde foram criadas as máquinas virtuais. Para prover homogeneidade aos 
experimentos, apresentada na Tabela 5.1, a configuração do servidor é a mesma tanto para o Xen quanto para o KVM. Assim como a configuração do servidor, a configuração das máquinas virtuais no servidor também é fixa.

Tabela 5.1: Configuração do Ambiente de Testes (Fatores Fixos)

\begin{tabular}{|r|r|r|}
\hline & Máquina Física & Máquina Virtual \\
\hline Sistema Operacional & Debian 6 & Ubuntu 10.04 \\
\hline Memória & $12 \mathrm{~GB}$ & $256 \mathrm{MB}$ \\
\hline Disco & $160 \mathrm{~GB}$ & $8 \mathrm{~GB}$ \\
\hline Processador & Intel Xeon 6 cores $(2.8 \mathrm{GHz})$ & 1 vCPU $(2.8 \mathrm{GHz})$ \\
\hline
\end{tabular}

Para a geração e padronização das cargas de trabalho foi utilizado o Phoronix Test Suite ${ }^{1}$. As cargas geradas pelo Phoronix foram: SmallPt ${ }^{2}$ e a compilação do Apache ${ }^{3}$. A geração da carga é apenas uma parte do planejamento de experimentos que conta ainda com o tipo de monitor de máquinas virtual utilizado e a quantidade de máquinas virtuais a ser gerada no host.

\subsection{Configuração dos Testes}

Como o objetivo é verificar a sobrecarga da virtualização e os tempos de resposta obtidos quando existe mais de uma VM em um host, foi realizado um primeiro conjunto de experimentos verificando a sobrecarga entre uma VM com configuração aproximada do host. Essa VM foi criada e monitorada usando tanto o KVM quanto o Xen.

O segundo conjunto de experimentos também seguiu a metodologia de avaliação de desempenho apresenta por Jain (1991). Essa avaliação conta como fatores fixos, os fatores apresentados na Tabela 5.1 e os fatores variáveis, apresentados na Tabela 5.2.

Tabela 5.2: Projeto de Experimento

\begin{tabular}{|c|c|c|c|c|}
\hline Exp & Virtualizador & Número de VMs & Benchmark 1 & Benchmark 2 \\
\hline 1 & xen 4.0 .1 & 5 & SmallPt & Apache \\
\hline 2 & xen 4.0 .1 & 10 & SmallPt & Apache \\
\hline 3 & kvm 0.12 .5 & 5 & SmallPt & Apache \\
\hline 4 & kvm 0.12 .5 & 10 & SmallPt & Apache \\
\hline
\end{tabular}

\footnotetext{
${ }^{1}$ www.phoronix-test-suite.com

${ }^{2}$ http://kevinbeason.com/smallpt

${ }^{3}$ http://httpd.apache.org
} 
A configuração da máquina virtual segue o modelo de configuração de um máquina básica apresentada pela UOLHost ${ }^{4}$, porém com uma limitação na quantidade de memória, devido as limitações de recursos físicos, embora com uma quantidade de processamento maior. Neste ultimo caso, mede-se a potência da CPU uma vez que esta é virtual e não física. Como os detalhes de implementação não são disponibilizados pelos provedores de serviços não é possivel saber se a potência da vCPU é relacionada à potência de um núcleo físico do host, devido a isso foi feita uma aproximação na configuração das VMs.

A quantidade de máquinas virtuais foi limitada em 10 máquinas no máximo, devido a arquitetura do Xen que não permite alocar toda a memória do host. Sendo assim, foi definido o mesmo número de máquinas virtuais para os dois monitores, uma vez que o objetivo é comparar o Xen e o KVM de forma equivalente.

A carga de trabalho utiliza dois benchmarks que possuem maior uso de CPU com a diferença que a compilação do Apache possui, além de uso intensivo de CPU, operações de entrada e saída, justamente por se tratar de uma compilação. Já o SmallPt produz uma carga que é exclusivamente CPU-bound. Essa definição de carga permite verificar a diferença entre as duas abordagens de processos orientados à CPU.

\subsection{Avaliação dos Resultados}

Para atingir o objetivo do primeiro conjunto de experimentos, foi instalado no host o mesmo sistema operacional das máquinas virtuais (Tabela 5.1) e foi executada a compilação do Apache com uma quantidade de 30 execuções do benchmark para cada máquina, nesse caso a máquina física e as virtuais monitoradas pelo Xen e KVM respectivamente.

\subsubsection{Testes de Sobrecarga dos Virtualizadores}

A diferença entre o host e as máquinas virtuais é a quantidade de memória, devido à limitação do Xen. Porém, foi utilizado pelas máquinas virtuais a quantidade de 4 GB de memória e a quantidade de núcleos ou vCPUs utiliza a quantidade total fornecida pelo host. A Figura 5.1 apresenta a sobrecarga gerada pelos virtualizadores.

Como observado na Figura 5.1, o host apresentou um melhor desempenho, sendo em torno de 30\% mais eficiente que a máquina virtual com o KVM e em torno de 34\% mais eficiente que a máquina virtual com Xen. A vantagem observada aqui é a possibilidade de executar mais de uma máquina virtual em uma mesma máquina física.

Apesar de apresentar uma grande diferença, para o uso de propósito geral, a virtualização não apresenta uma grande desvantagem uma vez que possibilita maximizar o uso dos recursos que estariam ociosos.

Como esperado, a virtualização apresentou maiores tempos de resposta. Sendo que, diferente do ocorrido nos trabalhos relacionados, o KVM apresentou melhores tempos

\footnotetext{
${ }^{4}$ http://www.uolhost.com.br/uol-cloud-computing.html\#rmcl
} 


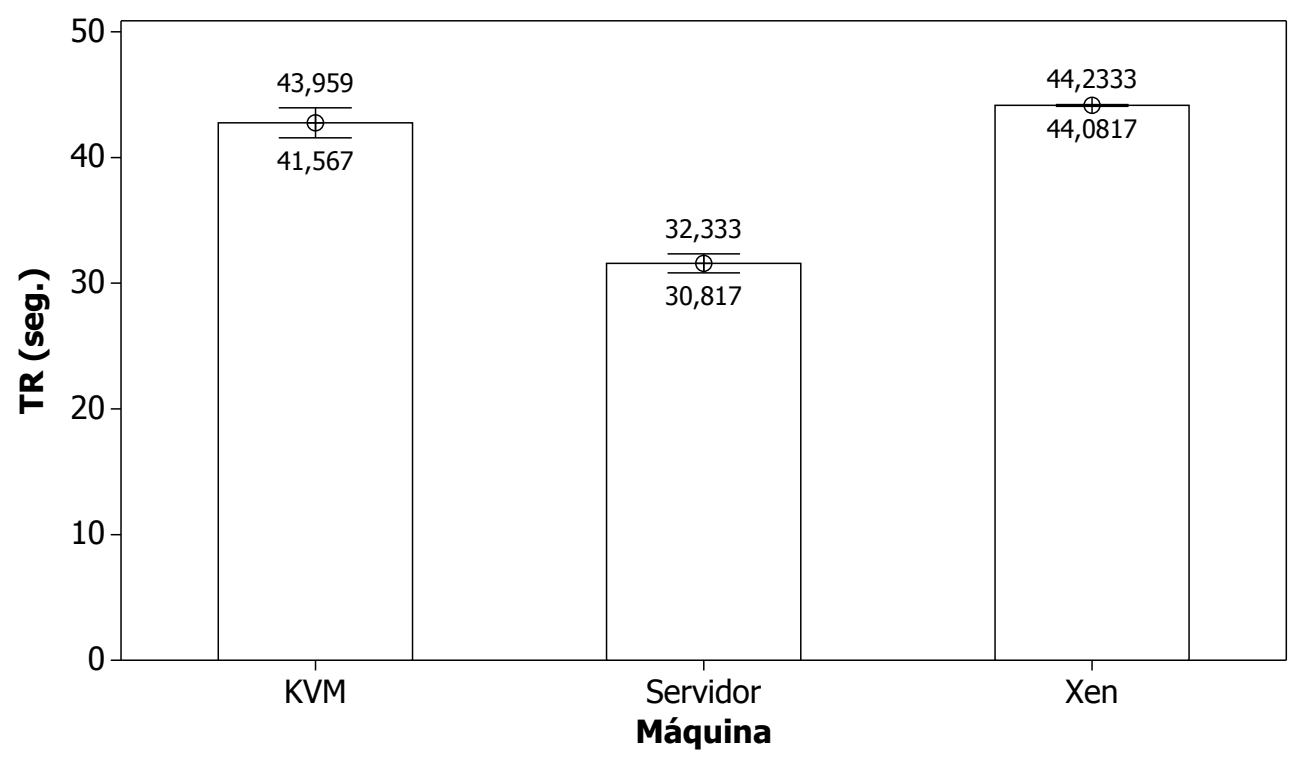

Figura 5.1: Resultados de Sobrecarga.

de resposta. Para alcançar o segundo objetivo, que é avaliar as diferenças entre os monitores, foi definido um ambiente de teste, apresentado na Tabela 5.2.

\subsubsection{Testes CPU-Bound}

Para verificar a diferença em um sistema de propósito específico, nesse caso manipulação de imagens, foi utilizado o benchmark SmallPt. Os resultados obtidos são apresentados na Figura 5.2.

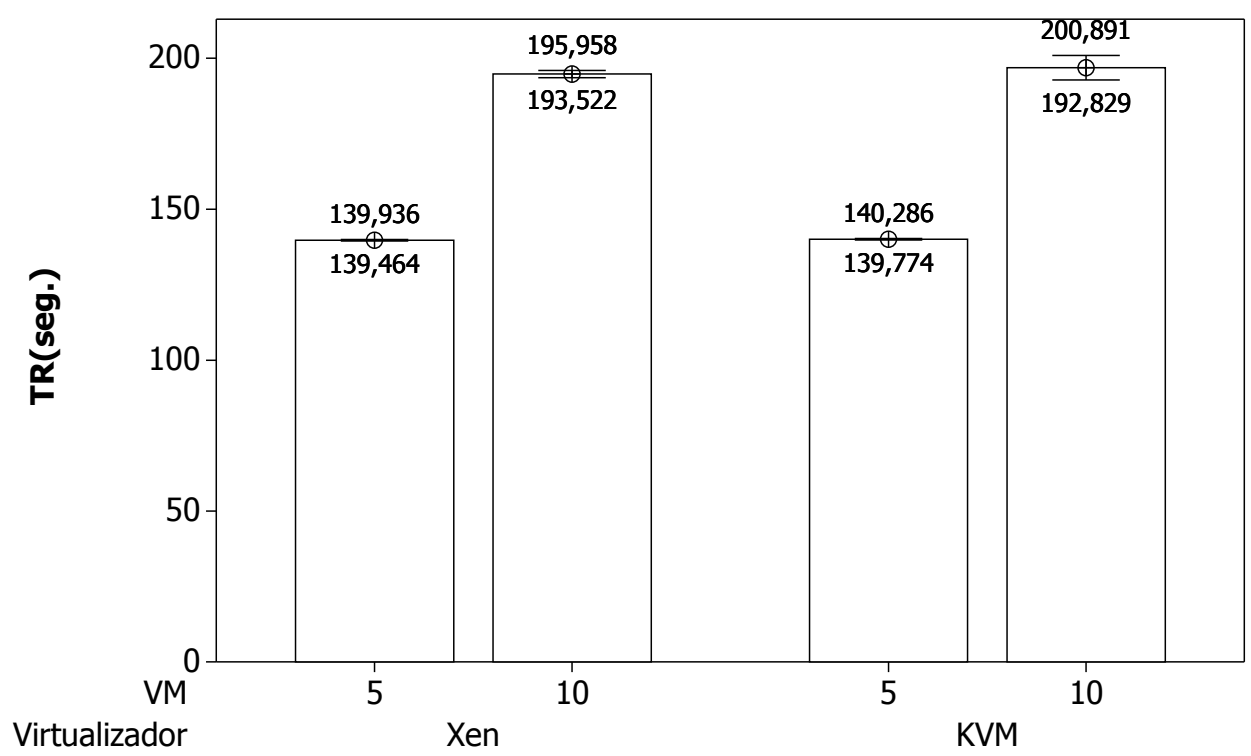

Figura 5.2: Diferenças nos tempos de resposta 
Nota-se, no campo com os valores, que a carga do Smallpt apresenta seus desvios maiores com o monitor de máquina virtual KVM com maior quantidade de máquinas virtuais. Para os experimentos considerados foi utilizado $5 \%$ de erro.

Sendo assim, a Figura 5.2 apresenta os gráficos dos tempos de resposta com o erro. O erro é obtido de acordo com a Formula 5.1, onde o desvio padrão (DesvPad) é o desvio obtido, a constante (Const) é obtida através da tabela $t$-student e o $\mathrm{N}$ representa o número de replicações de cada experimento.

$$
\frac{(\text { DesvPad } * \text { Const })}{\sqrt{N}}
$$

Os resultados apresentados na Figura 5.2 mostram que para a carga SmallPt o comportamento dos dois monitores foi estatisticamente semelhante, uma vez que, os intervalos de confiança estão sobrepostos tanto para o número menor quanto para o número maior de máquinas virtuais. A influência desses resultados nos experimentos realizados é apresentada na Figura 5.3 onde são apresentadas as influência dos fatores considerando a porcentagem de influência de cada fator.

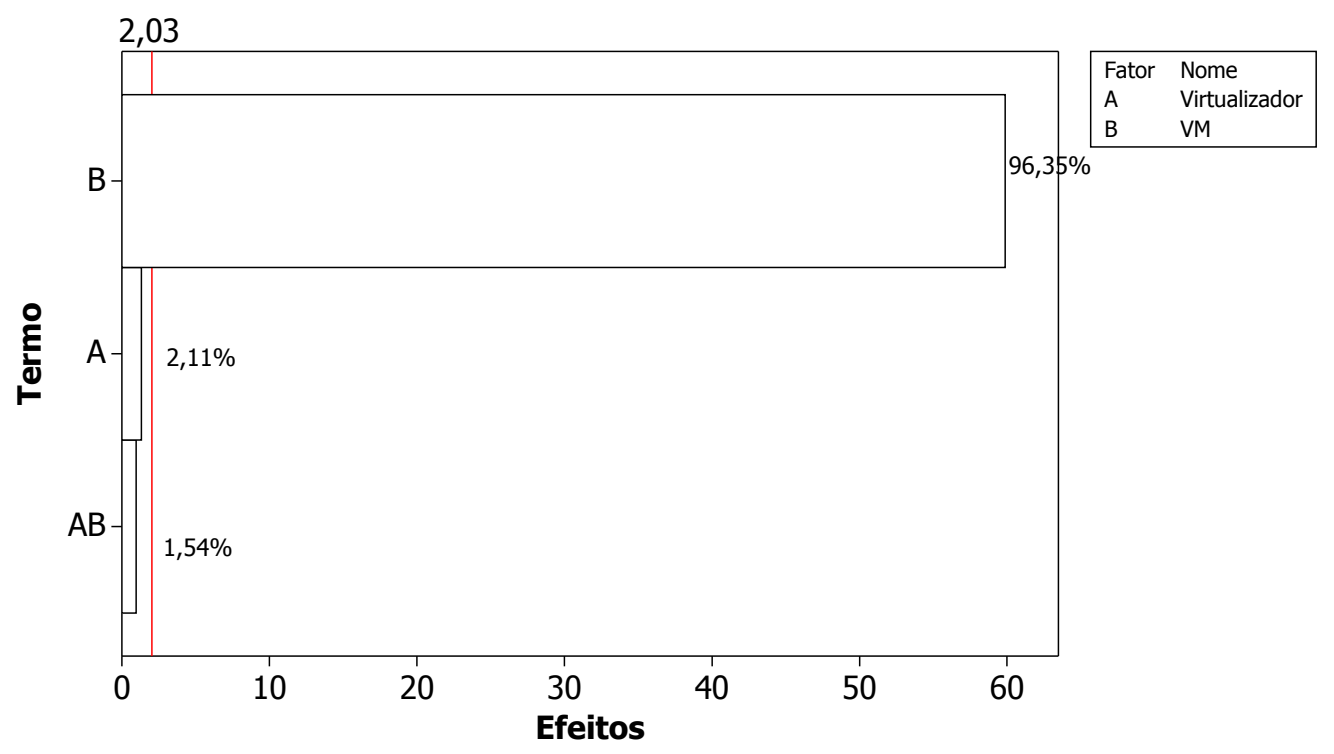

Figura 5.3: Influência dos fatores no Primeiro conjunto de Experimentos

Como apresentado na Figura 5.3, o fator que mais impactou nos tempos de resposta foi a quantidade de máquinas virtuais. Como os resultados são apresentados utilizando um gráfico de Pareto, existe um deslocamento, representado pela linha vermelha $(2,03 \mathrm{seg}$.) que indica o ponto onde os fatores começam a fazer influência. Em outras palavras, considerando um erro de $5 \%$ para o conjunto de experimentos, tem-se que os resultados com menos de 2,03seg. não influenciam nos tempos de resposta.

O acréscimo ou decréscimo nos tempos de resposta é apresentado na Figura 5.4 onde são apresentadas as mudanças de níveis considerados. Ou seja, como se comporta a variável de resposta com relação às mudanças de níveis ou as variações apresentadas nos experimentos. 


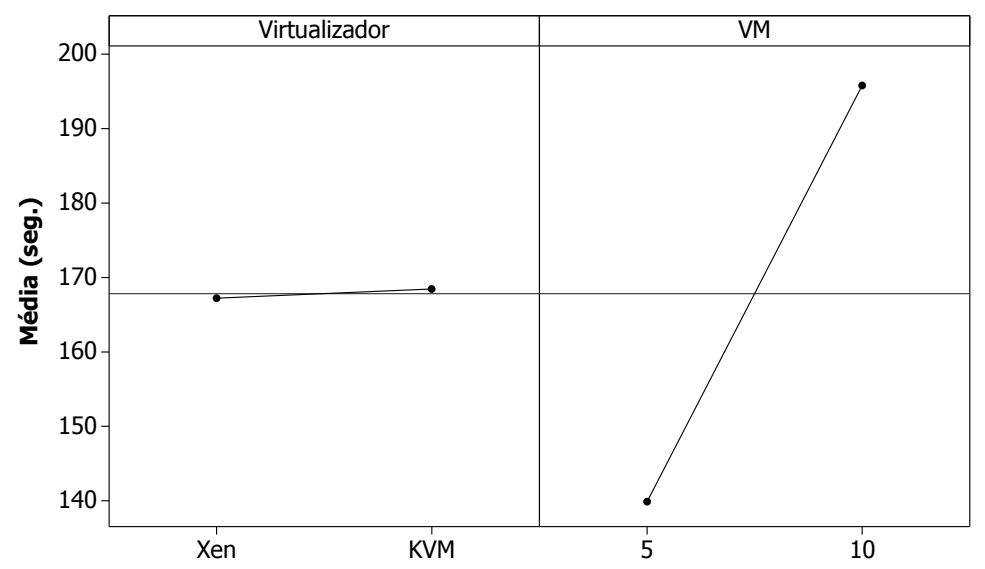

Figura 5.4: Diferenças nos Tempos de Resposta com a Mudança de Nível

Como apresentado na Figura 5.4, a mudança de tempo mais acentuada é na troca de cinco para dez máquinas virtuais. O virtualizador nesse caso não possui um impacto considerável nos tempos de resposta. Isso permite dizer que, para essa aplicação em específico, qualquer um dos monitores de máquinas virtuais pode ser utilizado.

\subsubsection{Testes I/O-Bound}

Para diferenciar os experimentos, foi utilizado um segundo benchmark a compilação do Apache. Esse benchmark foi selecionado por ter sido utilizado nos trabalhos relacionados, onde o Xen apresentou melhores tempos de resposta porém em apenas uma máquina virtual. A Figura 5.5 apresenta os tempos de resposta obtidos para os dois monitores de máquinas virtuais.

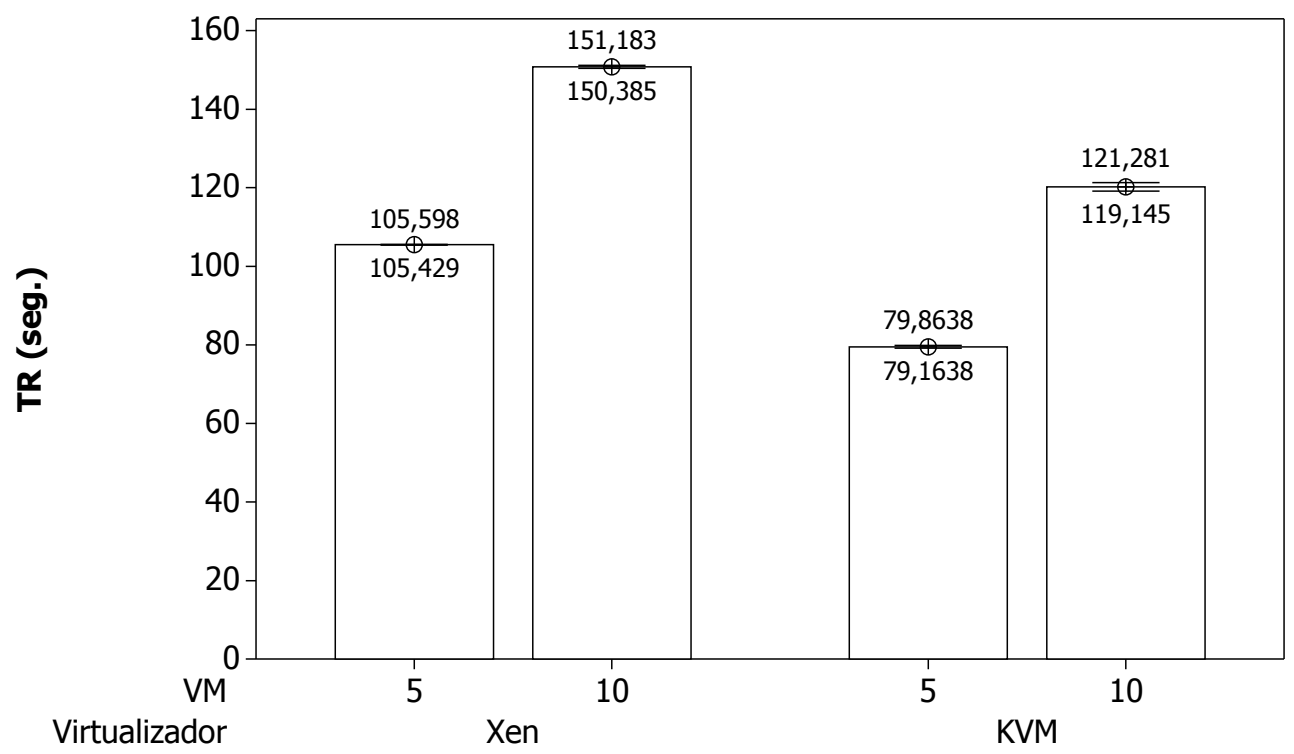

Figura 5.5: Tempos de Resposta obtido pela Compilação do Apache 
Na Figura 5.5 é possível observar que o KVM possui melhores tempos de resposta tanto para cinco quanto para dez máquinas virtuais. A diferença entre as cinco máquinas virtuais e uma, como apresentado na Figura 5.1, é em torno de 35,91seg. enquanto que a mesma quantidade de máquinas para o Xen obteve $61,36 \mathrm{seg}$ a mais de tempo de resposta.

Com relação à sobrecarga gerada, a diferença de tempos de resposta entre cinco e dez máquinas virtuais para o KVM é de 41,42seg enquanto que para o Xen esse crescimento fica em torno de $45,59 \mathrm{seg}$. Além dessa comparação, pode ser observado também que a diferença nos tempos de resposta de cinco máquinas virtuais com o KVM é de 25,73seg melhor que os apresentados pelo Xen. O KVM também apresenta melhores tempos em relação ao XEN com o número elevado de máquinas virtuais $29,9 \mathrm{seg}$ de superioridade.

A influência dos fatores nos tempos de resposta é apresentado na Figura 5.6 que apresenta as porcentagens de influência de cada fator considerado.

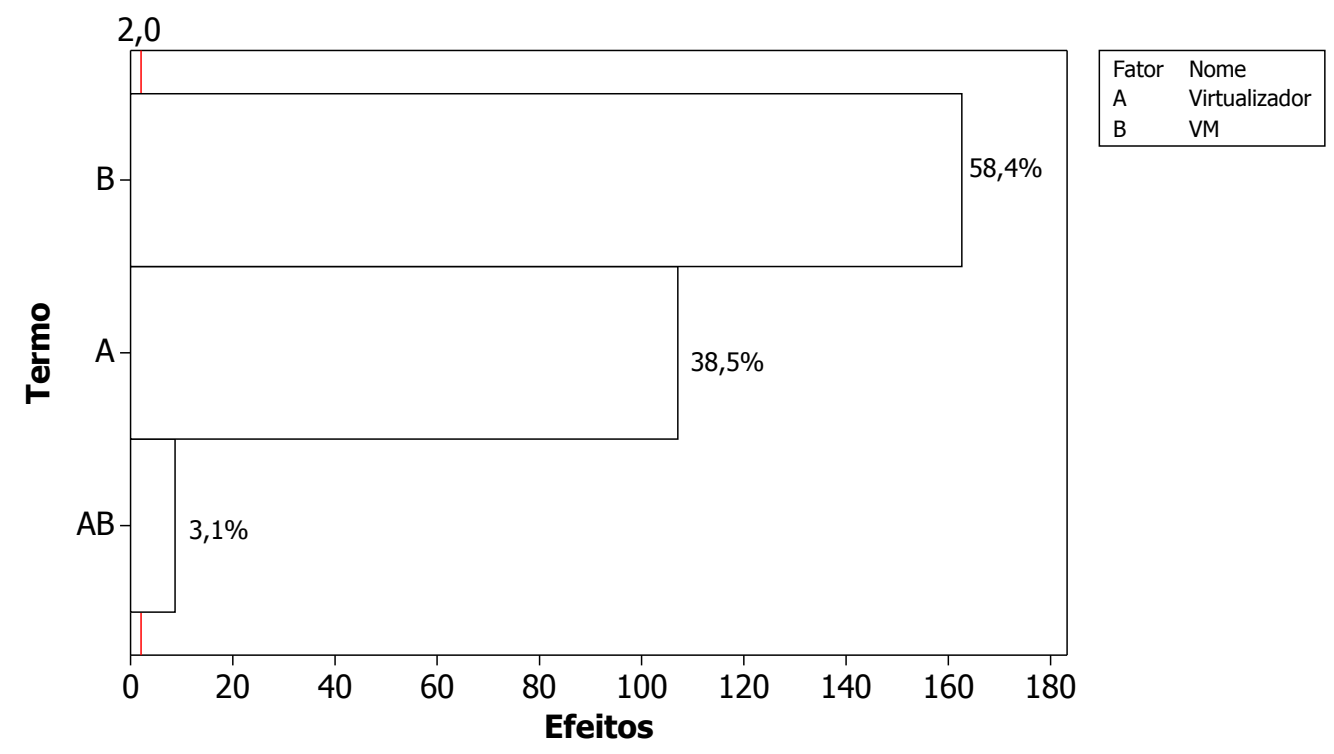

Figura 5.6: Influência dos Fatores nos Tempos de Resposta

Como apresentado na Figura 5.6, o virtualizador apresentou uma influência significativa nos tempos de resposta chegando a afetar 38,5\% desse tempo. Nesse caso, como esperado, a quantidade de máquinas virtuais apresentou um acréscimo nos tempos de resposta, porém com menos influência se comparado ao apresentado pelo SmallPt. Nesse caso a escolha do monitor de máquinas virtuais pode afetar no desempenho geral do sistema.

A Figura 5.7 apresenta as médias de tempos de resposta obtidos na mudança dos níveis, ou seja, as variações que foram feitas durante o conjunto de experimentos.

Como apresentado na Figura 5.7 os tempos médios obtidos pelo monitor de máquinas virtuais Xen obteve tempos em torno de $130 \mathrm{seg}$ na média enquanto o virtualizador KVM obteve em média 100seg. o que mostra uma melhora no desempenho geral do sistema. Além do monitor, a quantidade de máquinas virtuais teve um impacto grande no sistema devido ao crescimento proporcionado aos tempos de resposta que ficaram em torno de $42 \operatorname{seg}$. 


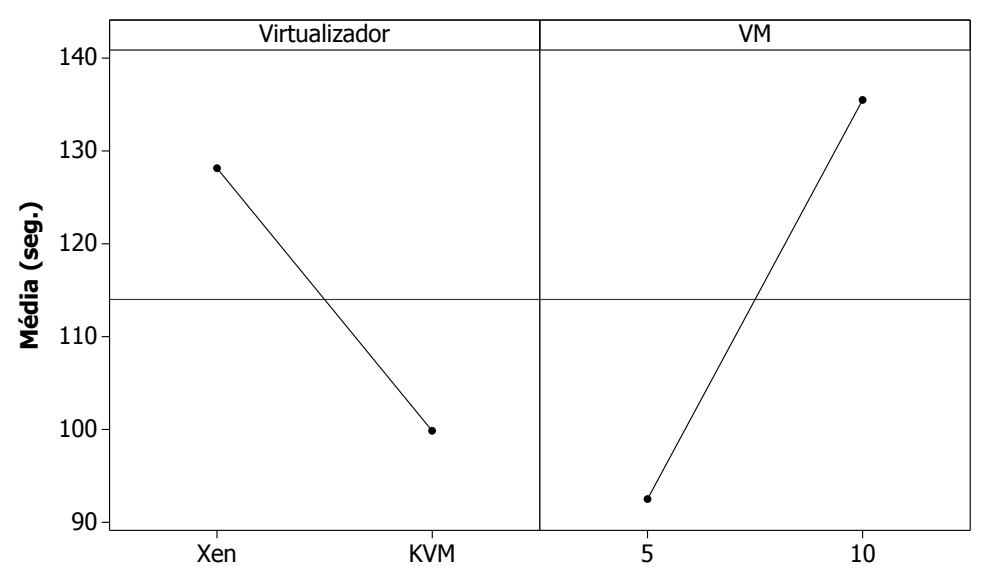

Figura 5.7: Principais Efeitos provocados na Mudança de Níveis

\subsubsection{Detalhamento da Carga nos Experimentos}

O detalhamento ou consideração da carga como fator nos experimentos serve para dar uma visão do impacto que os benchmarks avaliados podem gerar sobre o tempo de resposta obtido. A influência dos fatores é apresentado na Figura 5.8. As influências são apresentadas utilizando uma normal e a linha base, que corta o gráfico, auxiliando a identificar quais fatores são os mais influentes. Quanto mais próximo à linha base, menor é a influência nos tempos de resposta. Os pontos em quadrado, com a identificação, são os fatores que possuem influência nos tempos de resposta. Já os pontos em preto representam os fatores que não tem influência nos tempos de resposta.

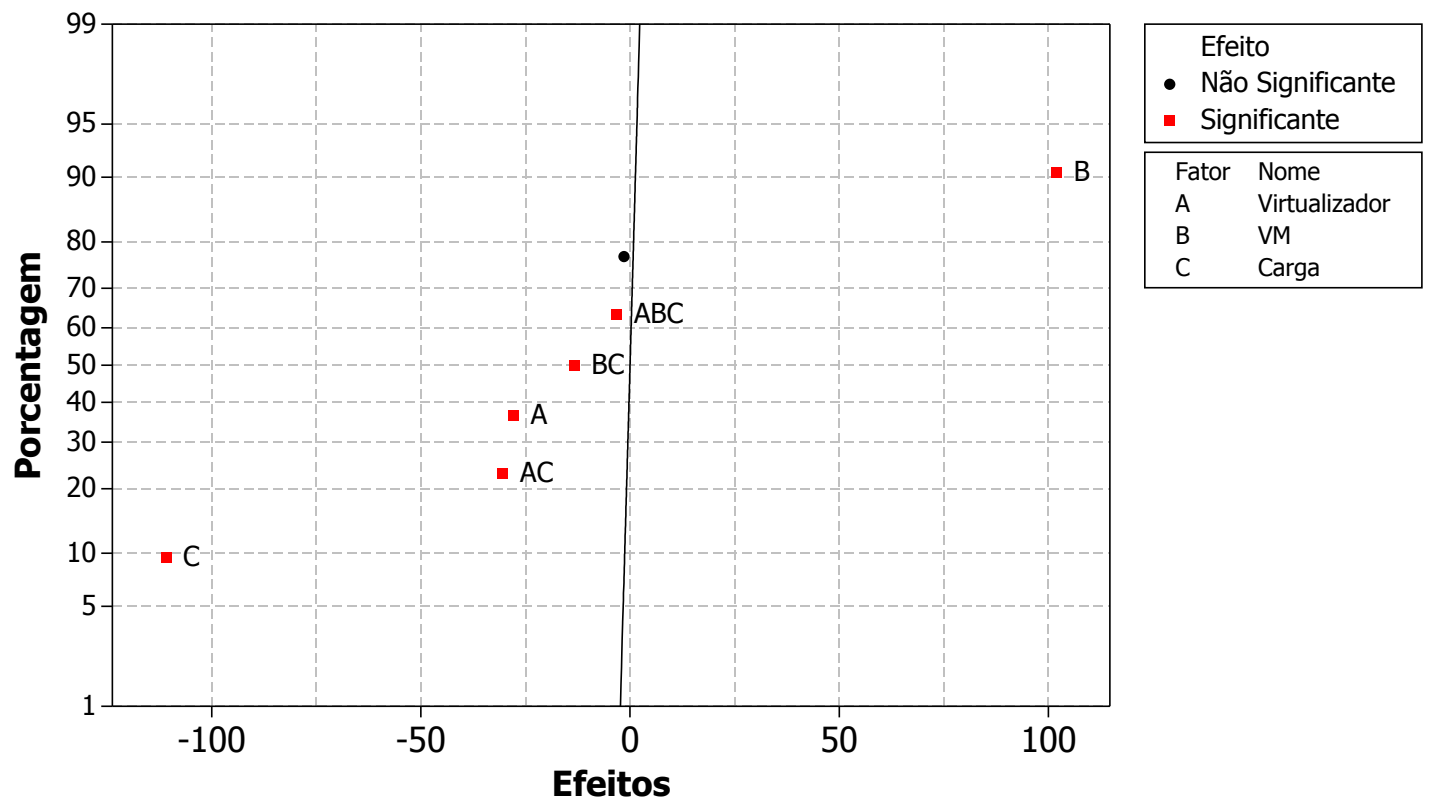

Figura 5.8: Influência dos fatores

No gráfico existem valores positivos e valores negativos. Os valores positivos representam o aumento nos tempos de resposta quando existe a mudança de nível, 
neste caso os níveis são as variações apresentadas na Tabela 5.2. Analisando o fator $\mathrm{B}$ (número de máquinas virtuais) quando o primeiro nível (cinco) muda para o segundo nível (dez) há um aumento no tempo de resposta.

Já com a carga de trabalho (fator C) ocorre o inverso do percebido pelo fator B. Quando a carga muda do Smallpt para o Apache, a tendência foi diminuir os tempos de resposta. Esse comportamento era esperado, uma vez que o Smallpt utiliza mais recursos e ocupa mais tempo o processador das máquinas virtuais. O fator $\mathrm{A}$ (virtualizador) e AC (virtualizador e carga de trabalho) possuem influências significativas, uma vez que estão mais afastados da linha base. O ponto principal é a diminuição dos tempos de resposta quando existe a mudança de virtualizadores.

A Figura 5.9 apresenta as principais mudanças obtidas nas mudanças de nível. As mudanças apresentadas são referentes aos tempos médios observados por cada fator, ou seja, no fator carga, por exemplo, é considerado a média obtida entre a soma dos valores obtidos diretamente pelos virtualizadores de máquinas virtuais e pela quantidade de máquinas virtuais para a carga específica. O mesmo se aplica aos demais fatores.

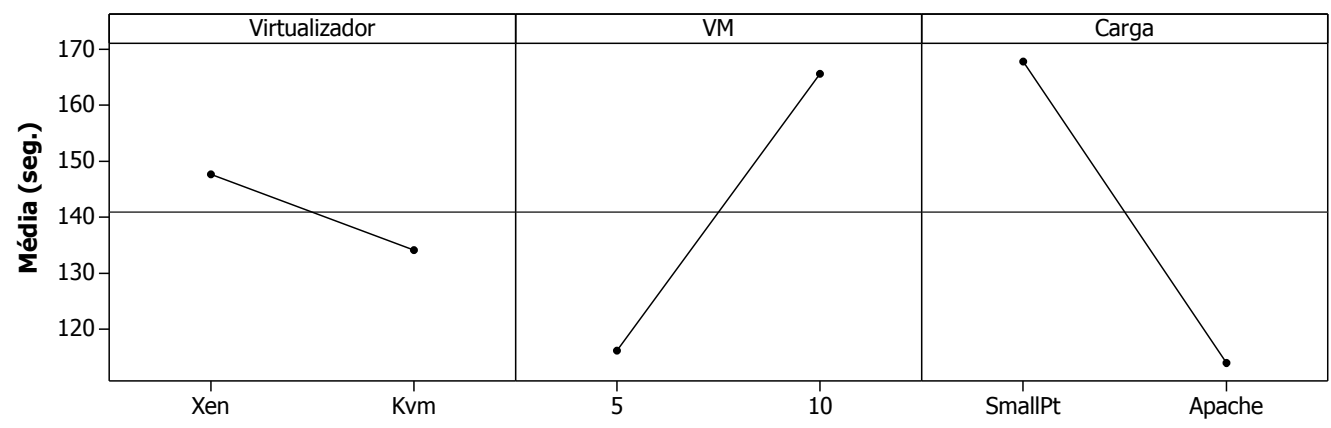

Figura 5.9: Principais mudanças nos níveis considerados

Como observado na Figura 5.9 a maior diferença entre as mudanças de níveis está na carga de trabalho (Smallpt e Apache). Essa grande mudança é o que faz com que o fator carga seja o mais influente no tempo de resposta. Além da carga de trabalho, a maior influência é sentida na mudança da quantidade de máquinas virtuais, sendo o segundo fator mais influente.

A Figura 5.10 apresenta a interação entre os fatores que são apresentados na Figura 5.8. Na Figura 5.10, o eixo $X$ de cada quadro representa os níveis considerados e o eixo Y representa os tempos médios de resposta obtidos. Os tempos médios são calculados da mesma forma que os dados da Figura 5.10.

As linhas paralelas da Figura 5.10 não representam influências combinadas. A mudança dos níveis representa o mesmo o comportamento do fator $\mathrm{AB}$ (virtualizador e máquinas virtuais).

As combinações que possuem influência são diretamente relacionadas à mudança de carga. Por exemplo, a carga (Smallpt e Apache) relacionada com o virtualizador (Xen e KVM) quando a carga estava em SmallPt o KVM e o Xen tinham os mesmos tempos médios, quando a carga muda para a compilação do Apache o Xen passa a ter piores 


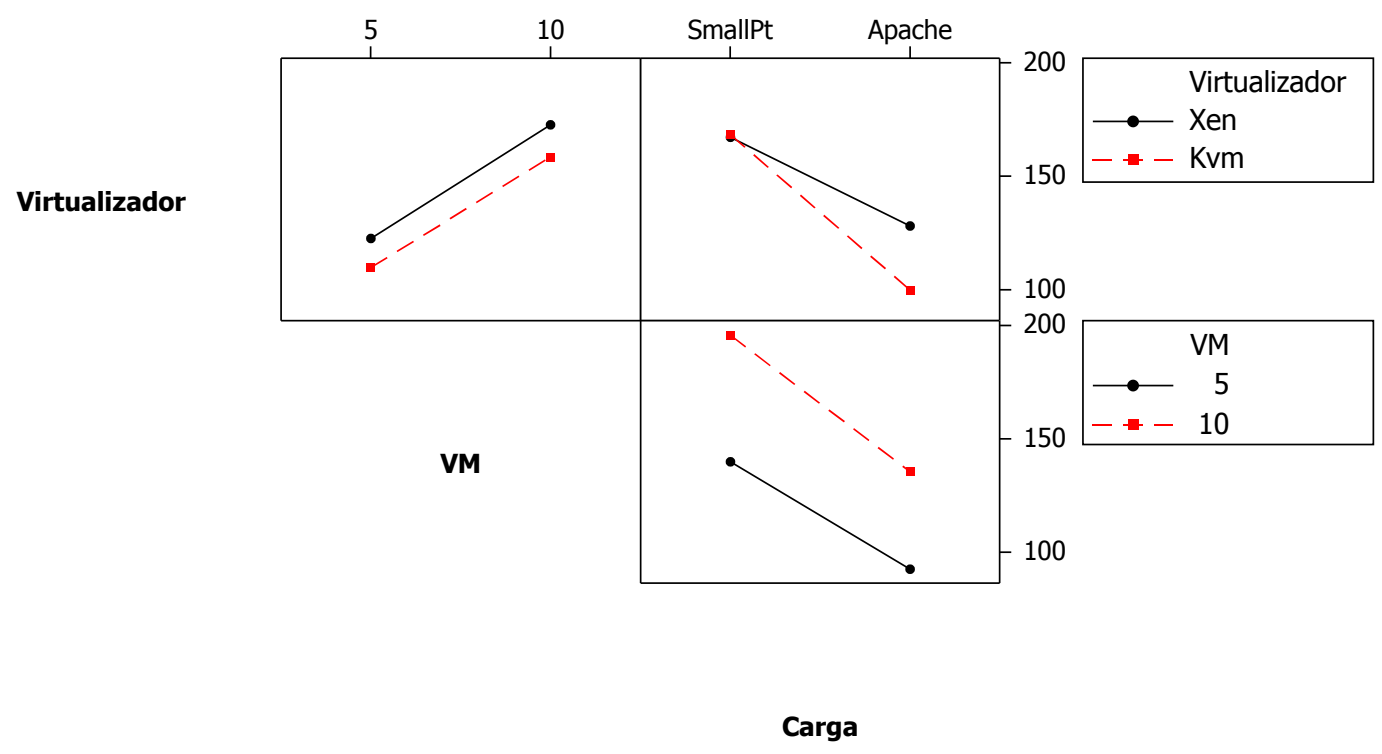

Figura 5.10: Interação entre os fatores

tempos de resposta o que não é acompanhado pelo KVM que passa a ter melhores tempos de resposta. O mesmo acontece para a quantidade de máquinas virtuais relacionada com o serviço.

\subsection{Considerações Finais}

Este capítulo realizou a avaliação de desempenho com relação a sobrecarga de virtualização e a avaliação dos virtualizadores (Xen e KVM). Sobre os resultados, observa-se que o uso de virtualização permite o uso de mais de uma máquina no servidor utilizado. Isso quer dizer que, dentre os tempos observados do primeiro experimento, no host sem virtualização uma quantidade de recursos ficou subutilizada. Analisando os tempos obtidos com cinco máquinas virtuais em relação ao host sem virtualização observa-se um aumento de $64 \%$ de diferença entre os tempos de resposta. E com dez máquinas virtuais o aumento ficou em torno de $76 \%$. Além de observar uma melhor utilização do host, foi verificado que o KVM possui melhores tempos de resposta que o Xen. Esse fato evidencia que para sistemas de propósito gerais, uma compilação que possui uso intensivo de entrada e saída, o KVM possui melhores tempos de resposta.

Outro ponto importante a ser ressaltado é a utilização desse estudo como forma de validação para as metodologias das políticas implementadas pelo MACC. De forma sintética, as metodologias das políticas do MACC realizam a alocação de recursos de CPU na forma fracionada. Essa técnica é viável, já que é permitida a alocação de uma fração da potência computacional presente nos cores do processador, pois tanto o Xen quanto o KVM implementam essa função.

Finalizando, a virtualização pode trazer benefícios aos seus utilizadores uma vez que sua manutenção e principalmente migração são mais simples se comparados a uma máquina real. Pode-se concluir que a utilização da virtualização é viável para 
otimizar a utilização dos seus recursos. Os resultados apresentados podem direcionar as pesquisas para o uso compartilhado de recurso entre as máquinas virtuais, uma vez que a pretensão de utilizar virtualização é em maximizar o uso de uma máquina física e não colocar uma camada a mais de sobrecarga (virtualização) para a utilização de apenas uma máquina.

O estudo apresentado neste capítulo pode auxiliar na manutenção e expansão dos serviços e na forma como os mesmos são ofertados pelos gerenciadores de recursos dos provedores nas Nuvens, por exemplo, o MACC. Seguindo os resultados obtidos nesta tese, os próximos capítulos tratam os resultados obtidos com a arquitetura de metaescalonamento (MACC), abordando a infraestrutura de sua comunicação. 


\section{Avaliação da Infraestrutura de Comunicação}

\subsection{Considerações Iniciais}

Este capítulo apresenta os resultados obtidos com a metodologia de comunicação do MACC. A comunicação é a primeira etapa de operações do MACC, funcionando como descoberta e distribuição dos serviços dos usuários pertencentes a Intercloud. A realização dessa tarefa pelo MACC é complexa devido à natureza dos vários elementos da camada de infraestrutura de rede. Esses elementos envolvem tecnologias, linguagens, ferramentas, desenvolvimento, e monitoramento do ambiente Intercloud. Pode-se acrescentar niveis maiores de dificuldade caso considere-se a configuração de segurança, protocolos econômicos, tratamento de dados na forma semântica, interfaces baseada em Web, requisitos de persitências e notificações.

O objetivo do MACC, dentro do contexto da camada de infraestrutura de rede, é de prover a distribuição adequada de recursos para os usuários pertencentes ao ambiente Intercloud. Essa é a primeira etapa das atividades desenvolvidas pelo MACC. Nessa primeira etapa, o MACC deve escolher o data center adequado para executar o serviço do usuário. Para isso, o MACC possui a implementação das políticas de roteamento: Round Robin, BCR-Latência, Chord-Latência e Pastry-Salto.

\subsection{Preparação do Ambiente de Testes}

Os experimentos foram realizados por meio de simulação. O simulador utilizado foi o CloudSim proposto por Calheiros et al. (2010). A topologia de rede apresentada nesse capítulo foi desenvolvida em relação ao número de entidades presentes no cenário de simulação. Essas entidades fazem parte do CloudSim e são utilizadas, como parâmetros, 
pelas políticas de roteamento para a definição do envio de serviços dos clientes. Com a definição do modelo de comunicação proposto pelo MACC foi possível definir quais abordagens utilizar na definição das políticas de roteamento.

A avaliação das abordagens de roteamento permite definir qual deve ser a abordagem utilizada pelo MACC em um determinado cenário. O uso de políticas de roteamento, que possuem baixos tempos de resposta, auxilia o MACC na entrega de serviços melhorando a qualidade de serviço oferecida aos clientes. Para a avaliação de desempenho do modelo de comunicação do MACC foram utilizadas as técnicas de planejamento de experimentos demonstradas em (Jain, 1991). Os experimentos adotados utilizam o método fatorial completo e foram executados dez vezes, sendo os intervalos configurados para apresentar $95 \%$ de confiança.

$\mathrm{Na}$ elaboração do planejamento de experimentos, um dos fatores utilizados foi o número de clientes que possui duas variações ou dois níveis. Por essa razão foram gerados dois arquivos de topologia. Como foram utilizadas duas topologias, as mesmas são apresentadas na Figura 6.1 e Figura 6.2.

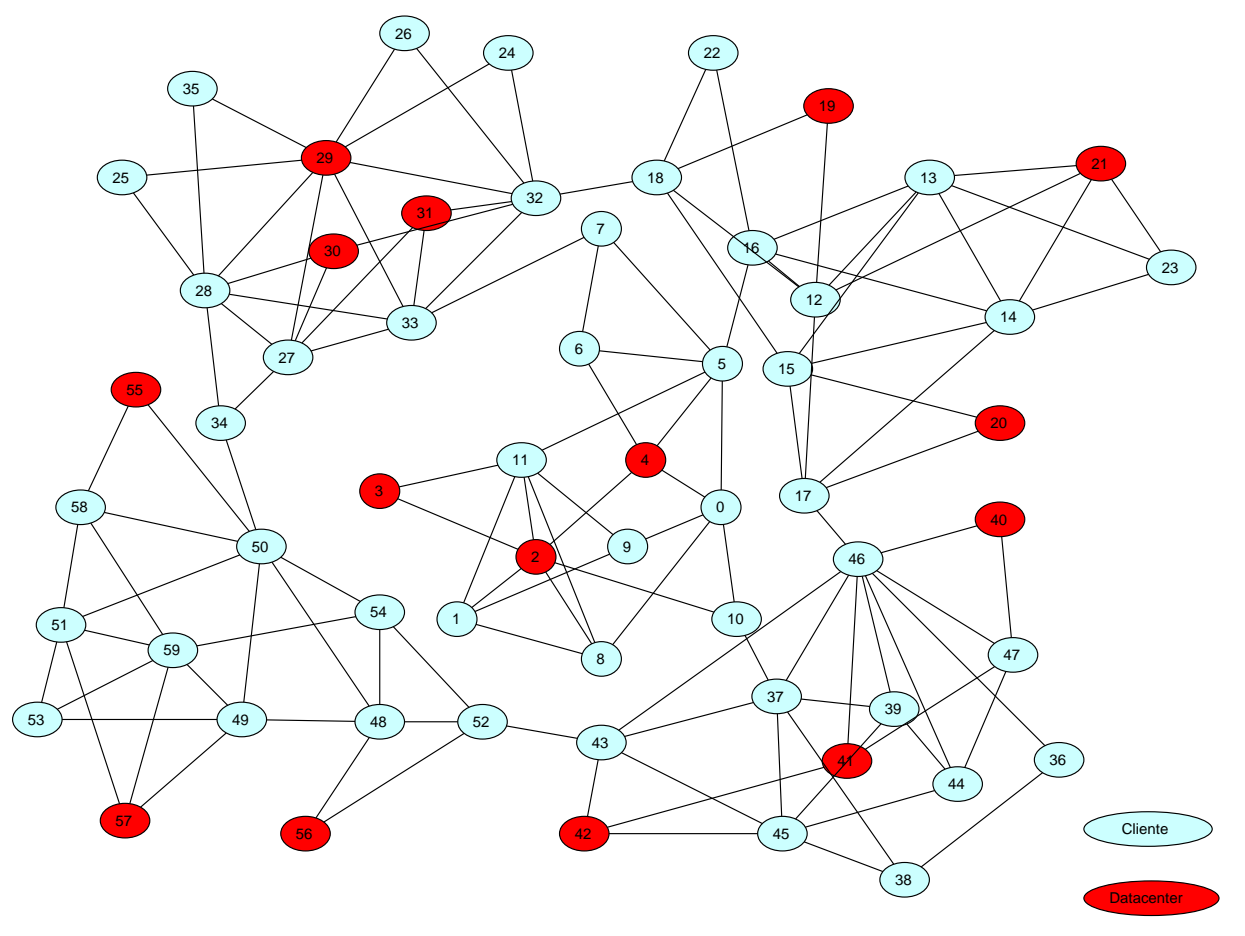

Figura 6.1: Rede utilizada para 30 clientes e 15 Data Centers.

No Capítulo 4 é apresentada a metodologia de funcionamento da camada de comunicação do MACC. Para permitir a criação de topologias com ligações variadas que se aproximam das ligações apresentadas por redes reais foi utilizado o BRITE (Cheswick et al., 2000); (Dodge, 2012). O BRITE trata dos aspectos técnicos e realiza o mapeamento de redes reais para servir de base para modelos.

O CloudSim, usando as topologias geradas pelo BRITE, faz um mapeamento de uma entidade (cliente ou data center) para um nó da topologia (Medina et al., 2001). Dessa 


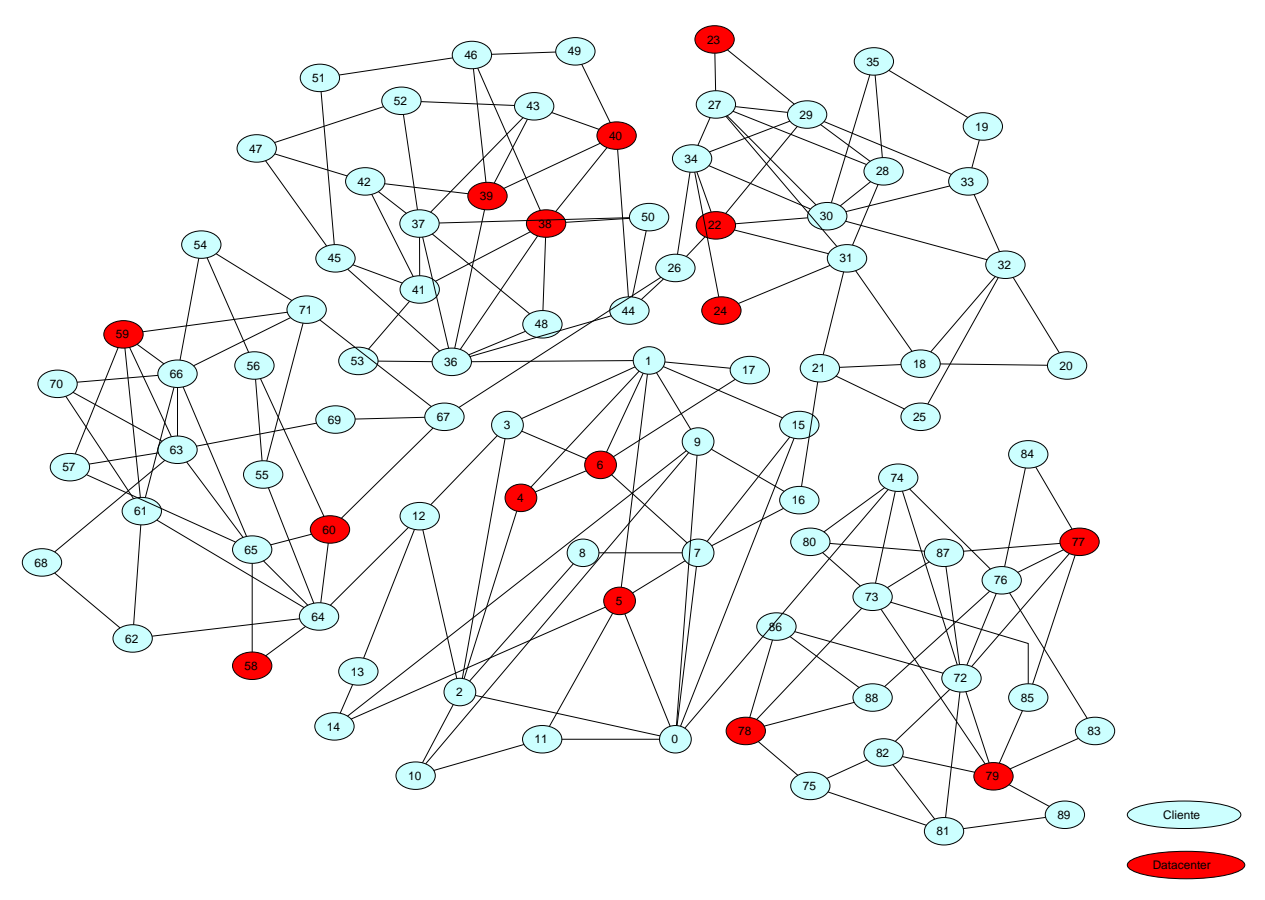

Figura 6.2: Rede Utilizada para 60 Clientes e 15 Data Centers.

forma, os nós que estão em negrito nas Figuras 6.1 e 6.2 representam os nós que podem ser utilizados pelos data centers e os outros nós representam os clientes. Essas topologias são utilizadas pelo MACC para o desenvolvimento e avaliação de seu modelo de comunicação.

Com relação ao tipo de serviço, os dois cenários existentes são: Leve ou Pesado. O primeiro cenário, leve, consiste de uma carga de trabalho de web services, o qual é composto de vinte requisições que necessitam de baixa necessidade de processamento (tais como a recuperação de páginas web ou transações de negócios on-line). O segundo cenário, pesado, considera um tipo de aplicação que lida com vinte requisições de processamento intensivo, por exemplo, representando a utilização de Computação em Nuvens por aplicações científicas, por exemplo, a renderização de imagens.

Os outros fatores do ambiente são descritas na Tabela 6.1. Esses fatores são considerados fixos, pois não possuem influenciam de forma significativa as variáveis de resposta.

\subsection{Comparação entre as Métricas}

A maioria das políticas de roteamento para a comunicação de ambientes em nuvens utilizam apenas uma métrica para avaliar qual o melhor caminho a ser percorrido. Assim, a princípio foi realizada uma avaliação para identificar qual a métrica mais adequada dentro do contexto considerado neste trabalho. O experimento foi conduzido para identificar o melhor par (política, métrica). Como pode ser visto na Tabela 6.2, 
Tabela 6.1: Fatores Fixos dos Experimentos

\begin{tabular}{|c|c|}
\hline Máquina & Valores \\
\hline Processador & Intel Quad 2 core \\
\hline Memória & 4 GB RAM \\
\hline Sistema Operacional & Ubuntu x64 10.04 \\
\hline Java & Cloudsim 2. 1.6_26 \\
\hline \hline Simulador & 15 \\
\hline Número de Data Centers & $16 \mathrm{~GB}$ \\
\hline Host_RAM & $1 \mathrm{~Gb}$ \\
\hline Host_Comunicação & RR, BCR, Chord e Pastry \\
\hline Política de Roteamento & Baseada em Classe de Serviços \\
\hline Tipo de Deadline & 20 \\
\hline Número de Serviço por Usuário &
\end{tabular}

considera-se ainda uma variação do número de usuários acessando o sistema, com o objetivo de verificar se esse fator influencia na definição da melhor métrica para cada algoritmo.

Os experimentos descritos na Tabela 6.2 foram executados para as seguintes políticas: Round Robin ${ }^{1}$ (RR), Baseada na Capacidade da Rede (BCR), Pastry (P) e Chord (C). A variável de resposta é dada pela variável RTT (Round Trip-time).

Tabela 6.2: Projeto de Experimento

\begin{tabular}{|c|c|c|}
\hline Exp & Métrica & Quantidade de Usuário \\
\hline 1 & Salto & 30 \\
\hline 2 & Salto & 60 \\
\hline 3 & Latência & 30 \\
\hline 4 & Latência & 60 \\
\hline
\end{tabular}

Cada política é avaliada segundo esse conjunto de experimentos, apresentando diferentes resultados com relação à melhor combinação (política, métrica). É importante ressaltar que as métricas escolhidas para esses experimentos, apesar de serem funcionalmente diferentes, possuem o mesmo objetivo que é realizar a entrega do serviço com o tempo de resposta mais baixo. A seguir, serão discutidas as políticas avaliadas supracitadas.

\subsubsection{BCR}

De acordo com a Figura 6.3 é possível notar que a variável RTT pode mudar dependendo do nível do fator. Nota-se que a utilização da Latência como métrica produz menores tempos para a variável RTT. Quando o número de usuários cresce de 30 para 60 o RTT sofre um aumento. Pode-se afirmar que existe interação entre os dois fatores

\footnotetext{
${ }^{1}$ Apesar de não considerar métrica essa política foi utilizada por motivos comparativos.
} 
(Métrica, Usuários), pois as linhas não estão paralelas, permitindo dizer que à medida que o ambiente muda de 30 para 60 usuários a métrica de salto possui uma sensibilidade maior ao apresentar valores maiores para o RTT.
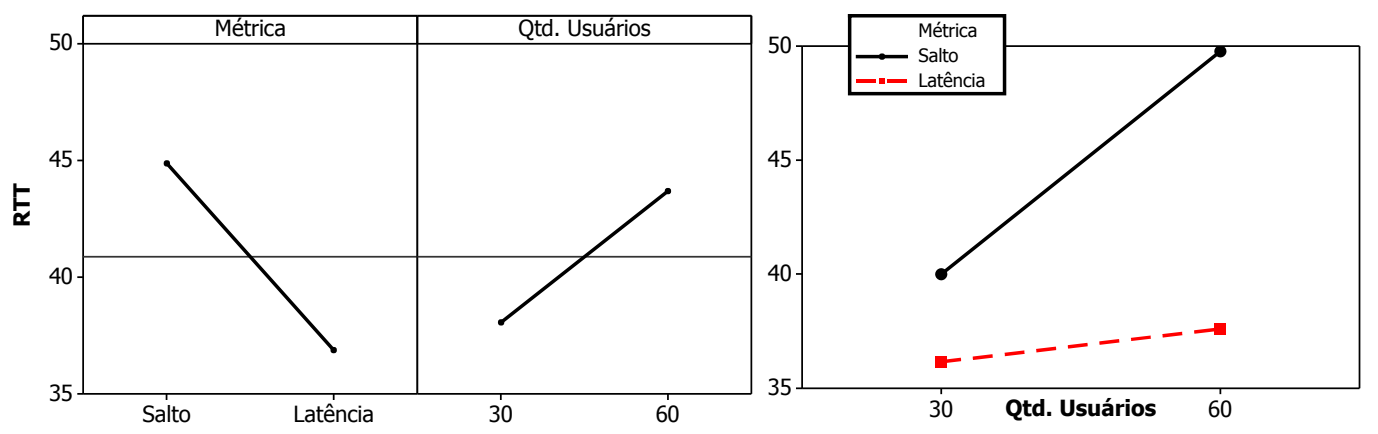

Figura 6.3: BCR - Efeito dos Fatores na variável RTT (s).

Como a inclinação da linha do fator métrica é mais íngreme do que a linha do fator quantidade de usuários é possivel dizer que o fator com maior importância é o de métrica para esse experimento. Assim, o algoritmo BCR, para os casos descritos nesse experimento, possui melhores resultados combinado à métrica de Latência.

\subsubsection{Chord}

Os resultados para a política de roteamento Chord, Figura 6.4, possui como fator mais impactante a quantidade de usuários. Ainda assim, a métrica Latência possui valores sensivelmente melhores do que a de salto. Já que as retas não estão em paralelo existe a interação dos fatores, porém sutil.
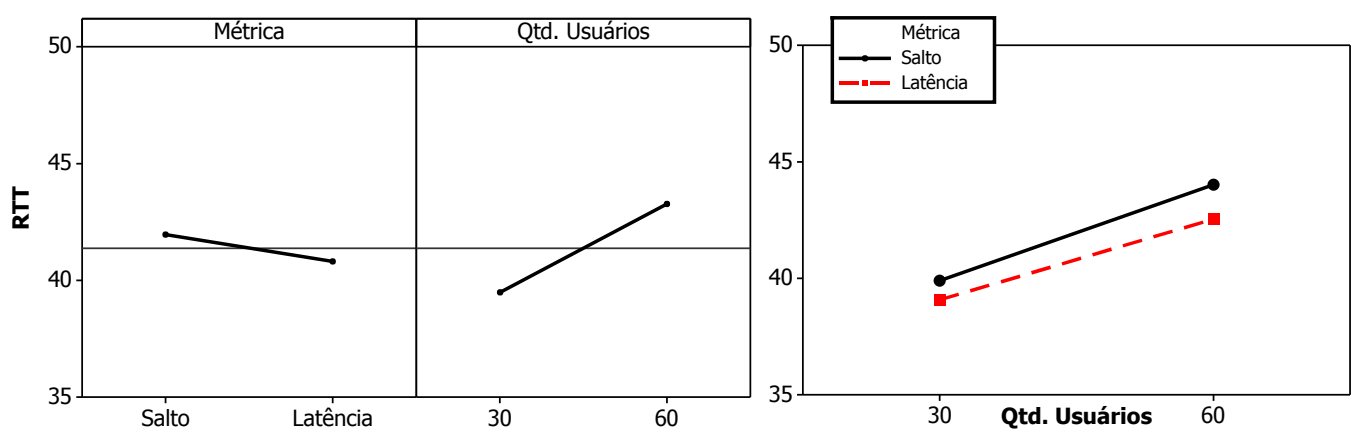

Figura 6.4: Chord - Efeito dos Fatores.

De acordo com essas informações, opta-se pelo Chord baseado em Latência para realizar os experimentos.

\subsubsection{Pastry}

De acordo com as observações feitas para a política Pastry, Figura 6.5, é possível notar a interação entre os fatores (métrica, quantidade de usuários). Essa interação leva a considerar o par (Pastry, Salto) para o ambiente com 30 usuários. Entretanto, com o 
aumento do número de usuários, as métricas (latência e salto) são classificadas como estatisticamente iguais.
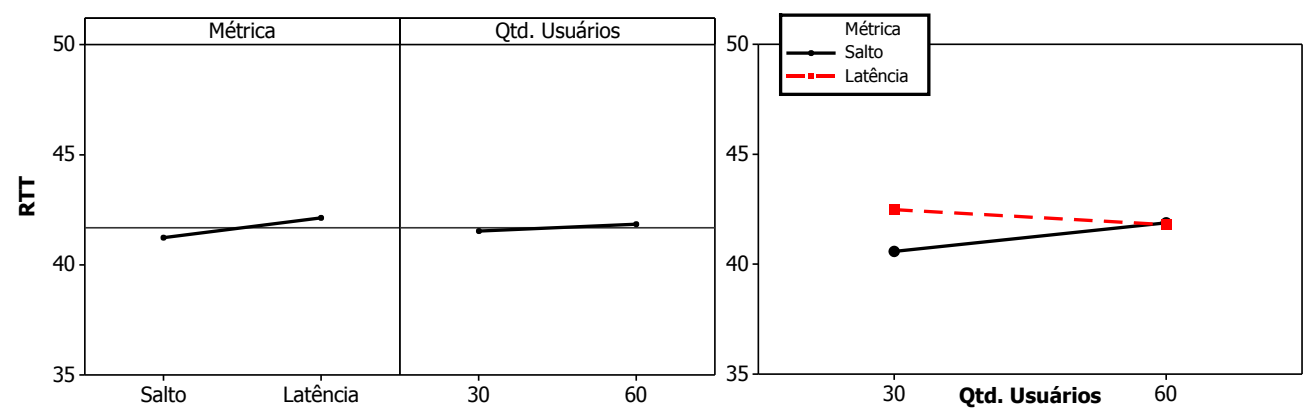

Figura 6.5: Pastry - Efeito dos Fatores.

Dadas essas informações, o par (Pastry, Salto) foi escolhido por ter um desempenho levemente melhor para o ambiente com 30 usuários e com resultados estatisticamente iguais ao par (Pastry, Latência) quando o ambiente possui 60 usuários.

\subsection{Comparação das Políticas de Roteamento}

Os experimentos foram realizados no formato "'dois-a-dois"' a partir da política de roteamento por meio do planejamento fatorial $2^{k}$. Dessa forma, será possível identificar o melhor algoritmo ou os melhores algoritmos para determinados cenários experimentados. A Figura 6.6 apresenta a disposição dos experimentos.

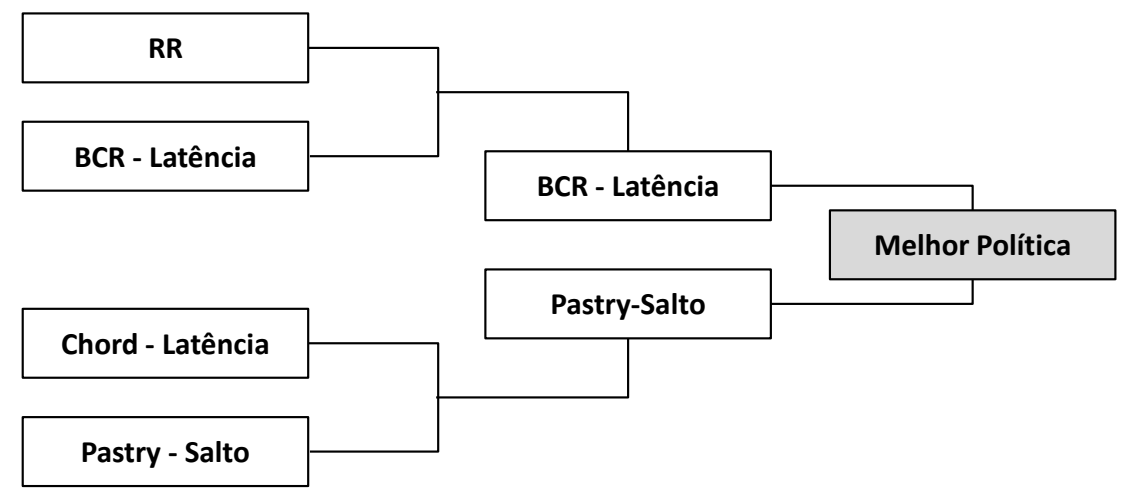

Figura 6.6: Condução dos Experimentos.

A Figura 6.6 já fornece as combinações de todos os experimentos de acordo com os resultados obtidos. Todos os algoritmos são avaliados e os melhores avançam; semelhante à disputa de um torneio. Os resultados citados são analisados nas próximas Subseções.

\subsubsection{Comparação entre as Políticas RR e a BCR-Latência}

A Tabela 6.3 mostra a distribuição do planejamento de experimentos utilizada para avaliar as políticas RR e BCR-Latência. 
Tabela 6.3: Projeto de Experimento

\begin{tabular}{|c|c|c|c|c|}
\hline Exp & Política de Roteamento & Tipo de Serviços & Quantidade de Usuários & RTT (s) \\
\hline 1 & RR & Leve & 30 & 65,33 \\
\hline 3 & RR & Pesado & 30 & 65,68 \\
\hline 5 & RR & Leve & 60 & 63,19 \\
\hline 7 & RR & Pesado & 60 & 63,52 \\
\hline 2 & BCR-Latência & Leve & 30 & 36,14 \\
\hline 4 & BCR-Latência & Pesado & 30 & 36,55 \\
\hline 6 & BCR-Latência & Leve & 60 & 37,59 \\
\hline 8 & BCR-Latência & Pesado & 60 & 38,03 \\
\hline
\end{tabular}

A Figura 6.7 apresenta o tempo de resposta com o intervalo de confiança para os experimentos realizados. Observa-se que os valores encontrados para a variável de resposta são menores quando se utiliza a política BCR-Latência. Isso ocorre independente do tipo de serviço ou da quantidade de usuários. Apesar da média RTT com 60 usuários ser sensivelmente menor (Política RR), os intervalos analisados estão sobrepostos, o que leva a considerar que tanto para 30 usuários quanto 60 usuários os resultados são estatisticamente iguais.

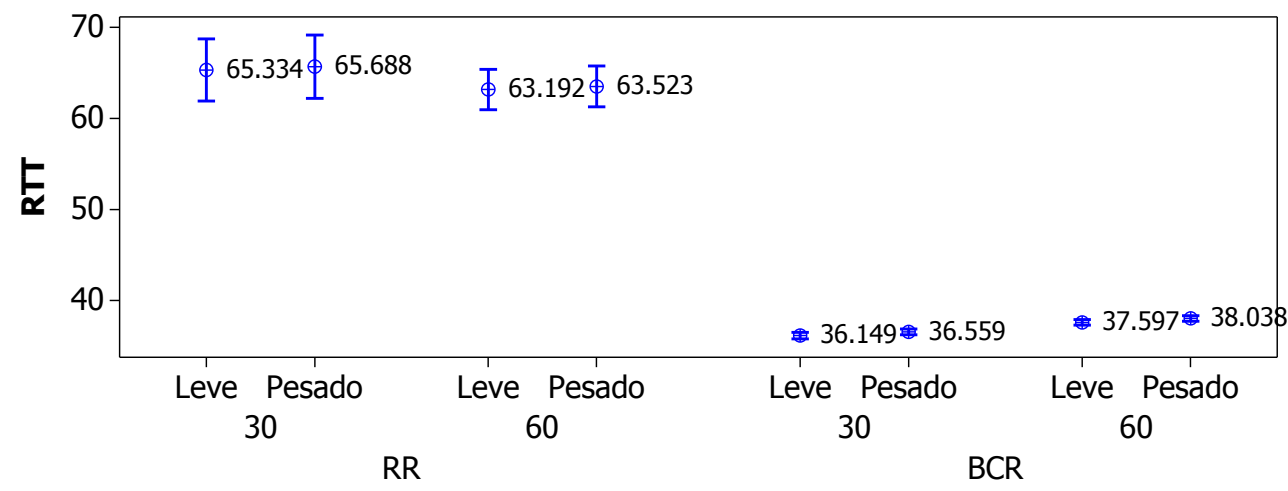

Figura 6.7: Intervalo de Confiança.

Outra observação que pode ser realizada é com relação ao desvio padrão. Os dados vistos na Figura 6.8 apontam que além da média, o desvio padrão para a variável de resposta também é menor para a política BCR. Isso mostra que a variabilidade da variável de resposta é baixa para os experimentos executados.

A Figura 6.9 mostra a interação dos fatores sobre a variável de resposta. A relação entre o roteamento e o tipo de serviço indica que não há interação. Dessa forma, a variável de resposta apresenta a média semelhante quando a política de roteamento utiliza serviços leves ou pesados.

Analisados os fatores de tipo de serviço e de quantidade de usuários, Figura 6.9, observa-se uma pequena interação. Essa interação ocorre pela leve diminuição na média RTT quando se tem 60 usuários para a política RR. Esse comportamento ocorre, pois a política RR não funciona utilizando algum conhecimento para fabricar a ordem de atendimento, sendo assim, a distribuição ocorre de forma circular aos dois modelos 


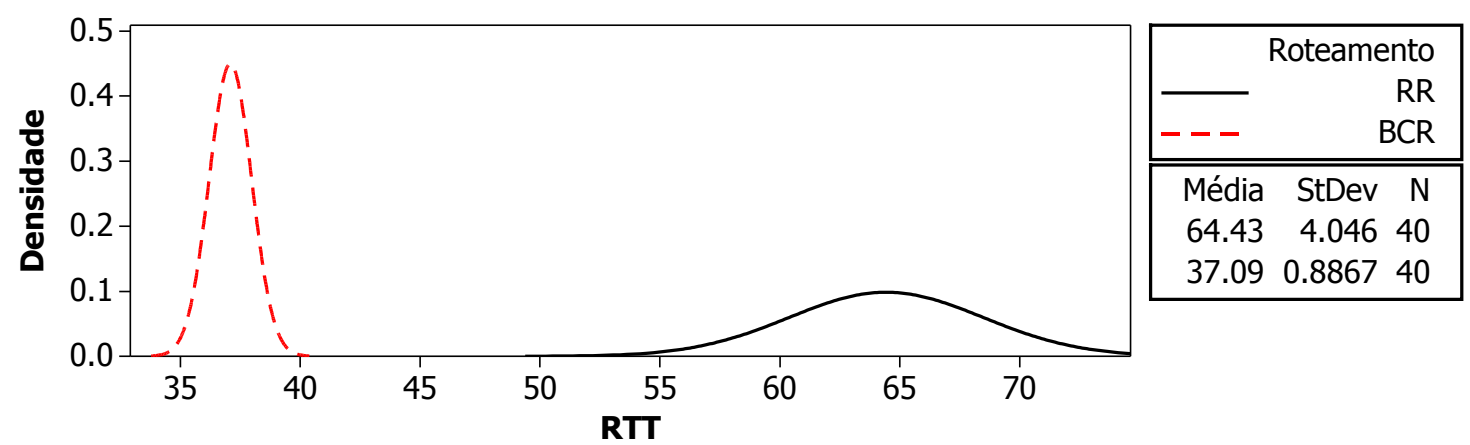

Figura 6.8: Histograma - RTT.

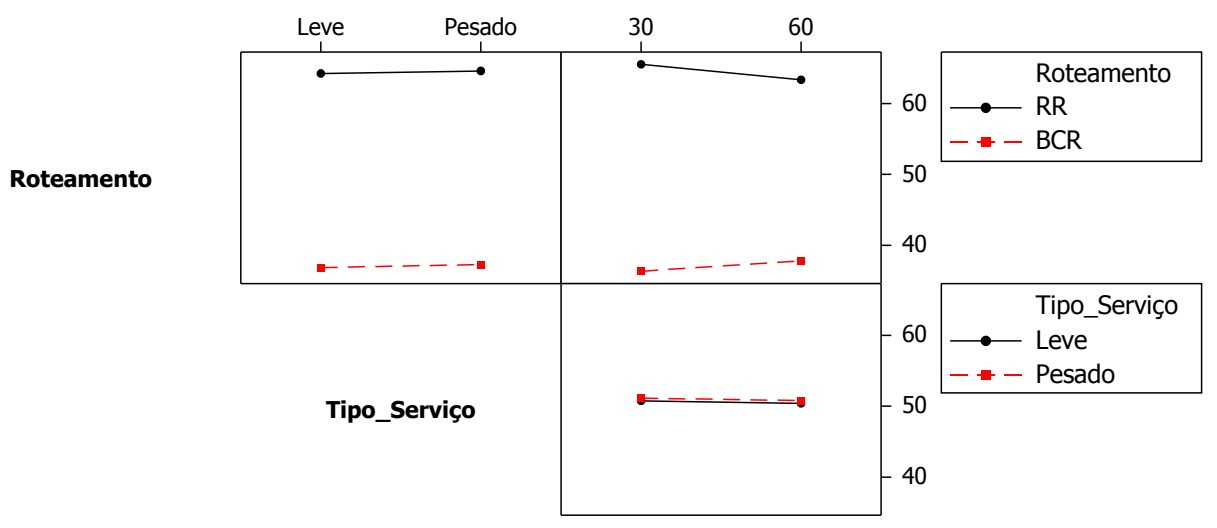

Quantidade_Usuário

Figura 6.9: Interação dos Fatores.

de rede experimentados, dependendo da disposição entre usuários e data centers constituídos por aquele ambiente.

A Figura 6.10 mostra os fatores que mais influenciam na variável de resposta. O fator A (Roteamento) é que mais influencia, pois ele é quem está mais distante da linha apresentada pela distribuição normal. Além disso, como o fator A está à esquerda da linha isso significa que à medida que as políticas de roteamento são aperfeiçoadas a variável de resposta tende a diminuir em valor. Em contrapartida a interação entre AC (Roteamento e Quantidade de Usuários) aumentaria o valor obtido para a variável de resposta RTT.

Dessa forma, é a política BCR-Latência a que possui os melhores resultados nesse conjunto de experimentos.

\subsubsection{Comparação entre as Políticas Chord-Latência e a Pastry-Salto}

A Tabela 6.4 mostra a distribuição do planejamento de experimentos utilizada para avaliar as políticas Chord-Latência e Pastry-Salto. 


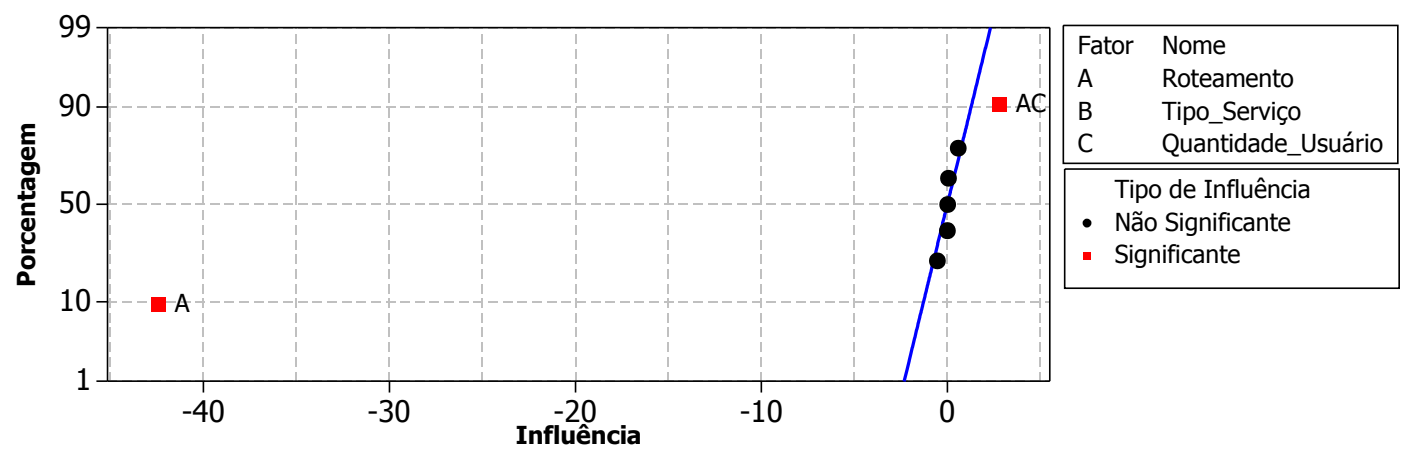

Figura 6.10: Influência RTT - Normal.

Tabela 6.4: Projeto de Experimento

\begin{tabular}{|c|c|c|c|c|}
\hline Exp & Política de Roteamento & Tipo de Serviços & Quantidade de Usuários & RTT (s) \\
\hline 1 & Chord-Latência & Leve & 30 & 39,06 \\
\hline 3 & Chord-Latência & Pesado & 30 & 39,45 \\
\hline 5 & Chord-Latência & Leve & 60 & 42,53 \\
\hline 7 & Chord-Latência & Pesado & 60 & 42,94 \\
\hline 2 & Pastry-Salto & Leve & 30 & 40,58 \\
\hline 4 & Pastry-Salto & Pesado & 30 & 40,98 \\
\hline 6 & Pastry-Salto & Leve & 60 & 41,88 \\
\hline 8 & Pastry-Salto & Pesado & 60 & 42,35 \\
\hline
\end{tabular}

A Figura 6.11 apresenta os tempos de RTT e respectivos intervalos de confiança para os experimentos realizados. Observa-se que a política Chord-Latência apresenta melhores resultados quando o ambiente possui 30 usuários. Entretanto, quando o ambiente passa a ter 60 usuários as políticas Chord-Latência e a Pastry-Salto apresentam resultados estatisticamente iguais, porém com a média levemente menor para a Pastry-Salto.

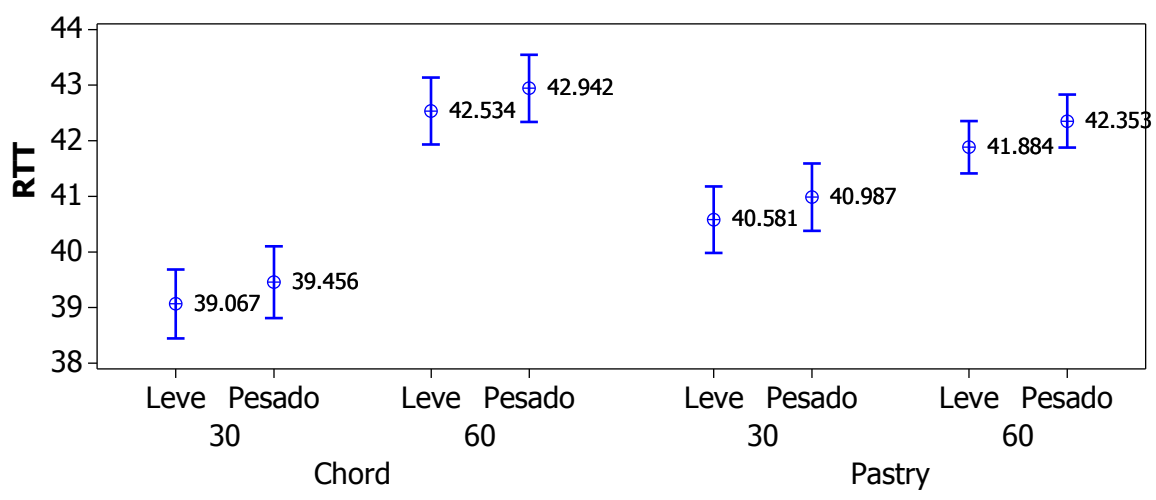

Figura 6.11: Intervalo de Confiança.

Os dados vistos na Figura 6.12 apontam que a política Pastry-Salto é mais estável com relação à mudança de quantidade de usuários no sistema. Isso é o observado, 
pois o desvio padrão para o Chord-Latência é maior do que o encontrado para a política Pastry-Salto.

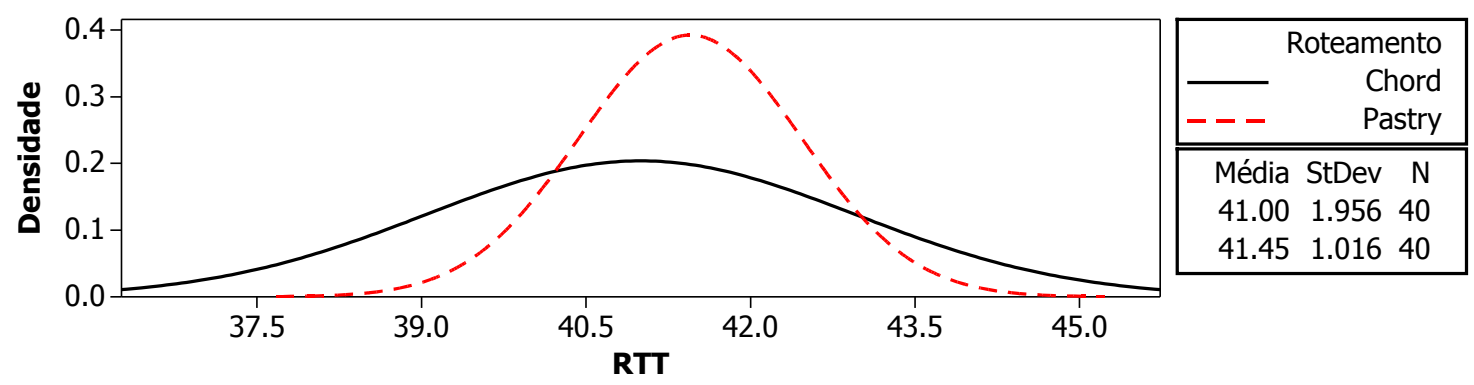

Figura 6.12: Histograma - RTT.

A Figura 6.13 mostra a interação dos fatores. Mesmo que o fator A (Política de Roteamento) não apresente interação com o fator B (tipo de serviço), observa-se que a média da variável de resposta é incrementada quando o tipo de serviço passa de leve para pesado. Entretanto, existe uma interação entre os fatores A (Política de Roteamento) e C (Quantidade de Usuários); esse tipo de interação ocorre pela inversão dos resultados apresentados pelas políticas em decorrência do número de usuários no ambiente.

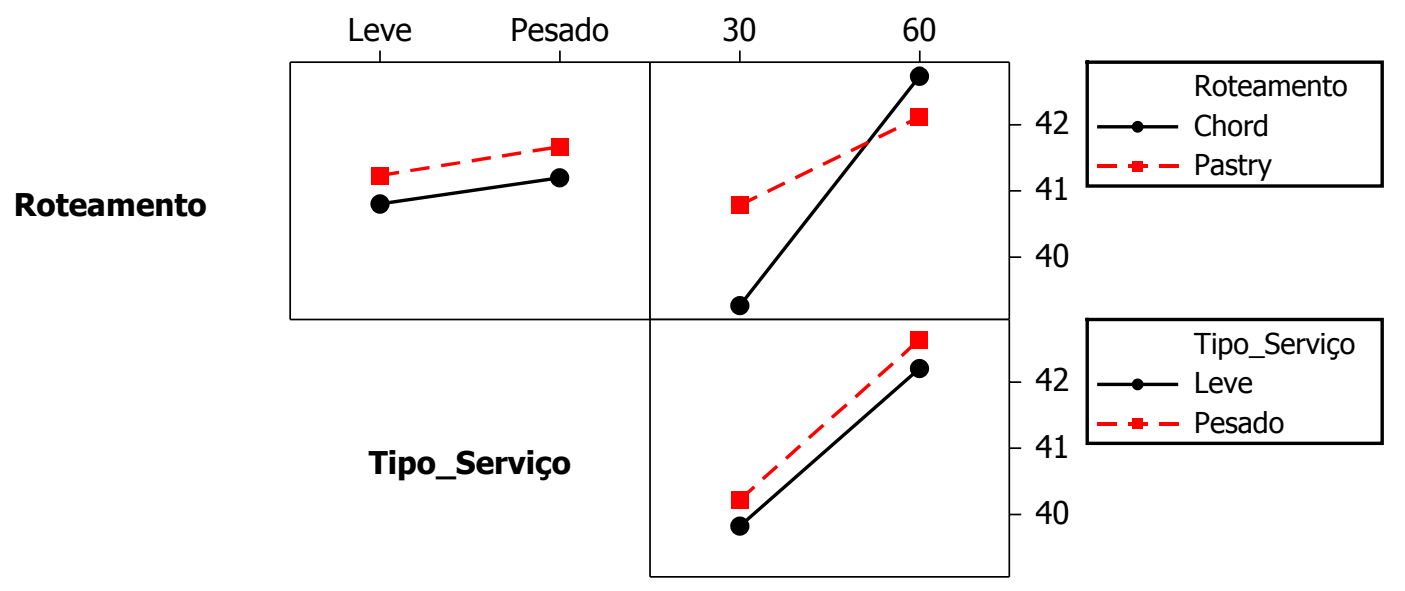

Qtd_usuários

Figura 6.13: Interação dos Fatores.

A Figura 6.14 mostra os fatores que mais influenciam na variável de resposta. O fator C (Quantidade de Usuários) é o que mais influencia, pois ele é quem está mais distante da linha apresentada pela distribuição normal. Além disso, como o fator C está à direita da linha isso indica que o aumento do número de usuários irá aumentar o valor médio obtido pela variável de reposta.

Por causa da estabilidade da política Pastry-Salto, mesmo em situações diferentes de cargas, opta-se por ela nesse experimento. 


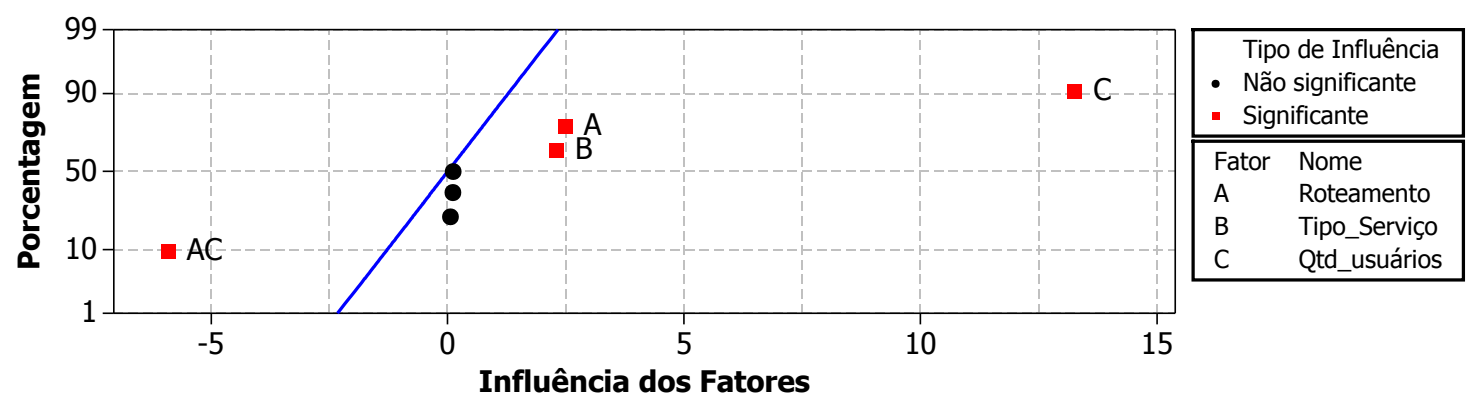

Figura 6.14: Influência RTT - Normal.

\subsubsection{Comparação entre as Políticas BCR-Latência e a Pastry-Salto}

A Tabela 6.5 apresenta a distribuição do planejamento de experimentos utilizada para avaliar as políticas BCR-Latência e Pastry-Salto.

Tabela 6.5: Projeto de Experimento

\begin{tabular}{|c|c|c|c|c|}
\hline Exp & Política de Roteamento & Tipo de Serviços & Quantidade de Usuários & RTT (s) \\
\hline 1 & BCR-Latência & Leve & 30 & 36,14 \\
\hline 3 & BCR-Latência & Pesado & 30 & 36,55 \\
\hline 5 & BCR-Latência & Leve & 60 & 37,59 \\
\hline 7 & BCR-Latência & Pesado & 60 & 38,03 \\
\hline 2 & Pastry-Salto & Leve & 30 & 40,58 \\
\hline 4 & Pastry-Salto & Pesado & 30 & 40,98 \\
\hline 6 & Pastry-Salto & Leve & 60 & 41,88 \\
\hline 8 & Pastry-Salto & Pesado & 60 & 42,35 \\
\hline
\end{tabular}

A Figura 6.15 apresenta os tempos para os intervalos de confianças dos experimentos realizados. Observa-se que os valores encontrados para a variável de resposta são menores quando se utiliza a política BCR-Latência. Isso ocorre independente do tipo de serviço ou da quantidade de usuários.

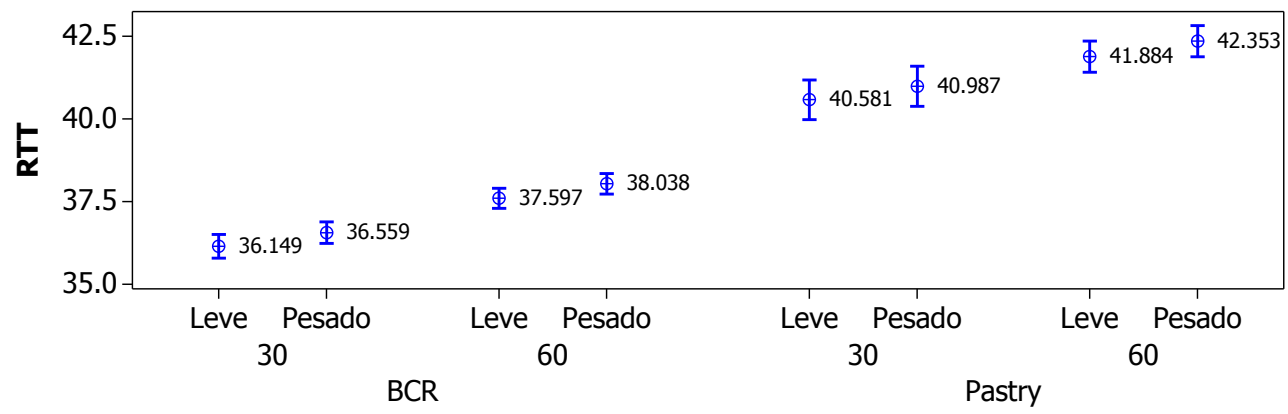

Figura 6.15: Intervalo de Confiança.

Os desvios padrão vistos na Figura 6.16 possuem caracterizações semelhantes para ambas políticas (BCR-Latência e Pastry-Salto). Além disso, entre os níveis abordados dos fatores, existe baixa variabilidade dos dados. 


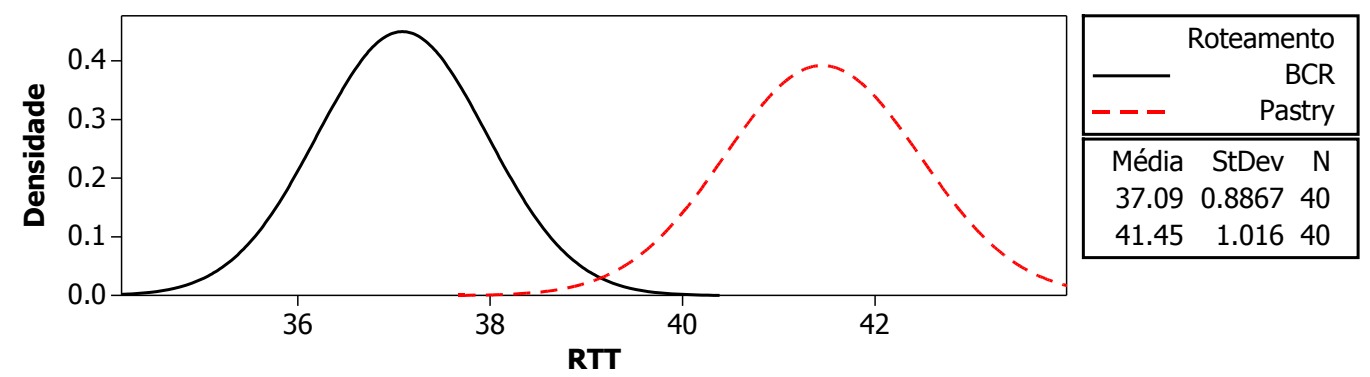

Figura 6.16: Histograma - RTT.

A Figura 6.17 mostra que não existem interações entre os fatores. Além disso, é possivel fazer a leitura de aumento da variável RTT quando os níveis são alterados. Isso ocorre porque as linhas crescem no sentido dos niveis mais baixos para os níveis mais altos.

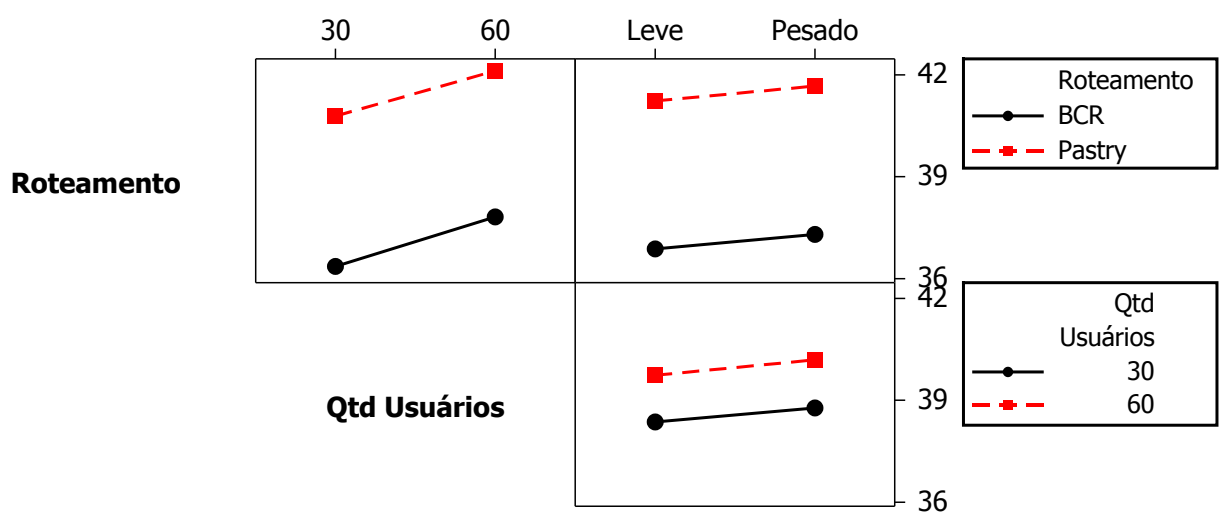

Tipo Serviço

Figura 6.17: Interação dos Fatores.

Por meio da Figura 6.18 nota-se que o fator que mais influência nesse experimento é a política de roteamento (A). Em seguida, é a quantidade de usuários o que mais influencia.

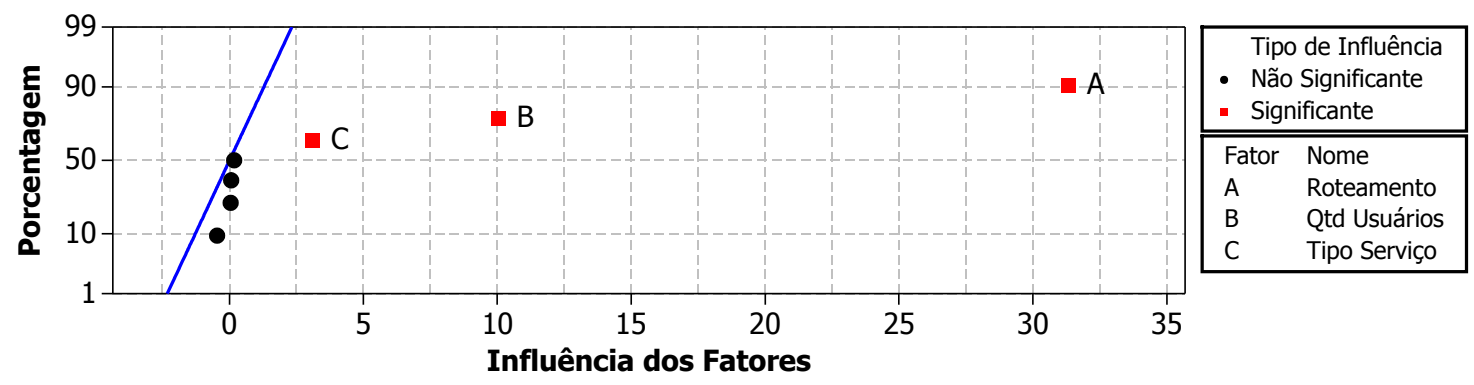

Figura 6.18: Interação dos Fatores. 


\subsection{Considerações sobre as Avaliações de Políticas de Rotea- mento}

Analisando-se os resultados observa-se que a Figura 6.19 apresenta a política BCR combinada à métrica Latência. Essa combinação possui os menores valores para o RTT. Essa política é baseada em força bruta para realizar a descoberta de serviços, sendo o tempo de descoberta desconsiderado; já que se admitiu que esse conhecimento estivesse previamente armazenado em uma base de dados.

Uma solução viável é utilizar políticas que possuam um número menor de iterações, apresentando tempos de resposta próximos do adequado. Esse é o caso da Chord-Latência, Figura 6.20, e da Pastry-Salto, Figura 6.21. A utilização de políticas baseadas em sistemas P2P proporciona escalabilidade e ainda promovem a estabilidade, garantindo variabilidade baixa entre os cenários ensaiados.

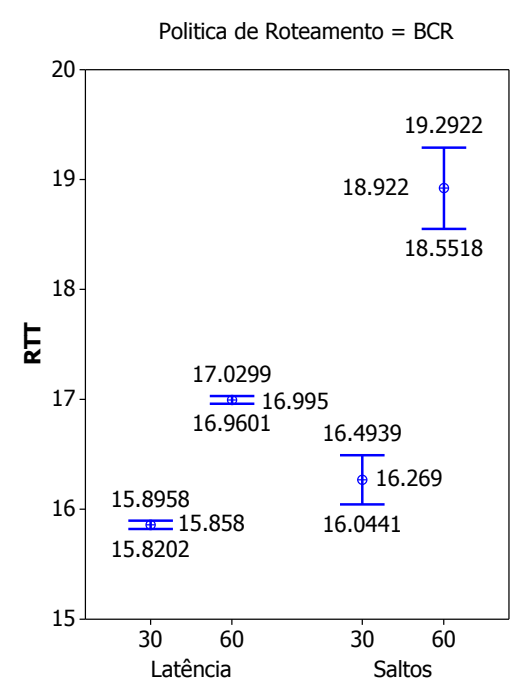

Figura 6.19: BCR.

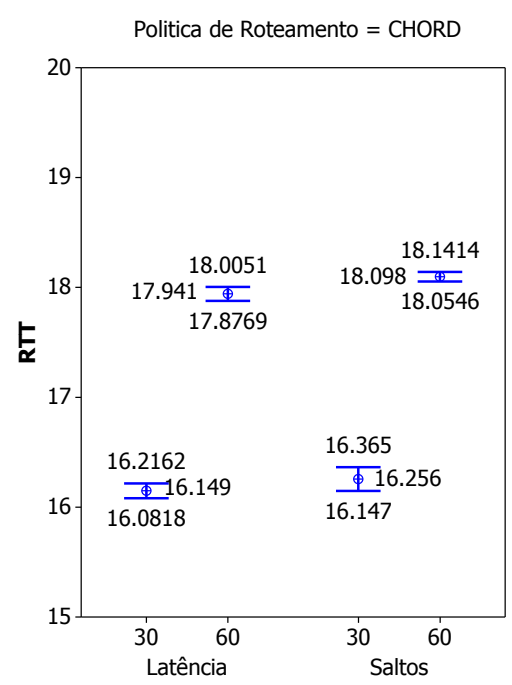

Figura 6.20: Chord.

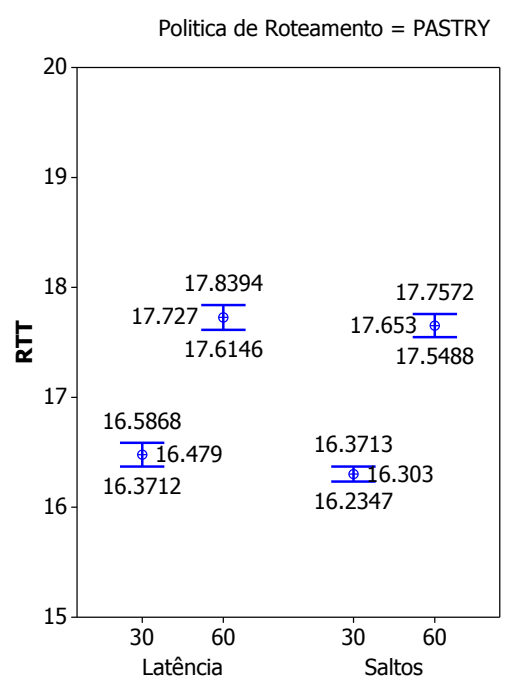

Figura 6.21: Pastry.

Outra informação importante a ser considerada está relacionada à sobrecarga do mecanismo de metaescalonamento. Durante os experimentos foram realizadas medições sobre o comportamento dos algoritmos de roteamento. Os resultados encontrados sobre a sobrecarga de cada algoritmo de roteamento podem ser vistos na Figura 6.22. Para o algoritmo Round Robin o tempo considerado é nulo e com ordem de complexidade igual a $O(1)$.

Como pode ser observado na Figura 6.22, a sobrecarga dos algoritmos está na ordem de milissegundos enquanto o tempo de processamento dos serviços está na ordem de segundos. Sendo assim, a sobrecarga dos algoritmos de roteamento pode ser considerada desprezível. 


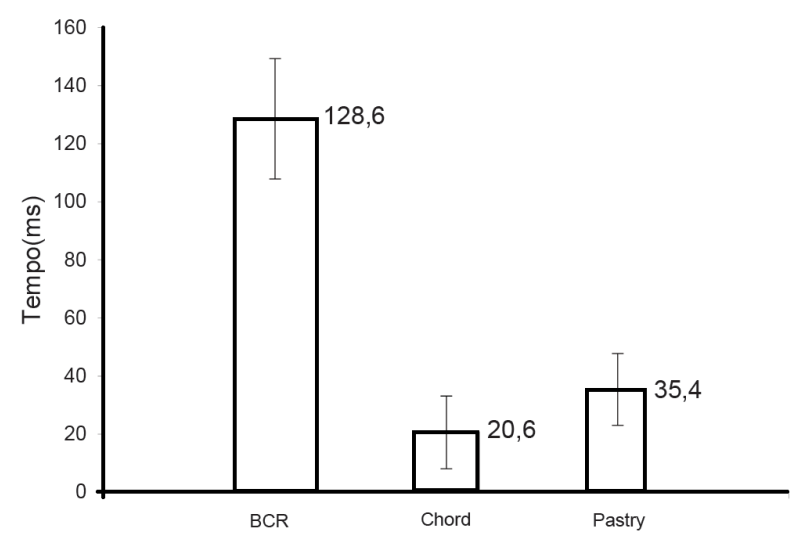

Figura 6.22: Sobrecarga dos Algoritmos de Roteamento.

\subsection{Considerações Finais}

De acordo com os resultados obtidos neste capítulo, pode-se observar que a política BCR-Latência (busca exaustiva) do MACC obtém os melhores resultados entre as políticas disponíveis. Entretanto, é observado que algoritmos que consideram busca exaustiva podem afetar a escalabilidade. Caso o número de data centers aumente consideravelmente, a sobrecarga pode ser um fator que cause problemas a política. Para resolver essa questão, os resultados apresentados neste trabalho mostram que as políticas Chord e Pastry podem ser consideradas, uma vez que os tempos de resposta obtidos para o Chord e para o Pastry são, no máximo, 8\% maiores que os obtidos na política BCR. Com relação a escolha entre as políticas Pastry e Chord tem-se que para cargas leves a política Chord é mais adequada e para cargas pesadas a política Pastry apresenta melhores resultados. Desta forma, a escolha entre essas políticas depende do tipo de carga considerada.

As políticas P2P tradicionais, Pastry e Chord, estão incorporadas no MACC. Os resultados mostram que com uma quantidade de iterações menor é possivel proporcionar uma qualidade de serviço similar a da política de busca exaustiva. Com relação a qual das políticas é mais adequada para o MACC, deve-se observar que com o modelo de comunicação do MACC pode-se adotar tipos diferentes de políticas de roteamento, o mais adequado seria considerar as três políticas que utilizam informação da rede avaliadas neste trabalho.

Como dito anteriormente, esse capítulo apresenta os resultados obtidos na primeira etapa de operações do MACC, que é a busca de um data center adequado para executar os serviços dos usuários. A segunda etapa do MACC é a responsável por realizar a alocação coordenada das máquinas virtuais e os seus resultados são descritos no próximo capítulo. 


\section{- \\ Avaliação da Alocação de Máquinas Virtuais}

\subsection{Considerações Iniciais}

Depois de realizada a descoberta e a distribuição do serviço dentro do ambiente Intercloud (etapa 1 do MACC), é necessária a alocação das máquinas virtuais que irão processar o serviço no data center. Para lidar com a alocação, o MACC possui implementado algoritmos de alocação de máquinas virtuais. Esses algoritmos são orientados a cumprirem três métricas. A primeira métrica é o tempo de resposta médio oferecido durante o processamento do serviço de um usuário. A segunda métrica é o Custo, determinando o preço a ser pago pelo serviço demandado. E a terceira métrica é a Confiabilidade e essa métrica está relacionada com a satisfação de um usuário sobre a prestração de um serviço.

O objetivo, na segunda etapa de operações do MACC, é alocar as máquinas virtuais de forma a não desperdiçar recursos físicos e financeiros. Esse é um problema considerado complexo, pois trata-se de uma questão multi-objetivo. Dessa forma, esse capítulo apresenta os resultados dos experimentos obtidos dos algoritmos de alocação de máquinas virtuais do MACC. Esses resultados são utilizados para determinar a eficiência dos algoritmos dentro do ambiente Intercloud.

\subsection{Preparação do Ambiente de Testes}

A presente investigação realizou experimentos com o simulador CloudSim (Calheiros et al., 2010). Este simulador coleta dados de desempenho de forma não intrusiva e foram adotados métodos estatísticos adequados para análise de tais dados. Considerando a necessidade de validar os resultados obtidos pelo MACC foi utilizada a técnica de 
planejamento de experimentos. Desse modo, dada a presença de várias variáveis do ambiente, cada experimento é executado dez vezes ${ }^{1}$ e, a partir dos resultados obtidos, obtém-se a média, o desvio padrão e é traçado o intervalo de confiança dos dados amostrais obtidos. As três principais métricas utilizadas pelo MACC, descritas no Capítulo 4, são:

- Tempo de Resposta Médio - (MRT - Mean Response Time) (segundos)

- Custo - (C - Cost) (\$)

- Confiabilidade - (R - Reliability) (\%)

Essas métricas são orientadas ao usuário. Em especial, existe a métrica confiabilidade. A confiabilidade está ligada a dependabilidade e ela cobre a maioria dos aspectos relacionados à satisfação de um usuário nesse contexto. Confiabilidade leva em consideração o tempo médio de resposta através do atendimento da variável deadline. Existem três classes com demandas diferentes por deadline de serviço. Todos os experimentos realizados, cada um desses usuários das três classes possui restrições temporais diferentes; O usuário A possui deadline de 10 segundos, o usuário B possui deadline de 25 segundos e o usuário C possui deadline de 40 segundos. Os usuários são distribuídos de forma igual entre as três classes. Dessa forma, a satisfação do usuário está diretamente proporcional ao tempo de resposta abaixo do tempo contratado.

Os principais fatores que influenciam as variáveis de resposta são:

A - Algoritmo de Alocação de Máquinas Virtuais do MACC - (RG, SD4c, PD2c, PDXc)².

B - Tipos de Serviços - (Leve ou Pesado).

C - Quantidade de usuários (30 e 60).

Com relação ao tipo de serviço, os dois cenários existentes são: Leve ou Pesado. O primeiro cenário, leve, consiste de uma carga de trabalho de web services, o qual é composto de vinte requisições que necessitam de baixa necessidade de processamento (tais como a recuperação de páginas web ou transações de negócios on-line). O segundo cenário, pesado, considera um tipo de aplicação que lida com vinte requisições de processamento intensivo, por exemplo, representando a utilização de Computação em Nuvens por aplicações científicas, por exemplo, a renderização de imagens. Com relação à quantidade de usuários, são utilizadas as mesmas redes elaboradas no Capítulo 6.

O modelo de simulação é composto por quinze data centers com mil hosts cada. Alguns pontos foram definidos como fatores fixos. Os fatores fixos são aqueles que a influência nos resultados não é considerada significativa, a Tabela 7.1 apresenta esses fatores.

Os experimentos serão realizados no formato "'dois-a-dois"' a partir do algoritmo de alocação por meio do planejamento fatorial $2^{k}$. Dessa forma será possível identificar o

\footnotetext{
${ }^{1}$ Dez vezes foi considerada uma quantidade adequada por causa da variação baixa encontrada entre os resultados de cada experimento.

${ }^{2}$ Esses algoritmos foram descritos no Capítulo 4
} 
Tabela 7.1: Fatores Fixos dos Experimentos

\begin{tabular}{|c|c|}
\hline Máquina & Valores \\
\hline Processador & Intel Quad 2 core \\
\hline Memória & 4 GB RAM \\
\hline Sistema Operacional & Ubuntu x64 10.04 \\
\hline Java & Cloudsim 2. 1.26 \\
\hline \hline Simulador & 15 \\
\hline Número de Data Centers & $16 \mathrm{~GB}$ \\
\hline Host_RAM & $1 \mathrm{~Gb}$ \\
\hline Host_Comunicação & BCR-Latência \\
\hline Política de Roteamento & 20 \\
\hline Tipo de Deadline & Baseada em Classe de Serviços \\
\hline Número de Serviço por Usuário & \\
\hline
\end{tabular}

melhor algoritmo ou os melhores algoritmos para cenários ensaiados. Os experimentos realizados são:

- Algoritmo SD4c $x$ Algoritmo RG

- Algoritmo PD2c $x$ Algoritmo RG

- Algoritmo PD2c $x$ Algoritmo SD4c

- Algoritmo PD2c $x$ Algoritmo PDXc

Além disso, foi utilizado o modelo fatorial completo, que mede cada uma das variáveis de resposta utilizando a combinação entre todos os níveis. Um planejamento fatorial completo para os $N$ fatores, com $k$ níveis, exige $N^{k}$ experimentos. Assim, nesse experimento, foram utilizados os seguintes fatores: Algoritmos de Alocação (A), Tipo de Serviços (B) e Quantidade de Usuários (C), produzindo a Tabela 7.2.

Tabela 7.2: Projeto de Experimento

\begin{tabular}{cccc}
\hline Exp & Algoritmo de Alocação & Tipo de Serviços & Quantidade de Usuários \\
\hline 1 & Alg_1 & Leve & 30 \\
2 & Alg_1 & Pesado & 30 \\
3 & Alg_1 & Leve & 60 \\
4 & Alg_1 & Pesado & 60 \\
5 & Alg_2 & Leve & 30 \\
6 & Alg_2 & Pesado & 30 \\
7 & Alg_2 & Leve & 60 \\
8 & Alg_2 & Pesado & 60 \\
\hline
\end{tabular}

Além desse formato, dois algoritmos por experimento, também é realizada de forma sintética um experimento que engloba todos os algoritmos, permitindo validar os resultados encontrados. 


\subsection{Avaliação das Políticas de Alocação do MACC}

De acordo com a metodologia proposta, os algoritmos de alocação de máquinas virtuais serão avaliados no formato "'dois a dois"'. Para cada conjunto de experimentos realizados serão demonstrados os resultados com os respectivos intervalos de confiança, estudo de influência dos fatores e as interações entre os fatores.

\subsubsection{Algoritmo SD4c X Algoritmo RG}

A Tabela 7.3 mostra a distribuição do planejamento de experimentos utilizada para avaliar as políticas SD4c e RG. É possivel ver na tabela as médias para o Tempo de Resposta Médio (MRT), Custo (C) e a Confiabilidade (Satisfação - R).

Tabela 7.3: Projeto de Experimento

\begin{tabular}{|c|c|c|c|c|c|c|}
\hline Exp & Algoritmo & Tipo de Serviços & Qtd de Usuários & MRT (s) & C (\$) & R (\%) \\
\hline 1 & SD4C & Leve & 30 & 11,24 & 409 & 72,55 \\
\hline 3 & SD4C & Pesado & 30 & 25,98 & 3219 & 45,93 \\
\hline 5 & SD4C & Leve & 60 & 11,14 & 176 & 71,82 \\
\hline 7 & SD4C & Pesado & 60 & 26,02 & 1158 & 43,70 \\
\hline 2 & RG & Leve & 30 & 9,81 & 10247 & 88,25 \\
\hline 4 & RG & Pesado & 30 & 43,42 & 11274 & 37,02 \\
\hline 6 & RG & Leve & 60 & 9,55 & 4467 & 88,53 \\
\hline 8 & RG & Pesado & 60 & 41,91 & 4896 & 39,27 \\
\hline
\end{tabular}

\section{Tempo Médio de Resposta}

De acordo com a Figura 7.1, é possível notar que o MRT para 30 usuários e para 60 usuários possuem resultados equivalentes. Embora o tempo total de resposta seja maior quando o ambiente possui 60 usuários, considerando o intervalo de confiança médio tem-se os valores estatisticamente iguais. Outra informação relevante é a inversão dos menores tempos apresentados pelos algoritmos quando o ambiente é alterado de serviços leves para serviços pesados. Assim, o algoritmo SD4c apresenta os resultados menores de MRT quando a carga imposta ao sistema é maior.

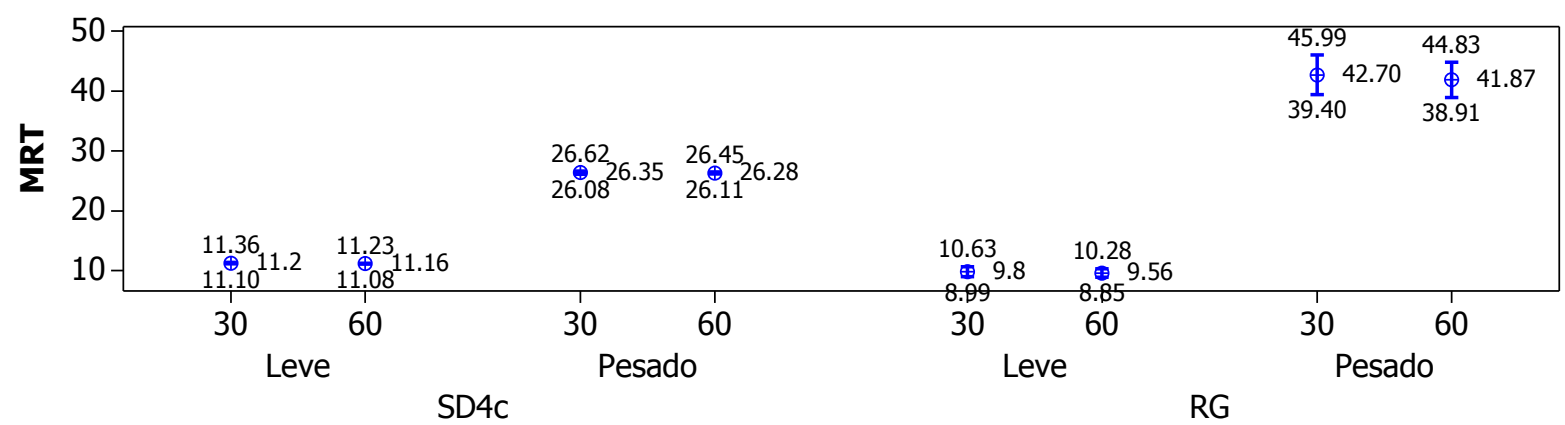

Figura 7.1: Intervalo de Confiança - Tempo de Resposta Médio. 
A Figura 7.2 considera a influência dos fatores sobre a MRT. É possivel notar que o fator Tipo de Serviço (B) é o que mais influência esse experimento para os algoritmos SD4c e RG. O fator B está mais distante da curva da normal a direita, significando que o MRT aumenta à medida que a carga de trabalho imposta ao sistema aumenta. Além disso, o fator algoritmo (A) e a interação entre os fatores (AB) também são responsáveis por determinar o MRT encontrado nesses experimentos.

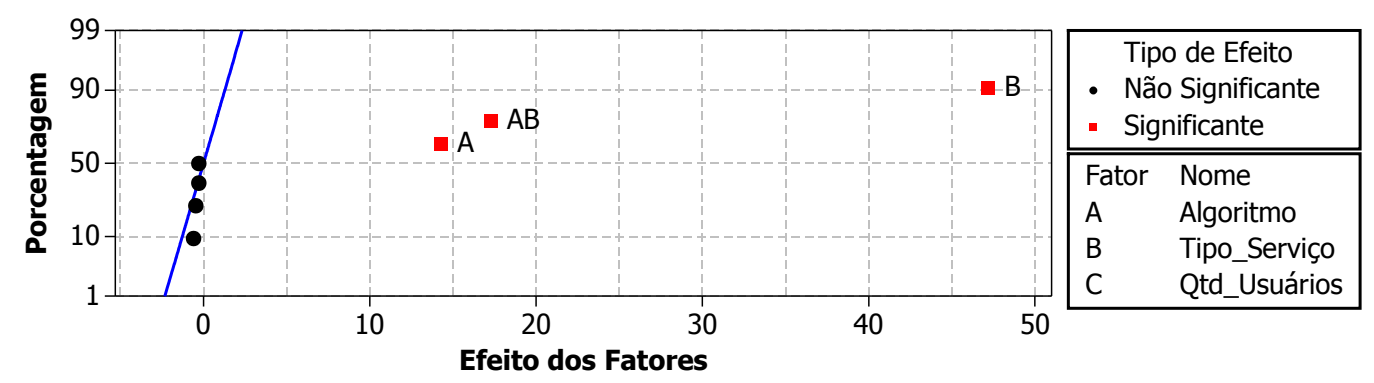

Figura 7.2: Influência dos Fatores - Tempo de Resposta Médio.

Os principais efeitos dos fatores sobre a MRT podem ser visto na Figura 7.3. Observa-se que o algoritmo SD4c influencia mais o MRT, obtendo menores resultados. O Efeito causado pelo fator B com peso maior também eleva o MRT. Entretanto, a quantidade de usuários, fator $\mathrm{C}$, não causa efeito sobre o MRT. Esse fato acontece porque, entre os experimentados realizados, o data center não alcança o nível de sobrecarregado.

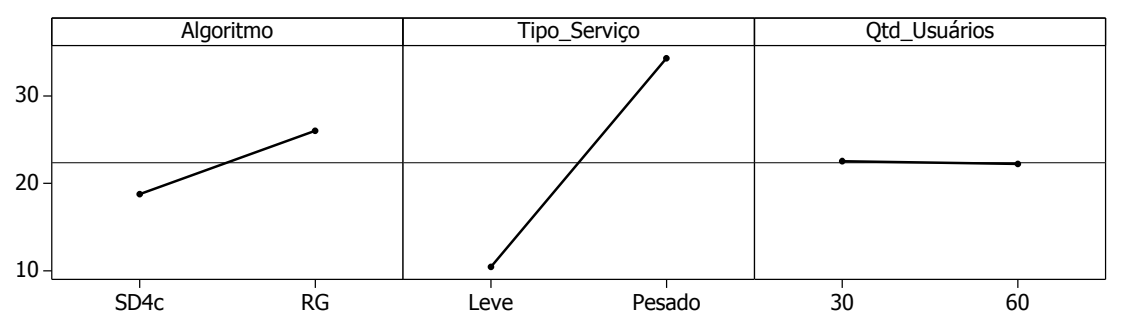

Figura 7.3: Principais Efeitos - Tempo de Resposta Médio.

A interação entre os fatores pode ser vista na Figura 7.4. Quando o tipo de serviço passa de leve para pesado ambos os algoritmos tem o MRT acrescidos, apesar do SD4c apresentar um acréscimo menor do que o RG para o caso de serviços pesados. Essa relação leva a identificação de um efeito de interação entre A e B sobre o MRT. As demais interações não são significativas.

\section{Custo}

De acordo com a Figura 7.5, é possivel notar o mesmo comportamento do MRT para o Custo, cujo ambiente com 30 usuários e 60 usuários apresentam resultados estatisticamente iguais. Essa consideração se deve ao fato da média de um experimento ser projetada dentro do intervalo de confiança do outro experimento. Observa-se que o algoritmo RG pratica custos elevados comparados aos custos do algoritmo SD4c. 


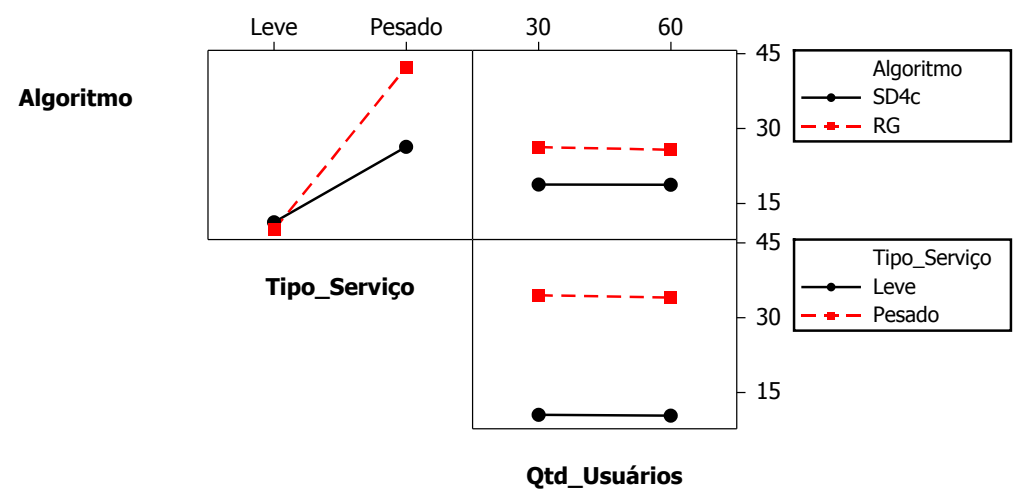

Figura 7.4: Interação entre os Fatores - Tempo de Resposta Médio.

Esse tipo de comportamento do algoritmo RG é porque ele não leva em consideração as necessidades do usuário, alocando recursos de forma aleatória.

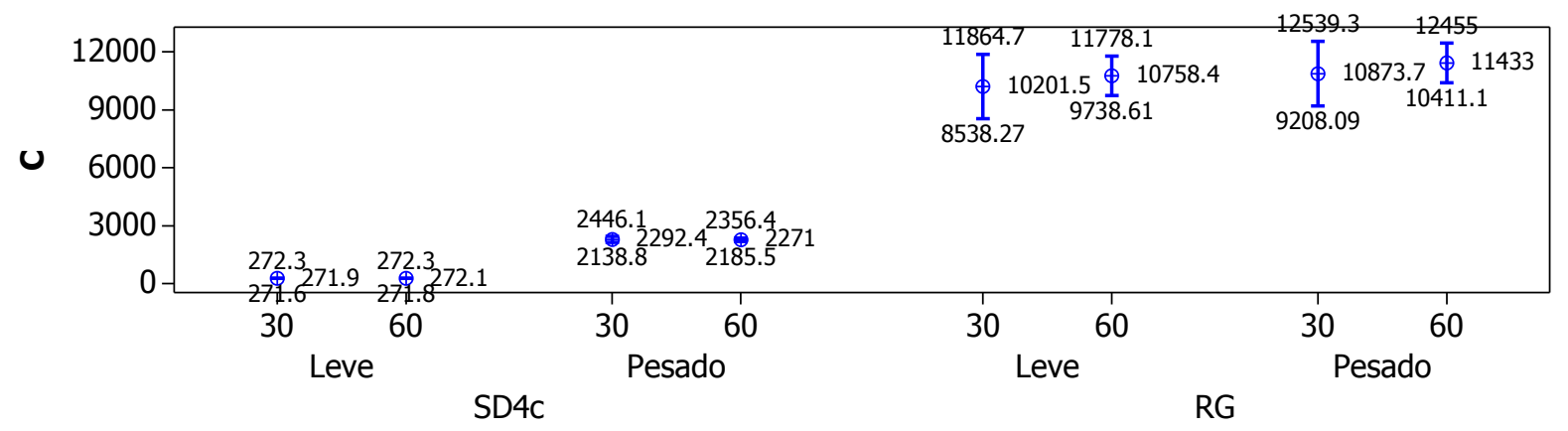

Figura 7.5: Intervalo de Confiança - Custo.

A Figura 7.6 considera a influência dos fatores sobre o Custo. O fator que mais influencia o Custo, nesse experimento, é o algoritmo (A), pois é o algoritmo quem determina a quantidade de recursos necessários a ser alocado para o usuário processar o serviço.

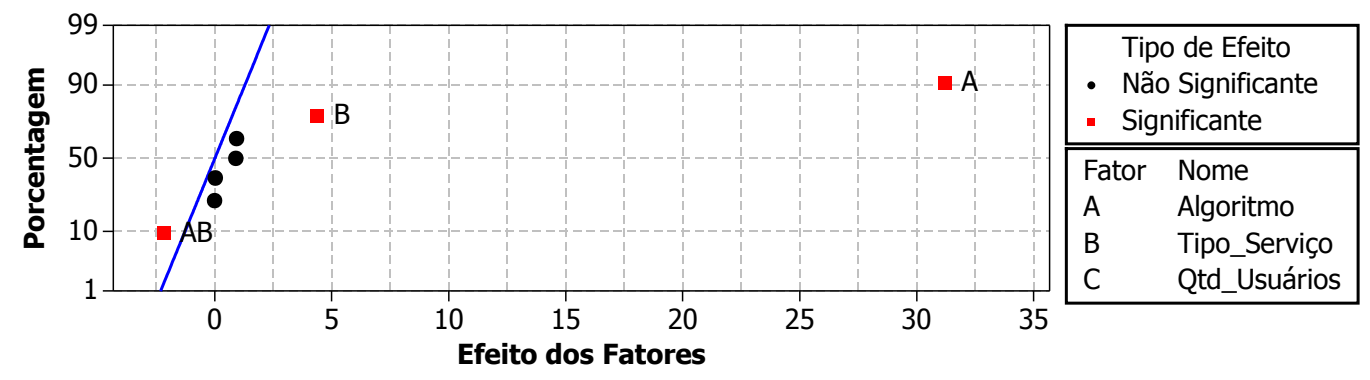

Figura 7.6: Influência dos Fatores - Custo.

Os principais efeitos dos fatores sobre o Custo são apresentados na Figura 7.7. Observa-se que o algoritmo SD4c possui os custos menores dos que os praticados pelo algoritmo RG. Isso é porque o RG cria as máquinas virtuais com a configuração aleatória, desperdiçando dinheiro e por vezes recursos também. Como esperado, o tipo de serviço 
leve possui o custo médio menor. Sobre a quantidade de usuários (C), observa-se que na média o custo é semelhante tanto para 30 usuários quanto 60 usuários.

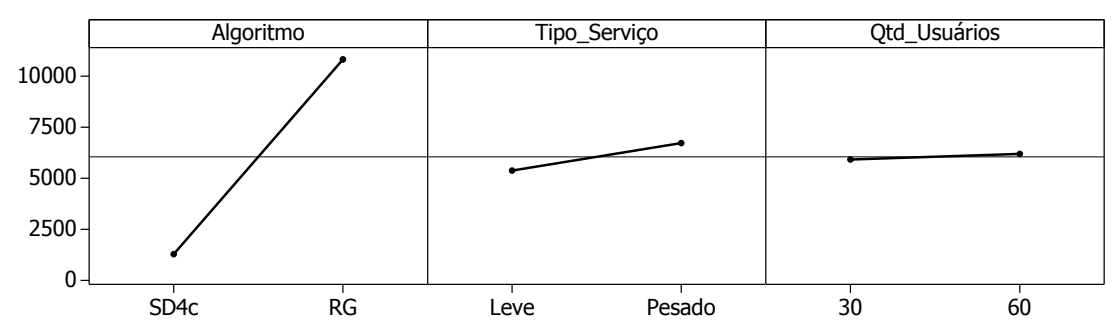

Figura 7.7: Principais Efeitos - Custo.

A Figura 7.8 mostra a interação entre os fatores e sua influência sobre o Custo. As retas A e B, representando os fatores, não estão em paralelo, configurando assim uma interação entre os fatores A e B. Essa interação não é significativa para exercer influência sobre o Custo.

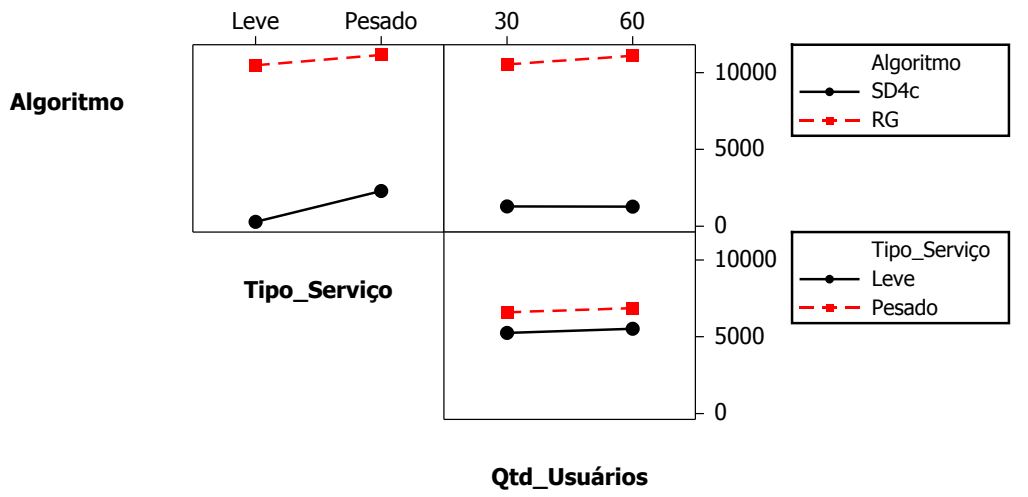

Figura 7.8: Interação entre os Fatores - Custo.

\section{Confiabilidade}

É possível notar, de acordo com a Figura 7.9, o mesmo comportamento sobre os resultados com o ambiente com 30 usuários e 60 usuários, considerando a média dos resultados. Observa-se que ambos os algoritmos, SD4c e RG, não conseguem manter a Confiabilidade do sistema em um nível desejado quando o tipo de serviço é o pesado. Dessa forma, os algoritmos se tornam instáveis às mudanças de cargas do sistema, comprometendo a satisfação do usuário.

A influência dos fatores sobre a Confiabilidade é apresentada na Figura 7.10. Nesse experimento, o principal fator a ser considerado para obter Confiabilidade e, portanto, a satisfação do usuário é o tipo de serviço (B). O fator B se apresenta a esquerda da linha da normal, e à medida que o tipo de serviço passa a apresentar uma carga mais pesada a tendência é que a Confiabilidade diminua.

A Figura 7.11 apresenta os principais efeitos dos fatores sobre a Confiabilidade. Comparando os dois algoritmos SD4c e RG, o algoritmo RG é o que possui os melhores resultados médios com relação a Confiabilidade fornecida. Porém, esse resultado deve 


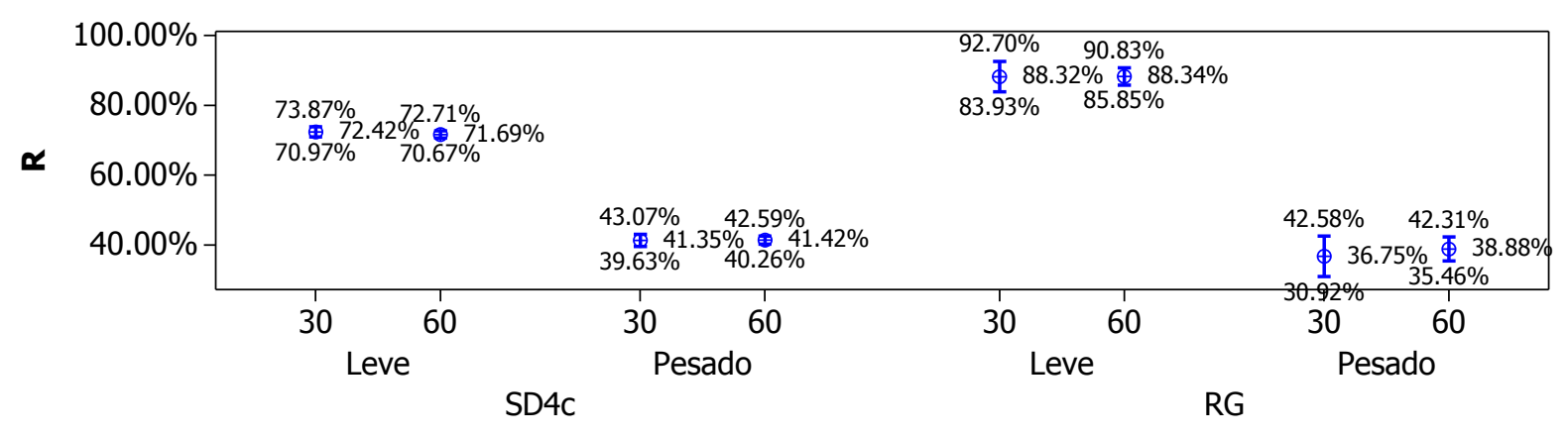

Figura 7.9: Intervalo de Confiança - Confiabilidade.

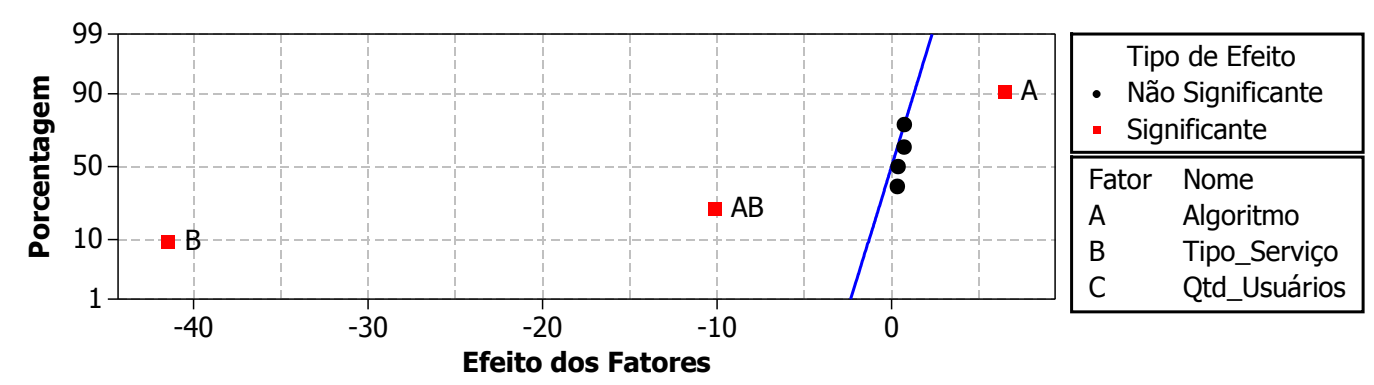

Figura 7.10: Influência dos Fatores - Confiabilidade.

ser comparado juntamente com os custos empregados, concluindo que os custos do algoritmo RG foram muito superiores para obter tais resultados.

Analisando o fator tipo de serviço da Figura 7.11 é possível observar que o aumento da carga leva a uma degradação da variável de resposta Confiabilidade.

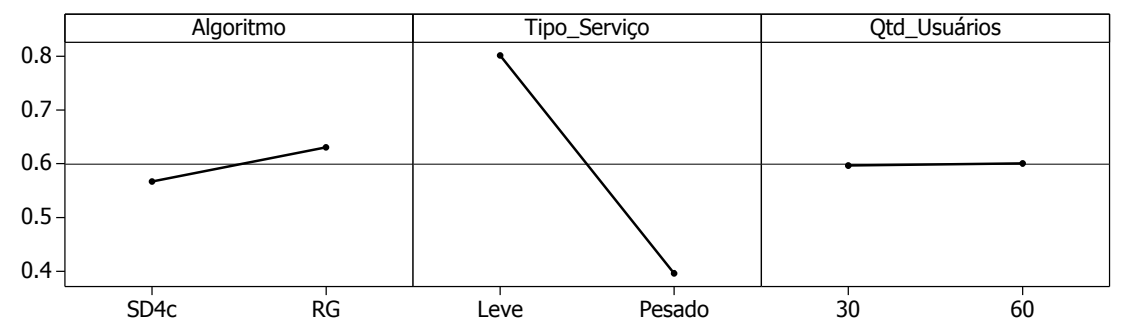

Figura 7.11: Principais Efeitos - Confiabilidade.

A interação entre os fatores e a influência dessa interação sobre a Confiabilidade podem ser vistas na Figura 7.12. Como as linhas estão fortemente inclinadas e ainda não paralelas, considera-se nessa situação, que há uma influência da interação (AB) sobre a métrica Confiabilidade.

\section{Análise do Comportamento das Políticas SD4c e RG}

A Figura 7.13 permite comparar os valores médios para as três variáveis de resposta. Sobre os valores encontrados para o MRT, observa-se que tanto o algoritmo SD4c quanto o RG apresentam uma média maior quando o tipo de serviço passar a ser pesado. Esse comportamento não é o mais desejado, pois se espera que o algoritmo seja estável 


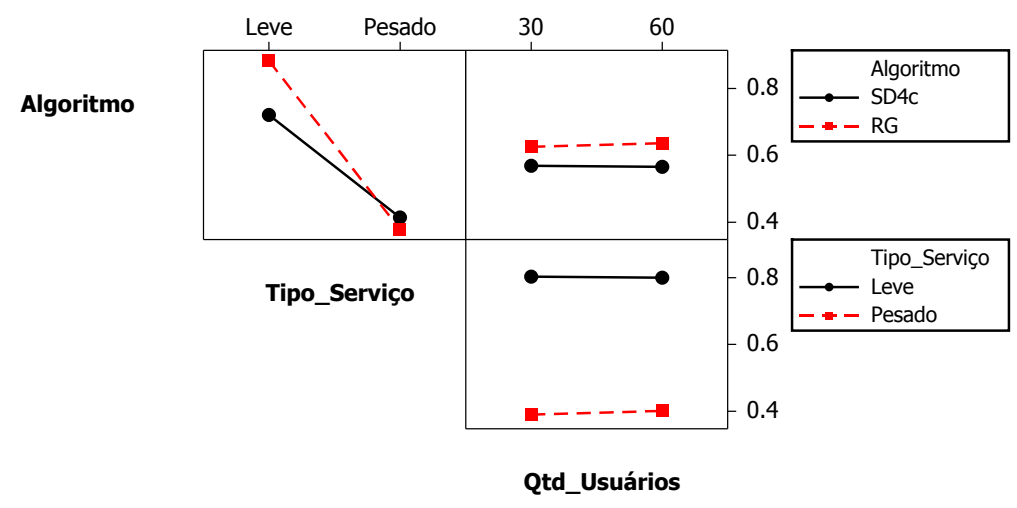

Figura 7.12: Interação entre os Fatores - Confiabilidade.

independente da carga imposta. Já a relação de quantidade de usuário não interfere nos resultados encontrados para a variável de resposta MRT. Essa característica ocorre pois são consideradas as médias dos valores. O mesmo comportamento com a MRT é visto para o Custo, nesse caso já esperado, pois à medida que se aumenta o processamento também se aumenta o custo por recurso.

Quanto a Confiabilidade, Figura 7.13, observa-se que para os serviços leves o algoritmo RG possui melhores resultados, com relação a satisfação do usuário. Contudo, esse resultado é comprometido pela enorme quantia adquirida de recursos. De maneira geral, o algoritmo RG aloca mais recursos do que o necessário, desperdiçando tanto recursos quanto dinheiro.
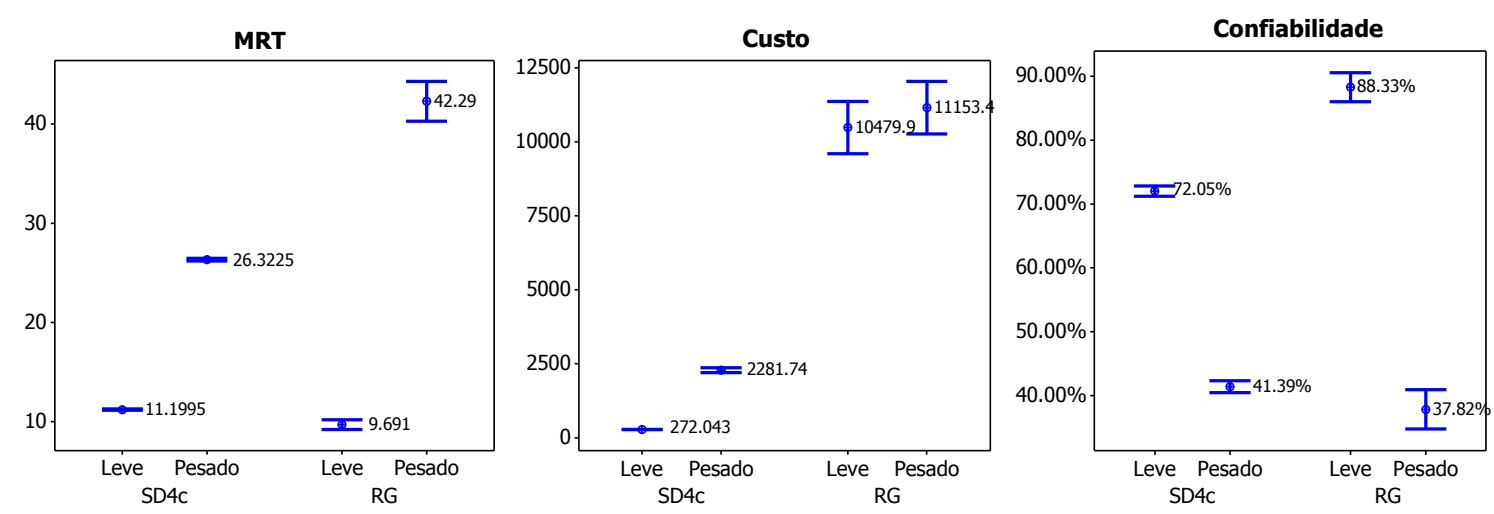

Figura 7.13: Intervalo de Confiança.

Observou-se que o algoritmo RG possui MRT menor do que o SD4c para cargas leves, esse tempo foi aproximadamente 13\% menor, mas a um custo 38 vezes maior. O mesmo ocorre em termos de confiabilidade, em que o algoritmo RG foi $16 \%$ melhor mas a um custo maior. Assim, o algoritmo RG só seria interessante nos casos em que a Confiabilidade fosse um parâmetro crucial. Caso contrário, os resultados obtidos para o SD4c são mais atrativos. 


\subsubsection{Algoritmo PD2c X Algoritmo RG}

A Tabela 7.4 mostra a distribuição do planejamento de experimentos utilizada para avaliar as políticas PD2c e RG. É possível ver na tabela as médias para o Tempo de Resposta Médio (MRT), Custo (C) e a Confiabilidade (Satisfação - R).

Tabela 7.4: Projeto de Experimento

\begin{tabular}{|c|c|c|c|c|c|c|}
\hline Exp & Algoritmo & Tipo de Serviços & Qtd de Usuários & MRT (s) & C (\$) & R (\%) \\
\hline 1 & PD2C & Leve & 30 & 11,31 & 358 & 99,55 \\
\hline 3 & PD2C & Pesado & 30 & 22,08 & 2801 & 85,38 \\
\hline 5 & PD2C & Leve & 60 & 11,22 & 154 & 99,81 \\
\hline 7 & PD2C & Pesado & 60 & 21,88 & 1243 & 86,76 \\
\hline 2 & RG & Leve & 30 & 9,81 & 10247 & 88,25 \\
\hline 4 & RG & Pesado & 30 & 43,42 & 11274 & 37,02 \\
\hline 6 & RG & Leve & 60 & 9,55 & 4467 & 88,53 \\
\hline 8 & RG & Pesado & 60 & 41,91 & 4896 & 39,27 \\
\hline
\end{tabular}

\section{Tempo Médio de Resposta}

É possivel notar, de acordo com a Figura 7.14, que o comportamento do experimento, para 30 ou 60 usuários, apresenta resultados equivalentes; dadas as configurações serem realizadas em torno de uma média. Outra informação relevante é a inversão dos menores tempos apresentados pelos algoritmos quando o ambiente é alterado de serviços leves para serviços pesados. O algoritmo PD2c reage melhor as mudanças de cargas apresentando resultados menores para o MRT.

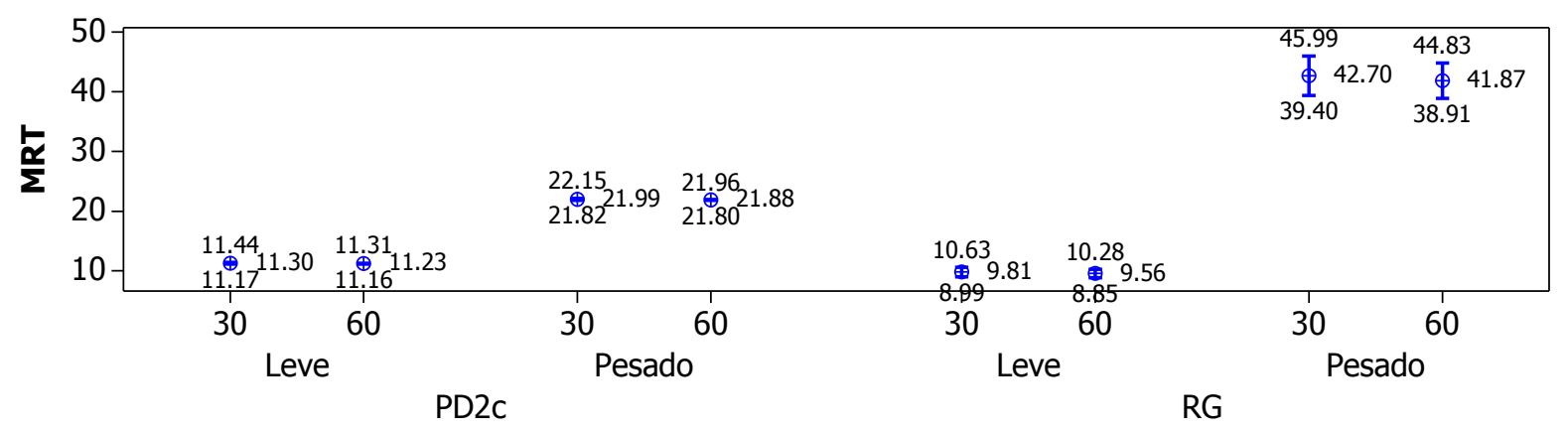

Figura 7.14: Intervalo de Confiança - Tempo de Resposta Médio.

O Tipo de Serviço (B) é o fator que mais influencia o experimento apresentado na Figura 7.15. O fator B está mais distante da curva da normal à direita, significando que o MRT aumenta à medida que a carga de trabalho aumenta, por causa do comportamento desses algoritmos ensaiados. Além disso, o fator algoritmo (A) e a interação entre os fatores $(\mathrm{AB})$ também são responsáveis por determinar o MRT encontrado nesses experimentos.

Através dos efeitos dos fatores vistos na Figura 7.16, é possível dizer que o algoritmo PD2c possui o MRT menor do que o RG. Ressalta-se que não há mudança nos valores de 


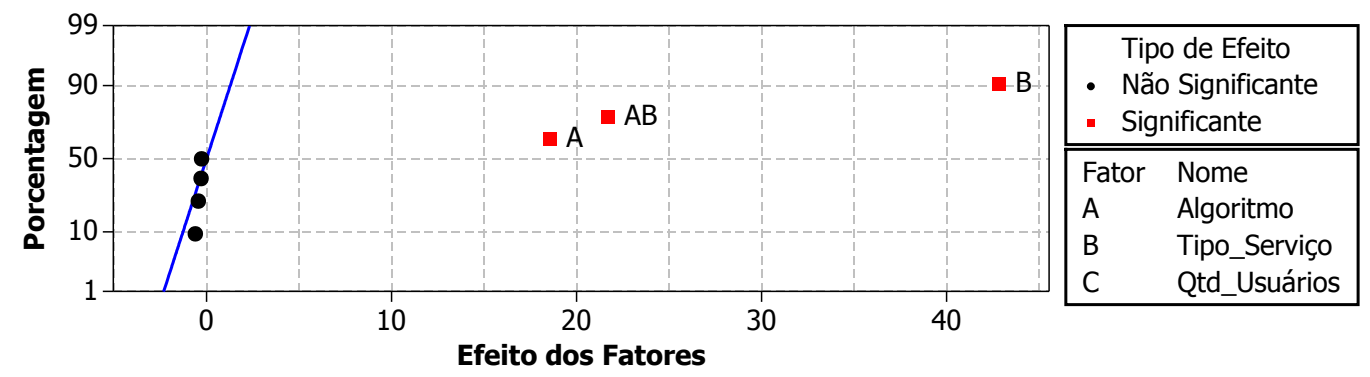

Figura 7.15: Influência dos Fatores - Tempo de Resposta Médio.

MRT quando o número de usuários cresce porque a variável de resposta MRT é composta por valores médios.

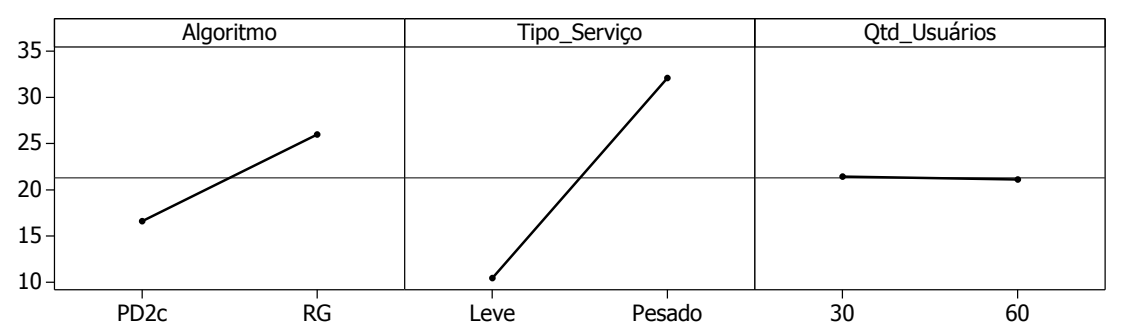

Figura 7.16: Principais Efeitos - Tempo de Resposta Médio.

A Figura 7.17 mostra a interação entre os fatores e a influência que essa interação exerce sobre o MRT. Como as linhas estão fortemente inclinadas e ainda não paralelas no caso Algoritmos e Tipo de Serviço, considera-se nessa situação, uma influência que interação (AB) exerce sobre o MRT. Entretanto, as demais interações de fatores não são significativas.

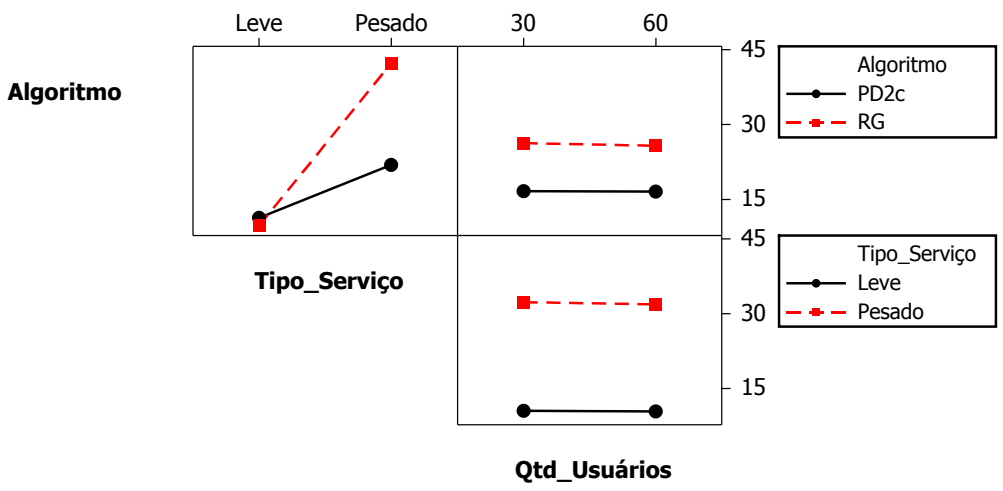

Figura 7.17: Interação entre os Fatores - Tempo de Resposta Médio.

\section{Custo}

É possivel observar na Figura 7.18 que os custos praticados em média pelo algoritmo PD2c são 10 vezes menores do que os praticados pelo algoritmo RG. Esse tipo de 
informação é relevante já que a alocação desordenada de recursos não representa MRT menores.

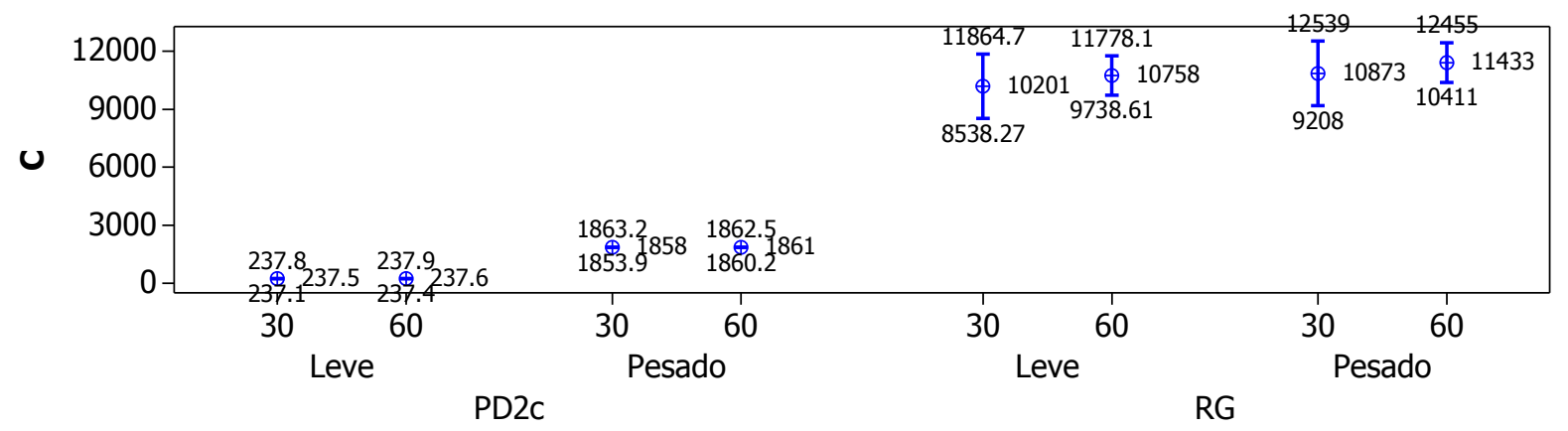

Figura 7.18: Intervalo de Confiança - Custo.

O algoritmo (A), de acordo com a Figura 7.19 é o fator que mais influencia o Custo. O algoritmo determina a quantidade de recursos alocados para a criação da máquina virtual. A combinação entre a quantidade e a configuração estabelecida para as máquinas virtuais formam o custo médio final. O tipo de serviço (B) apresenta pequena influência no experimento. Sendo assim, deduz-se que o custo médio praticado depende mais do algoritmo do que da carga imposta ao sistema.

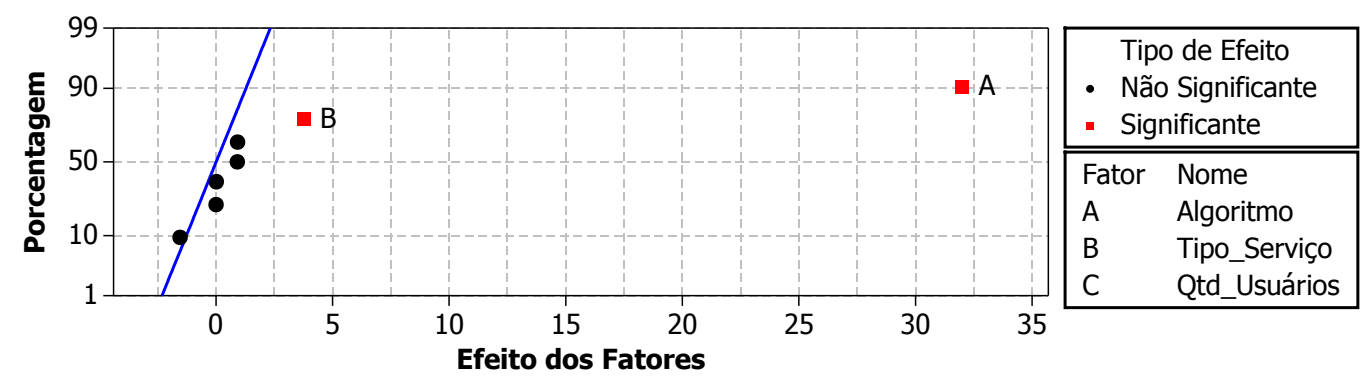

Figura 7.19: Influência dos Fatores - Custo.

A Figura 7.20 mostra que existe uma inclinação alta da linha de PD2c para RG, indicando que o algoritmo RG pratica maiores gastos do que o algoritmo PD2c. É possível notar que o tipo de serviço exerce mudança nos custos praticados, elevando seus valores para o caso de tipo de serviços mais pesados.

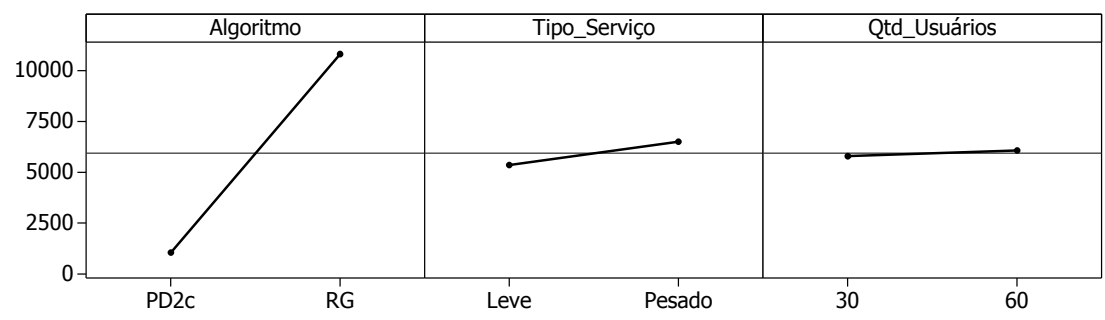

Figura 7.20: Principais Efeitos - Custo.

A Figura 7.21 mostra que não há interações significativas entre os fatores para que exerçam influência na variável de resposta Custo. 


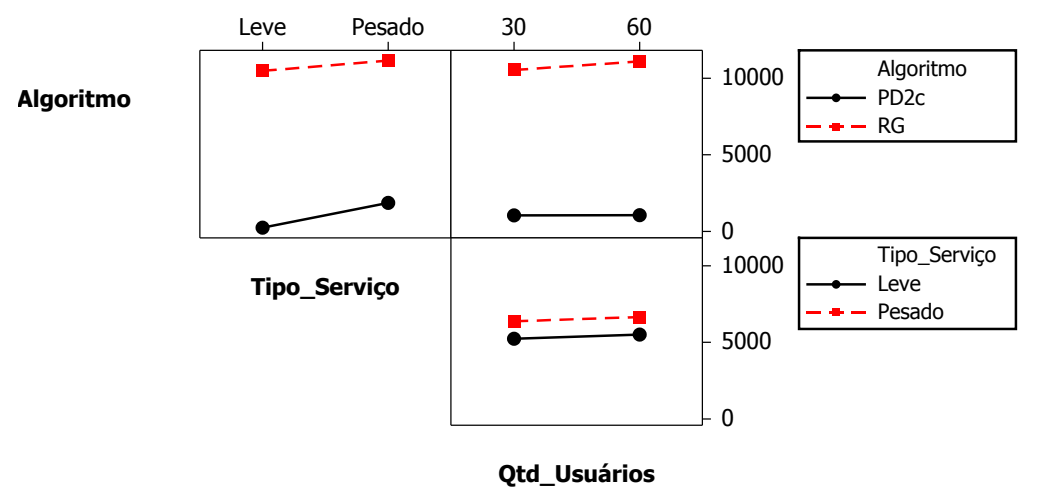

Figura 7.21: Interação entre os Fatores - Custo.

\section{Confiabilidade}

Com relação a satisfação do usuário, medida pela variável Confiabilidade, é possível notar que o algoritmo PD2c possui os melhores resultados. Esse comportamento fica mais visivel quando a carga imposta ao sistema é pesada, apresentando o algoritmo PD2c cerca de $100 \%$ de Confiabilidade a mais comparado ao algoritmo RG.

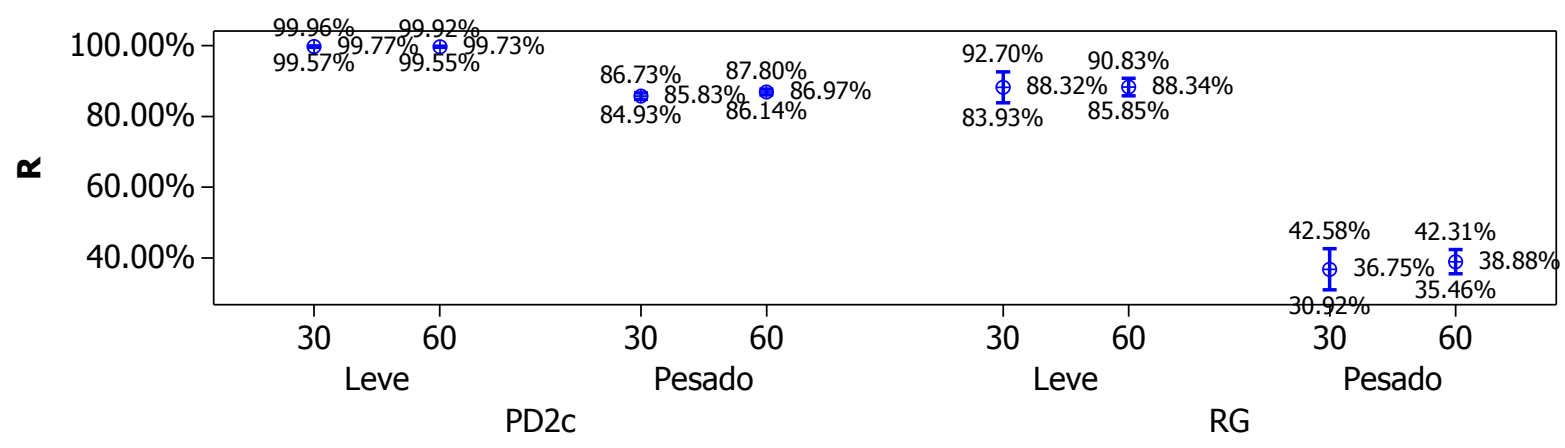

Figura 7.22: Intervalo de Confiança - Confiabilidade.

De acordo com a Figura 7.23, os fatores mais distantes da linha da normal são: tipo de serviço (B) e algoritmo (A). Esses dois fatores são os que mais influenciam, nesse experimento, a variável de resposta Confiabilidade, indicando que a satisfação do usuário está diretamente proporcional à carga imposta ao sistema e o algoritmo utilizado. O fator B encontra-se a esquerda da linha da normal; isso indica que o aumento da carga leva a diminuição da média encontrada para a Confiabilidade do sistema.

$\mathrm{O}$ algoritmo RG apresenta piores resultados comparados ao algoritmo PD2c, como pode ser visto na Figura 7.24. Além da Confiabilidade cair quando o algoritmo RG é utilizado, o tipo de serviço também exerce influência levando a diminuição da Confiabilidade.

A interação entre os fatores algoritmo (A) e tipo de serviço (B) leva a uma considerável influência sobre a variável de resposta Confiabilidade. Apesar de ambos os algoritmos terem uma queda da satisfação do usuário quando o tipo de serviço é pesado, é o algoritmo RG que tem a queda mais íngreme, apontando a uma interação (AB). 


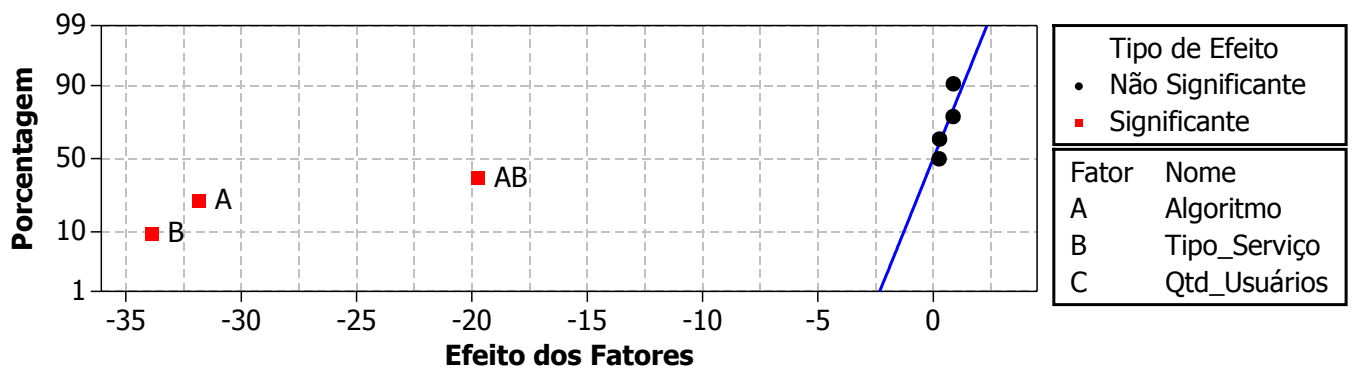

Figura 7.23: Influência dos Fatores - Confiabilidade.

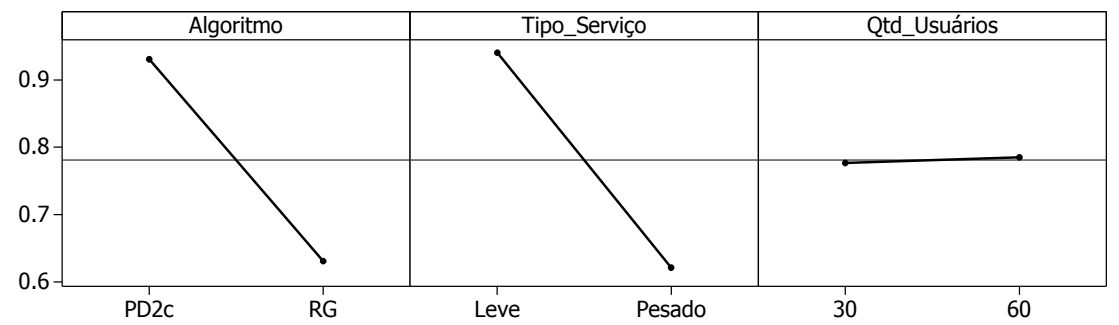

Figura 7.24: Principais Efeitos - Confiabilidade.

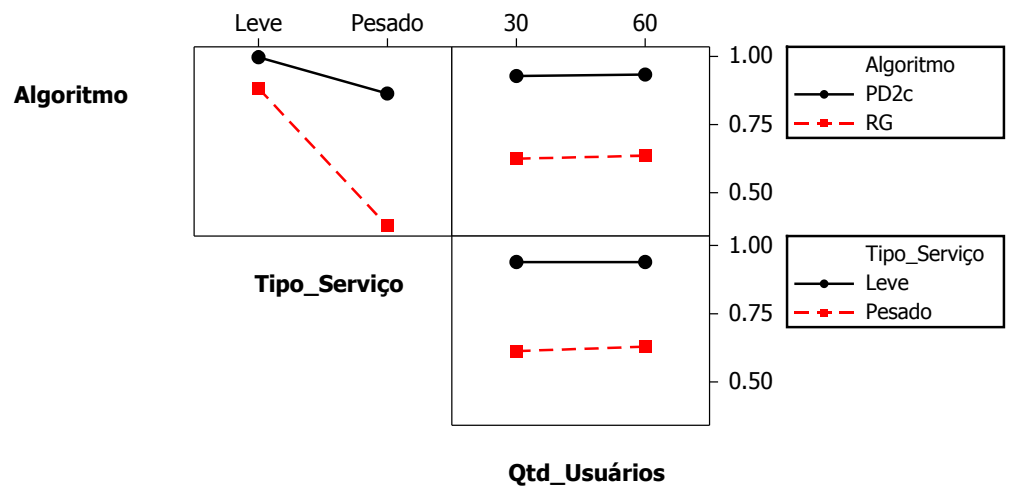

Figura 7.25: Interação entre os Fatores - Confiabilidade.

\section{Análise do Comportamento das Políticas PD2c e RG}

Analisando o comportamento de ambos os algoritmos, PD2c e RG vistos na Figura 7.26, verifica-se que apesar de ter gastos excessivos, com recursos o nível de Confiabilidade do algoritmo RG permanece abaixo do PD2c. Dessa forma, pode-se afirmar que apesar de gastar menos o algoritmo PD2c obtém resultados satisfatórios com relação a Confiabilidade do sistema em cumprir os requisitos temporais, ou seja, de prestar o serviço abaixo da deadline imposta pelo usuário.

A quantidade de usuários não interfere nos resultados encontrados para a variável de resposta MRT. Essa característica ocorre pois são consideradas as médias dos valores.

Observou-se que o algoritmo RG possui tempos de respostas menores do que o PD2c para cargas leves, similar à comparação RG e SD4c realizada anteriormente. O algoritmo RG apresenta um MRT 14\% menor do que PD2c, porém a um custo 44 vezes maior. Porém, mesmo com MRT menores e com custos maiores o RG é 11\% pior com relação a 

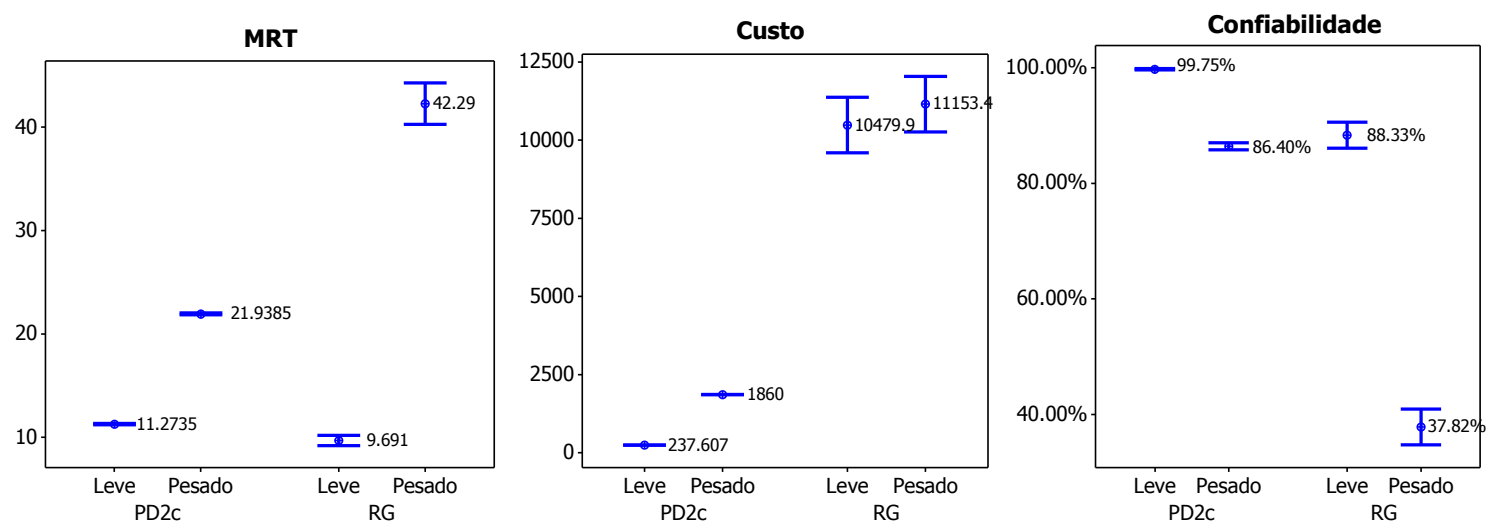

Figura 7.26: Intervalo de Confiança.

Confiabilidade. Isso acontece porque o RG pode apresentar baixos valores para MRT, já que é considerada a média, porém, quando analisados os usuários de forma individual os seus contratos podem ter sidos violados.

\subsubsection{Algoritmo PD2c X Algoritmo SD4c}

A Tabela 7.5 mostra a distribuição do planejamento de experimentos utilizada para avaliar as políticas PD2c e SD4c. É possível ver na tabela as médias para o Tempo de Resposta Médio (MRT), Custo (C) e a Confiabilidade (Satisfação - R).

Tabela 7.5: Projeto de Experimento

\begin{tabular}{|c|c|c|c|c|c|c|}
\hline Exp & Algoritmo & Tipo de Serviços & Qtd de Usuários & MRT (s) & C (\$) & R (\%) \\
\hline 1 & PD2C & Leve & 30 & 11,31 & 358 & 99,55 \\
\hline 3 & PD2C & Pesado & 30 & 22,08 & 2801 & 85,38 \\
\hline 5 & PD2C & Leve & 60 & 11,22 & 154 & 99,81 \\
\hline 7 & PD2C & Pesado & 60 & 21,88 & 1243 & 86,76 \\
\hline 2 & SD4C & Leve & 30 & 11,24 & 409 & 72,55 \\
\hline 4 & SD4C & Pesado & 30 & 25,98 & 3219 & 45,93 \\
\hline 6 & SD4C & Leve & 60 & 11,14 & 176 & 71,82 \\
\hline 8 & SD4C & Pesado & 60 & 26,02 & 1158 & 43,70 \\
\hline
\end{tabular}

\section{Tempo Médio de Resposta}

Os algoritmos PD2c e SD4c, mostrados na Figura 7.27, possuem MRTs estatisticamente iguais quando a carga do sistema é definida pelos serviços leves. Contudo, quando a carga do sistema passa de leve para pesado, é o algoritmo PD2c que possui os menores tempos médios de resposta (MRT).

A influência dos fatores sobre a MRT é mostrada na Figura 7.28. Nota-se que o fator tipo de serviço (B) é o que mais influencia esse experimento. O fator B está mais distante da linha da normal à direita, significando que o MRT aumenta à medida que a carga de 


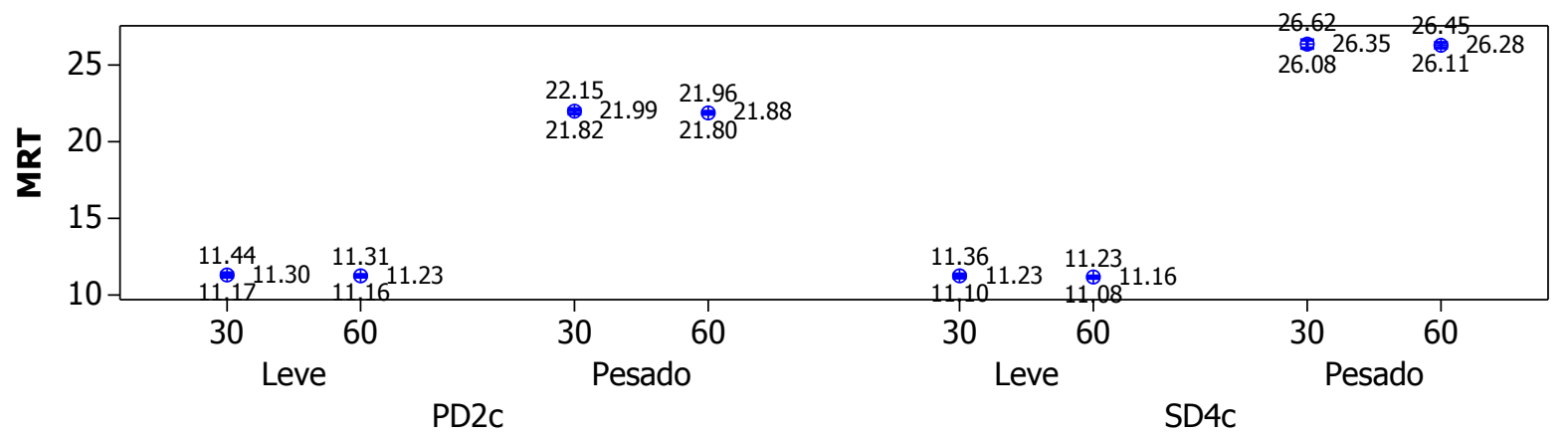

Figura 7.27: Intervalo de Confiança - Tempo de Resposta Médio.

trabalho aumenta. Além disso, o fator algoritmo (A) e a interação entre os fatores (AB) também são responsáveis por determinar o MRT encontrado nesses experimentos.

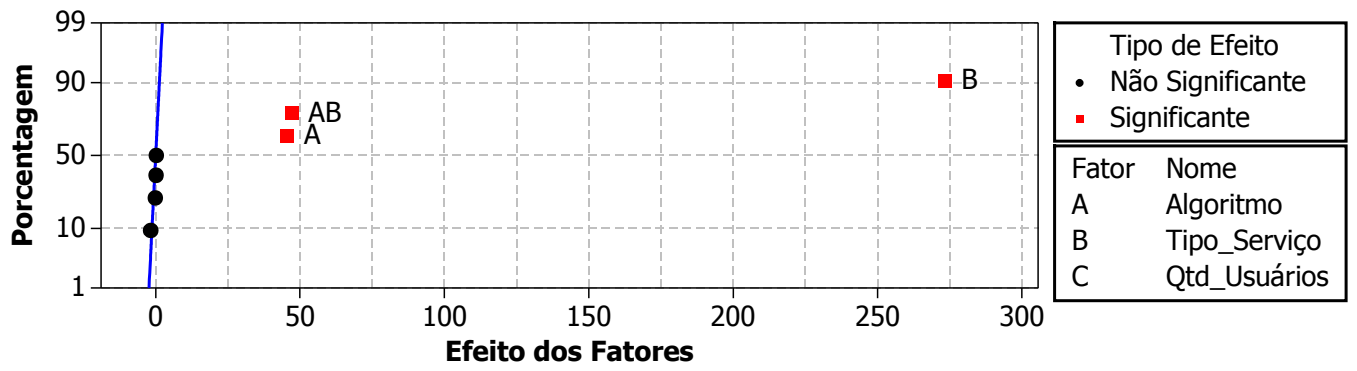

Figura 7.28: Influência dos Fatores - Tempo de Resposta Médio.

Os principais efeitos dos fatores sobre a MRT podem ser vistos na Figura 7.29. Observa-se que o algoritmo PD2c possui o MRT menor do que o algoritmo SD4c. O Efeito causado pelo tipo de serviço com peso maior também eleva o MRT, enquanto na média a quantidade de usuários não se modifica.

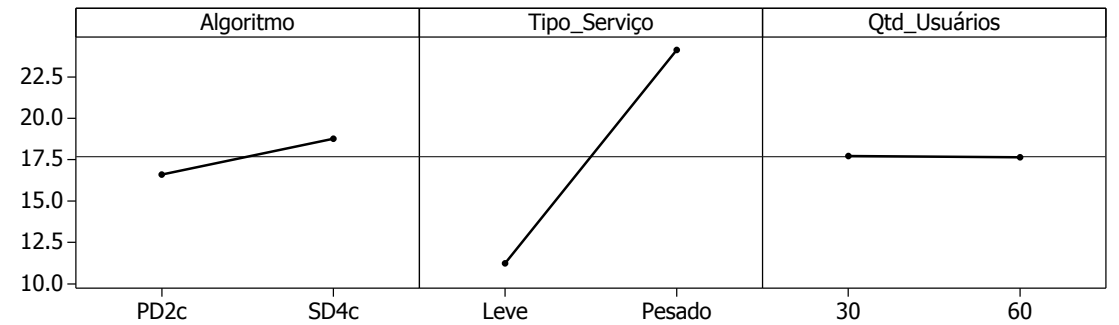

Figura 7.29: Principais Efeitos - Tempo de Resposta Médio.

A interação entre os fatores pode ser visualizada na Figura 7.30. Quando o tipo de serviço passa de leve pra pesado ambos os algoritmos tem o MRT acrescidos, apesar do PD2c apresentar um acréscimo levemente menor do que o SD4c para o caso de serviços pesados. Essa relação leva a identificação de um efeito de interação entre A e B sobre o MRT. 


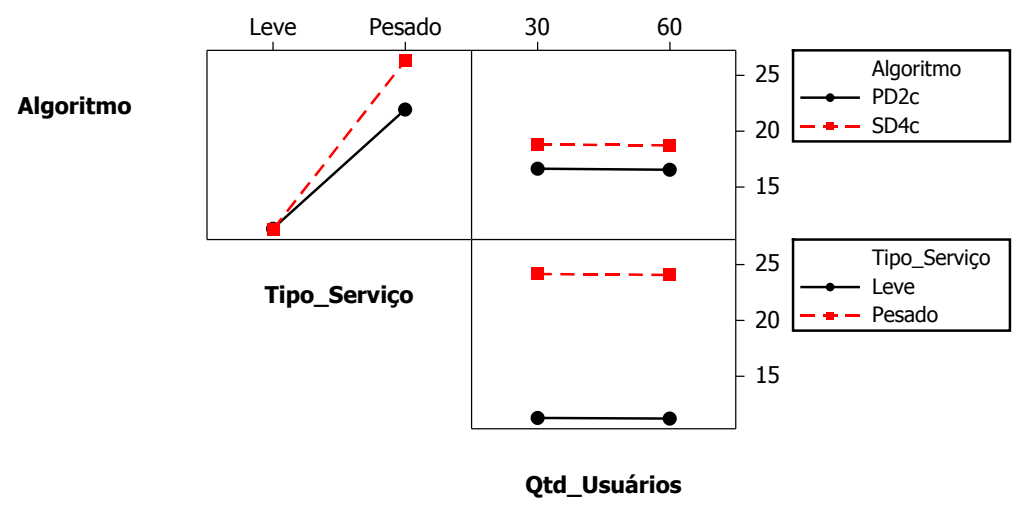

Figura 7.30: Interação entre os Fatores - Tempo de Resposta Médio.

\section{Custo}

É importante constatar, por meio da Figura 7.31, que apesar de apresentar menores MRT's o algoritmo PD2c consegue ser mais econômico do que o algoritmo SD4c quando a carga do sistema é baseada por serviços pesados.

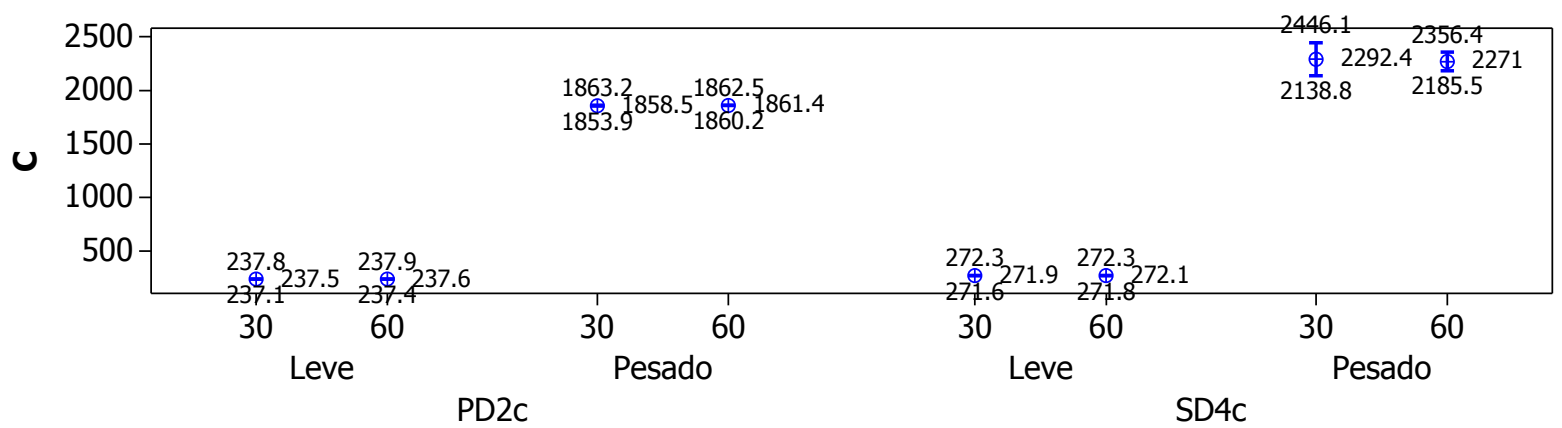

Figura 7.31: Intervalo de Confiança - Custo.

A Figura 7.32 mostra que a maior influência sobre o Custo é exercida pelo fator tipo de serviço (B). À medida que a carga imposta ao sistema eleva-se também aumenta a quantidade de recursos necessários para atender os serviços, acrescendo o Custo. Diferente dos outros experimentos efetuados até aqui, onde o fator predominante de influência do Custo era o algoritmo. Isso é porque ambos os algoritmos, PD2c e SD4c, praticam custos semelhantes na construção das máquinas virtuais. Isso gera uma flutuação de valor para o fator mais agravante, o fator B.

A Figura 7.33 mostra que existe uma leve inclinação da linha de PD2c para SD4c, indicando que o algoritmo SD4c pratica maiores gastos do que o algoritmo PD2c. É possível notar que o tipo de serviço exerce mudança nos custos praticados, elevando seus valores para o caso de tipo de serviços mais pesados.

A Figura 7.34 mostra que não há interações significativas entre os fatores para que exerçam influência na variável de resposta Custo. 


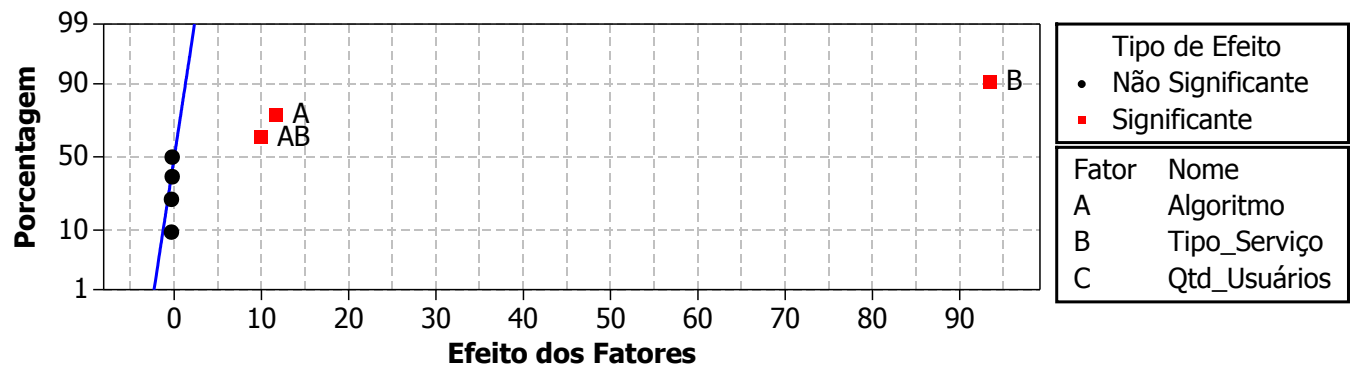

Figura 7.32: Influência dos Fatores - Custo.

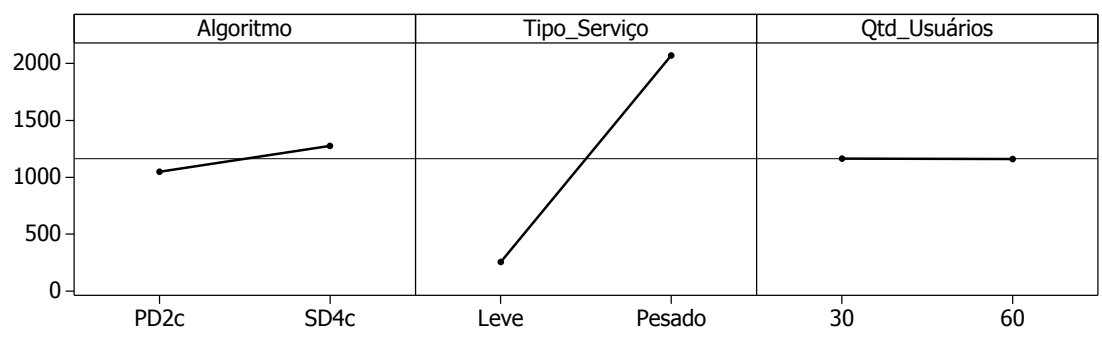

Figura 7.33: Principais Efeitos - Custo.

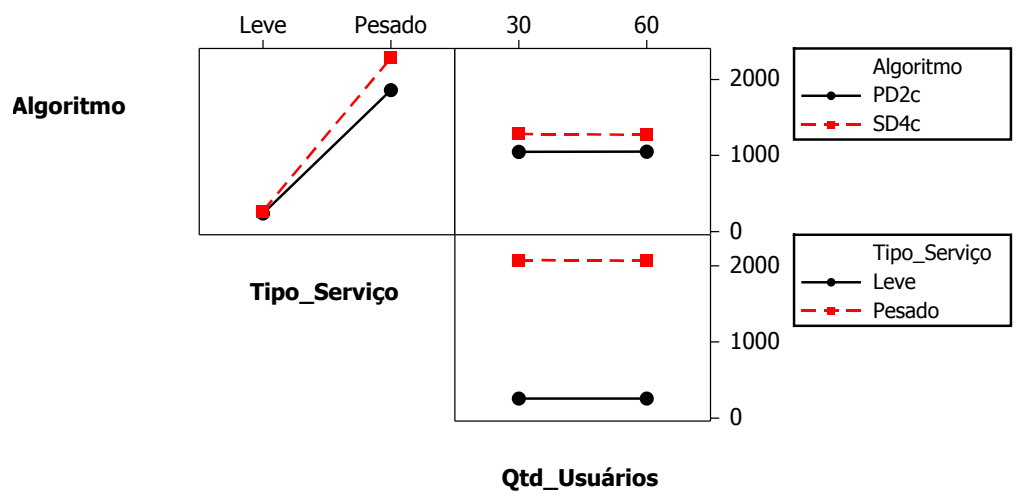

Figura 7.34: Interação entre os Fatores - Custo.

\section{Confiabilidade}

A Figura 7.35 permite uma interessante conclusão com relação aos dois algoritmos ensaiados, PD2c e o SD4c. Apesar de apresentar custos e MRT's menores, o algoritmo $\mathrm{PD} 2 \mathrm{c}$ é capaz de manter uma Confiabilidade maior do que a apresentada pelo algoritmo SD4c.

Segundo a Figura 7.36 os fatores que mais influenciam a Confiabilidade são: Algoritmo (A), Tipo de Serviço (B) e a interação (AB), respectivamente. Mais uma vez é realçada a função do algoritmo combinado com a carga imposta ao sistema na manutenção da @oS, mais especificamente da satisfação do usuário. Essa variação, a favor do algoritmo PD2c, é cerca de 30\% maior para os serviços leves e $40 \%$ maior quando utilizado serviços pesados.

$\mathrm{O}$ algoritmo $\mathrm{SD} 4 \mathrm{c}$ apresenta piores resultados comparados ao algoritmo $\mathrm{PD} 2 \mathrm{c}$, como pode ser visto na Figura 7.37. Além da Confiabilidade cair quando o algoritmo 


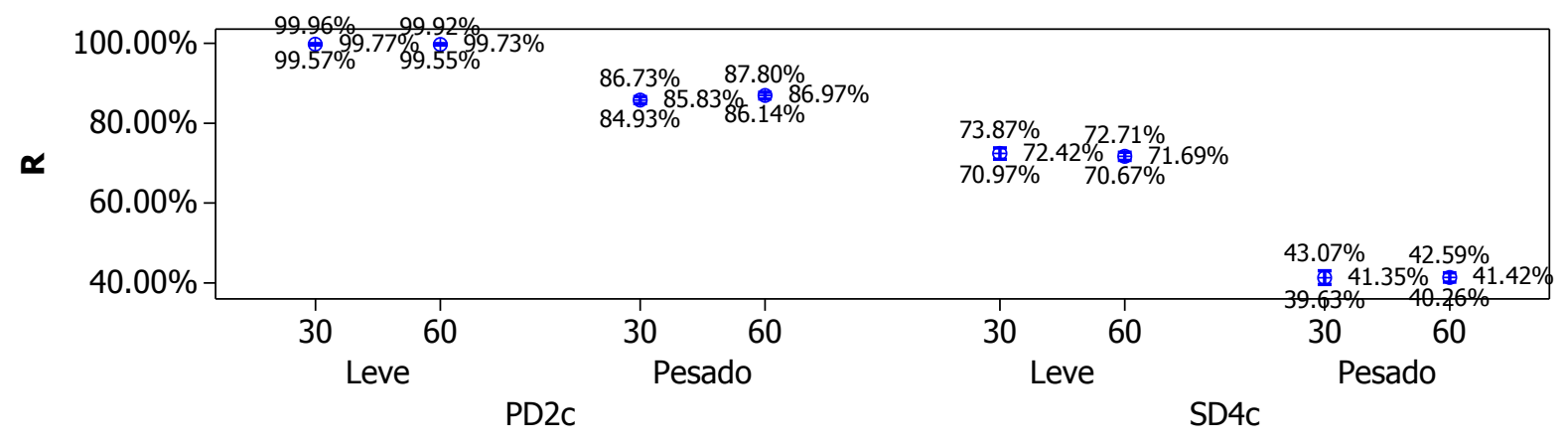

Figura 7.35: Intervalo de Confiança - Confiabilidade.

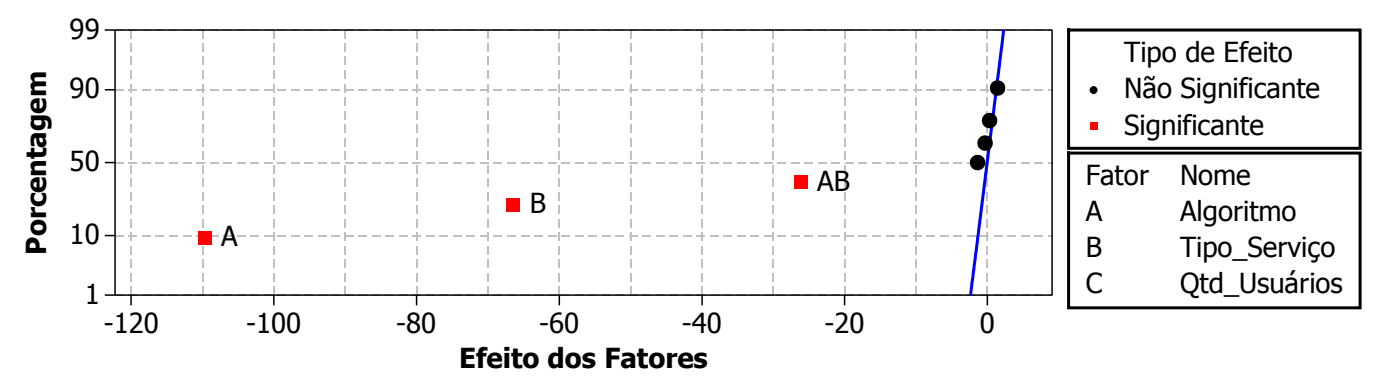

Figura 7.36: Influência dos Fatores - Confiabilidade.

SD4c é utilizado, o tipo de serviço também exerce influência levando à diminuição da Confiabilidade.

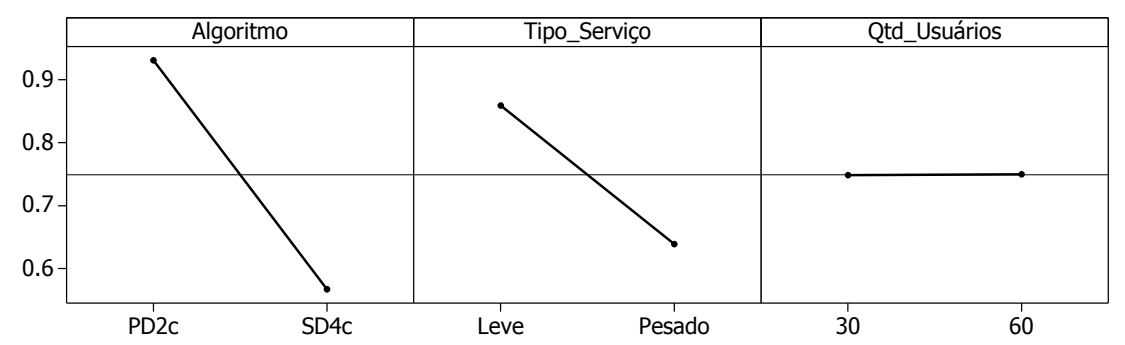

Figura 7.37: Principais Efeitos - Confiabilidade.

A interação entre os fatores algoritmo (A) e tipo de serviço (B) leva a uma leve influência sobre a variável de resposta Confiabilidade. Apesar de ambos os algoritmos apresentarem uma queda da satisfação do usuário quando o tipo de serviço é pesado, é o algoritmo SD4c que tem a queda mais íngreme, apontando a uma interação (AB). Já as outras interações não se mostram significativas.

\section{Análise do Comportamento das Políticas PD2c e SD4C}

É possivel notar, por meio da Figura 7.39, que apesar do algoritmo PD2c apresentar custos relativamente menores do que o SD4c, isso não afeta o atendimento dos serviços dentro dos tempos contratados. Pelo contrário, o algoritmo PD2c mesmo praticando custos menores obtém melhores resultados sobre a Confiabilidade do ambiente. 


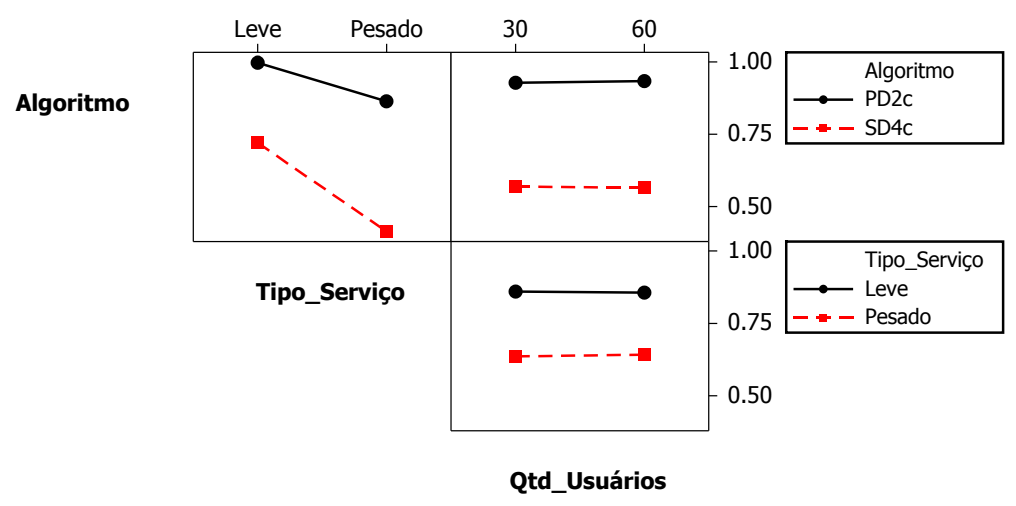

Figura 7.38: Interação entre os Fatores - Confiabilidade.

A quantidade de usuário não interfere nos resultados encontrados para a variável de resposta MRT. Essa característica ocorre pois são consideradas as médias dos valores.
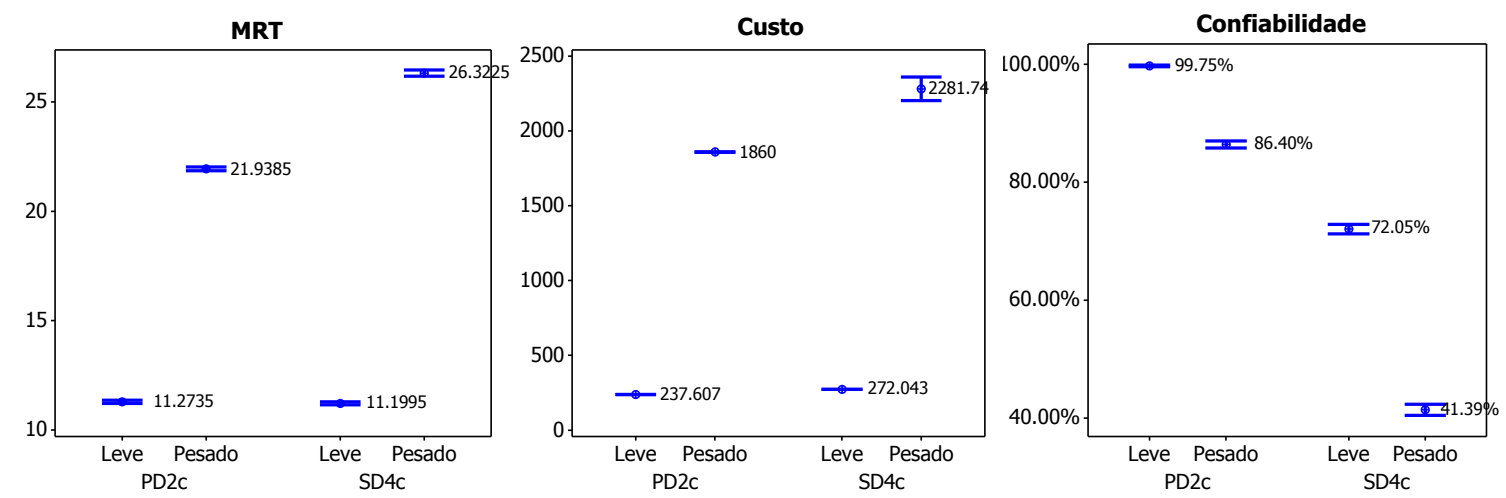

Figura 7.39: Intervalo de Confiança.

Nota-se que o algoritmo SD4c possui tempos de respostas próximos ao do PD2c para cargas leves e 19\% maior quando as cargas pesadas são avaliadas. Com relação ao custo, o SD4c pratica os maiores custos para ambas as cargas leves e pesadas. Analisando-se a Confiabilidade, mesmo com os custos maiores, o SD4c é cerca de $27 \%$ pior do que o PD2c para cargas leves e $45 \%$ quando as cargas são pesadas.

\subsubsection{Algoritmo PD2c X Algoritmo PDXc}

A Tabela 7.6 mostra a distribuição do planejamento de experimentos utilizada para avaliar as políticas PD2c e PDXc. É possivel ver na tabela as médias para o Tempo de Resposta Médio (MRT), Custo (C) e a Confiabilidade (Satisfação - R).

\section{Tempo Médio de Resposta}

A partir da Figura 7.40 é possível verificar que o algoritmo PDXc é mais estável do que o algoritmo PD2c quando ocorre a transição de serviços leves para serviços pesados. Esse comportamento é o desejado, pois o algoritmo PDXc procura manter as taxas de respostas praticadas mesmo quando é imposta uma variação à carga do ambiente. $\mathrm{O}$ algoritmo PDXc possui em seu mecanismo de alocação uma sensibilidade maior do que 
Tabela 7.6: Projeto de Experimento

\begin{tabular}{|c|c|c|c|c|c|c|}
\hline Exp & Algoritmo & Tipo de Serviços & Qtd de Usuários & MRT (s) & C (\$) & R (\%) \\
\hline 1 & PD2c & Leve & 30 & 11,31 & 358 & 99,55 \\
\hline 3 & PD2C & Pesado & 30 & 22,08 & 2801 & 85,38 \\
\hline 5 & PD2c & Leve & 60 & 11,22 & 154 & 99,81 \\
\hline 7 & PD2c & Pesado & 60 & 21,88 & 1243 & 86,76 \\
\hline 2 & PDXc & Leve & 30 & 16,02 & 353 & 99,75 \\
\hline 4 & PDXc & Pesado & 30 & 15,87 & 2335 & 92,62 \\
\hline 6 & PDXc & Leve & 60 & 17,23 & 151 & 99,90 \\
\hline 8 & PDXc & Pesado & 60 & 17,10 & 1030 & 93,38 \\
\hline
\end{tabular}

outros algoritmos no momento de determinar quantas máquinas virtuais a serem criadas e suas configurações refinadas.

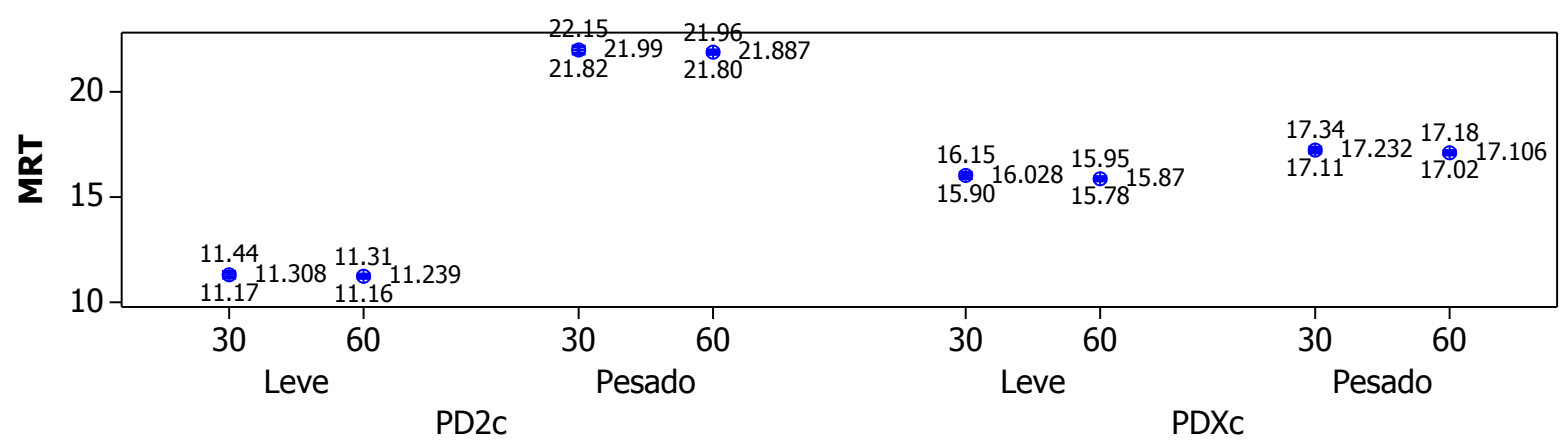

Figura 7.40: Intervalo de Confiança - Tempo de Resposta Médio.

O tipo de serviço (B) é o fator que mais influencia esse experimento, como pode ser visto na Figura 7.41. O fator B está mais distante da curva da normal à direita, significando que o MRT aumenta à medida que a carga de trabalho aumenta, por causa do comportamento desses algoritmos ensaiados. Além disso, a interação entre os fatores (AB) também são responsáveis por determinar o MRT encontrado nesses experimentos.

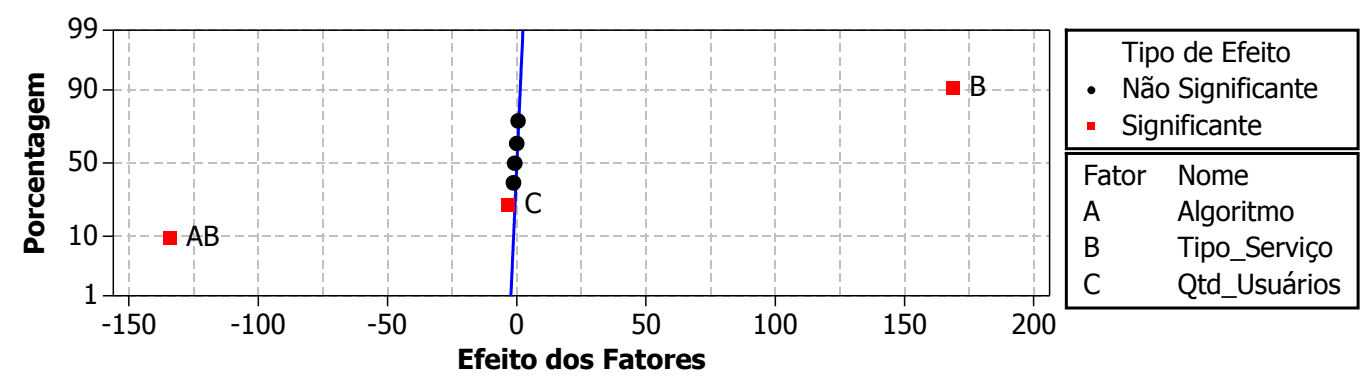

Figura 7.41: Influência dos Fatores - Tempo de Resposta Médio.

Com relação aos efeitos causados pelos fatores, visto na Figura 7.42, observa-se que a variável de reposta MRT é equivalente para ambos algoritmos, PD2c e PDXc. Entretanto, o comportamento do tipo de serviço é semelhantes aos demais experimentos quando existe um aumento da carga de trabalho, elevando também o MRT. 


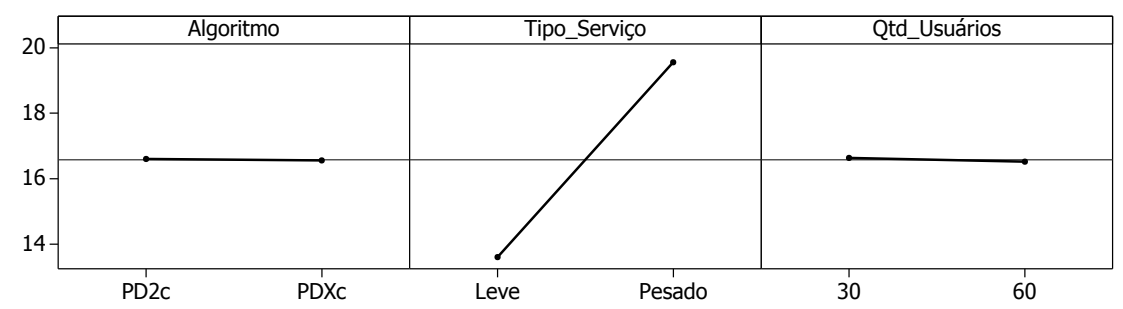

Figura 7.42: Principais Efeitos - Tempo de Resposta Médio.

A Figura 7.43 retrata um comportamento interessante com relação ao algoritmo PDXc. Enquanto o algoritmo PD2c eleva, significativamente, o MRT quando o tipo de serviço passa de leve para pesado, o algoritmo PDXc consegue relativa estabilidade com ambos tipos de serviços. Por isso é formada a interação entre os fatores (AB) que exercem influência sobre o MRT.

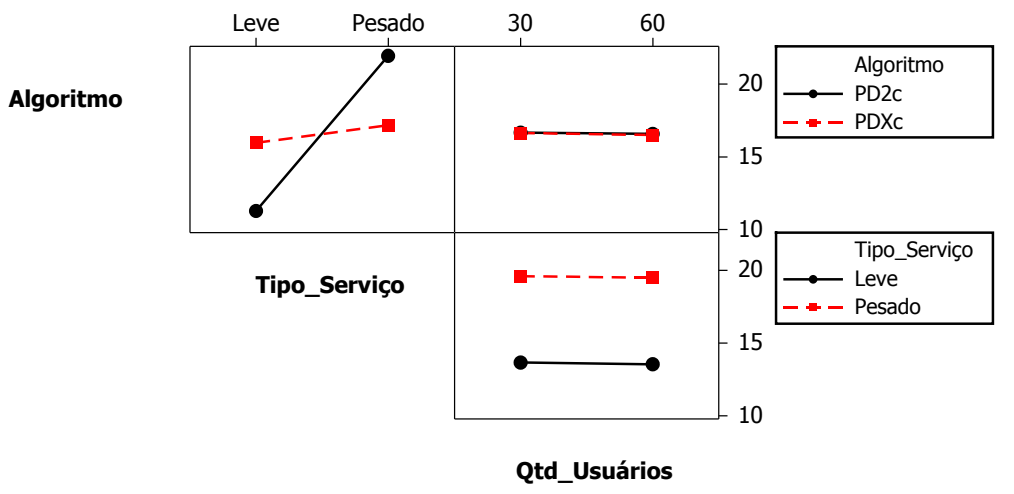

Figura 7.43: Interação entre os Fatores - Tempo de Resposta Médio.

\section{Custo}

Mesmo com as métricas de MRT estáveis em relação à carga imposta ao sistema, o algoritmo PDXc possui o menores custos praticados, como pode ser visto na Figura 7.44. $\mathrm{E}$ a diferença fica mais evidente quando o ambiente apresenta os serviços pesados. Nesse ponto é importante ressaltar que uma adequação à criação de máquinas virtuais leva a economia de dinheiro e a uma melhor utilização dos recursos.

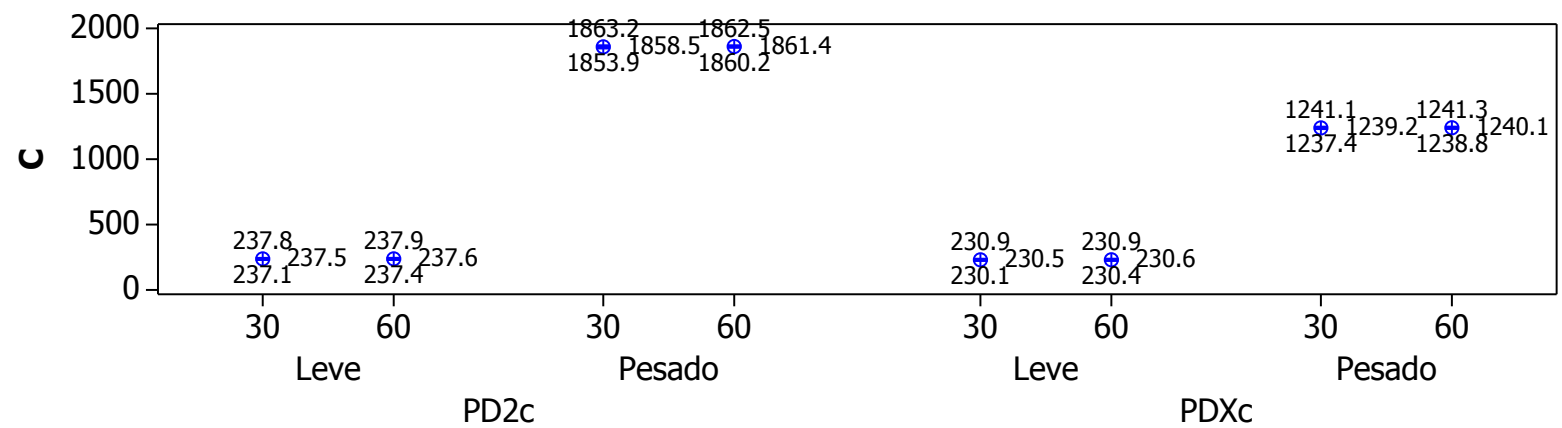

Figura 7.44: Intervalo de Confiança - Custo. 
A Figura 7.45 retrata o mesmo comportamento do último experimento (pd2c x sd4c), onde a influência sobre o Custo é exercida pelo fator tipo de serviço (B). À medida que a carga imposta ao sistema eleva-se também aumenta a quantidade de recursos necessários para atender os serviços, acrescendo o Custo.

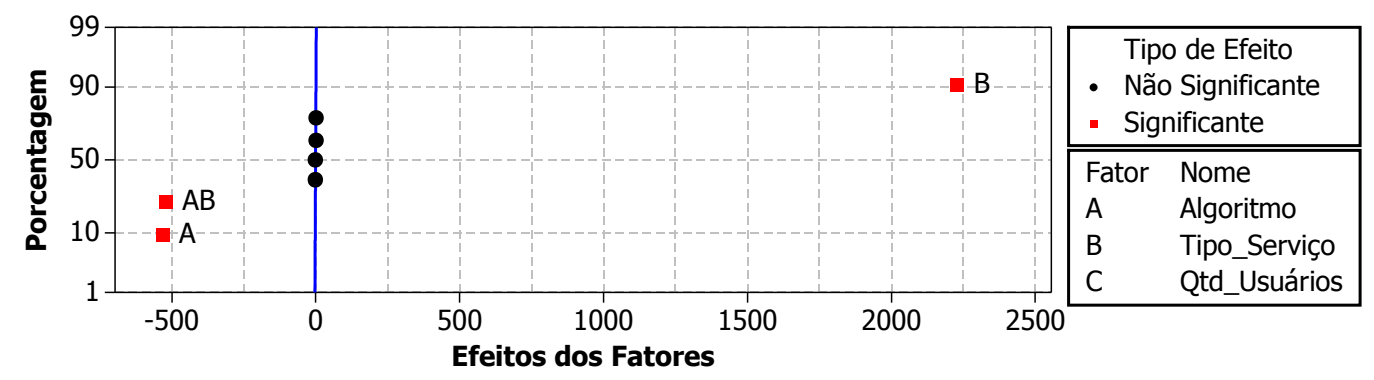

Figura 7.45: Influência dos Fatores - Custo.

A Figura 7.46 apresenta uma leve inclinação da linha de PDXc para PD2c, indicando que o algoritmo PD2c pratica maiores gastos do que o algoritmo PDXc. É possível notar que o tipo de serviço exerce mudança nos custos praticados, elevando seus valores para o caso de tipo de serviços mais pesados, sendo esse comportamento influenciado pelo comportamento do algoritmo PD2c.

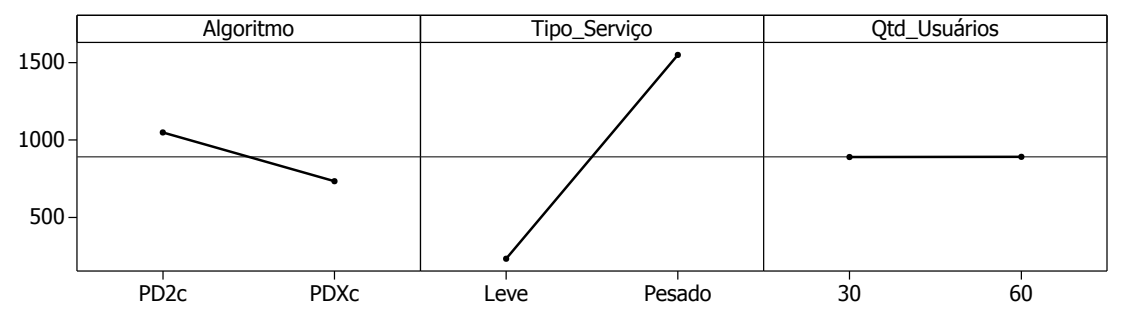

Figura 7.46: Principais Efeitos - Custo.

A Figura 7.47 mostra que a interação que exerce influência sobre o custo mais relevante é a $\mathrm{AB}$. Isso é porque os algoritmos aumentam significativamente os custos empregados quando a carga do sistema aumenta. As demais interações não apresentam considerações significativas.

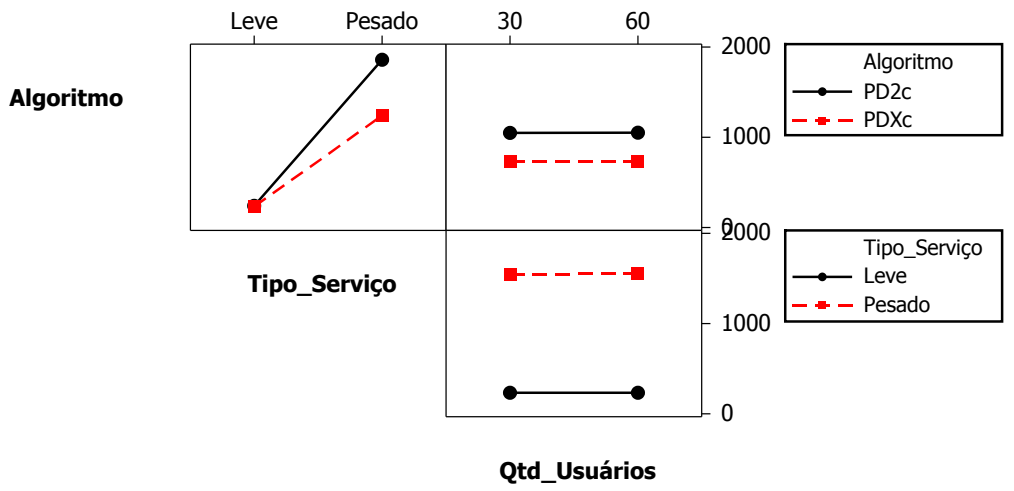

Figura 7.47: Interação entre os Fatores - Custo. 


\section{Confiabilidade}

A Figura 7.48 apresenta os intervalos de confiança para a confiabilidade dos algoritmos PD2c e PDXc. Embora o algoritmo PDXc gaste menos do que o algoritmo PD2c na construção das máquinas virtuais, é o algoritmo PDXc que possui os melhores resultados com relação a satisfação do usuário. O algoritmo PDXc permite que se obtenha Confiabilidade no cumprimento dos requisitos temporais (deadlines) à medida que economiza dinheiro, utilizando melhor os recursos disponíveis no sistema.

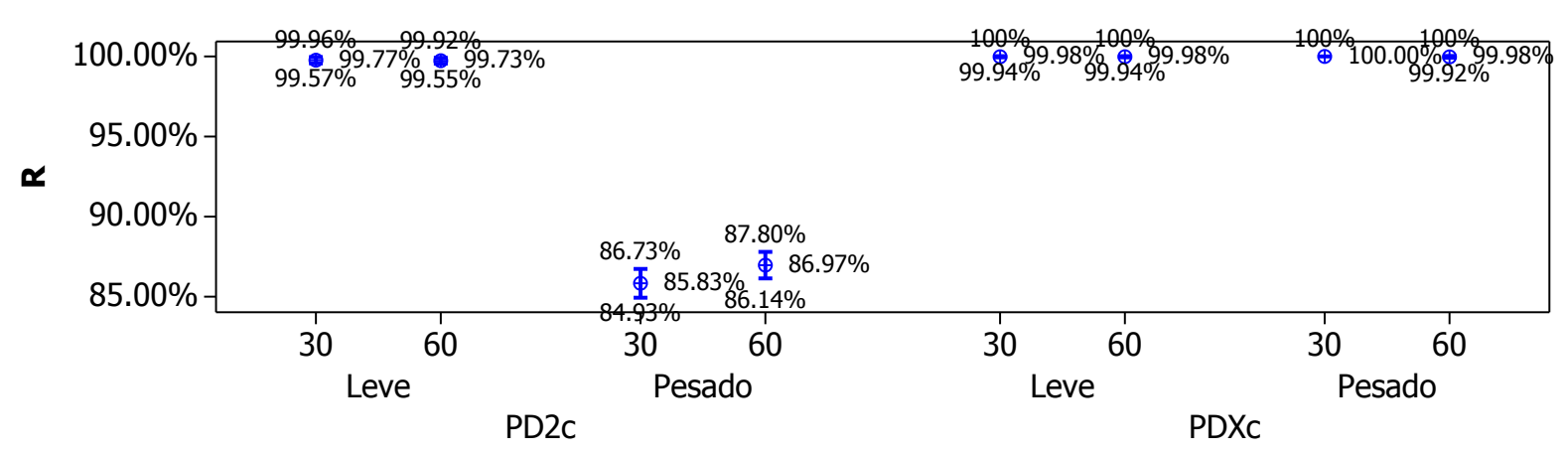

Figura 7.48: Intervalo de Confiança - Confiabilidade.

Segundo a Figura 7.49 os fatores que mais influenciam a Confiabilidade são: Algoritmo (A), Tipo de Serviço (B) e a interação (AB). Mais uma vez é realçada a função do algoritmo combinado com a carga imposta ao sistema para obter a manutenção da GoS, mais especificamente a satisfação do usuário.

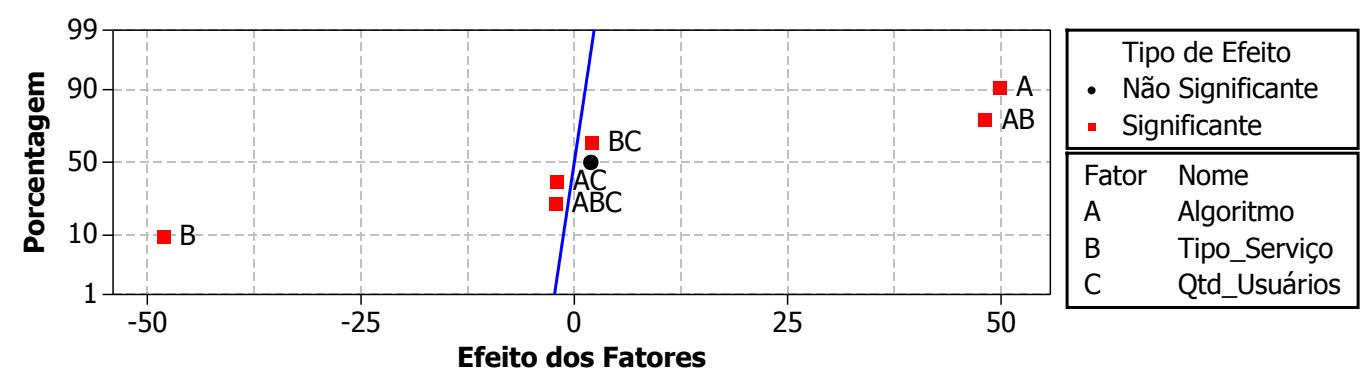

Figura 7.49: Influência dos Fatores - Confiabilidade.

O algoritmo PDXc apresenta melhores resultados comparados ao algoritmo PD2c, como pode ser visto na Figura 7.50. Além da Confiabilidade cair quando o algoritmo PDXc é utilizado, o tipo de serviço também exerce influência levando a diminuição da Confiabilidade. Entretanto, como nos demais experimentos, a quantidade de usuários não interfere na satisfação média dos usuários.

A interação entre os fatores algoritmo (A) e tipo de serviço (B), Figura 7.51, leva a uma leve influência sobre a variável de resposta Confiabilidade. Entretanto, apenas o algoritmo PD2c apresenta uma queda significativa da satisfação do usuário quando o tipo de serviço é pesado. Essa queda mais íngreme do algoritmo PD2c é a responsável por construir a interação (AB). Já as outras interações não se mostram significativas. 


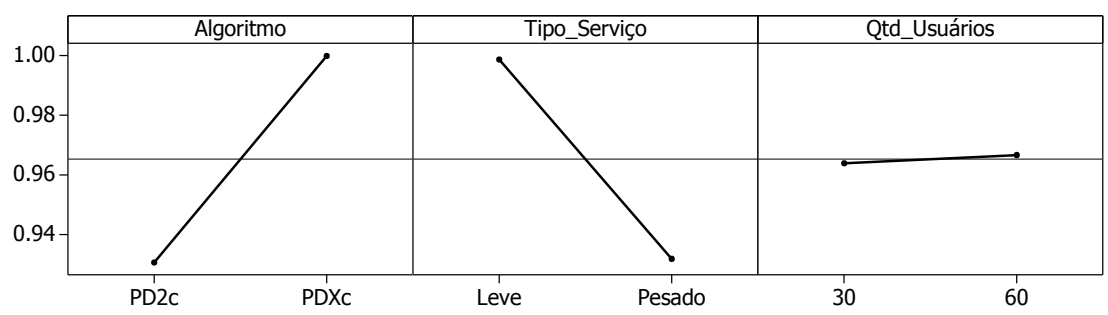

Figura 7.50: Principais Efeitos - Confiabilidade.

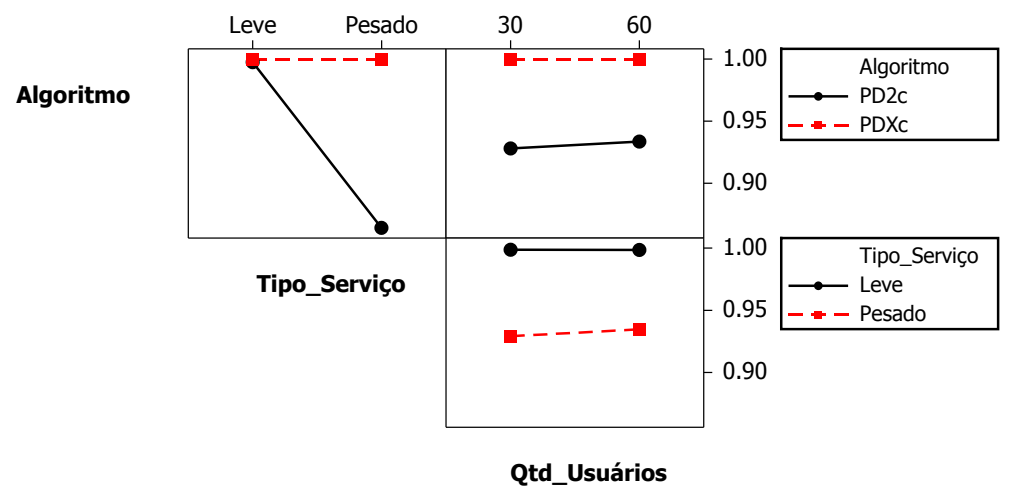

Figura 7.51: Interação entre os Fatores - Confiabilidade.

\section{Análise do Comportamento das Políticas PD2c e PDXc}

De acordo com a Figura 7.52 é possível notar que o algoritmo PD2c apresenta custos semelhantes aos empregados pelo algoritmo PDXc quando a carga do sistema é leve. Todavia, quando a carga de trabalho do sistema aumenta os custos mais baixos são oferecidos pelo algoritmo PDXc. Esse comportamento não afeta o atendimento dos serviços dentro dos tempos contratados pelo algoritmo PDXc, que é o algoritmo com os melhores resultados sobre a Confiabilidade. Resumindo, mesmo que o algoritmo PDXc apresente os custos menores, ele obtém melhores resultados sobre a Confiabilidade do ambiente, além de manter uma considerável estabilidade sobre o MRT.

A quantidade de usuário não interfere nos resultados encontrados para a variável de resposta MRT. Essa característica ocorre pois são consideradas as médias dos valores.
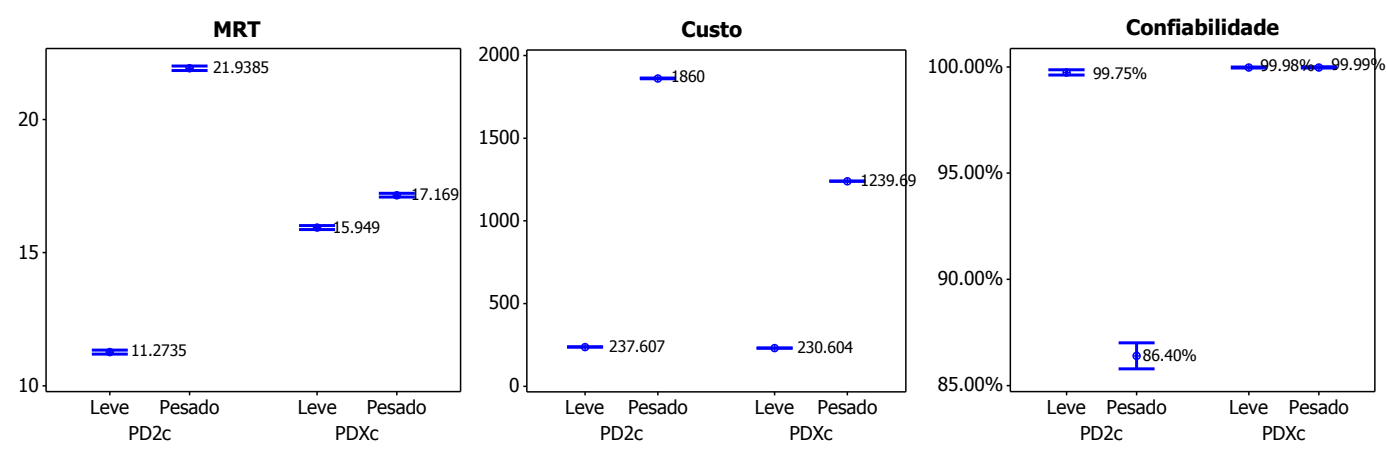

Figura 7.52: Intervalo de Confiança. 
Ambos os algoritmos, PD2c e PDXc, possuem o comportamento similar para o Custo e a Confiabilidade. Entretanto, o tempo de resposta médio que o PD2c obtém é menor do que o PDXc. Considerando que o importante é garantir o cumprimento dos requisitos impostos na SLA, ambas as políticas estão apresentando um bom comportamento. Nesse caso específico, o importante é cumprir a restrição temporal exigida pelo usuário, atingir valores significativamente menores não torna a política melhor, ressaltanto que o importante é cumprir a deadline. Em contrapartida, esse é um comportamento que pode causar desperdicio na utilização dos recursos. Quando avaliadas as cargas pesadas, o algoritmo PDXc obtém menores valores de MRT do que o PD2c a um custo 1,5 vez menor. Além disso, a Confiabilidade do PDXc é 13\% maior.

\subsection{Avaliação Conjunta dos Algoritmos}

De acordo com a Figura 7.53, nota-se que o gráfico de intervalo de confiança mostra as três variáveis de resposta: MRT, C, e R. Com relação a variável MRT, o algoritmo PDXc é o mais estável com respeito a variação de carga no ambiente de testes. Já o algoritmo RG é aquele que mais gasta dinheiro no processo de criação de máquinas virtuais, o qual ocorre de forma não organizada se considerado em conjunto com as outras variáveis de resposta.
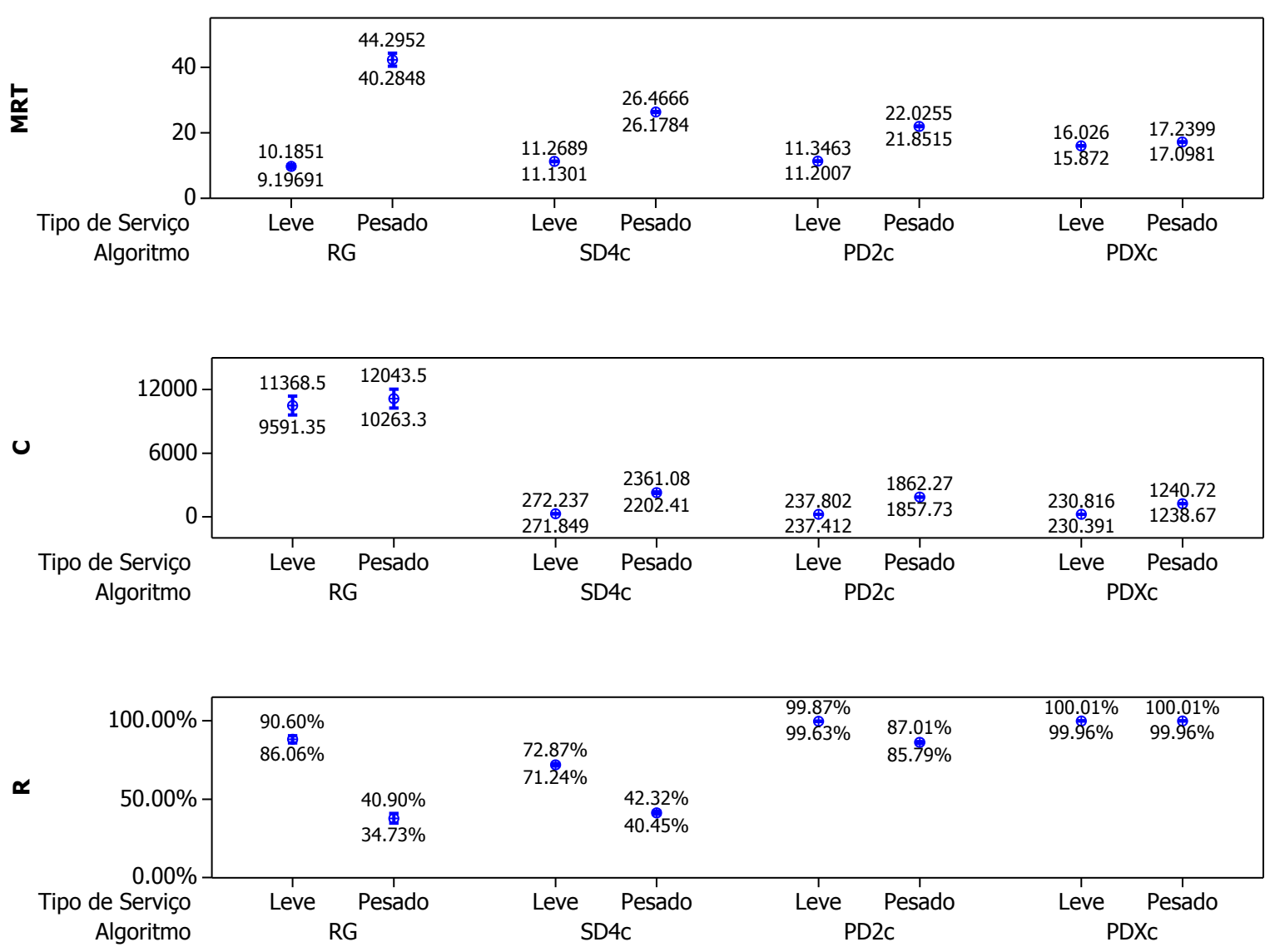

Figura 7.53: Intervalo de Confiança: Resumo. 


\subsubsection{Influência dos Fatores}

A Tabela 7.7 foi construída para ressaltar as informações sobre os fatores utilizados nos experimentos deste capítulo.

Tabela 7.7: Nome dos Fatores dos Experimentos

\begin{tabular}{|c|c|}
\hline Fator & Nome \\
\hline A & Algoritmo \\
\hline B & Tipo de Serviço \\
\hline C & Quantidade de Usuários \\
\hline
\end{tabular}

A influência dos fatores sobre a MRT pode ser vista na Figura 7.54. É possível observar que o fator Tipo de Serviço (B) possui a maior influência sobre os algoritmos nesse experimento. Além disso, o fator Algoritmo (A) e a interação entre eles (AB) também são responsáveis por determinar a MRT encontrada nesses experimentos. Deduz-se que à medida que a carga fica pesada, a MRT aumenta seu valor, como esperado.

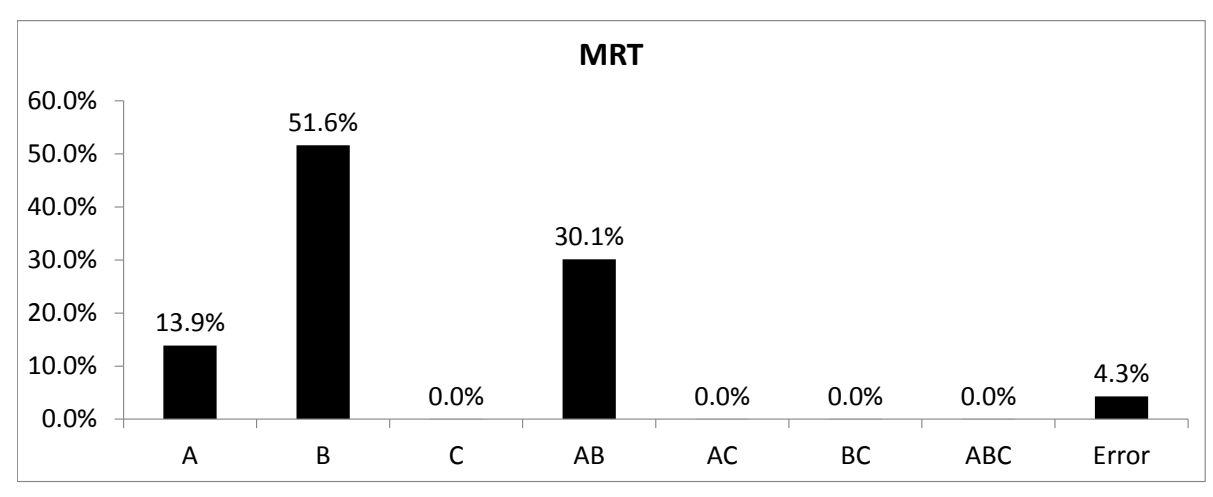

Figura 7.54: Influência dos fatores - Tempo de Resposta Médio.

A Figura 7.55 considera a influência dos fatores sobre o custo. Nesse experimento, o fator com a maior influência sobre o custo é o Algoritmo (A), porque é o algoritmo que determina a quantidade necessária de recursos para ser alocada para processar o serviço de um cliente. A combinação entre a quantidade e a configuração estabelecida para as máquinas virtuais formam o custo final médio. O Tipo de Serviço (B) tem uma pequena influência nesse experimento. Portanto, deduz-se que o custo médio depende mais do algoritmo do que a carga imposta ao sistema. É importante ressaltar que essa responsabilidade sobre o algoritmo é um ponto positivo caso o algoritmo seja um mecanismo de alocação com bons resultados, economizando dinheiro dessa forma. Caso contrário, o algoritmo pode não desempenhar uma alocação de recursos adequada, desperdiçando dinheiro.

A Figura 7.56 considera a influência dos fatores sobre a Confiabilidade. O principal fator a ser considerado com o objetivo de obter a Confiabilidade, e assim a satisfação do usuário, é o fator Algoritmo (A). Além disso, o fator (B) e a interação (AB) também tem contribuição sobre os valores de Confiabilidade obtidos. Esses fatores tem a maior 


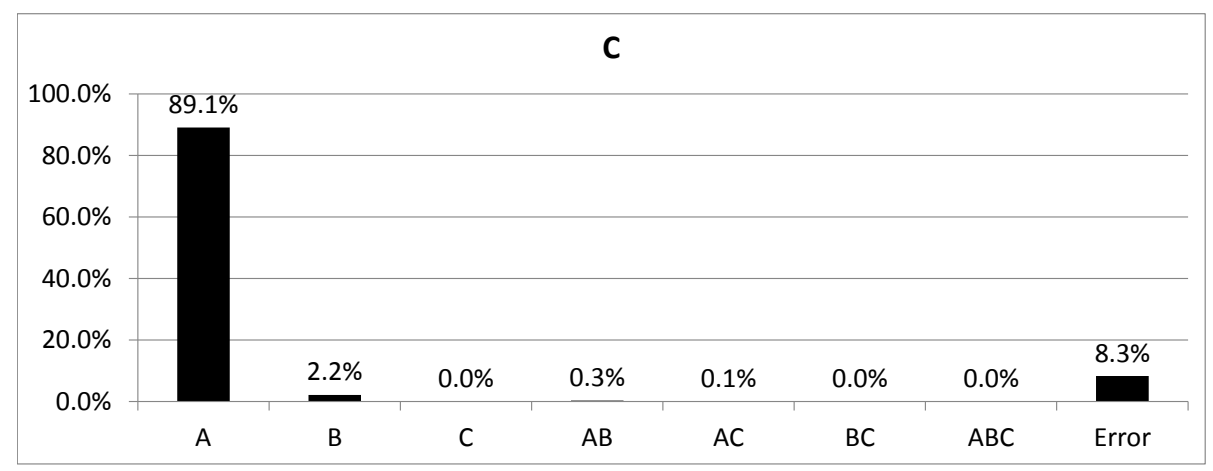

Figura 7.55: Influência dos fatores - Custo.

influência nas variáveis de resposta Confiabilidade, mostrando que a satisfação do usuário é proporcional a carga imposta ao sistema e a utilização de adequados algoritmos de alocação de máquinas virtuais.

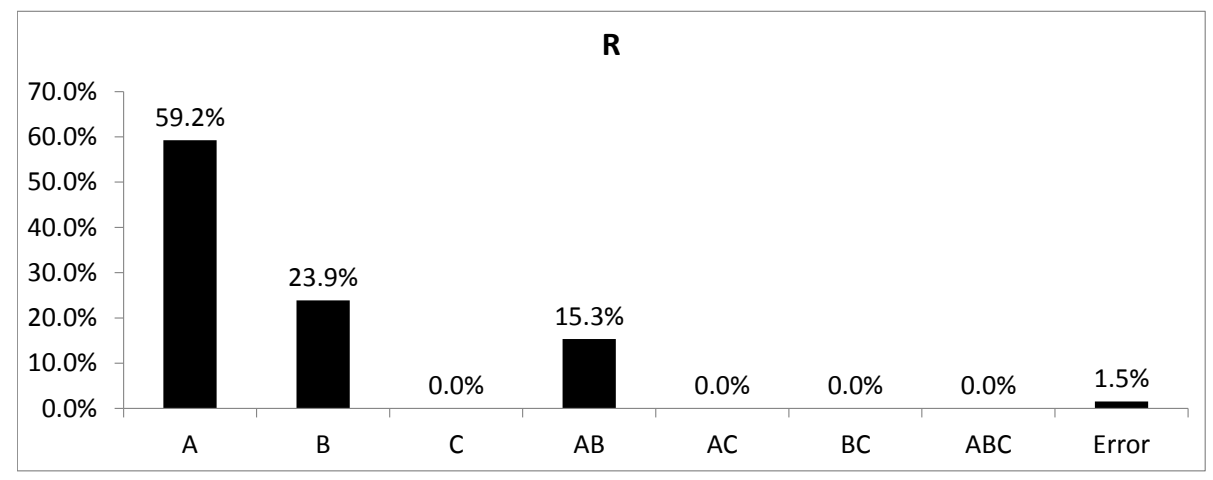

Figura 7.56: Influência dos fatores - Confiabilidade.

\subsubsection{Principais Efeitos dos Fatores}

A Figura 7.57 mostra os principais efeitos dos fatores sobre a MRT. Observa-se que o algoritmo PDXc obtém os menores valores. O efeito causado pelo tipo de serviço mais pesado também aumenta a MRT. Entretanto, a quantidade de usuários (Fator C) não causa efeito sobre a MRT. Esse fato ocorre porque no experimento é utilizado o custo médio tanto para 30 quanto para 60 usuários.

A Figura 7.58 apresenta os principais efeitos dos fatores sobre o Custo. O algoritmo PDXc pratica os menores custos. Por outro lado, o algoritmo RG pratica os maiores custos; o algoritmo RG realiza a criação de máquinas virtuais de forma aleatória, desperdiçando dinheiro e recursos. Como esperado, o serviço mais leve possui os menores custos. Sobre a quantidade de clientes (C), observa-se que o custo médio é similar para ambas as quantidades de usuários.

Além de praticar os menores custos e menores MRT, o algoritmo PDXc tem os melhores resultados em relação à Confiabilidade como apresentado na Figura 7.59. 


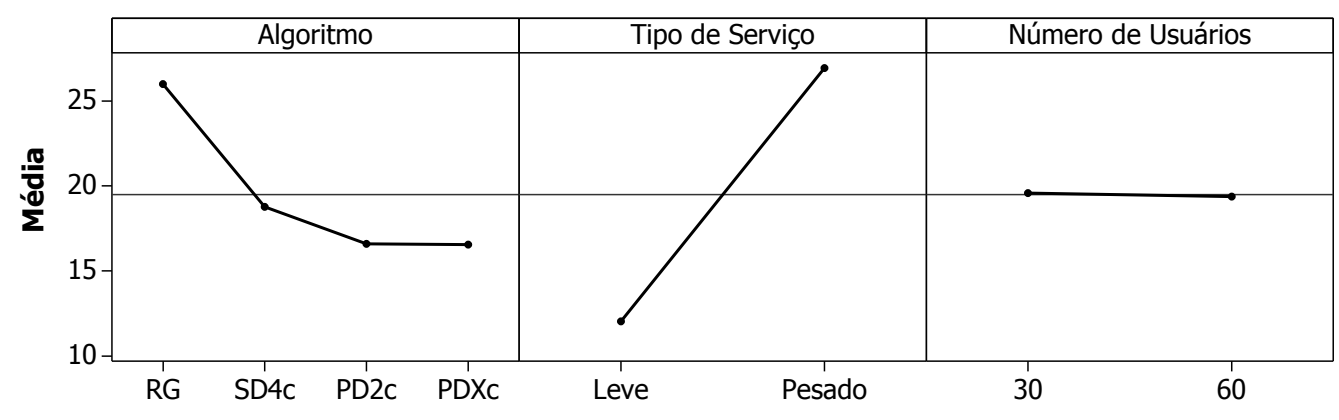

Figura 7.57: Efeitos dos fatores - Tempo de Resposta Médio.

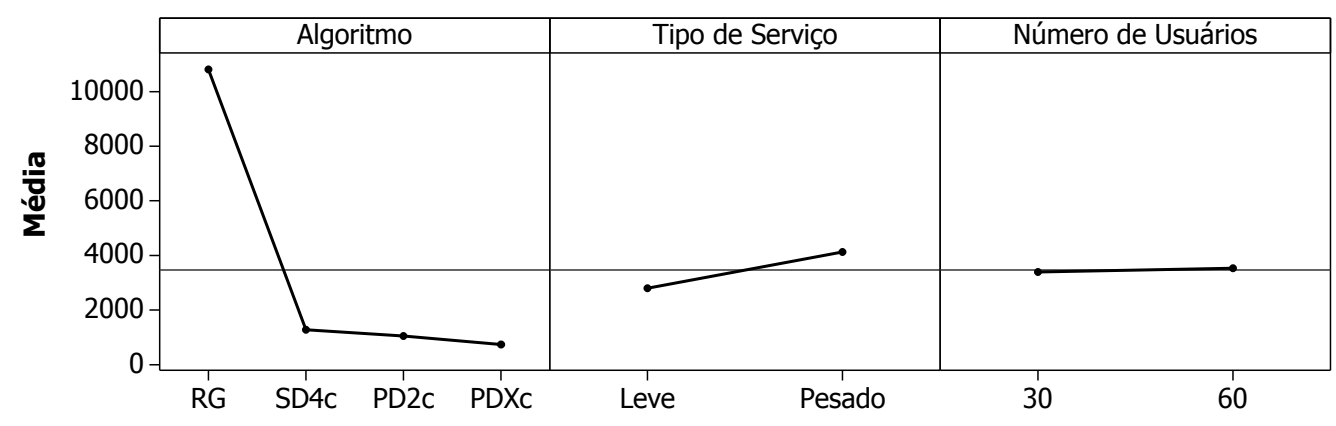

Figura 7.58: Efeitos dos fatores - Custo.

Nota-se que o Tipo de Serviço também possui influência, diminuindo a Confiabilidade quando o tipo de serviço torna-se mais pesado.

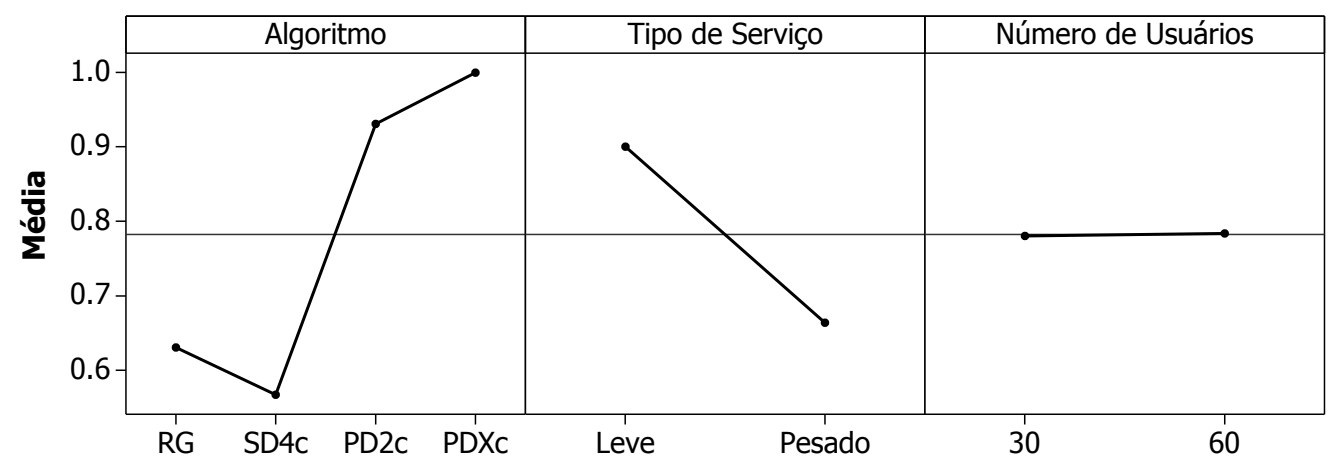

Figura 7.59: Efeitos dos fatores - Confiabilidade.

\subsubsection{Interação entre os Fatores}

A Figura 7.60 mostra a interação entre os fatores e suas influências sobre a MRT. Quando o tipo de serviço passa de leve para pesado, a MRT obtida pelos algoritmos aumenta. Apesar de todos os algoritmos aumentaram os valores encontrados na MRT, é o algoritmo PDXc que possui o menor acréscimo em relação aos outros algoritmos quando o tipo de serviço é pesado. Assim, existe uma influência da interação dos fatores A e B sobre a MRT. Essa interação mostra que os valores de resposta obtidos por esses algoritmos são dependentes da carga de trabalho imposta ao sistema. Quando a carga de 
trabalho é leve, o algoritmo RG possui baixos tempos de respostas e quando a carga de trabalho é pesada, o algoritmo PDXc possui os menores tempos de resposta. As outras possíveis interações não são significativas uma vez que as linhas de efeitos dos fatores estão em paralelo.

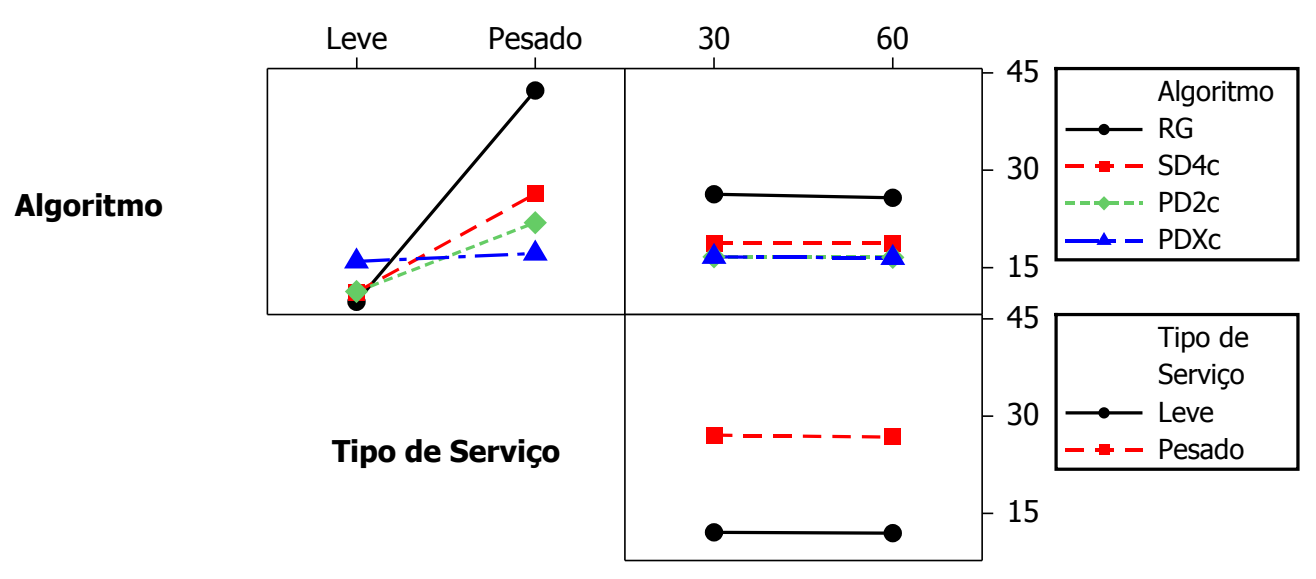

Número de Usuários

Figura 7.60: Interação dos fatores - Tempo de Resposta Médio.

A Figura 7.61 mostra que não tem interação entre os fatores sobre o custo. Essa observação é dada a partir das linhas de efeitos que estão todas em paralelo no gráfico. Entretanto, é possível notar que todos os algoritmos tem um acréscimo no custo quando o tipo de serviço passa de leve para pesado.

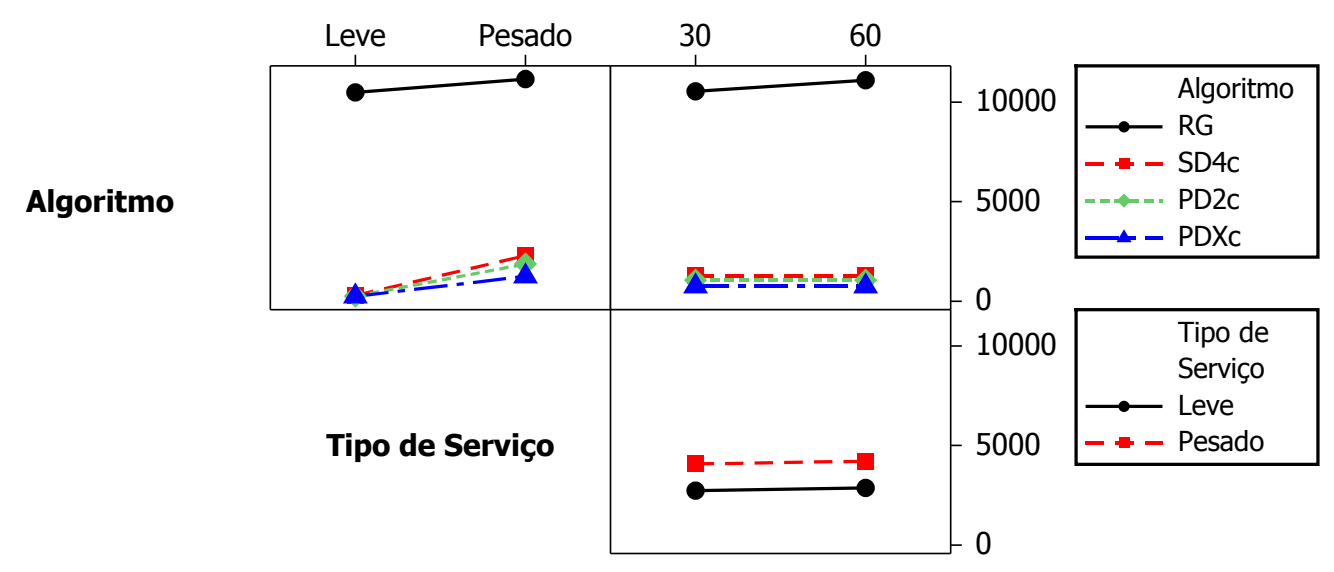

\section{Número de Usuários}

Figura 7.61: Interação dos fatores - Custo.

O comportamento relacionado a Confiabilidade é apresentado na Figura 7.62. Somente o algoritmo PDXc mantém a confiabilidade alta quando a carga de trabalho 
é pesada. Em outras palavras, é o algoritmo RG que tem o pior comportamento quando a carga imposta ao sistema é considerada mais pesada.

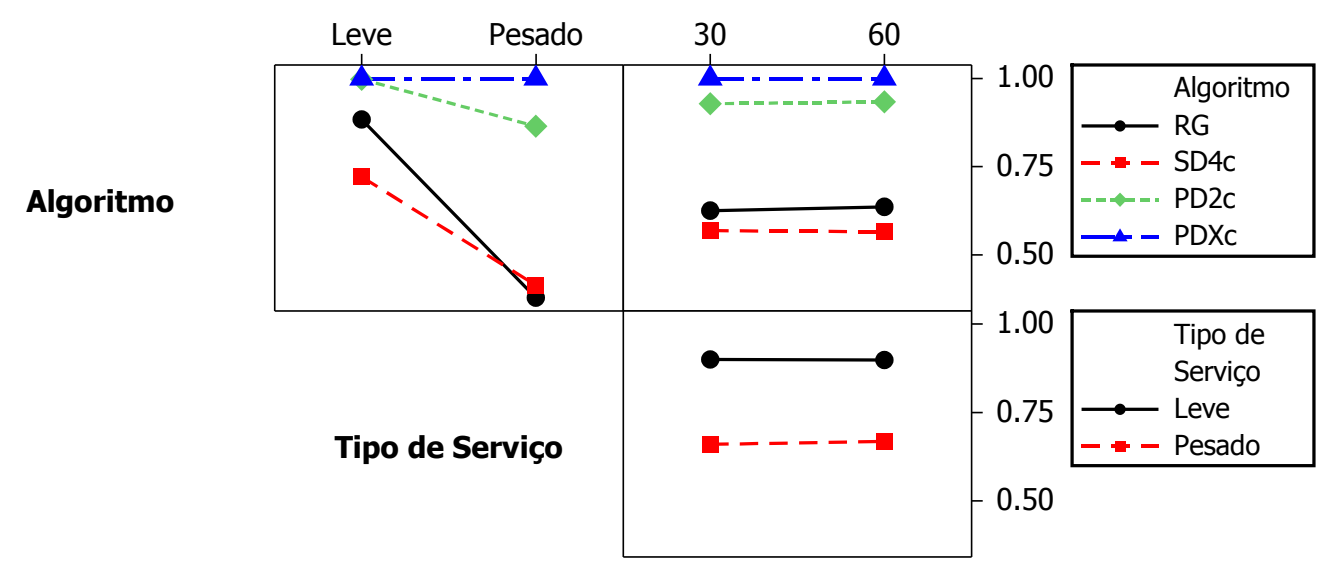

Número de Usuários

Figura 7.62: Interação dos fatores - Confiabilidade.

\subsection{Avaliação da Satisfação Individual dos Usuários}

É possível analisar o comportamento individual dos três usuários (A, B e C). Foi utilizado o tipo de cenário mais sobrecarregado dentre os experimentos construídos.

A Figura 7.63 apresenta o comportamento do algoritmo RG. Como o algoritmo RG desempenha a criação de máquinas virtuais de forma aleatória, ele não está ciente da necessidade de manter os tempos de resposta abaixo do tempo contratado. Apesar de apresentar uma satisfação adequada para os usuários B e C isso aconteceu através de gastos excessivos, como pode ser comparado com a Figura 7.67.

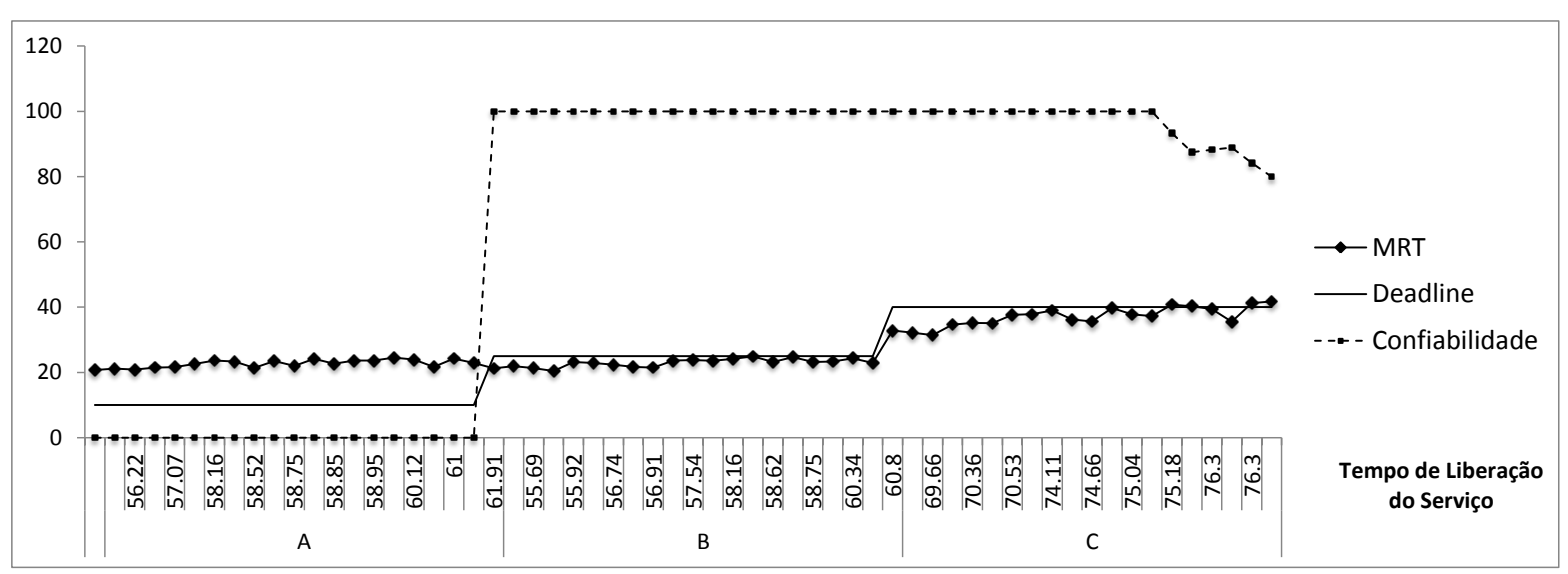

Figura 7.63: Eficiência do Algoritmo RG.

Como pode ser visto na Figura 7.64, o algoritmo SD4c não apresenta flexibilidade para atender as diferentes classes de usuários. Ainda que os custos praticados não 
sejam tão expressivos quanto o algoritmo RG, o algoritmo SD4c não é capaz de prover uma satisfação adequada para os usuários A, B.

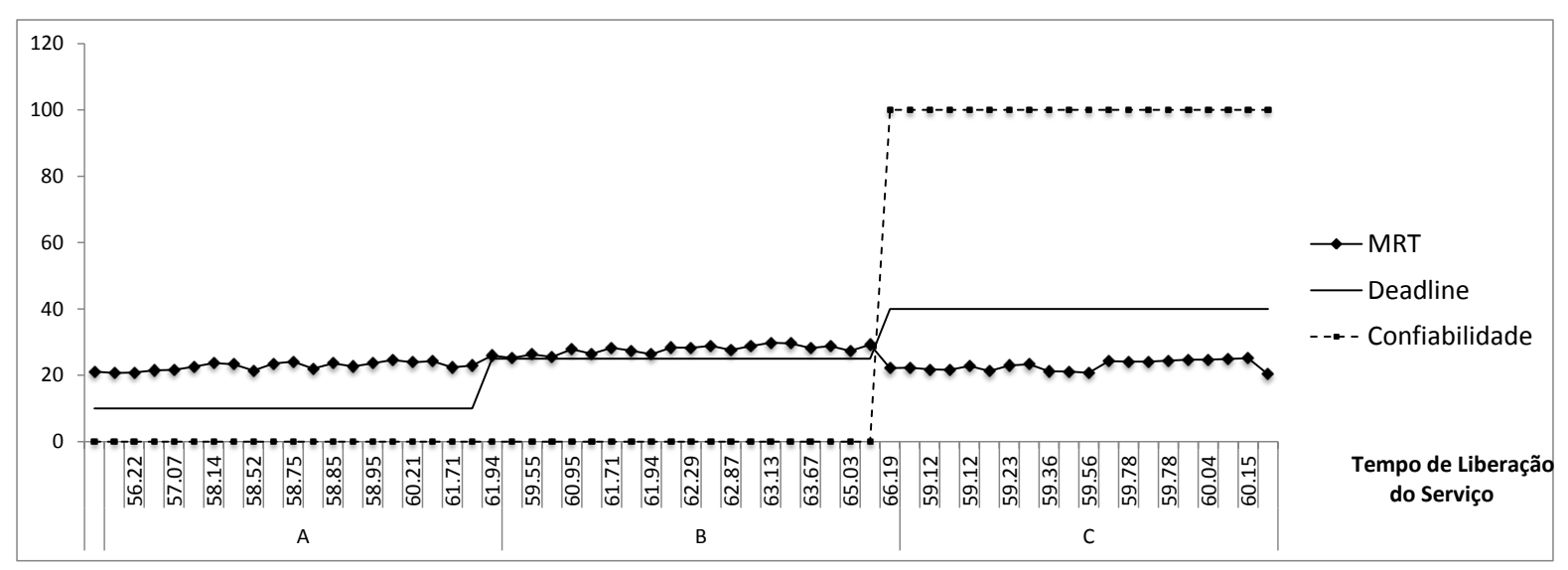

Figura 7.64: Eficiência do Algoritmo SD4c.

O comportamento do algoritmo PD2c apresentado na Figura 7.65 sugere uma interpretação de que ele age de maneira agressiva. O PD2c realiza a construção de máquinas virtuais em função da deadline imposta pela classe de serviços. Entretanto, o algoritmo PD2c permite que o tempo de resposta ultrapasse, em algumas situações, o desejado pelo usuário.

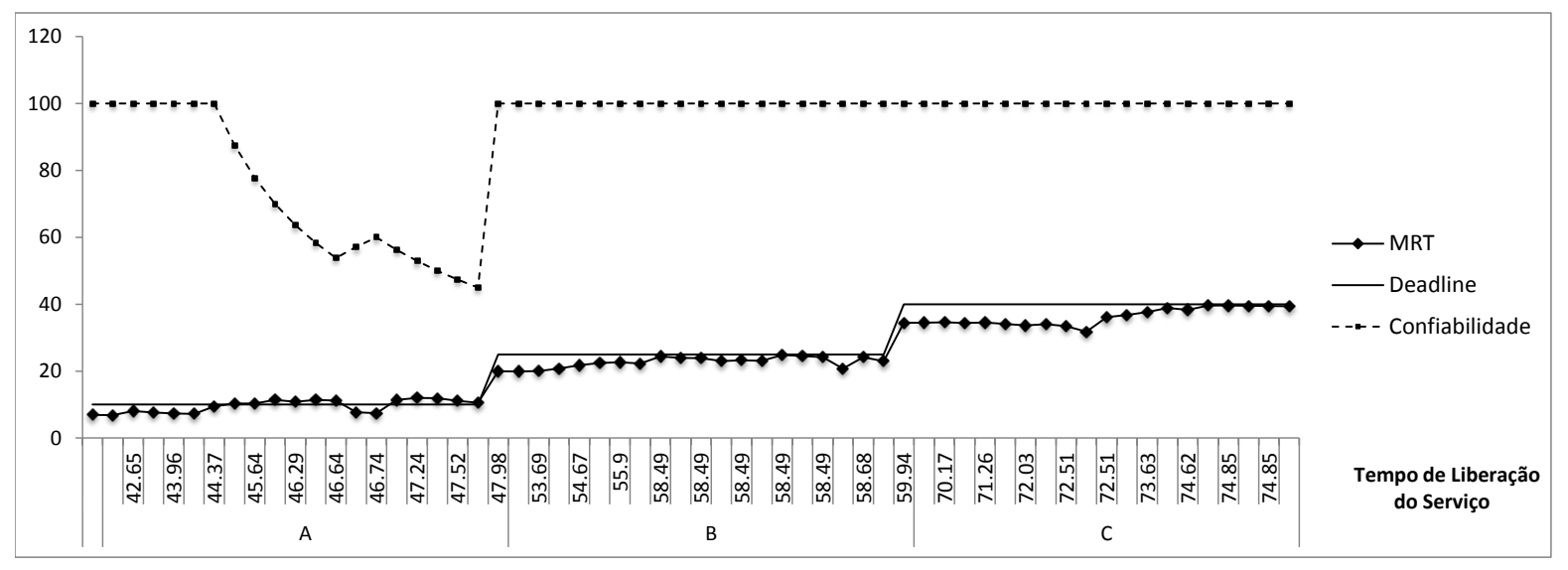

Figura 7.65: Eficiência do Algoritmo PD2c.

Já o algoritmo PDXc, apresentado na Figura 7.66, retrata o comportamento desejável. Todas as classes de serviços possuem o atendimento diferenciado com 100\% de satisfação dos usuários. Um ponto que deve ser ressaltado é a capacidade do algoritmo PDXc em construir as máquinas virtuais com a configuração adequada, à medida que economiza dinheiro. Como pode ser visto na Figura 7.67, o algoritmo PDXc é o que pratica os menores custos.

A Figura 7.67 apresenta os custos praticados pelos algoritmos de alocação de máquinas virtuais presentes no MACC. Observa-se que o algoritmo que mais gasta 


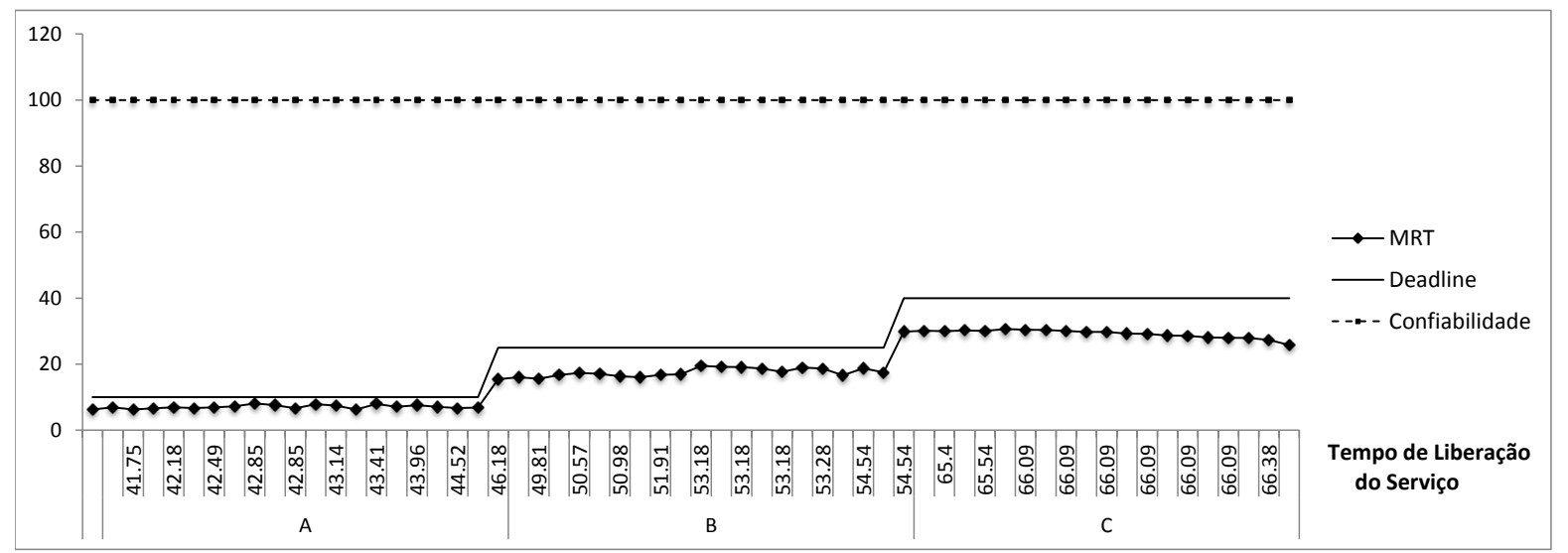

Figura 7.66: Eficiência do Algoritmo PDXc.

durante o processo de criação é o RG, por outro lado, é o algoritmo PDXc que apresenta os menores custos.

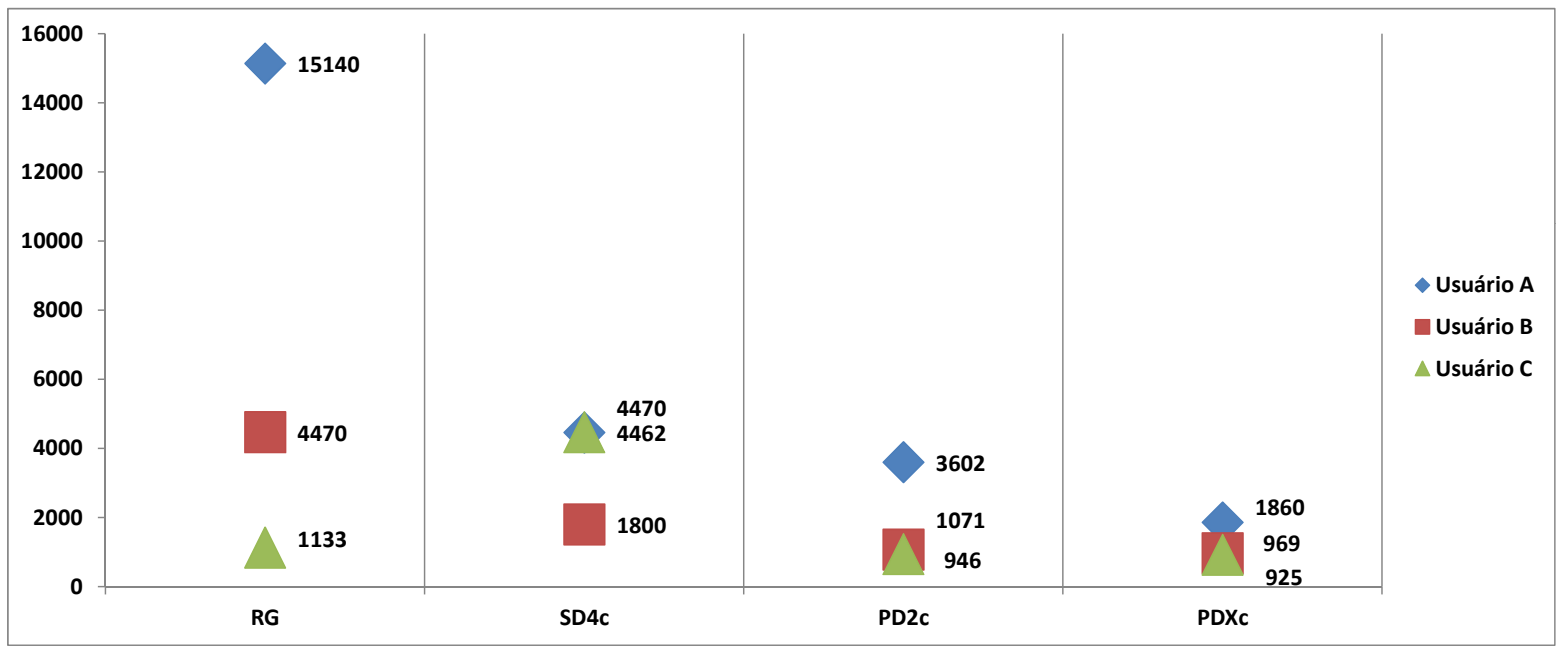

Figura 7.67: Custos Médios para os Usuários A, B e C.

\subsection{Avaliação da Sobrecarga dos Algoritmos de Alocação}

Outra informação importante a ser considerada está relacionada à sobrecarga do mecanismo de metaescalonamento. Durante os experimentos tratou-se de realizar medições sobre o comportamento dos algoritmos de alocação. Os resultados encontrados sobre a sobrecarga de cada algoritmo de roteamento podem ser vistos na Figura 7.68.

Como pode ser observado na Figura 7.68, a sobrecarga dos algoritmos de alocação estão na ordem de milissegundos enquanto o tempo de processamento dos serviços estão na ordem de segundos. Sendo assim, a sobrecarga dos algoritmos de alocação de máquinas virtuais pode ser considerada desprezivel. 


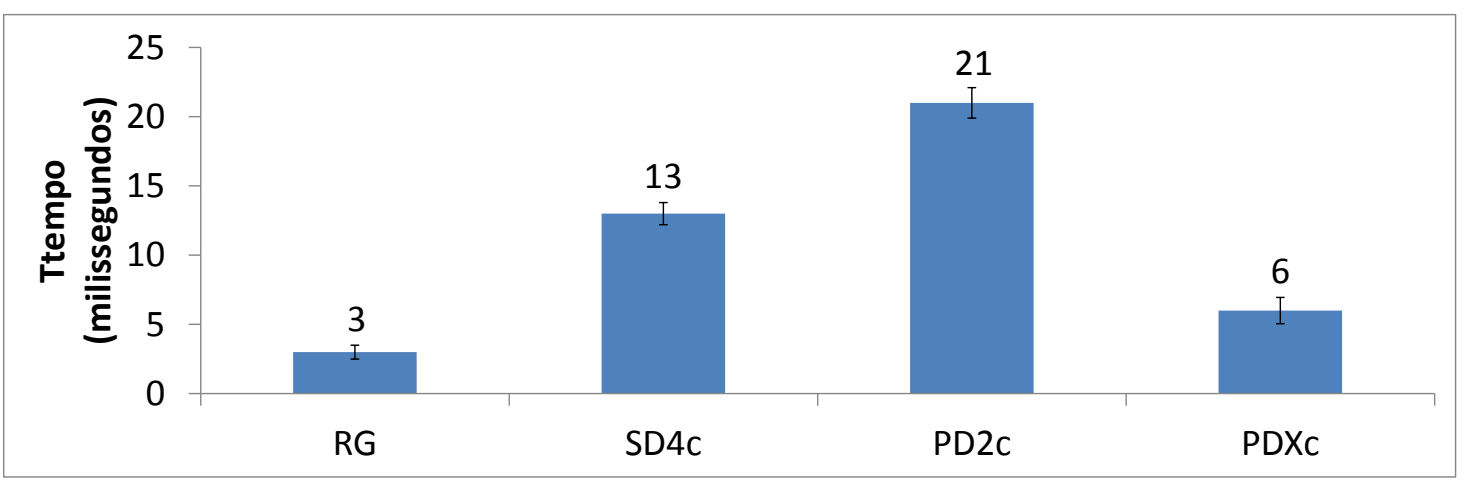

Figura 7.68: Sobrecarga dos Algoritmos de Alocação.

\subsection{Considerações Finais}

Este capítulo apresentou os resultados dos algoritmos de alocação de máquina virtual presentes no MACC. Os resultados obtidos nos experimentos mostraram que o tipo de serviço, seguido do algoritmo utilizado, são os fatores com as maiores influências sobre o tempo de resposta médio (MRT). Isso significa que a carga imposta ao sistema em conjunto com o algoritmo do MACC utilizado para gerenciar o processamento do serviço serão os responsáveis pelo valor do tempo de resposta encontrado. Por outro lado, o custo que o usuário paga pelo serviço é influenciado $89,1 \%$ pelo algoritmo utilizado. Assim, pode-se dizer que a economia ou desperdicio financeiro está ligado diretamente a forma como o MACC realiza a alocação de recursos para a execução do serviço. Por fim, a confiabilidade é influenciada pelo algoritmo seguido do tipo de serviço. Dessa forma, observa-se que os algoritmos $(59,2 \%)$ e o tipo de serviço $(23,9 \%)$ são os responsáveis por garantir a satisfação do usuário.

Diferentemente do algoritmo RG, os algoritmos SD4c, PD2c e PDXc possuem uma abordagem para alocação dinâmica de recursos para as máquinas virtuais em uma IaaS, levando em conta questões de GoS.

De forma geral, os experimentos mostraram a capacidade do algoritmo PDXc em adaptar-se mediante a carga imposta ao ambiente, melhorando a utilização global do sistema e respeitando os termos agregados na SLA. Os experimentos também mostraram que o algoritmo PDXc obtém resultados adequados construindo máquinas virtuais com a configuração desejável para que se cumpra a deadline e não desperdice recursos. Por isso, mesmo quando existe a alteração de carga de leve para pesado, o PDXc consegue manter-se estável. Nesse ponto, fornecer um tempo médio de resposta significativamente abaixo do contratado significa construir uma máquina virtual acima das necessidades solicitadas pelo usuário na SLA, deperdiçando recursos computacionais. 


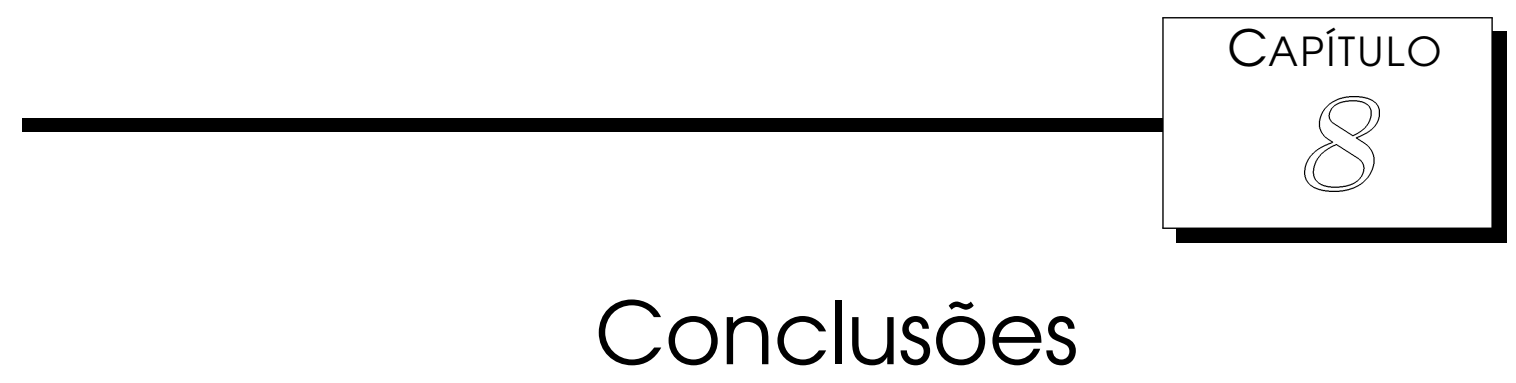

\subsection{Considerações Iniciais}

A proposta de uma arquitetura de metaescalonamento (MACC) para Computação em Nuvens surge da necessidade de se oferecer GoS aos usuários de um ambiente colaborativo (Intercloud). Apesar de alguns Metaescalonadores serem considerados para o caso de Grid, nas Nuvens os Metaescalonadores não estão preparados para prover transparência para os usuários durante o processo de descoberta e distribuição dos serviços para os recursos distribuídos (data centers). Dessa forma, esta Tese se propôs a criar e a avaliar o desempenho de uma arquitetura de Metaescalonador que seja responsável pelo oferecimento de GoS para o ambiente Intercloud. Assim, foi criado o MACC (Metascheduler Architecture to provide GoS in the Cloud Computing). O MACC tem como objetivo lidar com os recursos de computação em um ambiente Intercloud, fornecendo GoS para os usuários.

\subsection{Conclusões Finais}

O MACC funciona como uma arquitetura pró-ativa. O modelo de controle pró-ativo utilizado pelo MACC utiliza o componente Workload Engine para prever o comportamento de carga de trabalho do sistema e realizar a alocação de recursos de acordo com as necessidades dos usuários. O projeto do MACC permite que se ofereça QoS no ambiente Intercloud e que se assegure as condições necessárias para que os clientes tenham seus serviços cumpridos dentro dos termos agregados da SLA.

Para alcançar esses objetivos, o MACC trabalha com o metaescalonamento em duas etapas. Descritas assim: Primeira etapa: envolve a rede de comunicação da Intercloud, onde é necessário que o MACC localize o local mais adequado para o processamento dos serviços dos usuários. Nesse momento, é necessário que o MACC leve em conta alguns 
parâmetros da rede, tais como: delay, largura de banda, distância. Assim, os algoritmos responsáveis por essa etapa procuram aperfeiçoar o atendimento na busca pelo menor e mais rápido caminho de acesso à rede da Intercloud. Segunda etapa: inicia-se quando o data center já foi escolhido. Nesse ponto, o MACC deve realizar a alocação organizada de recursos para que as restrições impostas pela SLA possam ser cumpridas, tais como: deadline e custo. Para isso, o MACC deve criar a quantidade de máquinas virtuais com as configurações adequadas para cada caso, sem que haja desperdício de recursos e dinheiro.

Para a primeira etapa, em que foram desenvolvidas abordagens de roteamento, os resultados obtidos demonstram que as abordagens utilizadas em roteamento P2P (Chord e Pastry) apresentam tempos próximos à política BCR (Busca exaustiva). Os tempos de resposta obtidos para o Chord e para o Pastry são, no máximo, $8 \%$ maiores que os obtidos na política BCR. O problema a ser considerado no caso do BCR é a sobrecarga imposta na tomada de decisões. Para os experimentos realizados neste trabalho, essa sobrecarga não é significativa, uma vez que a sobrecarga é da ordem de milissegundo enquanto os tempos envolvidos nas comunicações são da ordem de segundos. No entanto, o problema observado em algoritmos que consideram busca exaustiva está relacionado a escalabilidade. Se o número de data centers aumentar consideravelmente a sobrecarga pode ser um fator que afete a política. Para esse caso, os resultados apresentados neste trabalho mostram que as políticas Chord e Pastry oferecem resultados aceitáveis em termos de resposta.

Analisando somente as políticas Pastry e Chord, tem-se que para cargas leves a política Chord é mais adequada e para cargas pesadas a política Pastry apresenta melhores resultados. Desta forma, a escolha entre essas políticas depende do tipo de carga considerada. Concluindo, os resultados obtidos pelas políticas P2P tradicionais demonstram que com uma quantidade de iterações menor é possivel proporcionar qualidade de serviço similar a da política de busca exaustiva.

Os resultados mostram que com uma quantidade de iterações menor é possivel proporcionar uma qualidade de serviço similar a da política de busca exaustiva BCR. Com relação a qual das políticas é mais adequada para o MACC, deve-se observar que como o modelo de comunicação do MACC pode adotar tipos diferentes de políticas de roteamento, o mais adequado seria considerar as três políticas que utilizam informação da rede avaliadas neste trabalho. A escolha da rotina deve ser feita de forma dinâmica considerando as características envolvidas no roteamento.

A segunda etapa envolve algoritmos que foram criados para lidar com a alocação de recursos. Os quatro algoritmos de alocação de máquinas virtuais considerados (RG, SD4c, PD2c e PDXc) utilizam três métricas para serem avaliados (MRT, Custo (C), Confiabilidade (R)).

A análise dos resultados permitiu identificar que a carga imposta ao sistema seguida do algoritmo de alocação são os fatores que mais influenciam a MRT. Por outro lado, o fator com a maior influência sobre o Custo é o Algoritmo utilizado, porque ele determina a quantidade necessária de recursos para ser alocada de recursos. Da mesma forma, o Algoritmo é o fator que determina a Confiabilidade obtida no sistema. Isso significa que 
a satisfação do usuário é proporcional à utilização de adequados algoritmos de alocação de máquinas e à carga imposta ao sistema.

Realizando uma análise comportamental dos algoritmos, nota-se que o algoritmo RG desempenha a criação de máquinas virtuais de forma aleatória, ele não está ciente da necessidade de manter os tempos de resposta abaixo do tempo contratado. Apesar de apresentar uma satisfação adequada para os usuários B e C, isso aconteceu através de gastos excessivos. Já o algoritmo SD4c não apresenta flexibilidade para atender as diferentes classes de usuários. Ainda que os custos praticados não sejam tão expressivos quanto o algoritmo RG, o algoritmo SD4c não é capaz de prover uma satisfação adequada para os usuários de classes mais exigentes. O comportamento do algoritmo PD2c sugere uma interpretação de que ele age de maneira agressiva. O PD2c realiza a construção de máquinas virtuais em função da deadline imposta pela classe de serviços. Entretanto, o algoritmo PD2c permite que o tempo de resposta ultrapasse, em algumas situações, o desejado pelo usuário. Por fim, o algoritmo PDXc retrata o comportamento desejável. Todas as classes de serviços possuem o atendimento diferenciado com 100\% de satisfação dos usuários. Um ponto que deve ser ressaltado é a capacidade do algoritmo PDXc em construir as máquinas virtuais com a configuração adequada, à medida que economiza dinheiro e recursos.

De acordo com a análise sobre os resultados obtidos, o algoritmo PDXc oferece os menores valores médios para o MRT e Custo, embora isso não prejudique seu desempenho em oferecer os maiores valores médios para a Confiabilidade do sistema. De forma geral, os experimentos mostraram a capacidade do algoritmo PDXc em adaptar-se mediante a carga imposta ao ambiente, melhorando a utilização global do sistema e respeitando os termos agregados na SLA. Os experimentos também mostraram que o algoritmo PDXc obtém resultados adequados construindo máquinas virtuais com a configuração desejável para que se cumpra a deadline e não desperdice recursos. Por isso, mesmo quando existe a alteração de carga de leve para pesado, o PDXc consegue manter-se estável. Nesse ponto, fornecer um tempo médio de resposta significativamente abaixo do contratado significa construir uma máquina virtual acima das necessidades solicitadas pelo usuário na SLA, deperdiçando recursos computacionais.

Assim, os resultados obtidos pelo MACC permitem que ele seja utilizado dentro de um ambiente Intercloud com o propósito de oferecimento de GoS para os usuários. Em geral, o MACC está preparado para cumprir com sucesso as restrições temporais impostas pelos usuários desse tipo de ambiente, economizando dinheiro e recursos. Entretanto, alguns requisitos mais rigorosos de desempenho, que envolvam cenários de indisponibilidade de rede e de data centers, precisam ser estudados cuidadosamente. Nesses casos, compensações por violações de SLA são cruciais.

\subsection{Dificuldades Relacionadas ao Projeto}

Por se tratar de um trabalho que utilizou simulação, algumas dificuldades relacionadas a essa metodologia foram encontrados. Dentre elas estão: 
- Pouca documentação técnica sobre o simulador CloudSim;

- O simulador está em constante desenvolvimento, alguns erros de implementação de classes foram encontrados e esses tratamentos foram contínuos, levando a 95 revisões do simulador durante o projeto de doutorado.

\subsection{Contribuições}

As contribuições com o desenvolvimento desse projeto são:

- Projeto, implementação e avaliação de uma arquitetura de Metaescalonamento (MACC) que permita a interoperabilidade entre diferentes sistemas: definição de serviços, interfaces de aplicações e ferramentas de desenvolvimento de software avaliados segundo métricas de provisão de GoS.

- Manutenção de GoS através do emprego de políticas de alocação de máquinas virtuais que levam em conta as restrições impostas pelo usuário.

- Proposta de um modelo de negócios para a gerência dos serviços que melhor aproveite os aspectos envolvidos com Computação em Nuvem, estendendo o domínio de aplicação sobre economia na Computação em Nuvens.

- Analise de como a arquitetura proposta pode incorporar as tecnologias presentes nos ambientes de Computação em Nuvem hoje existentes, ou seja, a migração para o modelo orientado a negócios e serviços proposto pela arquitetura base utilizada neste trabalho.

- Estudo que compreende a avaliação de dois monitores de virtualização (KVM e Xen), permitindo obter respostas com relação a sobrecarga que a virtualização exerce sobre uma máquina física e a sobrecarga que uma máquina virtual exerce sobre outra máquina virtual.

- Avaliação de algoritmos de roteamento em redes Intercloud, considerando métricas de distância, salto e latência.

- Criação e avaliação de algoritmos de alocação de máquinas virtuais. Esses algoritmos são incorporados ao MACC e funcionam de maneira pró-ativa, construindo as máquinas virtuais de acordo com as necessidades impostas pelos usuários.

- Revisão Bibliográfica: Foi feita uma revisão crítica da bibliografia existente, a fim de contextualizar o presente trabalho e relatar os mais recentes avanços obtidos na área. Destaca-se especialmente o levantamento feito sobre o fornecimento de GoS sobre Computação em Nuvem que permite avaliar quais suas funcionalidades, facilidades e passos futuros. 


\subsection{Produção Científica}

Esta seção apresenta a produção científica relacionada ao projeto de doutorado com participações em congressos e revistas especializadas.

\subsubsection{Artigos Publicados em Congressos}

- PEiXoto, M. L. M.; LEITE, D. M.; SANTANA, Marcos José; SANTANA, Regina H. C.; Gerenciamento de Máquinas Virtuais em um Cloud Multimídia por meio do Metaescalonamento. In: WebMedia - Simpósio Brasileiro de Sistemas Multimídia e Web, 2011, Florianópolis. WebMedia, 2011.

- Peixoto, M. L. M.; SANTANA, Marcos José; ESTRElla, J. C.; TAVARES , T. C.; KUEHNE, B. T.; SANTANA, Regina H. C.; A Metascheduler Architecture to provide $\mathrm{BoS}$ on the Cloud Computing. In: IEEE ICT - International Conference on Telecommunications, 2010, Doha. Track in Networking and Internet Computing, 2010.

- PEIXOTO, M. L. M.; SANTANA, Marcos José; SANTANA, Regina H. C.; A P2P Hierarchical Metascheduler to Obtain GoS in a Grid Economy Services. In: IEEE International Conference on Computational Science and Engineering - CSE, 2009, Vancouver. International Symposium on Scientific and Engineering Computing SEC, 2009. v. 1. p. 292-297.

\subsubsection{Artigos Aceitos para Publicação}

- LEITE, D. M.; PEIXOTO, M. L. M.; SANTANA, Marcos José; SANTANA, Regina H. C.; Evaluation of Routing Policies Performance to provide QoS in Cloud Computing. IEEE CloudPerf 2012 Workshop at IEEE Congress on Services (SERVICES 2012) Track of the ICWS (IEEE International Conference on Web Services). 2012.

\subsubsection{Artigos Submetidos para Revista}

- PEIXOTO, M. L. M.; LEITE, D. M.; BRUSCHI, Sarita; SANTANA, Marcos José; SANTANA, Regina H. C.; Proactive Metascheduler Architecture to provide GoS in Cloud Computing. In: Journal of Parallel and Distributed Computing, ISSN: 0743-7315, Qualis A2. 2012.

- LEITE, D. M.; PEIXOTO, M. L. M.; SANTANA, Marcos José; SANTANA, Regina H. C.; P2P Routing in the Metascheduler Architecture to provide GoS in Cloud Computing - International Journal of Cloud Applications and Computing (IJCAC). DOI: 10.4018/IJCAC, ISSN: 2156-1834, EISSN: 2156-1826. 2012. 


\subsubsection{Artigos Submetidos para Congresso}

- LEITE, D. M.; PEIXOTO, M. L. M.; SANTANA, Marcos José; SANTANA, Regina H. C.; Performance Evaluation of Virtual Machine Monitors for Cloud Computing. XIII Simpósio em Sistemas Computacionais. (WSCAD-SSC). 2012

- LEITE, D. M.; PEIXOTO, M. L. M.; SANTANA, Marcos José; SANTANA, Regina H. C.; P2P routing system performance to provide GoS in service search of Cloud Computing. International Symposium on DIStributed Computing (DISC). 2012.

\subsubsection{Colaboração em Projetos de Pesquisa}

\section{Mestrado}

- Avaliação de roteamento em redes P2P visando obtenção de GoS na busca de serviço em nuvem. Dionisio Machado Leite Filho. ICMC/USP. 2012.

\section{Iniciação Científica}

- Estudo, Modelagem e Avaliação de Desempenho de Cloud Computing. Lucas Moreira Laperuta. ICMC/USP. 2011.

- Avaliação de desempenho da aplicação de modelos econômicos ao ambiente de cloud computing colaborativa. Paulo Oliveira. ICMC/USP. 2011.

- Avaliação de Desempenho de Virtualizadores Utilizados no Processo de Mineração de Dados em Cloud Computing. Kemilly Dearo. IET/UFV. 2012.

\section{Trabalho de Conclusão de Curso}

- Alocação dinâmica de recursos em Cloud usando MACC. Paulo Gustavo Lopes Cândido. IET/UFV. 2012.

- Mineração de Dados Utilizando MACC. Helder Fernandes Silva. IET/UFV. 2012.

- Uso integrado do MACC e o Google Android O.S. no processo de Data Mining. Guilherme Santiago Ribeiro Silva. IET/UFV. 2012.

\subsection{Trabalhos Futuros}

A concepção do MACC envolveu inicialmente o aprendizado de diversas tecnologias de virtualização e metodologias científicas. Entretanto, a evolução do MACC é essencial para a obtenção de novos resultados. Muitas características presentes na especificação inicial do MACC, que por motivos relacionados ao tempo e em função de outras variáveis, devem ser ainda consideradas. Dentre as principais melhorias propostas como trabalho futuros, destacam-se:

- Controle de Admissão: Definição de um esquema parametrizado do Controle de Admissão. O mecanismo de controle de admissão pode ser utilizado como um 
importante meio de controle da qualidade serviço. A redução de requisições aceitas no sistema proporciona melhores tempos médios de resposta, mas aumenta o número de descartes, o que pode prejudicar a satisfação do cliente. Assim, poderia-se caracterizar melhor a penalização pelo descarte do Controle de Admissão, incluindo uma taxa de descarte de requisições. Esta taxa $\left(d_{i}\right)$ representa o peso que uma requisição descartada pelo controle de admissão influencia o $i$-ésimo usuário, tendo seu valor variando entre 0 e 1 . Isso significa que pode ser instituido por meio de um contrato qual o peso que um usuário dá para uma requisição descartada, coloborando com o mecanismo de negociação. Enquanto fixar $d_{i}=0$ significa ausência desse tipo de controle, fixar $d_{i}=1$ significa que nenhuma requisição do usuário $i$ pode ser descartada. Conforme a taxa de descarte aumenta, a satisfação do cliente diminui, como é o esperado.

$$
S_{i}=\frac{N_{i} \cdot\left(1-d_{i}\right)}{R_{i}}
$$

- Negociação: Um mecanismo de negociação de serviço no módulo de controle de admissão e outro no módudo Trade Cliente/Servidor, proporcionando com isso melhores médias de tempo de resposta e menores taxas de descarte de requisições, melhorando a qualidade de serviço oferecida.

- Melhorias na métrica de Satisfação do Cliente: pode ser conveniente transformar a variável $S_{i}$ de hard para soft, ou seja, ao passo que uma requisição não é atendida dentro do contrato estipulado ela é julgada segundo o critério de tempo de extrapolamento $\left(T e x_{i}\right)$, (Equação 8.2 ) faixa que varia de 0 a 1 , que representa a porcentagem do tempo ultrapassado com referência o contrato, isso torna eficiente o emprego de políticas com menores tempos médios de resposta, ainda que esses tempos tenham sido ultrapassados.

$$
S_{i}=\frac{N_{i}+\left(1-T e x_{i}\right)}{R_{i}}
$$

Essa métrica também proporciona um sistema de promoção para as requisições atendidas abaixo do contrato estipulado. (Tant $)_{i}$ ) representa a porcentagem do tempo médio de resposta atendido abaixo da referência do limite contratado, dado pela equação 8.3 .

$$
S_{i}=\frac{N_{i}+\text { Tant }_{i}}{R_{i}}
$$

- Migração de Máquinas Virtuais: Proposta e avaliação de algoritmos que utilizem a migração de máquinas virtuais como forma de obter o balanceamento de carga, além de oferecer um ambiente de Green Computing;

- Segurança: Prover mecanismos de segurança para todos os componentes do MACC. A segurança é um tópico não coberto pelo MACC, porém é considerado 
um tópico importante para a evolução da arquitetura. Os mecanismos de segurança em Computação em Nuvens estão em etapa de maturação e se utilizados incorretamente podem ocasionar diversos problemas.

- Modelagem de Carga de Trabalho: É necessário realizar um estudo aprofundado sobre o modelo da carga de trabalho para o ambiente Intercloud. Esse estudo deve ser capaz de levantar informações importantes com relação à variabilidade e dinamicidade da carga e como ela pode afetar as políticas de metaescalonamento utilizadas pelo MACC. 


\section{Referências Bibliográficas}

Abdelzaher, T. F.; Shin, K. G.; Bhatti, N. Performance guarantees for web server end-systems: A control-theoretical approach. IEEE Trans. Parallel Distrib. Syst., v. 13, p. 80-96, 2002.

Disponivel em http://dl.acm.org/citation.cfm?id=506156.506162

Adhipta, D.; Hassan, M.; Mahmood, A. Elasticity study: Dbrain project grid-cloud integration. Software Engineering and Computer Systems, p. 652-662, 2011.

De Alencar, J.; Andrade, R.; Viana, W.; Schulze, B. P2pscheme: a p2p scheduling mechanism for workflows in grid computing. Concurrency and Computation: Practice and Experience, 2011.

AN, B.; Lesser, V.; IRWIN, D.; ZINK, M. Automated negotiation with decommitment for dynamic resource allocation in cloud computing. In: Proceedings of the 9th International Conference on Autonomous Agents and Multiagent Systems: volume 1 Volume 1, AAMAS '10, Richland, SC: International Foundation for Autonomous Agents and Multiagent Systems, 2010, p. 981-988 (AAMAS '10, ).

Disponivel em http://dl.acm.org/citation.cfm?id=1838206.1838338

AnAnd, L.; Ghose, D.; MANi, V. Elisa: an estimated load information scheduling algorithm for distributed computing systems. Computers \& Mathematics with Applications, v. 37, n. 8, p. 57-85, 1999.

Andrade, N.; Cirne, W.; Brasileiro, F.; Roisenberg, P. Ourgrid: An approach to easily assemble grids with equitable resource sharing. In: Job scheduling strategies for parallel processing, Springer, 2003, p. 61-86.

Androutsellis-Theotokis, S.; Spinellis, D. A survey of peer-to-peer content distribution technologies. ACM Computing Surveys, v. 36, p. 335-371, 2004. 
Assunção, M.; Gelas, J.; Lefevre, L.; Orgerie, A. The green grid 5000: Instrumenting and using a grid with energy sensors. Remote Instrumentation for eScience and Related Aspects, p. 25-42, 2012.

Assunção, M. D.; Costanzo, A.; BuyYa, R. A cost-benefit analysis of using cloud computing to extend the capacity of clusters. Cluster Computing, v. 13, p. 335-347, 2010.

Disponível em http://dx.doi.org/10.1007/s10586-010-0131-x

AuYoung, A.; Chun, B.; Snoeren, A.; Vahdat, A. Resource allocation in federated distributed computing infrastructures. In: Proceedings of the 1st Workshop on Operating System and Architectural Support for the On-demand IT InfraStructure, 2004.

Balakrishnan, H.; KaAshoek, M. F.; Karger, D.; Morris, R.; StoicA, I. Looking up data in p2p systems. Commun. ACM, v. 46, n. 2, p. 43-48, 2003.

Barham, P.; Dragovic, B.; Fraser, K.; Hand, S.; Harris, T.; Ho, A.; Neugebauer, R.; Pratt, I.; WARFIEld, A. Xen and the art of virtualization. SIGOPS Oper. Syst. Rev., v. 37, p. 164-177, 2003.

Disponivel em http://doi.acm.org/10.1145/1165389.945462

Baset, S. A.; Schulzrinne, H. An analysis of the skype peer-to-peer internet telephony protocol. 2004.

Benkner, S.; Engelbrecht, G. A generic qos infrastructure for grid web services. In: AICT-ICIW'06: Proceedings of the Advanced Int'l Conference on Telecommunications and Int'l Conference on Internet and Web Applications and Services, Washington, DC, USA: IEEE Computer Society, 2006, p. 141.

Berman, F.; Fox, G.; Hey, T. The grid: Past, present, future, grid computing: Making the global infrastructure a reality. New York: Wiley Press, 2003.

Bernstein, D.; ViJ, D.; Diamond, S. An intercloud cloud computing economy technology, governance, and market blueprints. 2011, p. 293-299.

BI, J.; ZHU, Z.; TIAN, R.; WANG, Q. Dynamic provisioning modeling for virtualized multi-tier applications in cloud data center. In: Cloud Computing (CLOUD), 2010 IEEE 3rd International Conference on, 2010, p. $370-377$.

Bobroff, N.; Kochut, A.; BeAty, K. Dynamic placement of virtual machines for managing sla violations. In: Integrated Network Management, 2007. IM '07. 10th IFIP/IEEE International Symposium on, 2007, p. $119-128$.

Brun, A.; Vogt, E. M. G.; DA Silveira Mendes, A. Gos - qualidade de servico em tcp/ip. 78 p., 2002. 
ButT, A. R.; ZHANG, R.; Hu, Y. C. A self-organizing flock of condors. In: Proceedings of the 2003 ACM/IEEE conference on Supercomputing, SC '03, New York, NY, USA: ACM, 2003, p. 42- (SC '03, ).

Disponivel em http://doi.acm.org/10.1145/1048935.1050192

BUYYA, R. Market-oriented cloud computing: Vision, hype, and reality of delivering computing as the 5th utility. In: CCGRID '09: Proceedings of the 2009 9th IEEE/ACM International Symposium on Cluster Computing and the Grid, Washington, DC, USA: IEEE Computer Society, 2009, p. 1.

BuyYa, R.; ABRAmson, D.; GIDDY, J. Nimrod/g: an architecture for a resource management and scheduling system in a global computational grid. In: High Performance Computing in the Asia-Pacific Region, 2000. Proceedings. The Fourth International Conference/Exhibition on, 2000.

BuYYA, R.; ABRAmson, D.; GIDDY, J. A case for economy grid architecture for service oriented grid computing. In: IPDPS '01: Proceedings of the 10th Heterogeneous Computing Workshop â HCW 2001 (Workshop 1), Washington, DC, USA: IEEE Computer Society, 2001, p. 20083.1.

Buyya, R.; Abramson, D.; Giddy, J.; Stockinger, H. Economic models for resource management and scheduling in grid computing. Wiley Press, 2002, p. 1507-1542.

Buyya, R.; Abramson, D.; Venugopal, S. The grid economy. Proceedings of the IEEE, v. 93, n. 3, p. 698-714, 2005.

Buyya, R.; RANJAN, R.; CALHEIROS, R. N. Intercloud: Utility-oriented federation of cloud computing environments for scaling of application services. Proceedings of the 10th International Conference on Algorithms and Architectures for Parallel Processing (ICA3PP 2010, Busan, South Korea, May 21-23), LNCS, Springer, Germany, 2010., v. abs/1003.3920, 2010.

Buyya, R.; Venugopal, S. The gridbus toolkit for service oriented grid and utility computing: an overview and status report. In: Grid Economics and Business Models, 2004. GECON 2004. 1st IEEE International Workshop on, 2004, p. 19 - 66.

CAlHeiros, R.; RANJAn, R.; Buyya, R. Virtual machine provisioning based on analytical performance and qos in cloud computing environments. In: Parallel Processing (ICPP), 2011 International Conference on, 2011, p. 295 -304.

Calheiros, R.; Toosi, A.; Vecchiola, C.; Buyya, R. A coordinator for scaling elastic applications across multiple clouds. Future Generation Computer Systems, 2012.

Calheiros, R. N.; Ranjan, R.; Beloglazov, A.; Rose, C. A. F. D.; Buyya, R. Cloudsim: A toolkit for modeling and simulation of cloud computing environments and 
evaluation of resource provisioning algorithms. In: Software: Practice and Experience, Wiley Press, 2010.

CANDY, J. V. Model-based signal processing. New York, NY, USA: McGraw-Hill, Inc., 2006.

CAO, B.-Q.; LI, B.; XIA, B.-M. A service-oriented qos-assured and multi-agent cloud computing architecture. In: Proceedings of the 1st International Conference on Cloud Computing, CloudCom '09, Berlin, Heidelberg: Springer-Verlag, 2009, p. 644-649 (CloudCom'09, ).

Cardosa, M.; Korupolu, M. R.; Singh, A. Shares and utilities based power consolidation in virtualized server environments. In: Proceedings of the 11th IFIP/IEEE international conference on Symposium on Integrated Network Management, IM'09, Piscataway, NJ, USA: IEEE Press, 2009, p. 327-334 (IM'09, ).

Disponível em http://dl.acm.org/citation.cfm?id=1688933.1688986

CARISsimi, A. Virtualizacao: da teoria a solucoes. In: 26 Brazilian Symposium on Computer Networks and Distributed Systems, SBRC 2008, pag. 173-207. May 26th-30th, 2008, Rio de Janeiro, Brazil, 2008.

Carolan, J.; GaEde, S. Sun microsystems: Optimizing applications for cloud computing enviroments. In: White Paper, 2009, p. 01-20.

Disponivel em http://www.pointsource.com/staff/docArchive/ CloudRefactoring-Final-091109.pdf

Carolan, J.; Gaede, S.; Baty, J.; Brunette, G.; licht, A.; Remmell, J.; Tucker, L.; WeISE, J. Sun microsystems - introduction to cloud computing architecture. In: White paper 1st edition, pp.9-12, june 2009. Retrieved in December 07, 2009, from: http://www.sun.com/featured-articles/CloudComputing.pdf, 2009.

CAYIRCI, E., R. C. Intercloud for simulation federations. 2011, p. 397-404.

CHARD, K. Drive: A distributed economic meta-scheduler for the federation of grid and cloud systems. Wellington, Nova Zelandia: Tese de Doutorado - Victoria University of Wellington, 2011.

Chase, J. S.; Anderson, D. C.; Thakar, P. N.; Vahdat, A. M.; Doyle, R. P. Managing energy and server resources in hosting centers. In: Proceedings of the eighteenth ACM symposium on Operating systems principles, SOSP '01, New York, NY, USA: ACM, 2001, p. 103-116 (SOSP'O1, ).

Disponível em http://doi.acm.org/10.1145/502034.502045

Che, J.; He, Q.; GaO, Q.; HuAng, D. Performance measuring and comparing of virtual machine monitors. In: Embedded and Ubiquitous Computing, 2008. EUC'08. IEEE/IFIP International Conference on, IEEE, 2008, p. 381-386. 
Che, J.; Yu, Y.; Shi, C.; Lin, W. A synthetical performance evaluation of openvz, xen and kvm. In: Services Computing Conference (APSCC), 2010 IEEE Asia-Pacific, IEEE, 2010, p. 587-594.

Chen, C.-Y.; Tseng, H.-Y. An exploration of the optimization of excutive scheduling in the cloud computing. In: Advanced Information Networking and Applications Workshops (WAINA), 2012 26th International Conference on, 2012, p. 1316-1319.

CHen, S.; ChAng, H.; ZoU, X. Inter-cloud operations via ngson. IEEE Communications Magazine, v. 50, n. 1, p. 82-89, 2012.

Cheswick, B.; Burch, H.; Branigan, S. Mapping and visualizing the internet. In: In Proceedings of the 2000 USENIX Annual Technical Conference, 2000, p. 1-12.

Chieu, T. C.; Mohindra, A.; Karve, A. A.; Segal, A. Dynamic scaling of web applications in a virtualized cloud computing environment. In: ICEBE '09: Proceedings of the 2009 IEEE International Conference on e-Business Engineering, Washington, DC, USA: IEEE Computer Society, 2009, p. 281-286.

Christodoulopoulos, K.; Sourlas, V.; Mpakolas, I.; Varvarigos, E. A comparison of centralized and distributed meta-scheduling architectures for computation and communication tasks in grid networks. Comput. Commun., v. 32, p. 1172-1184, 2009.

Disponivel em http://dl.acm.org/citation.cfm?id=1542555.1542766

Chu, X.; Nadiminti, K.; Jin, C.; Venugopal, S.; Buyya, R. Aneka: Next-generation enterprise grid platform for e-science and e-business applications. In: e-Science and Grid Computing, IEEE International Conference on, IEEE, 2007, p. 151-159.

Crosby, S.; Brown, D. The virtualization reality. Queue, v. 4, n. 10, p. 34-41, 2006.

Daval-Frerot, C.; Lacroix, M.; Guyennet, H. Federation of resource traders in object-oriented distributed systems. In: Parallel Computing in Electrical Engineering, 2000. PARELEC 2000. Proceedings. International Conference on, 2000, p. 84 -88.

Deshane, T.; Shepherd, Z.; Matthews, J.; Ben-Yehuda, M.; Shah, A.; Rao, B. Quantitative comparison of xen and kvm. Xen Summit, Boston, MA, USA, p. 1-2, 2008.

DoDGe, M. An atlas of cyberspaces. Www.personalpages.manchester.ac.uk/staff/m.dodge/ cybergeography/atlas/isp_maps.html. Acesso: Janeiro/2012, 2012.

Fölling, A.; Christian, G.; Lepping, J.; PApaspyrou, A. Job scheduling strategies for parallel processing. cap. Decentralized Grid Scheduling with Evolutionary Fuzzy Systems, Berlin, Heidelberg: Springer-Verlag, p. 16-36, 2009.

Disponível em http://dx.doi.org/10.1007/978-3-642-04633-9_2 
Foster, I.; Kesselman, C. Globus: A metacomputing infrastructure toolkit. International Journal of High Performance Computing Applications, v. 11, n. 2, p. 115-128, 1997.

Foster, I.; Kesselman, C.; Lee, C.; Lindell, B.; Nahrstedt, K.; Roy, A. A distributed resource management architecture that supports advance reservations and co-allocation. Quality of Service, 1999. IWBoS '99. 1999 Seventh International Workshop on, p. 27-36, 1999.

Foster, I.; ZhaO, Y.; Raicu, I.; LU, S. Cloud computing and grid computing 360-degree compared. In: Grid Computing Environments Workshop - GCE '08 , vol., no., pp.1-10, 12-16 Nov, 2008.

FRINCU, M. E.; CRACIUN, C. Multi-objective meta-heuristics for scheduling applications with high availability requirements and cost constraints in multi-cloud environments. In: Utility and Cloud Computing (UCC), 2011 Fourth IEEE International Conference on, 2011 , p. $267-274$.

Fu, Y.; Chase, J.; Chun, B.; Schwab, S.; Vahdat, A. Sharp: an architecture for secure resource peering. SIGOPS Oper. Syst. Rev., v. 37, p. 133-148, 2003.

Disponivel em http://doi.acm.org/10.1145/1165389.945459

Gienger, P. Hybrid methods: Kvm.

http://southbrain.com/south/virtualization/6-hybrid-methods-kvm.html, 2011 a.

Gienger, P. Xen: Hypervisor-based virtualization.

http://southbrain.com/south/virtualization/3-xen-hypervisor-based-virtual.html, $2011 b$.

Gmach, D.; Rolia, J.; Cherkasova, L. Satisfying service level objectices in a self-managing resource pool. In: Proceedings of the 2009 Third IEEE International Conference on Self-Adaptive and Self-Organizing Systems, SASO '09, Washington, DC, USA: IEEE Computer Society, 2009, p. 243-253 (SASO '09, ).

Disponivel em http://dx.doi.org/10.1109/SASO.2009.27

GolRI, I.; Guitart, J. Autonomic resource management for the xen hypervisor. In: First Workshop on Execution Environments for Distributed Computing, 2007, p. 17.

Guo, L.; McGough, A. S.; Akram, A.; Colling, D.; Martyniak, J.; Krznaric, M. Enabling qos for service-oriented workflow on grid. In: CIT '07: Proceedings of the 7th IEEE International Conference on Computer and Information Technology, Washington, DC, USA: IEEE Computer Society, 2007, p. 1077-1082.

HABIB, I. Virtualization with kvm. Linux Journal, v. 2008, n. 166, p. 8, 2008. 
Heidt, M.; Dornemann, T.; Dornemann, K.; Freisleben, B. Omnivore: Integration of grid meta-scheduling and peer-to-peer technologies. In: Cluster Computing and the Grid, 2008. CCGRID '08. 8th IEEE International Symposium on, 2008, p. 316 -323.

Huang, Y.; Bessis, N.; Norrington, P.; Kuonen, P.; Hirsbrunner, B. Exploring decentralized dynamic scheduling for grids and clouds using the community-aware scheduling algorithm. 2011.

IBRAHIM, S.; HE, B.; JIN, H. Towards pay-as-you-consume cloud computing. In: Services Computing (SCC), 2011 IEEE International Conference on, 2011, p. 370 -377.

Iosup, A.; Epema, D. H. J.; Tannenbaum, T.; Farrellee, M.; Livny, M. Inter-operating grids through delegated matchmaking. In: Proceedings of the 2007 ACM/IEEE conference on Supercomputing, SC '07, New York, NY, USA: ACM, 2007, p. 13:1-13:12 (SC '07, ).

Disponivel em http://doi.acm.org/10.1145/1362622.1362640

JAIN, R. The art of computer systems performance analysis: techniques for experimental design, measurement, simulation, and modeling. Wiley, 1991.

JIN, H.; TAO, Y.; WU, S.; SHI, X. Scalable dht-based information service for large-scale grids. In: CF 08: Proceedings of the 5th conference on Computing frontiers, New York, NY, USA: ACM, 2008, p. 305-312.

Jung, G.; Hiltunen, M.; Joshi, K.; Schlichting, R.; Pu, C. Mistral: Dynamically managing power, performance, and adaptation cost in cloud infrastructures. In: Distributed Computing Systems (ICDCS), 2010 IEEE 30th International Conference on, 2010, p. $62-73$.

KAmal, M. Potential of cloud-based infrastructure for small business development. Hawaii International Conference on System Sciences, v. 0, p. 4860-4867, 2012.

Keahey, K.; Foster, I.; Freeman, T.; Zhang, X. Virtual workspaces: Achieving quality of service and quality of life in the grid. Sci. Program., v. 13, n. 4, p. 265-275, 2005. Disponível em http://dl .acm.org/citation.cfm?id=1239655.1239657

Kertesz, A.; Kacsuk, P. A taxonomy of grid resource brokers. In: 6th Austrian-Hungarian Workshop on Distributed and Parallel Systems (DAPSYS, Basil Blackwell, 2006, p. 318-66.

Khanna, G.; Beaty, K.; Kar, G.; Kochut, A. Application performance management in virtualized server environments. In: Network Operations and Management Symposium, 2006. NOMS 2006. 10th IEEE/IFIP, 2006, p. 373 -381.

Khoshdel, V.; Motamedi, S.; Sharifian, S.; Farhadi, M. A new approach for optimum resource utilization in cloud computing environments. In: ICCKE2011, 
International Conference on Computer and Knowledge Engineering, Machhad, Iran, 2011 , p. $285-292$.

KIM, W.; KIM, S.; LEE, E.; LEE, S. Adoption issues for cloud computing. In: Proceedings of the 11th International Conference on Information Integration and Web-based Applications \& Services, ACM, 2009, p. 3-6.

Krauter, K.; Buyya, R.; Maheswaran, M. A taxonomy and survey of grid resource management systems for distributed computing. Softw. Pract. Exper., v. 32, p. 135-164, 2002.

Disponível em http://dl.acm.org/citation.cfm?id=565293.565296

Kusic, D.; Kephart, J. O.; Hanson, J. E.; Kandasamy, N.; Jiang, G. Power and performance management of virtualized computing environments via lookahead control. In: Proceedings of the 2008 International Conference on Autonomic Computing, ICAC '08, Washington, DC, USA: IEEE Computer Society, 2008, p. 3-12 (ICAC '08, ). Disponível em http://dx.doi.org/10.1109/ICAC.2008.31

KVM Kernel-based virtual machine. site oficial da ferramenta. http://www.linux-kvm.org/page/Main_Page, 2011.

L. Adzigogov, J. S.; Polymenakos, L. Emperor: An ogsa grid meta-scheduler based on dynamic resource predictions. Journal of Grid Computing, v. 3, n. 1-2, p. 19-37, 2005.

Lai, K.; Rasmusson, L.; Adar, E.; Zhang, L.; Huberman, B. A. Tycoon: An implementation of a distributed, market-based resource allocation system. Multiagent Grid Syst., v. 1, p. 169-182, 2005.

Disponível em http://dl.acm.org/citation.cfm?id=1233813.1233816

Leal, K.; Huedo, E.; Llorente, I. M. A decentralized model for scheduling independent tasks in federated grids. Future Gener. Comput. Syst., v. 25, p. 840-852, 2009.

Disponível em http://dl.acm.org/citation.cfm?id=1550955.1551001

LEAVITT, N. Is cloud computing really ready for prime time? Computer, v. 42, n. 1, p. 15-20, 2009.

LEE, C. A. A perspective on scientific cloud computing. In: Proceedings of the 19th ACM International Symposium on High Performance Distributed Computing, HPDC '10, New York, NY, USA: ACM, 2010, p. 451-459 (HPDC'10, ).

LEE, L.-T.; LeE, S.-T.; ChAng, J.-C. An extenics-based dynamic resource adjustment for the virtual machine in cloud computing environment. In: Ubi-Media Computing (U-Media), 2011 4th International Conference on, 2011, p. 65 -70. 
Lee, Y. C.; Wang, C.; Zomaya, A. Y.; Zhou, B. B. Profit-driven service request scheduling in clouds. In: Cluster, Cloud and Grid Computing (CCGrid), 2010 10th IEEE/ACM International Conference on, 2010, p. 15 -24.

LEITE, D. M. Avaliação de roteamento em redes $p 2 p$ visando obtenção de qos na busca de serviço em nuvem. São Carlos, SP, Brasil: Instituto de Ciências Matemáticas e de Computação (ICMC/USP). Dissertação de Mestrado em Ciências de Computação e Matemática Computacional, 2012.

LI, X.; LO, J.-C. Pricing and peak aware scheduling algorithm for cloud computing. In: Innovative Smart Grid Technologies (ISGT), 2012 IEEE PES, 2012, p. 1 -7.

LinNolaht, J. Gos routing for p2p networking. In: HUT T-110.551 Seminar on Internetworking, 2004.

LiU, Q.; WenG, C.; LI, M.; Luo, Y. An in-vm measuring framework for increasing virtual machine security in clouds. Security Privacy, IEEE, v. 8, n. 6, p. 56-62, 2010.

Liu, Y.; Masoud Sadjadi, S.; Fong, L.; Rodero, I.; Villegas, D.; Kalayci, S.; Bobroff, N.; MARTINEZ, J. Enabling autonomic meta-scheduling in grid environments. In: Autonomic Computing, 2008. ICAC 'O8. International Conference on, 2008, p. $199-200$.

Lopes, N.; Baguero, C. Análise da disponibilização de um índice invertido em p2p. In: 6th Conferencia sobre Redes de Computadores - Protocolos, Tecnologias e Aplicações para Ambientes Móveis, Bragança, Portugal, 2003.

LU, X.; WANG, H.; WANG, J.; XU, J.; LI, D. Internet-based virtual computing environment: Beyond the data center as a computer. Future Generation Computer Systems, 2011.

LuO, M.; ZHANG, L.-J.; LEI, F. An insuanrance model for guranteeing service assurance, integrity and qos in cloud computing. In: Proceedings of the 2010 IEEE International Conference on Web Services, ICWS '10, Washington, DC, USA: IEEE Computer Society, 2010, p. 584-591 (ICWS '10, ).

Disponível em http://dx.doi.org/10.1109/ICWS.2010.113

Ma, Z.; Sheng, Z.; Gu, L.; Wen, L.; Zhang, G. Dvm: Towards a datacenter-scale virtual machine. Cited By (since 1996) 0, 2012, p. 39-50.

MANn, V. Metascheduling: an elixir for performance-tuning of compound sessions based on the cm-resource model. In: Advanced Communication Technology, 2005, ICACT 2005. The 7th International Conference on, 2005, p. $661-664$.

Massie, M.; Chun, B.; Culler, D. The ganglia distributed monitoring system: design, implementation, and experience. Parallel Computing, v. 30, n. 7, p. 817-840, 2004. 
Mather, T.; Kumaraswamy, S.; Latif, S. Cloud security and privacy: an enterprise perspective on risks and compliance. O’Reilly Media, Inc., 2009.

Medina, A.; Lakhina, A.; MAtTA, I.; Byers, J. Brite: An approach to universal topology generation. In: Modeling, Analysis and Simulation of Computer and Telecommunication Systems, 2001. Proceedings. Ninth International Symposium on, IEEE, 2001, p. 346-353.

Mehdi, N.; Mamat, A.; Ibrahim, H.; Subramaniam, S. On the fly negotiation for urgent service level agreement on intercloud environment. Journal of Computer Science, v. 7, n. 10, p. 1596-1604, 2011.

MEINL, T. Advance reservation of grid resources via real options. In: Proceedings of the 2008 1Oth IEEE Conference on E-Commerce Technology and the Fifth IEEE Conference on Enterprise Computing, E-Commerce and E-Services, Washington, DC, USA: IEEE Computer Society, 2008, p. 3-10.

Disponível em http://dl.acm.org/citation.cfm?id=1509871.1510098

Mell, P.; Grance, T. The NIST Definition of Cloud Computing. Relatório Técnico, 2011. Disponivel em http: //www.csrc.nist.gov/groups/SNs/cloud-computing/

Menasce, D. A.; Bennani, M. N. Autonomic virtualized environments. In: Proceedings of the International Conference on Autonomic and Autonomous Systems, ICAS '06, Washington, DC, USA: IEEE Computer Society, 2006, p. 28- (ICAS '06, ).

Disponível em http://dx.doi.org/10.1109/ICAS.2006.13

Moltó, G.; Hernández, V.; Alonso, J. M. A service-oriented wsrf-based architecture for metascheduling on computational grids. Future Gener. Comput. Syst., v. 24, p. 317-328, 2008.

Disponível em http://dl.acm.org/citation.cfm?id=1321789.1322003

Mu'Alem, A.; Feitelson, D. Utilization, predictability, workloads, and user runtime estimates in scheduling the ibm sp2 with backfilling. Parallel and Distributed Systems, IEEE Transactions on, v. 12, n. 6, p. 529-543, 2001.

Murata, Y.; Egawa, R.; Higashida, M.; Kobayashi, H. A history-based job scheduling mechanism for the vector computing cloud. In: Applications and the Internet (SAINT), 2010 10th IEEE/IPSJ International Symposium on, 2010, p. 125 -128.

Myers, R. H.; Montgomery, D. C.; Anderson-Cook, C. M. Response Surface Methodology: Process and Product Optimization Using Designed Experiments (Wiley Series in Probability and Statistics). 3 ed. Wiley, 2009.

Disponivel em http://www.amazon.com/exec/obidos/redirect?tag= citeulike07-20\&path=ASIN/0470174463 
NetTo, M.; BuyYA, R. Offer-based scheduling of deadline-constrained bag-of-tasks applications for utility computing systems. In: Parallel Distributed Processing, 2009. IPDPS 2009. IEEE International Symposium on, 2009, p. $1-11$.

Neumann, D.; Stoesser, J.; Anandasivam, A.; Borissov, N. Sorma - building an open grid market for grid resource allocation. In: Proceedings of the 4th international conference on Grid economics and business models, GECON'07, Berlin, Heidelberg: Springer-Verlag, 2007, p. 194-200 (GECON'07, ).

Disponível em http://dl.acm.org/citation.cfm?id=1792210.1792232

Nguyen Van, H.; Dang Tran, F.; Menaud, J.-M. Autonomic virtual resource management for service hosting platforms. In: Proceedings of the 2009 ICSE Workshop on Software Engineering Challenges of Cloud Computing, CLOUD '09, Washington, DC, USA: IEEE Computer Society, 2009, p. 1-8 (CLOUD '09, ).

Disponível em http://dx.doi.org/10.1109/CLOUD.2009.5071526

Nurmi, D.; Wolski, R.; Grzegorczyk, C.; Obertelli, G.; Soman, S.; Youseff, L.; Zagorodnov, D. The eucalyptus open-source cloud-computing system. In: Proceedings of the 2009 9th IEEE/ACM International Symposium on Cluster Computing and the Grid, CCGRID '09, Washington, DC, USA: IEEE Computer Society, 2009, p. 124-131 (CCGRID '09, ).

Disponível em http://dx.doi.org/10.1109/CCGRID.2009.93

Oprescu, A.; Kielmann, T. Bag-of-tasks scheduling under budget constraints. In: Cloud Computing Technology and Science (CloudCom), 2010 IEEE Second International Conference on, 2010, p. $351-359$.

Peixoto, M. L. M.; Santana, M. J.; Estrella, J. C.; Tavares, T. C.; Kuehne, B.; SantanA, R. H. C. A metascheduler architecture to provide qos on the cloud computing. In: ICT'10: 17th International Conference on Telecommunications, Doha, Qatar: IEEE Computer Society, 2010, p. 650 - 657.

Peng, J.; Zhang, X.; Lei, Z.; Zhang, B.; Zhang, W.; Li, Q. Comparison of several cloud computing platforms. In: ISISE '09: Proceedings of the 2009 Second International Symposium on Information Science and Engineering, Washington, DC, USA: IEEE Computer Society, 2009, p. 23-27.

PokHAREL, M.; PARK, J. S. Cloud computing: future solution for e-governance. In: Proceedings of the 3rd International Conference on Theory and Practice of Electronic Governance, ICEGOV '09, New York, NY, USA: ACM, 2009, p. 409-410 (ICEGOV '09, ).

Pu, X.; LiU, L.; MeI, Y.; Sivathanu, S.; KOH, Y.; PU, C. Understanding performance interference of i/o workload in virtualized cloud environments. In: Cloud Computing (CLOUD), 2010 IEEE 3rd International Conference on, 2010, p. 51 -58. 
Pu, X.; Liu, L.; Mei, Y.; Sivathanu, S.; Koh, Y.; Pu, C.; CaO, Y.; LiU, L. Who is your neighbor: Net i/o performance interference in virtualized clouds. Services Computing, IEEE Transactions on, v. PP, n. 99, p. 1, 2012.

Quinellato, D. G. Um sistema de reputação para redes $p 2 p$ estruturado baseado na reputação de arquivos com verificação pela reputação dos nós. Tese de Doutoramento, Universidade Estadual de Campinas - UNICAMP, 2009.

Quiroz, A.; Kim, H.; Parashar, M.; Gnanasambandam, N.; Sharma, N. Towards autonomic workload provisioning for enterprise grids and clouds. In: Grid Computing, 2009 10th IEEE/ACM International Conference on, 2009, p. 50 -57.

RANJAN, R. Coordinated resource provisioning in federated grids. Australia: Tese de Doutorado - Universidade de Melbourne, 2007.

RANJAN, R.; BuYYA, R.; HARWOOD, A. A case for cooperative and incentive-based coupling of distributed clusters. In: Cluster Computing, 2005. IEEE International, IEEE, 2005, p. 1-11.

RANJAn, R.; HARWOOD, A.; BuYYA, R. Peer-to-peer-based resource discovery in global grids: a tutorial. Communications Surveys \& Tutorials, IEEE, v. 10, n. 2, p. 6-33, 2008.

RANJAN, R.; HARWOOD, A.; BUYYA, R. Coordinated load management in peer-to-peer coupled federated grid systems. 2010.

Ratnasamy, S.; Stoica, I.; Shenker, S. Routing algorithms for dhts: Some open questions. In: IPTPS '01: Revised Papers from the First International Workshop on Peer-to-Peer Systems, London, UK: Springer-Verlag, 2002, p. 45-52.

Rimal, B. P.; Choi, E.; Lumb, I. A taxonomy and survey of cloud computing systems. In: NCM '09: Proceedings of the 2009 Fifth International Joint Conference on INC, IMS and IDC, Washington, DC, USA: IEEE Computer Society, 2009, p. 44-51.

Rodero, I.; Guim, F.; Corbalan, J. Evaluation of coordinated grid scheduling strategies. In: Proceedings of the 2009 11th IEEE International Conference on High Performance Computing and Communications, Washington, DC, USA: IEEE Computer Society, 2009, p. 1-10.

Disponível em http://dl.acm.org/citation.cfm?id=1581383.1582202

Rodero, I.; Guim, F.; Corbalan, J.; Fong, L.; Sadjadi, S. M. Grid broker selection strategies using aggregated resource information. Future Gener. Comput. Syst., v. 26, p. 72-86, 2010.

Disponível em http://dx.doi.org/10.1016/j.future.2009.07.009 
Rose, R. Survey of system virtualization techniques. In: Special Interest Group on Operating Systems (SIGOPS), December 2004. Retrieved May, 2010, 2004.

Rosenblum, M. Vmware virtual platform. In: Proceedings of Hot Chips, 1999, p. 185-196.

Rowstron, A. I. T.; Druschel, P. Pastry: Scalable, decentralized object location, and routing for large-scale peer-to-peer systems. In: Middleware '01: Proceedings of the IFIP/ACM International Conference on Distributed Systems Platforms Heidelberg, London, UK: Springer-Verlag, 2001, p. 329-350.

SAntos, N.; Gummadi, K.; Rodrigues, R. Towards trusted cloud computing. In: Proceedings of the 2009 conference on Hot topics in cloud computing, USENIX Association, 2009, p. 3.

Schwiegelshohn, U.; Yahyapour, R. Resource allocation and scheduling in metasystems. In: Proceedings of the 7th International Conference on High-Performance Computing and Networking, HPCN Europe '99, London, UK: Springer-Verlag, 1999, p. 851-860 (HPCN Europe '99, ).

Disponível em http://dl.acm.org/citation. cfm?id=645563.660323

Shah, R.; Veeravalli, B.; Misra, M. On the design of adaptive and decentralized load balancing algorithms with load estimation for computational grid environments. Parallel and Distributed Systems, IEEE Transactions on, v. 18, n. 12, p. $1675-1686$, 2007.

Singh, A.; Korupolu, M.; Mohapatra, D. Server-storage virtualization: integration and load balancing in data centers. In: Proceedings of the 2008 ACM/IEEE conference on Supercomputing, SC '08, Piscataway, NJ, USA: IEEE Press, 2008, p. 53:1-53:12 (SC '08, ).

Disponível em http://dl.acm.org/citation.cfm?id=1413370.1413424

Singhal, S.; WANG, Z.; ZHU, X. Utilization and slo-based control for dynamic sizing of resource partitions. IFIP Lecture Notes in Computer Science (LNCS), v. 3775, n. 3775, p. 133-144, 2011.

Sotiriadis, S.; Bessis, N.; Antonopoulos, N. Towards inter-cloud schedulers: A survey of meta-scheduling approaches. In: P2P, Parallel, Grid, Cloud and Internet Computing (3PGCIC), 2011 International Conference on, 2011, p. 59 -66.

Stantchev, V.; Schröpfer, C. Negotiating and enforcing qos and slas in grid and cloud computing. In: Proceedings of the 4th International Conference on Advances in Grid and Pervasive Computing, GPC '09, Berlin, Heidelberg: Springer-Verlag, 2009, p. 25-35 (GPC '09, ). 
Stoica, I.; Morris, R.; Karger, D.; KaAshoek, M. F.; Balakrishnan, H. Chord: A scalable peer-to-peer lookup service for internet applications. In: SIGCOMM 01: Proceedings of the 2001 conference on Applications, technologies, architectures, and protocols for computer communications, New York, NY, USA: ACM, 2001, p. 149-160.

Subramani, V.; Kettimuthu, R.; Srinivasan, S.; Sadayappan, P. Distributed job scheduling on computational grids using multiple simultaneous requests. In: HPDC '02: Proceedings of the 11th IEEE International Symposium on High Performance Distributed Computing, Washington, DC, USA: IEEE Computer Society, 2002, p. 359.

Subramanian, R.; Goodman, B. Peer-to-peer computing: the evolution of a disruptive technology. IGI Global, 2005.

Suresh, A.; ViJAYAKARTHick, P. Improving scheduling of backfill algorithms using balanced spiral method for cloud metascheduler. In: Recent Trends in Information Technology (ICRTIT), 2011 International Conference on, 2011, p. 624 -627.

TEIXEIRA, F. C. Um escalonador para grades computacionais utilizando modelos economicos. Campinas, SP, Brasil: Dissertacao de Mestrado - UNICAMP, 2006.

TolnAI, A.; vON Solms, S. Securing the cloud's core virtual infrastructure. In: Broadband, Wireless Computing, Communication and Applications (BWCCA), 2010 International Conference on, 2010, p. $447-452$.

Toosi, A.; Calheiros, R.; Thulasiram, R.; BuyYa, R. Resource provisioning policies to increase iaas provider's profit in a federated cloud environment. 2011, p. 279-287.

VADHIYAR, S. S.; DongarRa, J. J. A metascheduler for the grid. In: HPDC 'O2: Proceedings of the 11th IEEE International Symposium on High Performance Distributed Computing, Washington, DC, USA: IEEE Computer Society, 2002, p. 343.

Vanderster, D. C.; Dimopoulos, N. J.; Sobie, R. J. Metascheduling multiple resource types using the mmkp. In: GRID, IEEE, 2006, p. 231-237.

VAsconcellos, M. A. S. Economia: Micro e macro. Sao Paulo, SP, Brasil: 3 edicao, Editora Atlas, 2002.

VASILIOU, N. Overview of internet qos and web server qos. 2000.

Vecchiola, C.; SuraJ, P.; BuyYA, R. High-performance cloud computing: A view of scientific applications. In: Pervasive Systems, Algorithms, and Networks (ISPAN), 2009 10th International Symposium on , pp.4-16, Dec. 2009, 2009.

Venugopal, S.; Chu, X.; Buyya, R. A negotiation mechanism for advance resource reservation using the alternate offers protocol. 2008. 
Vernekar, S.; Game, P. Component based resource allocation in cloud computing. In: Proceedings of the International Conference on Information Systems Design and Intelligent Applications 2012 (INDIA 2012) held in Visakhapatnam, India, January 2012, Springer, 2012, p. 907-914.

WÄLdRICH, O.; WiEder, P.; ZIEGLER, W. A meta-scheduling service for co-allocating arbitrary types of resources. Parallel Processing and Applied Mathematics, p. 782-791, 2006.

Walsh, W.; Tesauro, G.; Kephart, J.; Das, R. Utility functions in autonomic systems. In: Autonomic Computing, 2004. Proceedings. International Conference on, 2004 , p. $70-77$.

WAnG, C.-M.; Chen, H.-M.; Hsu, C.-C.; LEE, J. Dynamic resource selection heuristics for a non-reserved bidding-based grid environment. Future Gener. Comput. Syst., v. 26, p. 183-197, 2010.

Disponível em http://dl.acm.org/citation.cfm?id=1630168.1630309

Wang, L.; Tao, J.; Kunze, M.; Castellanos, A. C.; Kramer, D.; Karl, W. Scientific cloud computing: Early definition and experience. In: Proceedings of the 2008 10th IEEE International Conference on High Performance Computing and Communications, Washington, DC, USA: IEEE Computer Society, 2008, p. 825-830.

WATson, J. Virtualbox: bits and bytes masquerading as machines. Linux Journal, v. 2008, n. 166, p. 1, 2008.

Weissman, J.; Grimshaw, A. A federated model for scheduling in wide-area systems. In: High Performance Distributed Computing, 1996., Proceedings of 5th IEEE International Symposium on, 1996, p. $542-550$.

Wood, T.; Shenoy, P.; Venkataramani, A.; Yousif, M. Black-box and gray-box strategies for virtual machine migration. In: Proceedings of the 4th USENIX conference on Networked systems design, NSDI'07, Berkeley, CA, USA: USENIX Association, 2007, p. 17-17 (NSDI'O7, ).

Disponível em http://dl.acm.org/citation.cfm?id=1973430.1973447

Xhafa, F.; Abraham, A. Computational models and heuristic methods for grid scheduling problems. Future Gener. Comput. Syst., v. 26, p. 608-621, 2010.

Disponível em http://dx.doi.org/10.1016/j.future.2009.11.005

Xiaohui, W.; Zhaohui, D.; Shutao, Y.; Chang, H.; Huizhen, L. Csf4: A wsrf compliant meta-scheduler. In: The 2006 World Congress in Computer Science, Computer Engineering, and Applied Computing, GCA, 2006, p. 61-67. 
Xiong, K.; Perros, H. Service performance and analysis in cloud computing. In: SERVICES '09: Proceedings of the 2009 Congress on Services - I, Washington, DC, USA: IEEE Computer Society, 2009, p. 693-700.

Xu, B.; ZHAO, C.; Hu, E.; Hu, B. Job scheduling algorithm based on berger model in cloud environment. Adv. Eng. Softw., v. 42, p. 419-425, 2011.

Disponível em http://dx.doi.org/10.1016/j.advengsoft.2011.03.007

Xu, D.; Ruth, P.; Rhee, J.; Kennell, R.; GoAsguen, S. Short paper: Autonomic adaptation of virtual distributed environments in a multi-domain infrastructure. In: High Performance Distributed Computing, 2006 15th IEEE International Symposium on, 2006, p. $317-320$.

XU, X.; ZHOU, F.; WAN, J.; JIANG, Y. Quantifying performance properties of virtual machine. In: Information Science and Engineering, 2008. ISISE'08. International Symposium on, IEEE, 2008, p. 24-28.

Yamini, L.; LathaSelvi, G.; MukherJee, S. Efficient metascheduling in a cloud extended grid environment. In: Recent Trends in Information Technology (ICRTIT), 2011 International Conference on, 2011, p. $667-672$.

YEO, C. S.; BUYYA, R. A taxonomy of market-based resource management systems for utility-driven cluster computing. Softw. Pract. Exper., v. 36, n. 13, p. 1381-1419, 2006.

You, X.; XU, X.; WAn, J.; JiAng, C. Analysis and evaluation of the scheduling algorithms in virtual environment. In: Embedded Software and Systems, 2009. ICESS 'O9. International Conference on, 2009, p. 291 -296.

ZhaO, W.; Olshefski, D.; SchulzRinne, H. Internet quality of service: an overview. Technical Report CUCS-003-00. http://www.cs.columbia.edu/techreports/cucs-003-00.pdf. Acessado em Maio de 2007, 2000.

Disponível em http://www.cs.columbia.edu/techreports/cucs-003-00.pdf

ZHu, Q.; Agrawal, G. Resource provisioning with budget constraints for adaptive applications in cloud environments. In: Proceedings of the 19th ACM International Symposium on High Performance Distributed Computing, HPDC '10, New York, NY, USA: ACM, 2010, p. 304-307 (HPDC'10, ).

Disponivel em http://doi.acm.org/10.1145/1851476.1851516

ZHU, X.; WANG, Z.; Singhal, S. Utility-driven workload management using nested control design. In: American Control Conference, 2006, 2006, p. 6 pp. 
Zhu, X.; Young, D.; Watson, B.; Wang, Z.; Rolia, J.; Singhal, S.; McKee, B.; Hyser, C.; Gmach, D.; Gardner, R.; Christian, T.; Cherkasova, L. 1000 islands: Integrated capacity and workload management for the next generation data center. In: Autonomic Computing, 2008. ICAC '08. International Conference on, 2008, p. $172-181$.

ZHU, Y.; HU, Y. Efficient, proximity-aware load balancing for dht-based p2p systems. IEEE Trans. Parallel Distrib. Syst., v. 16, n. 4, p. 349-361, 2005. 